\title{
Platelet receptors and procoagulant activity in thrombus formation
}

Citation for published version (APA):

Kuijpers, M. J. E. (2006). Platelet receptors and procoagulant activity in thrombus formation. [Doctoral Thesis, Maastricht University]. Datawyse / Universitaire Pers Maastricht.

https://doi.org/10.26481/dis.20060413mk

Document status and date:

Published: 01/01/2006

DOI:

10.26481/dis.20060413mk

Document Version:

Publisher's PDF, also known as Version of record

\section{Please check the document version of this publication:}

- A submitted manuscript is the version of the article upon submission and before peer-review. There can be important differences between the submitted version and the official published version of record.

People interested in the research are advised to contact the author for the final version of the publication, or visit the DOI to the publisher's website.

- The final author version and the galley proof are versions of the publication after peer review.

- The final published version features the final layout of the paper including the volume, issue and page numbers.

Link to publication

\footnotetext{
General rights rights.

- You may freely distribute the URL identifying the publication in the public portal. please follow below link for the End User Agreement:

www.umlib.nl/taverne-license

Take down policy

If you believe that this document breaches copyright please contact us at:

repository@maastrichtuniversity.nl

providing details and we will investigate your claim.
}

Copyright and moral rights for the publications made accessible in the public portal are retained by the authors and/or other copyright owners and it is a condition of accessing publications that users recognise and abide by the legal requirements associated with these

- Users may download and print one copy of any publication from the public portal for the purpose of private study or research.

- You may not further distribute the material or use it for any profit-making activity or commercial gain

If the publication is distributed under the terms of Article $25 \mathrm{fa}$ of the Dutch Copyright Act, indicated by the "Taverne" license above, 


\section{Platelet receptors}

\section{and procoagulant activity}

\section{in thrombus formation}


Platelet receptors and procoagulant activity in thrombus formation Martjke Kuijpers

Thesis Universiteit Maastricht - with summary in Dutch

ISBN-10: $90-5278-517-1$

ISBN-13: $978-90-5278-517-2$

Printed by: Datawyse / Universitaire Pers Maastricht, the Netherlands Coverdesign by: Paul Eken

(C) M.J.E. Kuijpers, Maastricht 2006 


\title{
Platelet receptors
}

\section{and procoagulant activity \\ in thrombus formation}

\author{
PROEFSCHRIFT
}

\author{
ter verkrijging van de graad van doctor \\ aan de Universiteit Maastricht, \\ op gezag van de Rector Magnificus, \\ Prof. mr. G.P.M.F. Mols, \\ volgens het besluit van het College van Decanen, \\ in het openbaar te verdedigen op \\ 13 april 2006 om $16: 00$
}

door

Marijke Johanna Elfrieda Kuijpers

Geboren op 20 juli 1977 te Weert

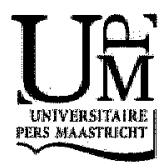




\section{PROMOTOR}

Prof. Dr. J. Rosing

\section{COPROMOTORES}

Dr. J.W.M. Heemskerk

Dr. M.G.A. oude Egbrink

\section{BEOORDELINGSCOMMISSIE}

Prof. Dr. D.W. Slaaf, voorzitter

Prof. Dr. J.W.N. Akkerman (Universiteit Utrecht)

Prof. Dr. J. van Engelshoven

Prof. Dr. M.J Post

Prof. Dr. J. Waltenberger

Financial support by the Netherlands Heart Foundation and the Dr. Ir. van de Laar Stichting for the publication of this thesis is gratefully acknowledged.

Additionally, gratitude is expressed to NovoNordisk, Unilever Research and the AZD6140 GPT and the Exanta Team from AstraZeneca R\&D for their financial support. 


\section{Contents}

Chapter 1 General introduction 9

Chapter $2 \quad$ Platelet collagen receptors and coagulation -

A characteristic platelet response as possible target of antithrombotic treatment

Chapter 3

Complementary roles of glycoprotein VI and $\alpha 2 \beta 1$ integrin in collagen-induced thrombus formation in flowing whole blood ex vivo

Chapter 4

Role of integrin $\alpha 2 \beta 1$ in thrombus stabilization and embolization

Chapter 5

Facilitating roles of murine platelet glycoprotein $\mathrm{Ib}$ and $\mathrm{al} / \mathrm{b} / \mathrm{B} 3$ in phosphatidylserine exposure during WWF-collagen-induced thrombus formation

Chapter 6

Regullation of tissue factor-induced coagulation and platelet aggregation in flowing whole blood

Chapter 7

Role of platelet procoagulant response in collagen- and tissue

factor-induced thrombosis in arterioles and venules

Chapter 8

General discussion

Summary / Samenvatting

Dankwoord

Curriculum vitae

Publications

Awards 

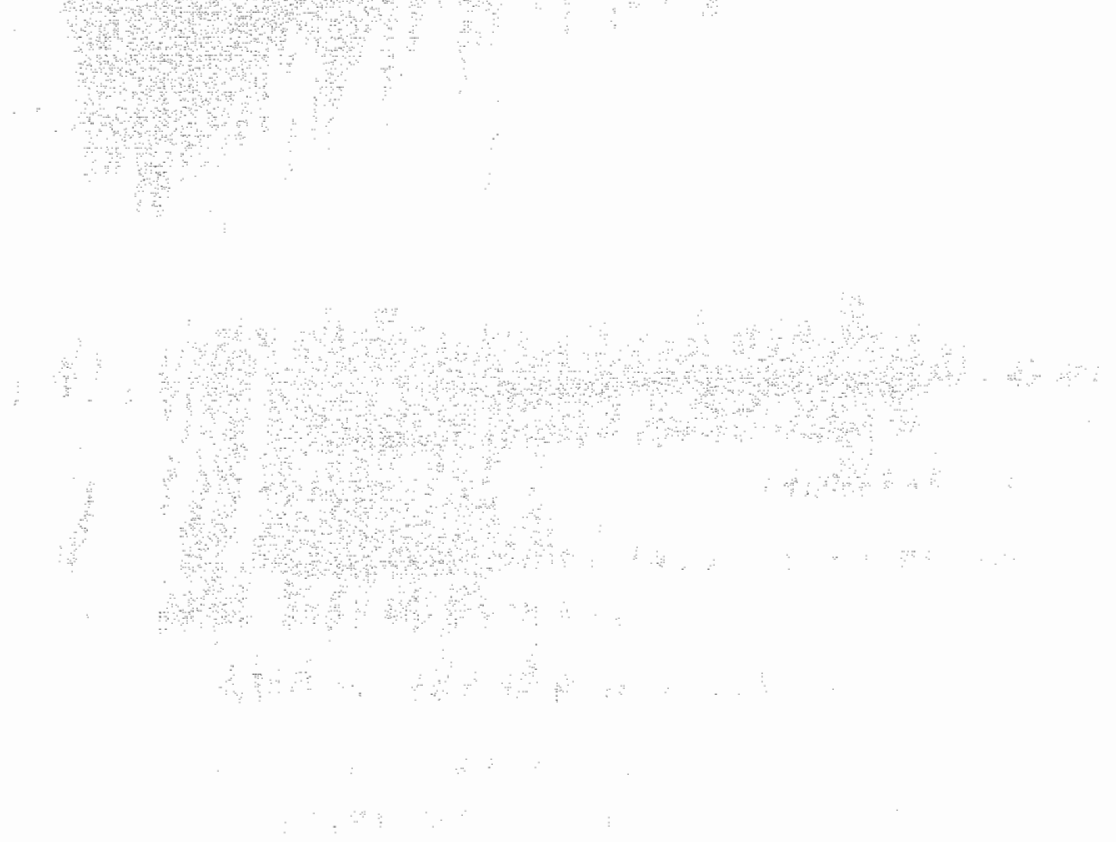

.

i. 
Chapter 1

General introduction 
Hemostasis is the physlological process responsible for cessation of bleeding from an injured vessel, while thrombosis is pathophysiological thrombus formation that may develop into vascular occlusion, causing venous or arterial thrombosis, resulting in heart attack or stroke. in hemostasis and thrombosis interactions of platelets with components from the vessel wall play a very important role. Also, the coagulation process is activated upon vascular injury, generating fibrin and consolidating thrombus formation. The processes of platelet activation and coagulation are closely entwined and both are essential for effective thrombus formation. Furthermore, hemastasis is the result of a balance between anti- and prothrombotic factors. When this balance is disturbed, this may lead to bleeding or thrombosis. Nowadays, mice are frequently used as models to study hemostasis and thrombosis, which leads to important knowledge regarding the factors involved in these processes and subsequently to improved treatment of patients.

\subsection{Discovery of platelets}

Platelets have been recognized as separate entities in blood in the middle of the mineteenth century. At that time a number of scientists claimed to be the first to describe blood platelets (1). The first drawings of platelets were made independently by George Gulliver and William Addison around 1840. However, the roles of platelets in hemostasis and experimental thrombosis were not discovered until the studies of Giulio Bizzozero in 1881 and $1882(2,3)$. As a medical doctor, he studied mesenteric venules in guinea pigs using intravital microscopy and observed that platelets circulate as isolated disk-shaped cells, but adhere to the vessell wall after vascular injury and then aggregate with each other. Ironically, Bizzozero was also the first to identify bone marrow megakaryocytes (4), but he never recognized them as the precursors of platelets. This discovery was made by James Homer Wright in 1906 (5). Around 1880 William Osler established the role of blood platelets (which he called blood "plaques") in human thrombotic disease, identifying them in white thrombit that were formed on "atheromatous ulcers" and on vegetations on heart valves and in aortic aneurisms (6). At that time, the development of thrombosis (thrombogenesis) had already been described by Rudolph Virchow in 1856 (7). He described the nowadays classical triad of factors that are associated with the development of venous thrombosis: endothelial injury/damage, changes in blood flow and blood hypercoagulability.

Why were platelets discovered so late, while erythrocytes were known already in the seventeenth century and leukocytes in the eighteenth century? Antoni van Leeuwenhoek first observed the erythrocyte (and many other minute objects) with a simple home-made microscope (1670), which magnified up to 250 times (8). Earlier, the compound microscope had been developed, which in its simplest form ${ }_{\sharp}$ consisted of two convex lenses aligned in series and achieved a two-step magnification. Compound microscopes developed during the 
seventeenth and eighteenth centuries were hampered by optical aberration, a flaw that was worsened by the use of multiple lenses. These microscopes were actually inferior to single lens micrascopes of that time because of these artifacts. The images they produced were often blurred and had colorful halos associated with chromatic aberrations that not only degraded image quality, but also hampered resolution. Hence, it is not surprising that before 1830 nobody was able to identify a translucent object of only $3 \mu \mathrm{m}$ in diameter. A significant optimization of the compound microscope has been made by Joseph Jackson Lister in 1826. One year later; Thomas Hodgkin and Joseph Lister wrote a paper on 'Microscopical observations of the blood and animall tissues' (9), which marks the beginning of reall animal histology; with Lister's microscope it was now possible to resolve objects about 1 mm apart.

Since Bizzozero's early description of platelets in 1881, our understanding of hemostasis and thrombosis and the important roles of platelets in these processes has been greatlly increased. Hemostasis is the physiological process which results in stopping the bleeding from a damaged vessel, while thrombosis is an acute complication that develops on chronic atherosclerotic lesions and causes heart attacks and stroke $(10,11)$. Nowadays, atherothrombosis, i.e. thrombus formation at the surface of atherosclerotic plaques in arteries (12) is the main cause of morbidity and mortality in the western world (13). As an important tool in the fight against these diseases, better understanding of the mechanisms involved in platelet adhesion to the vessel wall and subsequent events leading to thrombus formation is needed. This chapter reviews current literature on platelet morphology, platelet adhesion to the vessel wall and subsequent platelet activation and thrombus formation. Since the majority of the experiments in this thesis have been performed with (genetically modified) mice, attention is also paid to similarities and differences between human and mouse platelets.

\subsection{Platelet morphology}

Platelets are the smallest anuclear cellular elements present in human blood in concentrations of $150-350 \times 10^{9} / \mathrm{L}$, where they circulate mostly in close proximity to the endothelial lining of the vessel wall (14). They are shed from megakaryocytes in bone marrow and lung. Once released, platelets circulate in the human body for 7-10 days, after which they are cleared by spleen, liver and bone marrow. In general, resting platelets have a discoid shape, with a longitudinal diameter of $3 \mu \mathrm{m}$, a thickness of $0.5 \mu \mathrm{m}$ and a volume of $7.5-10 \mathrm{fL}$ in humans $(15,16)$. In mice, the species studied in the present thesis, platelets are smaller (mean platelet volume $4.7 \pm 0.3 \mathrm{fL}$ ) and have a life span of $4.5-5.5$ days, whereas the platelet count is generally higher than in humans $\left(450-1690 \times 10^{9} / \mathrm{L}\right)(16)$. Apart from differences in size and number, human and mouse platelets have similar morphologic structures and react in similar ways to environmental stimuli. 


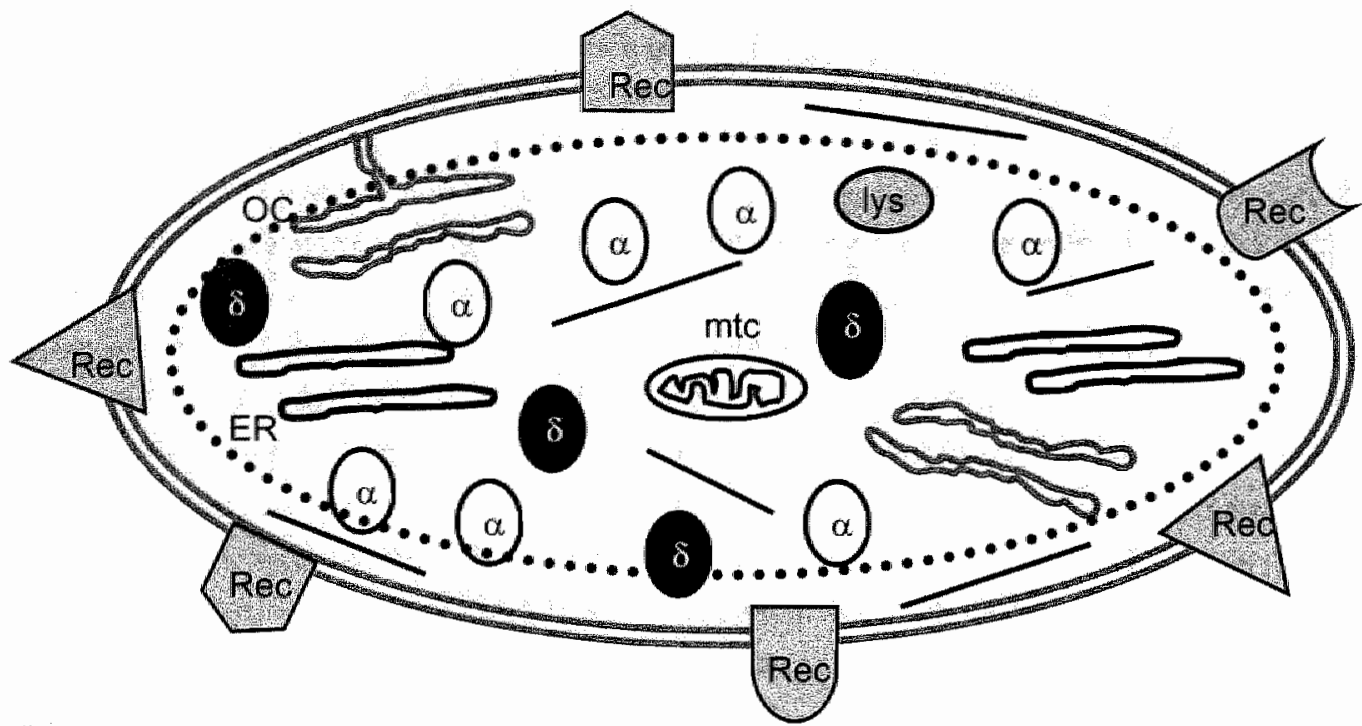

Figure 1.1. Schematic drawing of platelet morphology. This cartoon represents a cross-section through a platelet. The plasma membrane and the open canalicular system (OCS) are shown in grey; in the plasma membrane several types of receptors (Rec) are anchored. ER = endoplasmatic reticulum $\mathrm{mtch}^{\circ}=$ mitochondrion; lys = lysosome; $\alpha=\alpha$-granule; $\delta=$ dense granule. The microtubule coil is represented by the dotted line and the actin microfilaments and intermediate filaments are depicted as straight lines.

Platelets react, adhere, spread, secrete, and also interact with each other instantly upon changes in their environment, particularly after vessel wall injury. These responses require platelets to undergo rapid morphological changes, as they convert from their resting discoid shape into an activated shape. To enable these swift morphological changes, platelets are equipped with several features, such as an extensive surface-connected membrane system (Fig. 1.1). The bilamellar plasma membrane extends into the cytoplasm through an open canalicular system, which greatly enlarges the surface area of the platelet. In close contact to the apen canicular system lies the dense tubular system or endoplasmatic reticulum (ER), in which $\mathrm{Ca}^{2+}$ ions are sequestered; $\mathrm{Ca}^{2+}$ is an important intracellular messenger during platelet activation. The ER membrane also contains enzymes, including those needed for thromboxane $A_{2}$ (TxA $A_{2}$ synthesis, i.e. the cyclooxygenase $(C O X-1)$ and TxA plasma membrane numerous receptor proteins are embedded, which are required for interaction of the platelet with proteins present in plasma, on other blood cells and vascular tissue.

The platelet's shape is determined by the cytoskeleton, which consists of microtubules, microfilaments and intermediate filaments. A thick bundle of microtubules in the periphery of the platelet (microtubule coil) forms a solid, egg-like structure that is responsible for the discoid form of the platelet (15), whereas the actin microfilaments and intermediate filaments (mainly desmin 
and vimentin) form an integrated network that coats the inner surface of the plasma membrane and that is involved in platelet shape change (15).

Platelets also disperse several organelles and secretory granules within their cytoplasm (Fig. 1.1). The $\alpha$-granules are most abundant and contain proteins such as filbrinogen, von Willebrand factor (VWF), P-selectin, platelet factor 4, coagulation factor $V$, growth arrest specific gene 6 (Gas6) and thrombospondin. The dense granules are rich in serotonin, adenosine diphosphate (ADP), adenosine triphosphate (ATP) and the divalent cations $\mathrm{Ca}^{2+}$ and $\mathrm{Mg}^{2+}$. The contents of these granules are released upon platelet activation and strongly support the subsequent aggregation of platelets and formation of a thrombus.

\subsection{Platelet adhesion, aggregation and thrombus formation}

Following damage or alterations of endothelial cells (the inner lining of blood vessels), the subendothelial extracellular matrix (ECM) may be exposed, after which platelets can come into contact with thrombogenic components in the ECM. The ECM contains different macromolecules that are suitable ligands for platelet adhesion molecules, including various types of fibrillar collagen, laminin "fibronectin, proteoglycans, vitronectin, thrombospondin and von Willebrand factor (WWF). The hemostatic response to vascular injury is dependent on the extent of damage, the specific matrix proteins exposed and on the local blood flow conditions. Collagen plays an important role as it not only supports platelet adhesion, but also strongly activates the cells (17). Under conditions of elevated shear, as in arteries, platelet adhesion to collagen is strictly dependent on the interaction of platelets with collagen-bound VWF (18). Together, collagen and WWF are key components of the extracellular matrix initiating platelet adhesion and activation.

There are genes for more than 20 forms of collagen in the human genome, 9 of which are expressed in the vessel wall: types I, III, IV, V, VI, VIII, XII, XIII and XIV. Collagens represent up to $40 \%$ of the total protein of the vessel wall and fibrillar types I and III are the major constituents of the extracellular matrix. Three polypeptide chains ( $\alpha$-chains) form the fundamental structure of the collagen molecule, which is characterized by the presence of one or more triple-helical domains. Mature WWF is a large multimeric glycoprotein consisting of a variable number of subunits (minimal 2, up to 50-100). WWF is synthesized in endothellal cells and megakaryocytes, and is composed of 4 types of domains (A-D), arranged in the following order: D1-D2-D'-D3-A1-A2-A3-D4-B1-B2-B3-C1-C2 (19). In endothelial cells, VWF is stored in the Weibel-Palade bodies and can be released, either constitutively or via secretion, in two directions: luminal (into the circulating blood) and abluminal (into the extracellular matrix), where it binds directly to collagen types I and III via its A3 domain. 


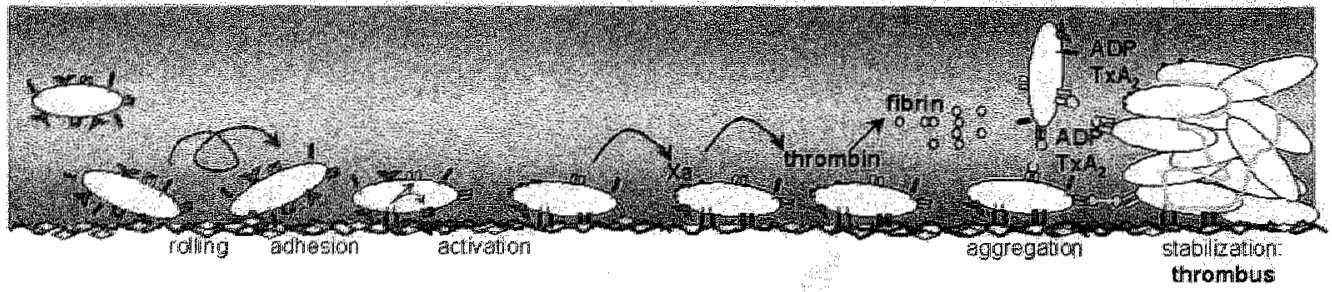

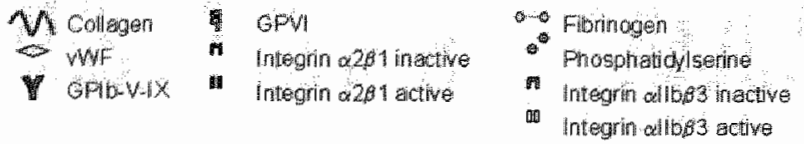

Figure 1.2. Model of platelet-collagen interaction leading to thrombus formation. After endothelial cell denudation, platelets tether to subenidothelial collagen fibers by interaction of their GPIb-V-IX receptors with von Willebrand factor (WWF), which leads to initial rolling of the platelets over the surface. Subsequent stable adhesion to collagen is mediated through direct binding of glycoprotein VI (GPVI) and integrin $\alpha 2 \beta 1$ and indirect binding of integrin oll b/ 33 to WWF. GPVI binding to collagen leads to activation of the integrins $\alpha 2 \beta 1$ and $\alpha$ llb $\beta 3$ (indicated by black arrows inside platelet). Activation of integrins involves a conformational change of the receptor from an inactive to an active state. Platelet-collagen interaction also induces exposure of phosphatidylserine on the outer membrane of the platelet, which forms a catalytic surface for the assembly and activation of coagulation factors, leading to the formation of factor Xa and thrombin. Activated platelets form the aggregate via cross-linking of fibrinogen bound to integrin all $\mathrm{b} \beta 3$. Further crosslinking is establishedl by binding of WWF and fibronectin to allbP3 and GPlb-V-IX. Also, activated platelets will release TXA and ADP. These autocrine agents, together with thrombin, activate other platelets via their specific receptors, leading to growth of the aggregate. The platelet aggregate is stabilized by fibrin, which is formed out of fibrinogen by thrombin, through the formation of a network.

When collagen is exposed, binding of plasma WWF is a crucial step in the response to vascular injury. Soluble WWF does not bind to resting platelets, but when immobilized on a surface it forms a reactive surface capable of capturing platelets in flowing blood (19). Several residues in the $A 3$ domain display multiple conformations, a flexibility which suggests that binding of A3 to collagen involves an induced-fit mechanism (17). High shear stress induces conformational changes of $W W F_{\text {, }}$ resulting in a fast, reversible interaction between platelet glycoprotein (GP) |b-V-IX and the A1 domain of WWF (20). Moreover, WWF also contains a unique Arg-Gly-Asp-Ser (RGDS) sequence in its $\mathrm{C} 1$ domain, the essential binding site for GPIlbilla (integrin allb $\beta 3$ ). Hence, WWF can act as a bridging molecule in platelet-collagen interactions, since it can bind to both collagen and the platelet receptors GPIb-V-IX and allib $\beta 3$. The interaction between WWF and GPIb-V-IX reduces the velocity of platelets flowing over (collagen-bound) WWF and results in transient attachment ('rolling') to a collagen surface (Fig. 1.2) (21)

Following platelet rolling, direct interactions between collagen and platelets lead to adhesion (Fig. 1.2) (11,22). Platelets adhere to collagen via two receptors, GPVI and GPla-lla (integrin $\alpha 2 \beta 1)(22,23)$. This direct binding to collagen induces platelet activation, which is predominantly mediated by GPVI (22). The activated platelets change shape and expose phosphatidyl-serine (PS) on their outer membrane (Fig. 1.2). The availability of PS greatly 
accelerates the conversion of prothrombin into coagulant thrombin and thus, enhances clot formation (24-26). Chapter 2 addresses the typical morphological changes accompanying PS exposure in these procoagulant platelets.

Following adhesion to a collagen surface, activated platelets can recruit platelets from flowing blood to form a platelet aggregate. They activate nearby platelets via secretion of autocrine agents such as ADP and TXA membrane. $\mathrm{TXA}_{2}$ is formed from arachidonic acid, that is released from membrane phospholipids by phospholipase $A_{2}$ upon platelet activation. Once formed, $T \times A_{2}$ diffuses through the platelet membrane and activates other platelets by binding to the thromboxane-prostanoid receptors, TP $\alpha$ and TPB (27). ADP, secreted from dense granules by exocytosis, activates platelets via two receptors, $\mathrm{P}_{2} \mathrm{Y}_{1}$ and $\mathrm{P}_{2} \mathrm{Y}_{12}$; the first receptor mediates shape change and initiates aggregation, while the latter is required for complete aggregation (28). Platelets also contain $\mathrm{P} 2 \mathrm{X}_{\|}$receptors, which enhance collagen-induced platelet aggregation through a rapid ATP-induced $\mathrm{Ca}^{2+}$ influx (29).

Formation of a platelet aggregate is strongly dependent on the presence of integrin $\alpha$ llb $\beta 3$, which upon platelet activation binds several adhesive molecules to form cross-links between platelets (Fig. 1.2) (30). Fibrinogen is the major platelet cross-linker, present both in plasma and platelet $\alpha$-granules (15). It is an extended dimeric molecule with unique RGDS binding sites for $\alpha$ llb $\beta 3$ on both ends. Integrin $\alpha$ llb 33 can also cross-link platelets via WWF and fibronectin (31,32). Moreover, platelet cross-linking by interaction of VWF and GPIb-V-IX supports aggregation, particularly under high shear conditions (33).

Thrombin is a crucial protein linking coagulation, platelet activation and thrombus formation. It is formed during coagulation (Fig. 1.3) and cleaves fibrinogen into fibrin, which forms networks and stabilizes the platelet aggregate and, hence, consolidates the formation of the thrombus (Fig. 1.2). Thrombin is also a potent platelet agonist. Three thrombin receptors have been identified on human platelets, namely the GPIb-V-IX complex and the protease activated receptors, PAR-1 and PAR-4 (34). Activation of PARs occurs when thrombin cleaves the $\mathrm{N}$-terminus of the receptors, exposing a new $\mathrm{N}$-terminus, which serves as a ligand for the receptor. Current data indicate that the vast majority of thrombin responses is due to PAR-1 (35). Interestingly, mouse platelets do not express PAR-1, and in these cells low concentrations of thrombin can bind to PAR-3, enabling PAR-3 to function as a co-factor for PAR-4 (36). However, at high thrombin concentrations, PAR-4 can signal independently of PAR-3 (37). In humans, PAR-1 and PAR-4 signal independently in response to thrombin, with PAR-1 responding at low concentrations of thrombin, whereas PAR-4 responds only at higher thrombin concentrations $(38,39)$. 


\subsection{The platelet procoagulant response}

The plasma mernbrane of resting platelets has an asymmetric distribution of phospholipids. The outer leaflet is composed predominantly of the choline phospholipids sphingomyelin and phosphatidylcholine, whereas the inner leaflet mostly contains the aminophosphollipids phosphatidyl-ethanolamine (PE) and phosphatidylserine (PS). At least two transporter proteins are involved in maintaining this phospholipid asymmetry: the aminophospolipid translocase (40), which transports PS and PE from outter to inner leaflet, and floppase, which transports all phospholipids outward with a halftime about 10 times longer than transllocase. Upon platelet activation, intracellular calcium levels rise and inhibit translocase and floppase activity. In addition, the high calcium levels activate a non-selective phospholipid scramblase, which allows phopholipids to move randomly between the two leaflets and results in the appearance of PS and PE on the outer surface of the platelet $(40,41)$. Until now, the identities of translocase and scramblase are still unknown (26). The prolonged rise in intracellular calcium required for the procoagulant response can be mediated by collagen or high doses of thrombin; secreted ADP is known to potentiate this response (as discussed below) $(26,42)$.

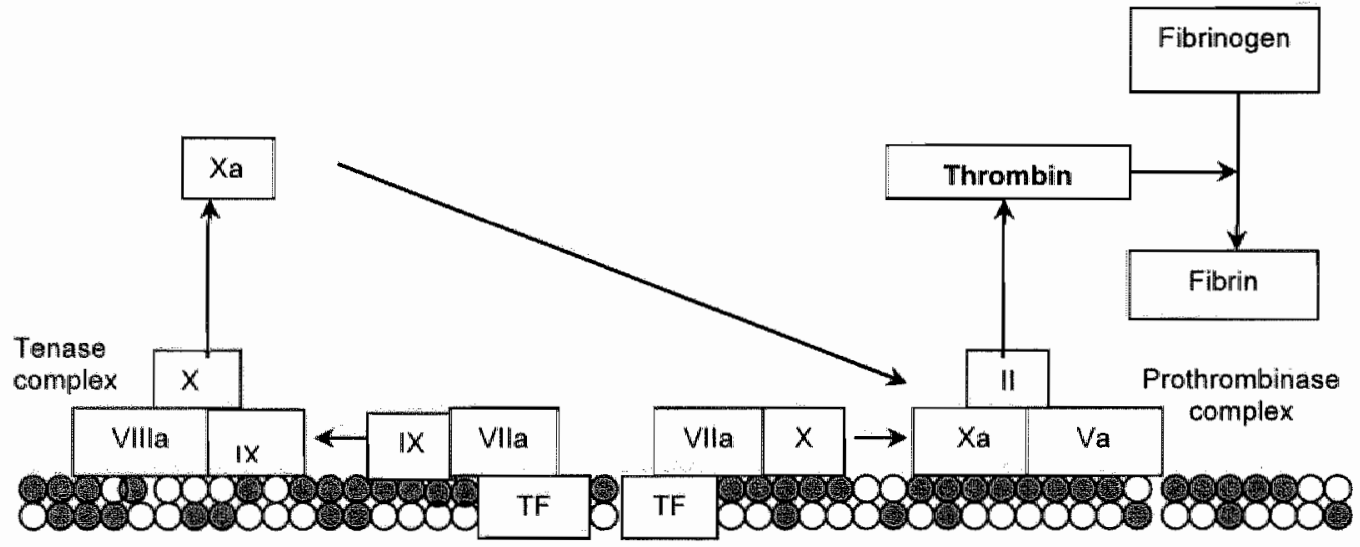

Figure 1.3. Tissue factor induced coagulation. Upon vascular injury, tissue factor (TF) is exposed at surfaces of smooth muscle cells and fibroblasts in the vessel wall, or inflammatory cells at the site of injury. Circulating factor VIla or VIII binds to TF and VII is consequently activated. The membrane-bound TF/FVIIa complex converts factors $\mathrm{XX}$ and $X$ into their active forms (initiation phase). Factor $\mathrm{IX}$ and $\mathrm{X}$ bind to exposed PS (dark circles) on procoagulant platelets and assemble into the tenase and prothrombinase complexes. which respectively convert the zymogens Factor $X$ and prothrombin (Factor $I I$ ) in to their active forms factor $X a$ and thrombin. During the propagation phase of coagulation, factor IXa stimulates the tenase reaction, after which factor $X a$ stimulates prothrombinase. Thrombin subsequently converts soluble fibrinogen into fibrin and stimulates the formation of factors XIIIa, Va, VIIIa and Xla. 
The exposure of PS on the platelet surface strongly promotes two important reactions of the coagulation cascade, the tenase and prothrombinase reactions (Fig. 1.3). This involves the binding of the vitamin $K$-dependent coagulation factors $\|$ (prothrombin), $V \| I_{1} \mid X_{2}, X_{n} V$ and $V\|\|$ to PS. Factors $\mathrm{II}, \mathrm{VI}, \mathrm{IX}$ and $X$ contain glutamate residues which are carboxylated by vitamin $K$ dependent carboxylase to gamma-carboxylglutamate (Gla)-residues. These Gla-residues can bind to PS in a calcium-dependent way. The cofactors Factor V and VIII can bind to platelets, independently of exposed PS. The mechanism by which this occurs is presently unknown.

\subsection{Main intracellular signaling pathways}

Many of the functional platelet responses, including secretion, $\operatorname{TxA}_{2}$ formation and the PS exposure are mediated by a rise in the intracellular $\mathrm{Ca}^{2+}$ concentration $\left(\left[\mathrm{Ca}^{2+}\right]_{i}\right) .\left[\mathrm{Ca}^{2+}\right]_{i}$ elevation is to a large extent due to the activation of phosphoinositide-specific phospholipase $C$ (PLC) $\beta$ and $\gamma$ isoforms, which hydrolyze phosphatidylinositol 4,5-biphosphate to generate the second messengers inositol 1,4,5-triphosphate (InsP3) and sn-1,2-diacylglycerol (DAG). Ins $P_{3}$ binds to $\mathrm{Ca}^{2+}$-channels in the endoplasmatic reticulum, which release stored $\mathrm{Ca}^{2+}$ into the cytosol (43). This depletion of the $\mathrm{Ca}^{2+}$ stores triggers the influx of extracellular $\mathrm{Ca}^{2+}$ into the cell through store-regulated $\mathrm{Ca}^{2+}$ influx channels. Together, this results in a series of transient $\left[\mathrm{Ca}^{2+}\right]$ increases (spikes) with irregular frequency and amplitude (44). However, upon platelet stimulation by collagen or high concentrations of thrombin, a non-oscillating prolonged rise in $\left[\mathrm{Ca}^{2+}\right]_{\mathrm{i}}$ is seen (43). The other second messenger DAG activates protein kinase $\mathrm{C}_{\|}$which in turn phosphorylates many effector molecules. Activated protein kinase $C$ in combination with elevated $\left[\mathrm{Ca}^{2+}\right]_{\text {i }}$ causes secretion of autocrine agents and contributes to integrin activation and hence, platelet aggregation. Rises in $\left[\mathrm{Ca}^{2+}\right]_{i}$ are also implicated activation of phospholipase $\mathrm{A}_{2}$ in actin rearrangements and shape change (43). In addition, [Ca $\left.{ }^{2+}\right]_{i}$ is necessary to activate the alleged enzyme phospholipid scramblase, a membrane activity that is assumed to regulate the procoagulant response $(26,41)$.

The PLCy2/Ca ${ }^{2 *}$ signaling cascade is triggered by collagen via GPVI (22). GPVI recognizes the specific sequence Gly-Pro-Hyp (GPO) within collagen, and activation is achieved by dimerization of two GPVI receptors (17). GPVI is a member of the immunoglobulin receptor superfamily (45) and is non-covalently associated with the signal transducing FcR $\gamma$-chain $(46,47)$. Crass-linking of GPVI induces tyrosine phosphorylation on the FCR $\gamma$-chain immunoreceptor tyrosine-based activation motive (ITAM) (46) by the Src kinases Fyn and Lyn (48). This is followed by the binding and activation of another tyrosine kinase Syk, which initiates downstream signaling events that lead to the activation of a number of effector enzymes, including PLC 2 , small G-proteins and phosphoinositide-3 kinase (PI-3 kinase). The many adaptor proteins, including LAT and SLP-76 play criticall roles in the further signaling cascade (reviewed in $(22,49)$ ). In vitro, platelet GPVI can be selectively stimulated by a 
Synthetic, triplethelical GPO-containing peptide, termed collagen-related peptide (CRP) or by convulxin, atoxin isolated from venom of the tropical rattle snake.

The integrin $\alpha 2 \beta 1$ is a heterodimeric type I transmembrane receptor, which is present in a low-affinity state on the membrane of resting platelets, like the other main platelet integrin allbB3. Ligand binding upon platelet activation requires a conformational switch mechanism, which shifts the integrin to a high-affinity state, and probably also induces receptor clustering (23,50-52). This so-called inside-out signaling can be achieved by several agonists, most importantly collagen (via GPVI), but also thrombin, TXA,$A D P(53$ ) and WWF (via GPIb-V-IX) (54). Once in its active state, integrin $\alpha 2 \beta 1$ recognizes its own specific sequence within collagen, Gly-Phe-Hyp-Gly-Glu-Arg (GFOGER), through a particular extracellular domain located on $\alpha 2$, the so-called inserted (or 1 -) domain (55). Like GPVI" the integrin $\alpha 2 \beta 1$ has been proposed to couple to the intracellular signaling proteins Syk, SLP-76 and PLCy2, but not to the FcR $\gamma$-chain (56). The relative roles of GPVI and integrin $\alpha .2 \beta 1$ in platelet activation on coliagen have been a subject of considerable debate in recent years, and this topic is investigated in chapter 3 of this thesis.

The PLC $\beta / \mathrm{Ca}^{2+}$ pathway is triggered by several members of the G-protein coupled receptor familly. Several heterotrimeric GTP-binding proteins (G-proteins) are involved in the signal transduction process in platelets $(57) . G_{q}$ couples to PLC $\beta$ following activation of the

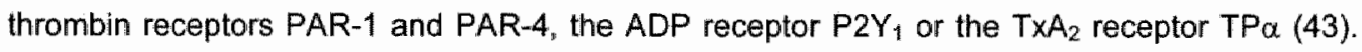
Since $G_{q}$ can interact with several types of receptors, it is involved in platelet responses to several agonists. As a result, $G_{q}$-deficient platelets show severely impaired responses to thrombin, ADP and the TxA 2 analog U46619 (58). Typically these platelets are still capable of shape change in response to thrombin and $U 46619$, in a way independently of elevated [Ca ${ }^{2+}$. Recent studies show that this shape change is mediated by other $G$-proteins, $G_{12}$ and $G_{13}$, which activale a Rho/Rho-kinase (ROCK) mediated pathway after platelet activation by thrombin or $T \times A_{2}(59)$. Experiments with $G_{12}$ and $G_{13}$-deficient mice showed that the $G_{12 / 13^{-}}$ mediated effects are mainly caused by $G_{13}(60)$. Another important $G$-protein is $G_{i}$, which couples to PAR-1, P2Y 12 and possibly TPB, and inhibits the enzyme adenylate cyclase (61). This results in reduced levels of the platelet-inhibitory second messenger cyclic adenosine monophospate (CAMP). However, $G_{i}$ likely also mediates another signaling pathway, leading to activation of phosphoinositide (PI) 3 -kinase, which is involved in the activation of allb $\beta 3$ and potentiation of secretion $(62,63)$. It has been shown that full platelet activation via $G$-protein couplled receptors needs stimulation of two out of the three G-protein coupled pathways $(64,65)$. However, the three G-protein pathways are tightly entwined and all play an important role in platelet responses in humans $(66,67)$ and mice $(58,60)$.

It is known that certain combinations of agonists lead to high levels of $\left[\mathrm{Ca}^{2+}\right]_{1}$ and PS exposition. More than twenty years ago, Bevers and colleagues demonstrated that thrombin 
and collagen only moderately affect the platelet procoagulant response individually, while dual stimulation with both agonists appeared to be the most potent inducer of procoagulant activity (68). Collagen induces PS exposure mainly via GPVI (as described above), while thrombin mediates procoagulant activity mainly via PAR-1 (35,69). Moreover, it has been shown that ADP is also involved in the expression of $P S$, mediated via $P 2 Y_{12}\left(70_{11} 71\right)$.

Signaling towards aggregation is regulated in a manner that differs from signaling towards procoagulant activity. In fact, signaling which leads to aggregation, ie. activation of integrin allbß3, has not been clearly defined (50). Briefly, most agonists cause integrin allbB3 activation via the $A D P-P 2 Y_{12}$ pathway (72). This makes $P 2 Y_{12}$ receptor antagonists (such as clopidogrel) interesting pharmacological agents for the treatment of thrombotic patients. Further, aggregation is inhibited when intracellular cAMP levels are elevated, which is mediated via protein kinase A. Protein kinase $A$ is activated by prostacyclin or prostaglandin $E_{1}$. As P2Y 12 antagonists and prostaglandin $E_{1}$ can also suppress procoagulant activity and thrombin generation $(70,73,74)$, it is possible that their effects on thrombin generation are via regulation of integrin activation. This subject is the topic of chapter 6 .

At arterial shear conditions, the first platelet-vessel wall contact is mediated via GPIb$\mathrm{V}-\mathrm{IX}$ interaction with WWF. The importance of this interaction in supporting platelet-vessel wall and platelet-platelet interactions is clearly delineated "but the contribution of this interaction to platelet activation is less clear. Controversy exists with respect to the question whether ligandbound GPlb-V-IX is signaling. In various reports it is proposed that there are no, weak or strong activating signals generated by wWF binding (reviewed in (49)). Also, the mechanism by which GPIb generates signals is controversial (75), with some studies suggesting direct signals through the cytoplasmic tails of GPIb-V-1X and the accessory protein 14-3-3- $\zeta$ (75), while others point to signaling through associated surface molecules like the FcR $\gamma$-chain $(76,77)$ or indirect mechanisms via ADP release and $T \times A_{2}$ generation (49).

Besides the collagen receptors GPVI and integrin $\alpha 2 \beta 1$, other proteins have also been proposed as receptors for collagen in platelets (22). One of these is glycoprotein IV (CD36), which has been shown to bind to collagen (78). GPIV is now no longer considered as a functional receptor for collagen, as human and mouse platelets that lack GPIV respond to collagen normally $(79,80)$. Furthermore, GPV is also a serious candidate collagen receptor. GPV $/$ - mouse platelets show a moderate decrease in collagen-dependent adhesion and aggregation and additional studies demonstrated that GPV specifically binds to collagen (81). However in vivo studies have yielded conflicting results regarding the significance of GPV deficiency $(81,82)$. Thus, the question whether there is a third, functional collagen receptor remains open. 


\subsection{Human disorders of platelet receptors or ligands}

The process of thrombus formation is a intricately orchestrated response of platelets and coagulation factors to damage of the vessel wall, involving many receptor-ligand interactions and signaling pathways. The importance of a platelet receptor or adhesive protein becomes evident when it is missing. which may have severe consequences for hemostasis in humans. Table 1.1 summarizes some disorders in which (the function of) platelet receptors or their ligands are disturbed and, hence, clearly demonstrates their importance in physiology. These receptors are also very interesting with respect to platelet procoagulant activity, although in most patients this has not been studied.

Deficiency of collagen receptors is very rare in humans. Integrin $\alpha 2 \beta 1$ deficiency has been described in only three patients (Table 1.1), and was associated with a bleeding phenotype. One patient had platelets with about 15 to $25 \%$ of normal GPla (integrin $\alpha 2$ ) expression, and her platelets failed to adhere to collagen, but spread normally on other subendothelial surfaces $(83,84)$. Platelets from this patient showed defective binding to a number of adhesion molecules, raising the possibility that the bleeding effect was caused by defective binding to other ligands besides collagen (85). In another patient, collagen-induced platelet aggregation was markedly reduced, but these platelets were deficient not only in GPla but also in thrombospondin-1 (86). Platelet aggregation in response to collagen could be restored in this patient by the addition of thrombospondin. Soon after the initial studies, the patient passed through menopause, after which collagen responsiveness recovered. A similar recovery of the platelet functions was seen in the first patient after passing menopause. The third (male) patient had an acquired deficiency of platelet GPla, due to a myeloproliferative disorder (87). His platelets also completely lacked collagen-induced aggregation and adhesion.

Only seven patients lacking GPVI have been reported so far (Table 1.1). Given the important role of GPVI in platelet adhesion to and activation by collagen (see above), it is surprising that these patients only show a mild bleeding tendency with a slightly prolonged bleeding time. The first patient was reported almost 20 years ago. She appeared to carry antibodies recognizing a $62 \mathrm{kD}$ platelet membrane protein and her platellets did not react to collagen (88). In 2001 and 2004, two other female patient were reported with auto-antibodies against GPV/; their platelets also showed defective collagen-induced aggregation and an impaired adhesion to collagen $(89,90)$. Furthermore, 4 other patients have been discovered, who were (almost) completely lacking the GPVI receptor on their platelets (91-94). All patients were women, three Japanese and one French, and their platelets failed to aggregate in response to collagen, but had an almost normal response to ADP and other agonists. In the French patient GPVI deficiency accompanied gray platelet syndrome (characterized by a low platelet count and absence of $\alpha$-granules). The investigators suggested that such GPVI 


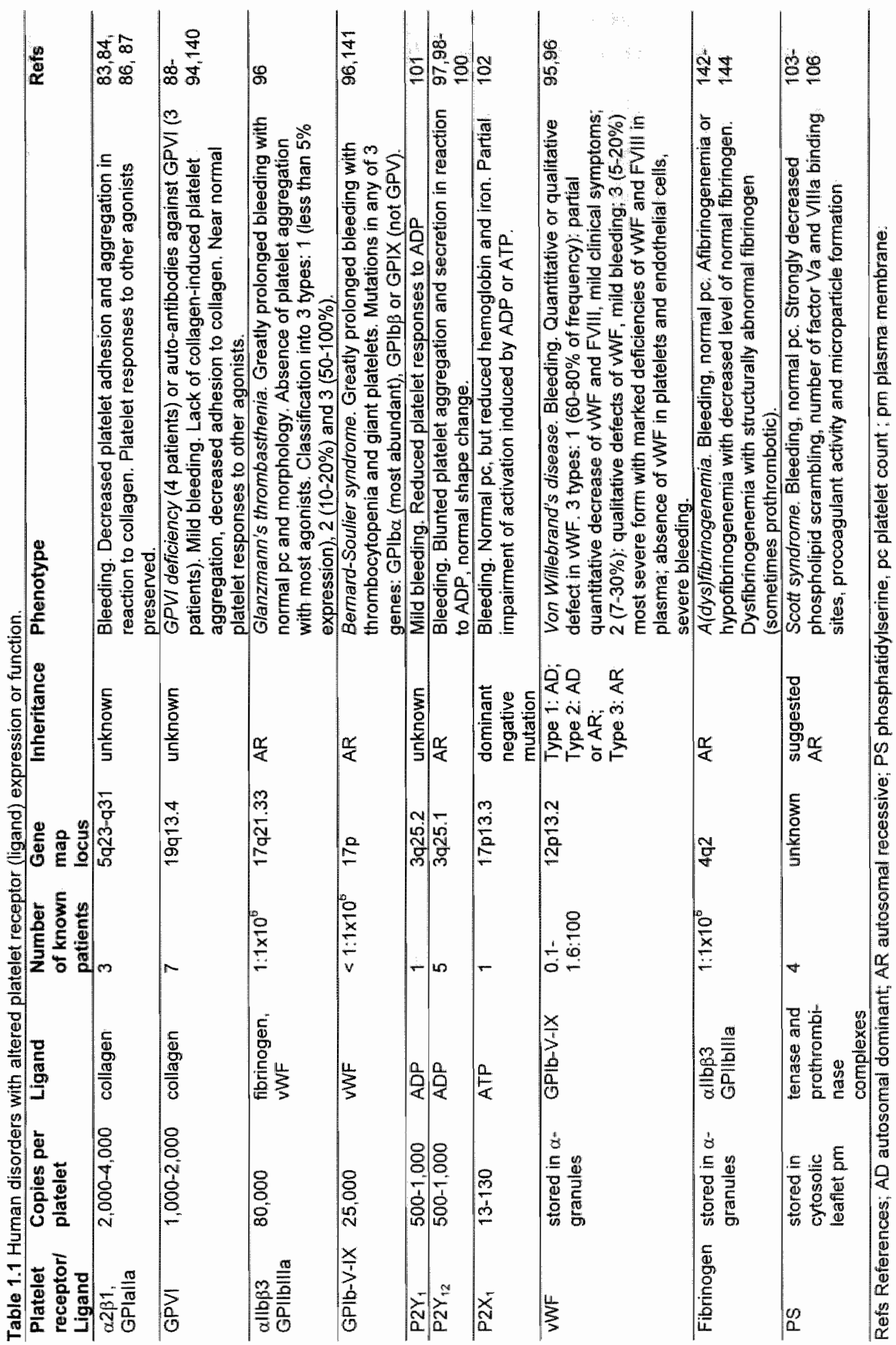


deficiency may be present in more patients with this syndrome, since abnormal collageninduced aggregation has been reported more often (94).

Deficiencies of integrin allbק3 or GPIb-V-1X are more common (about $1: 1,000,000$ ), and are designated as Glanzmann's thrombasthenia and Bernard-Soulier syndrome. respectively (Table 1.1). These patients have severe bleeding problems in common. While Glanzmann patients have normal platelet counts and morphology. Bernard-Soulier patients display thrombocytopenia and extremely large ("giant) platelets. A large number of individuals suffer from von Willebrand's disease (WWF deficiency). The latter is the most common disorder of platelet activity occurring in about $1 \%$ of the general population $(95,96)$. The severity of symptoms is dependent on the type of von Willebrand's disease (Table 1.1); the majority of patients have only mild clinical symptoms (type 1).

Two unrelated patients with prolonged bleeding times and $P 2 Y_{12}$ receptor deficiency are described, whose platelets change shape normally, but undergo no rapidly reversible aggregation when exposed to ADP (97,98). Furthermore, a family is described in which two sisters have a defect in the $\mathrm{P}_{2} \mathrm{Y}_{12}$ receptor. Both show easy bruising, menorrhagia and severe bleeding complications after surgery (99). Recently, another patient was described with a homozygous mutation in the translation initiation codon of the $P 2 Y_{12}$ gene (100). This patient had a mild bleeding tendency, impaired platelet aggregation at low agonist concentrations, impaired platelet spreading and small, unstable thrombus formation in flow experiments over collagen. Preliminary reports of congenital defects of platelet $P 2 Y_{1}$ and $P 2 X_{1}$ receptors have also been presented $(101,102)$. In either case, this is associated with a bleeding diathesis and reduced platelet aggregation (Table 1.1).

The Scott syndrome is a rare deficiency in platelet procoagulant activity. It is associated with severe bleeding and platelets from these patients show strongly decreased phospholipid scrambling and a decreased number of factor $\mathrm{Va}$ and Vllla binding sites. Moreover, these platelets lack the ability to promote tenase and prothrombinase activity in response to agonists and show impaired capacity to shed microparticles (103-105). As intracellular calcium responses are normal, the defect should lay downstream of calcium signaling (106).

\subsection{Targeted gene disruption of platelet receptor proteins and ligands in mice}

The piatelet, coagulation and extracellular matrix proteins of the common laboratory mouse show striking similarities to the human systems, with virtually every protein represented in both species and with every cascade appearing to serve similar functions in both species (16). Nonetheless, significant differences exist at the molecular and structural level, with varying 


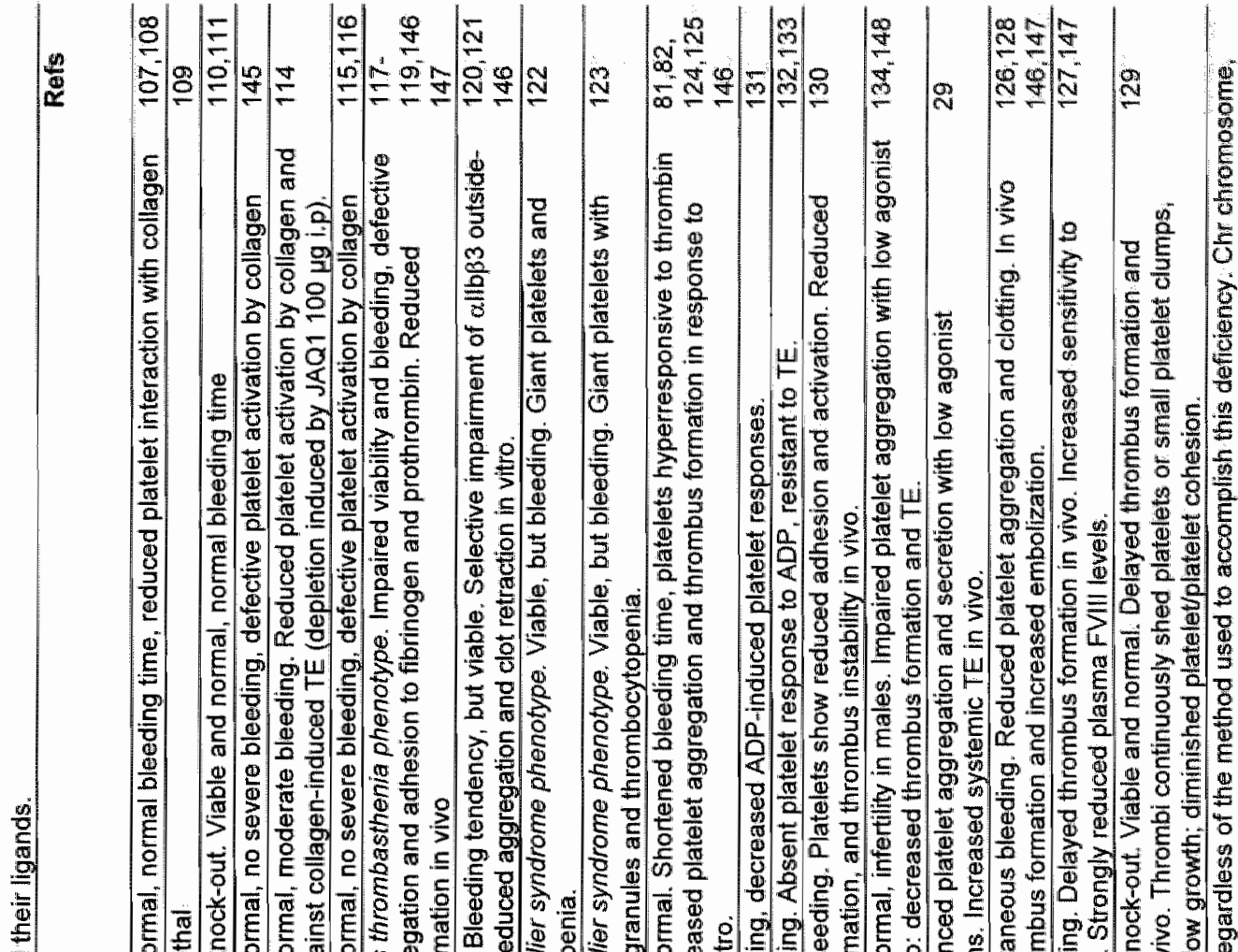

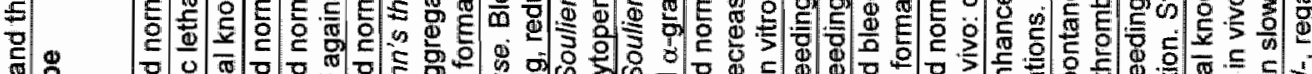

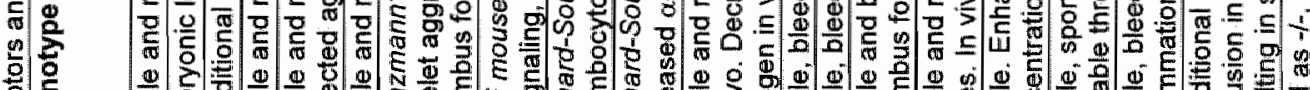

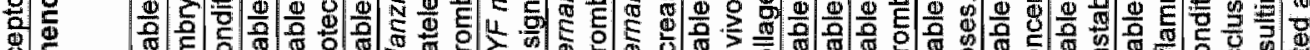
兽立 $\quad$ 兴

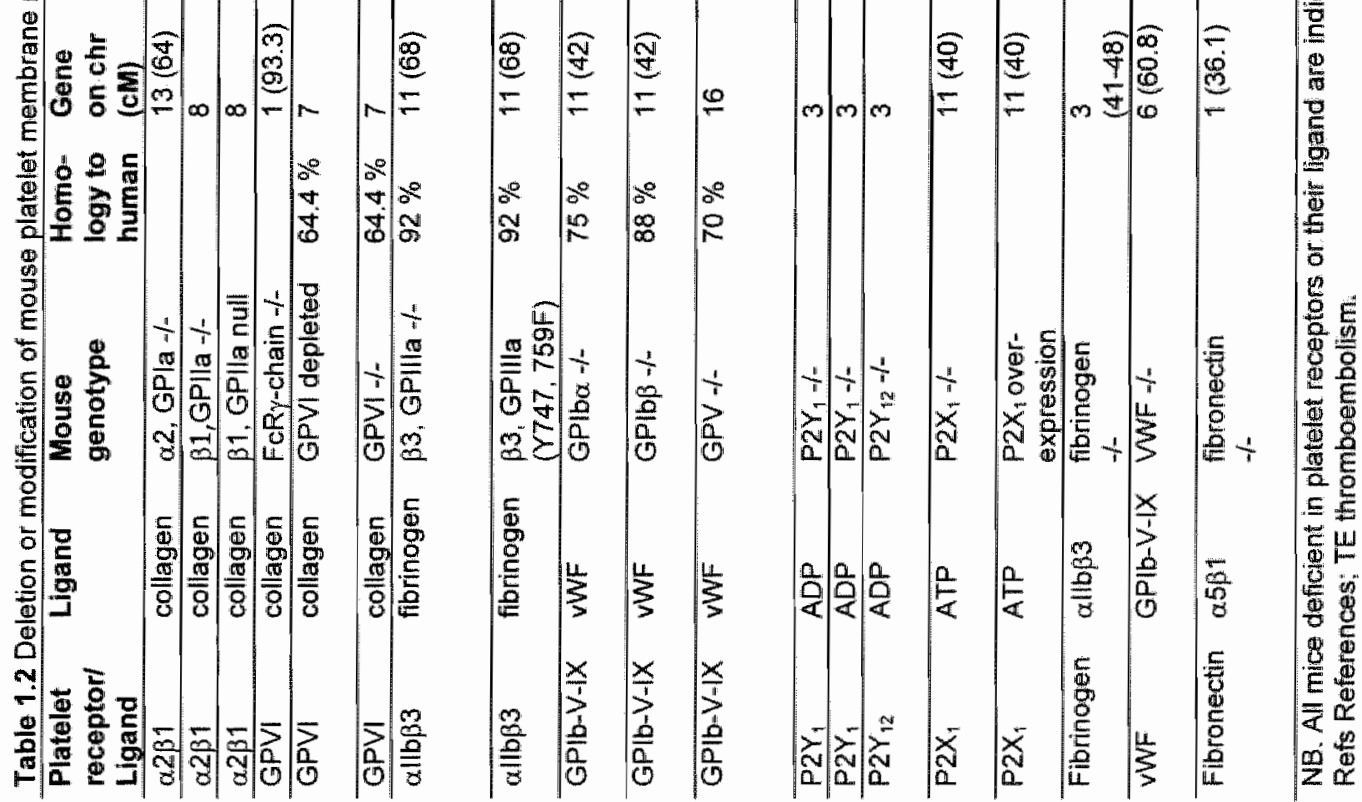


degrees of homology between corresponding mouse and human proteins (Table 1.2). The intraduction of targeted gene disruption in mice has provided unique opportunities to study platelet function, and of every patient described in Table 1.1 a mouse deficient in the same receptor or ligand has been generated (Table 1.2). Comparison of both tables reveals many similarities regarding the regulation of platelet activation, aggregation and procoagulant activity. Undoubtedly many of the observations in these animal models will have direct relevance for human thrombosis and hemostasis.

Murine integrin $\alpha 2 \beta 1$ can be knocked-out from platelets by targeting either the $\alpha 2$ - or the 31 gene. Two research groups almost simultaneously reported the generation of $\alpha 2$ integrin-deficient mice (Table 1,2) $(107,108)$. General depletion of the $\beta 1$ gene is embryonically lethal (109) and this lethality was overcome by the generation of conditional $\beta 1$-integrin-deficient mice $(110,111)$. All these mice were found to have normal tail bleeding times, although in vitro their platelets display partial defects in interaction with collagen. These unexpected findings have led to considerable debate in literature. Therefore, we decided to investigate the contribution of integrin $\alpha 2 \beta 1$ to platelet activation and thrombus formation in more detail using $\beta 1 \%$ (chapter 3 ) and $\alpha 2-1$ (chapter 4 ) animais.

Mouse GPVI has been depleted by different methods (Table 1.2). Platelets lacking the FcR $\gamma$-chain were found to lack expression of GPVI on their surface as well (112). As these platelets are refractory to stimulation by various types of collagen, it was argued that the GPVII/FcR $\gamma$-chain complex is a key receptor for platelet-collagen interactions (79). However, some defects of these platelets may also be related to the absence of GPIb, which has also been reported to signal via the FCR -chain $(76,77)$. Another strategy to deplete platelets from GPVI was used in studies with mice that were injected with JAQ1, an anti-mouse GPVI monoclonal antibody (113). This treatment leads to a transient GPVI deficiency, while the expression of other platelet receptors is not affected, including that of $\alpha 2 \beta 1, \alpha \| b \beta 3, G P I b$ and GPV (114). Like FCR $y$-chain - - platelets, the GPVI-depleted platelets are refractory to activation by collagen. Only recently the GPVI gene has been deleted in mice $(115,116)$. Platelets from these mice also failed to aggregate in response to collagen, and showed defective platelet activation following normal initial tethering to a collagen surface, as well as complete abolishment of thrombus formation. Similarly to GPVI-deficient patients, the various GPVIdeficient or -depleted mice did not reveal severe bleeding tendencies.

Mice deficient in $\beta 3$-integirin lack both $\alpha / l b \beta 3$ and $\alpha V \beta 3$ on their platelets. These animals have a bleeding diathesis and platelet function abnormalities similar to those of patients with Glanzmann's thrombasthenia (117). In addition to impaired aggregation, $\beta 3$-integrindeficient mouse platelets are unable to adhere to fibrinogen and prothrombin (118). Furthermore, $\beta 3$-integrin-deficient mice are protected from thrombosis in vivo (119). Upon outside-in signaling, integrin allbp3 becomes tyrosine phosphorylated at the $\beta 3$-integrin 
cytoplasmic tyrosine (ICY) domain (reviewed in (120)). The critical role of this $\beta 3$ tyrosine phosphorylation in platelet function has been established in diYF mice, which express an $\alpha 11 b \beta 3$ form in which the two $\beta 3 \mathrm{ICY}$ domain tyrosines $(Y)$ are mutated to phenylalanine $(F)(121)$. These mice are selectively impaired in outside-in allbp3 signaling, and show defective aggregation and clot-retraction responses in vitro, and also a bleeding phenotype in vivo (102).

Genetic deletion of either GPlba or GPIbP in mice produces a Bernard-Soulier syndrome phenotype $(122,123)$. These mice present all characteristics of the human disease, i.e. prolonged bleeding times, giant platelet size and thrombocytopenia. Moreover, platelets from GPIb $\beta-1$ - mice have $\alpha$-granules with increased size (123). In contrast, mice lacking GPV on platelets do not present a Bernard-Soulier syndrome phenotype, but instead appear to have hyperresponsive platelets, manifested in a shorter bleeding time (124). GPV-deficient piatelets appear to be more sensitive to activation by low concentrations of thrombin, suggesting that GPV acts as a negative modulator of the thrombin response (125). In vitro aggregation studies demonstrated a decreased response of GPV-deficient platelets to collagen (81), while in vivo studies showed accelerated platelet adhesion and thrombus formation, as well as compromised thrombus stability, probably due to increased thrombiin sensitivity (82).

Also, mice lacking fibrinogen (126) and WWF (127), i.e. the ligands of integrin $\alpha$ llib $\beta 3$ and GPIb-V-IX, have been generated (Table 1.2). Surprisingly, thrombi are still formed abundantly in the absence of fibrinogen, but they detached from the subendothelium causing downstream occlusion, as investigated by intravital microscopy of ferric chloride-injured mesenteric vessels (128). Absence of murine WWF significantly delayed platelet deposition and increased the time required for the formation of a first thrombus (127). Importantly, VWFdeficient mice closely mimic the phenotype of severe human von Willebrand's disease. Mice deficient in both fibrinogen and WWF have delayed thrombus formation, but are still capable of forming occlusive thrombi at later time points (128). It was shown that platelets from these mice excessively accumulate fibronectin in their $\alpha$-granules, suggesting that fibronectin is the ligand supporting platelet aggregation via allibp3 in these double knock-out animals. Studies in fibronectim knock-out mice show that initial platelet adhesion is not affected, but thrombus formation is delayed for several minutes. Moreover, thrombi of fibronectin-deficient mice continuously shed platelets or small platelet aggregates, leading to slow thrombus growth (129).

Like platelets from $\mathrm{P}_{2} \mathrm{Y}_{12}$-deficient patients, platelets from $\mathrm{P}_{2 \mathrm{Y}_{12}}-/$-mice change shape normally and do not undergo rapidly reversible aggregation when exposed to ADP or to low doses of collagen or PAR-4-activating peptide (130). Adhesion of P2Y $12 \%$ plattelets to vWF is impaired, whereas adhesion to collagen and fibrinogen appear normal; thrombi raised in vitro are less dense and less activated compared to wildtype counterparts. In vivo experiments point to delayed thrombus formation with small unstable thrombi in a mesenteric artery injury model (130). $\mathrm{P}_{2 Y_{9}}$-deficient mice have been generated by two research groups $(131,132)$. Platelets 
from these mice are unable to aggregate at low doses of ADP or collagen, but they aggregate without shape change in response to high concentrations of $A D P$. In vivo, $P 2 Y$, deficiency increases bleeding time and protects from collagen- and ADP-induced thromboembolism. $P 2 Y_{Y}$ deficient mice display significantly less arterial thrombosis in reaction to ferric chloride compared to controls, and in combination with $\mathrm{P} 2 \mathrm{Y}_{12}$ inhibition the $\mathrm{P} 2 \mathrm{Y}_{1}$ deficiency leads to additive antithrombotic effects (133).

The importance of the $\mathrm{P} 2 \mathrm{X}_{1}$ cation receptor channell has become clear from the generation of mice with altered expression levels. In vitro, $\mathrm{P} 2 \mathrm{X}_{1}$-deficient mouse platelets show impaired aggregation in response to collagen, both in the presence and absence of flow, and reduced secretion of autocrine agents. In vivo, $P 2 X_{1}-$ mice have a reduced mortality in a model of collagen-provoked systemic thromboembolism. The size of thrombi formed after laserinduced vessel wall injury is decreased as compared to normal mice (134). These findings are confirmed with transgenic mice over-expressing the human $P 2 X_{1}$ ion channel in the megakaryocytic cell lineage (29). $P 2 X_{1}$ over-expression results in a prothrombotic phenotype, characterized by enhanced platelet secretion and aggregation evoked by low doses of collagem and other agonists, as well as increased aggregate formation under flow conditions.

\subsection{Methods to study platelet-matrix interactions: whole blood perfusion chamber versus in vivo studies}

Much knowledge about platelets has been generated by in vitro studies under static conditions using blood, platelet-rich plasma, or isolated platelets from healthy subjects, patients or animals. However, shear forces generated by flowing blood have a significant impact on platelet adhesion and thrombus formation. Flow chambers have been devised to mimic these shear conditions in perfusion studies with flowing blood $(135,136)$. In combination with (fluorescence) microscopy and novel real-time imaging facilities, these devices enable data collection under well-controlled conditions of exposure time, thrombogenic surface and reproducible shear stress. In this thesis most studies have been performed using the parallelplate perfusion chamber shown in Fig. 1.4 (42). This setup allows real-time monitoring of sheardependent platelet adhesion and aggregate formation, as well as platelet activation and generation of platelet procoagulant activity using suitable fluorescent probes.

Although the parallel-plate flow chamber is an excellent instrument to study (single) platelet activation and thrombus formation under controlled flow conditions, this type of studies is still relatively far away from the in vivo situation. The endothelial cells, lining the vessel wall, with their pro- and antithrombotic properties significantly influence platelet behavior in vivo (reviewed in (137)). Hence, it is also important to study platelet-vessel wall interactions in vivo, where cells are in their natural environment. Therefore, in the present thesis (chapters 4 and 7 ), 


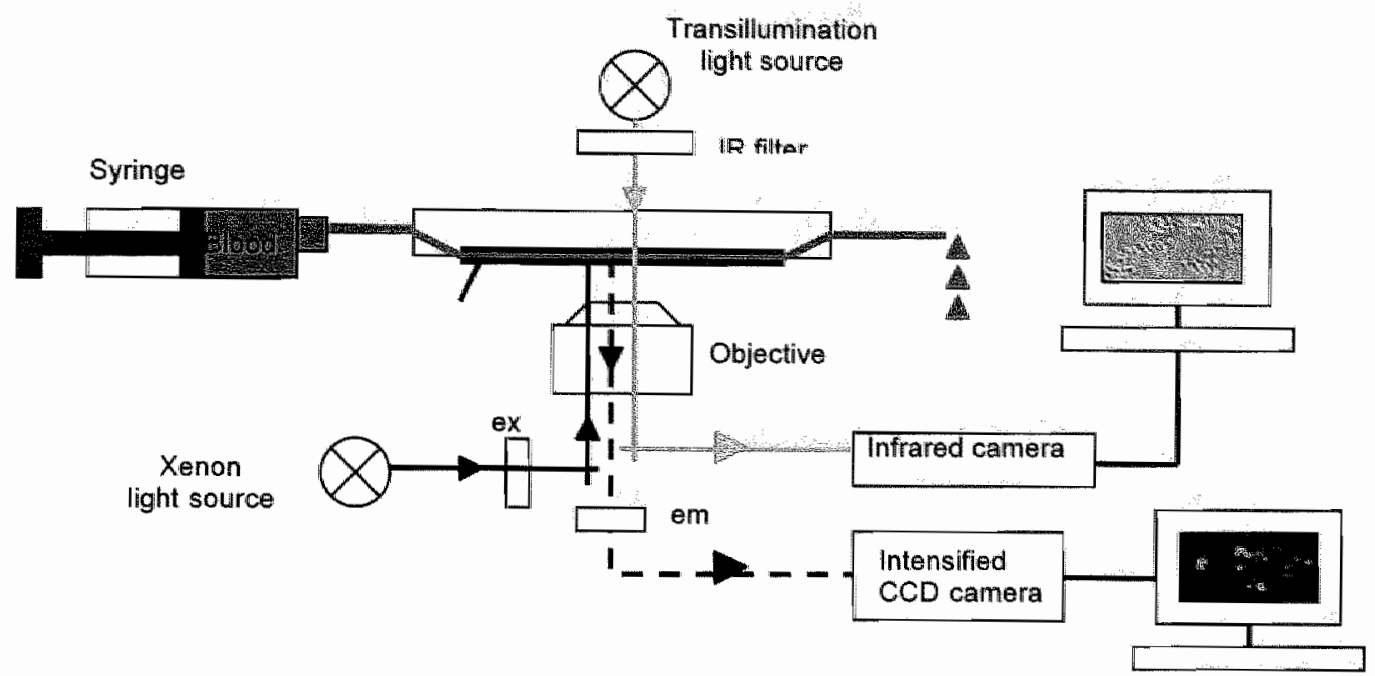

Figure 1.4 Schematic drawing of experimental setup used in chapters 3-7 of this thesis. Thrombus-forming experiments under flow conditions were performed with (mouse) blood anticoagulated with PPACK and heparin or citrate. Rectangular coverslips $(24 \times 60 \mathrm{~mm})$ were coated with collagen fibers (chapters $3-5)$ or fibrinogen (chapter 6). A coverslip was placed in a parallel-plate transparent flow chamber (slit depth of 50 $\mu \mathrm{m}$ ), which was provided with polyethylene tubing (diameter $1 \mathrm{~mm}$ ). Blood was perfused through the flow chamber using a syringe and a pulse-free pump, at low or high wall-shear rate (150-1500 $\left.\mathrm{s}^{-1}\right)$. Phasecontrast microscopy was performed by illumination with a tungsten lamp through an infrared (IR) filter, when required. Fluorescence microscopy was performed under epi-illumination with a xenon light source. The light passed through an excitation band-pass filter and a dichroic mirror, while emitted light from the sample was filtered with an emission filter (em; long-pass). During and after perfusion, high-resolution microscopic transmission and/or fluorescent images were recorded in real-time with a Visitech imaging system (Sunderland, UK). Digital images were captured with two parallel-placed intensified, charge-coupled device (CCD) cameras, recording phase-contrast (infrared) light and epifluorescence light. Fluorescent probes were added to the blood or to the rinsing buffer medium

platelet-vessel wall interactions and ensuing thrombus formation were also studied in an established murine microvascular thrombosis model $(127,128)$. In this model, the thrombotic process was induced by topical application of ferric chloride $\left(\mathrm{FeCl}_{3}\right)$ on mouse mesenteric arterioles and venules, which resulted in the formation of intravascular thrombi. $\mathrm{FeCl}_{3}$ induces local free radical production, which leads to denudation of endothelial cells and exposure of the extracelllular matrix (128). The resulting thromboembolic process can be studied by intravital microscopy by bright-field microscopy using trans-illumination and/or by fluorescence microscopy under epi-illumination (chapter 7). Many conclusions on the alleged anti-thrombotic or thrombophilic phenotypes of genetically modified mice (Table 1.2) have been drawn from studying microvascular thrombosis using similar equipment $(127,128,138,139)$. This model allows real-time imaging of platelet-vessel wall interactions, with separate quantification of thrombus formation and embolization. Furthermore " activation processes in participating piatelets can be studied with the use of fluorescent probes (chapter 7). This in vivo model, as 
well as the parallet-plate flow chamber, has many advantages but, of course, also has its limitations ${ }_{n}$ as will be elaborated in the general discussion (chapter B).

\subsection{Aim and outline of this thesis}

The main goal of the present thesis is to investigate the involvement of key platelet receptors involved in collagen-induced platelet activation and in the platelet procoagulant response. While most research groups have limited their focus on platelet adhesion and aggregation, the studies in this thesis particularly address the signaling towards procoagulant activity $_{1}$ the regulation of PS exposure and the subsequent generation of thrombin and fibrin. The studies were performed using an in vitro model of thrombus formation under controlled conditions of flow and coagulation, as well as in an in vivo model of intravascular thrombus formation. The results indicate that platelet aggregation and procoagulant activity are differently regulated processes, which, however, involve similar sets of receptors. In chapter 2 the present understanding of how platelet interaction with vascular collagen supports the process of thrombin generation and coagulation is addressed. In this chapter the profound morphological changes of procoagulant platelets are also described.

As the role of the integrin $\alpha 2 \beta 1$ receptor for collagen in platelet adhesion and activation was controversial, in chapter 3 the precise function of this integrin in both platelet adhesion and procoagulant activity was investigated using various genetically modified mice with platelets deficient in either GPVI or $\alpha 2 \beta 1$. It was discovered that the integrin has a secondary, yet complementary role to GPVI in collagen-dependent platelet activation and PS exposure. The flow experiments in chapter 3 also demonstrated that $\alpha 2 \beta 1$-deficient platelets formed thrombi of a decreased stability with higher tendency of detachment from the collagen surface. These results provide novel insights into the differential roles of these platelet receptors in the hemostatic process. In chapter 4 this subject was taken further by in vitro and in vivo studies determining how $\alpha 2 \beta 1$ contributes to thrombus growth and stability. Attention was paid to the contribution of autocrine thromboxane $A_{2}$ and $P S$ exposure.

Since platelet-collagen interaction under high shear is also dependent on WWF, GPIb and $\alpha / 1 b \beta 3$, the focus of chapter 5 was to determine the contribution of these proteins to the generation of the platelet procoagulant surface under flow conditions. It was demonstrated that at high shear rates WWF and GPIb - and allb33 further downstream - enhance GPVI-mediated PS exposure, especially undler conditions of reduced GPVI activity.

The flow studies described in chapters 3 and 5 have been performed in the absence of thrombin and coagulation. To include the role of thrombin, in chapter 6 the thrombus-forming process is followed in flowing blood upon triggering of coagulation with tissue factor. We concentrated on the antithrombotic potential of platelet-inhibiting agents which can also prevent thrombin generation. The compounds studied (a cyclic AMP-elevating agent and a P2Y 42 
receptor antagonist) appeared to retain their platelet-inhibiting activity under conditions where the anticoagulant effect had disappeared.

Knowing that only in vitro studies have been performed to establish the mutual interaction of (collagen-induced) platelet activation and thrombin generation, the studies of chapter 7 were designed to give first evidence for the interaction of these two processes in thrombus formation in vivo. It was found that in an in vivo model, relying on both collagen and tissue factor, the propagation of thrombin generation by PS-exposing platelets is a key regulatory step in thrombus formation not only in arterioles but also in venules. Further, evidence was obtained that in the venous circulation, local thrombin generation may be too high to be suppressed by classical platelet inhibitors. In the general discussion in chapter 8 the relevance of the present findings in relation to literature are described.

\subsection{References}

1. Robb-Smith AH. Why the platelets were discovered. Br J Haematol. 1967; 13: 618-637.

2. Bizzozero G. Su di un nuovo elemento morfologico del sangue dei mammiferi e della sua importanza nella trombosi e nella coagulazione. L"Osservatore. $1881 ; 17: 785-787$.

3. Bizzozero $G$. Ueber einen neuen Formbestandtheil des Blutes und dessen Rolle bei der Trombose und der Blutgerinnung. Virchows Arch Pathol Anat Physilol. 1882; 90: 261-332.

4. Bizzozero G. Sul midollo delle ossa. II Margagni. 1869.

5. Wright JH. The origin and nature of blood plates. Boston Med Surg J. 1906; 154:643-645.

6. Osler $W$. On certain problems in the physiology of the blood corpuscles. The medical news. 1886; 48 : 421-425.

7. Virchow RLK. Gesammelte Abhandlungen zur Wissenschaftlicher Medizin. Von Meidinger Sohn. Frankfurt-am-Mein, Germany; 1856.

8. Schierbeek A. Antoni van Leeuwenhoek en zijn voornaamste ontdekkingen. Den Haag: Kruseman; 1963.

9. Hodgkin T, Lister JW. Microscopical observations of the blood and animal tissues. Phil Mag. 1827; 2: 130.

10. Sixma JJ, Wester J. The hemostatic plug. Semin Hematol. 1977; 14: 265-299.

11. Ruggeri ZM. Platelets in atherothrombosis. Nat Med. 2002; 8: 1227-1234.

12. Badimon L. Atherosclerosis ands thrombosis: lessons from animal models. Thromb Haemostas. 2001; 86: 356-365.

13. Murray $C J_{x}$ Lopez $A D$. Mortality by cause for eight regions of the world: Global Burden of Disease Study. Lancet. 1997; 349: 1269-1276.

14. Tangelder $G .$, , Teirlinck HC, Slaaf DW, Reneman RS. Distribution of bllood platelets flowing in arterioles. Am J Physiol. 1985; 248: H318-323.

15. Hartwig JH. Platelet structure. In: Michelson AD, ed. Platellets. San Diego, USA: Academic Press, Elsevier Science; 2002: 37-52.

16. Tsakiris DA, Scudder L, Hodivala Dilke K, Hynes RO, Coller BS. Hemostasis in the mouse (Mus musculus): a review. Thromb Haemost. 1999; 81: 177-188.

17. Farndale RW, Sixma JJ, Barnes MJ, de Groot PG. The role of collagen in thrombosis and hemostasis. $J$ Thromb Haemost. 2004; $2: 561-573$.

18. Savage B, Almus-Jacobs F, Ruggeri ZM. Specific synergy of multiple substrate-receptor interactions in platelet thrombus formation under flow. Cell. 1998; 94: 657-666.

19. Ruggeri ZM. Structure and function of von Willebrand factor. Thromb Haemost. 1999; 82: $576-584$.

20. Huizinga EG, Tsuji S, Romijn RAP. Schiphorst ME, de Groot PG, Sixma JJ, Gros P. Structures of glycoprotein Ib $\alpha$ and its complex with von Willebrand factor A1 domain. Science. 2002; 297: 1176-1179.

21. Savage $B_{n}$ Saldivar $E$, Ruggeri $Z M$. Initiation of platelet adhesion by arrest onto fibrinogen or translocation on von Willebrand factor. Cell. $1996 ;$; $4: 289-297$.

22. Nieswandt B. Watson SP. Platelet collagen interaction: is GPVI the central receptor? Blood . 2003; 102: 449-461.

23. Jung $S M$, Moroi $M$. Activation of the platelet collagen receptor integrin $\alpha .2 \beta 1$ : its mechanism and participation in the physiological functions of platelets. Trends Cardiovasc Med. 2000; 10: 285-292. 


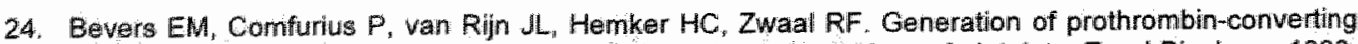
activity and the exposiure of phosphatidylserine at the outer surface of platelets. Eur $\mathrm{J}$ Biochem. 1982: 122: $429 \% 436$.

25. Beguin $S$, Kumar $\mathbb{R}$. Thrombin, fibrin and platelets: a resonance loop in which von Willebrand factor is a necessary link. Thromb Haemost. 1997; $78: 590-594$

26. Heemskerk JWM, Bevers EM, Lindhout T. Platelet activation and blood coagulation. Thromb Haemost. 2002; 88:166-193.

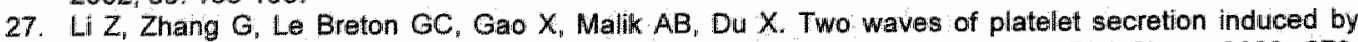
thromboxane $A_{2}$ receptor and a critical role for phosphoinositide 3-kinases. J Biol Chem. 2003; 278: 30725-30731.

28. Gachet $C$. $A D P$ receptors of platelets and their inhibition. Thromb Haemast. 2001; 86: 222-232.

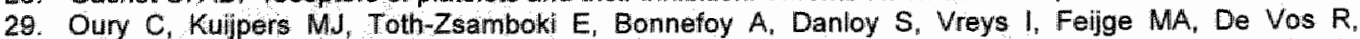
Vermylen $J_{1}$ Heernskerk JW, Hoylaerts MF. Overexpression of the platelet $P 2 X_{1}$ ion channel in transgenic mice generates a novel prothrombotic phenotype. Blood. 2003; 101: 3969-3976.

30. Kulkarmi S, Dopheide SM, Yap CL, Ravanat $C$, Freund M, Mangin P. Heel KA, Street A, Harper IS, Lanza $F_{n}$ Jackson SP. A revised model of platelet aggregation. $J$ Clin invest. 2000; 105: 783-791.

31. Plow EF, Srouji AH, Meyer D, Marguerie G, Ginsberg MH. Evidence that three adhesive proteins interact with a common recognition site on activated platelets. J Biol Chem. 1984; $259: 5388-5391$.

32. Parise LV, Phillips DR. Fibronectin-binding properties of the purified platelet glycoprotein IIb-llla complex. J Biol Chem. 1986: 261: 14011-14017.

33. Ruggeri $Z M$, Dent $J A$, Saldivar $E$. Contribution of distinct adhesive interactions to platelet aggregation in flowing blood. Blood. 1999; 94: 172-178.

34. Brass LF. Thrombin and platelet activation. Chest. 2003; 124: 18S-25S

35. Keuren JF, Wielders SJ, Ulrichts H, Hackeng T, Heemskerk JW, Deckmyn H, Bevers EM, Lindhout T. Synergistic effect of thrombin on collagen-induced platelet procoagulant activity is mediated through protease-activated receptor-1. Arterioscler Thromb Vasc Biol. 2005.

36. Nakanishi-Matsuil M, Zheng YW, Sulciner DJ, Weiss EJ, Ludeman MJ, Coughlin SR. PAR3 is a cofactor for PAR4 activation by thrombin. Nature. 2000; 404:609-613.

37. Major CD, Santulli RJ, Derian $C K$ Andrade-Gordon $P$. Extracellular mediators in atherosclerosis and thrombosis: lessons from thrombin receptor knockout mice. Arterioscler Thiomb Vasc Biol. 2003; 23: $931-939$

38. Shapiro MJ, Weiss EJ, Faruqi TR, Coughlin SR. Protease-activated receptors 1 and 4 are shut off with distinct kinetics after activation by thrombin. J Biol Chem. 2000; 275: 25216-25221.

39. Covic L, Gresser AL, Kuliopulos A. Biphasic kinetics of activation and signaling for PAR1 and PAR4 thrombin receptors in platelets. Biochemistry. 2000; 39: 5458-5467.

40. Heemskerk JW, Siljander PR. Bevers EM, Farndale RW, Lindhout T. Receptors and signalling mechanisms in the procoagulant response of platelets. Platelets. $2000 ; 11: 301-306$.

41. Zwaal RF, Schroit AJ. Pathophysiologic implications of membrane phospholipid asymmetry in blood cells. Blood. 1997; 89: 1121-1132.

42. Heemskerk JW, Vuist WM, Feijge MA, Reutelingsperger CP, Lindhout $T$, Collagen but not fibrinogen surfaces induce bleb formation, exposure of phosphatidylserine, and procioagulant activity of adherent platelets: evidence for regulation by protein tyrosine kinase-dependent $\mathrm{Ca}^{2+}$ responses. Blood. 1997: 90: $2615-2625$.

43. Heemskerk JWM. Calcium and platelets. In: The Molecular Basis of Calcium Action in Biology and Medicine (Pochet, R, Donato, R, Halech, J, Heinzmann, $C$ and Gerke, $V$, eds). Kluwer Acad Publ, The Hague (the Netherlands). 2000; 45-71.

44. Heemskerk JW, Willems GM, Rook MB, Sage SO. Ragged spiking of free calcium in ADP-stimulated human platelets: regulation of puff-like calcium signals in vitro and ex vivo. J Physiol. 2001; 535; 625-635.

45. Clemetson JM. Polgar J, Magnenat E, Wells TN, Clemetson KJ. The platelet collagen receptor glycoprotein $\mathrm{V} 1$ is a member of the immunoglobulin superfamily clasely related to FcaR and the natural killer receptors. J Bilol Chem. 1999; 274: 29019-29024.

46. Gibbins $J M$, Okuma $M$, Farndale $R$, Barnes $M$, Watson $S P$. Glycoprotein $V /$ is the collagen receptor in platelets which underlies tyrosine phosphorylation of the Fc receptor $\gamma$-chain. FEBS Lett. 1997; 413: 255-259.

47. Tsuji M, Ezumi Y, Arai M, Takayama H. A novel assaciation of Fe receptor $\gamma$-chain with glycoprotein VI and their co-expression as a collagen receptor in human platelets. J Biol Chem. 1997; 272: 23528-23531.

48. Quek LS, Pasquet JM. Hers I, Cornall R, Knight G, Barnes M, Hibbs ML, Dunn AR, Lowell CA, Watson $\mathrm{SP}$. Fyn and Lyn phosphorylate the $\mathrm{Fc}$ receptor $\gamma$-chain downstream of glycoprotein $\mathrm{VI}$ in murine platelets, and Lyn regulates a novel feedback pathway. Blood. 2000; 96: 4246-4253.

49. Jackson SP, Nesbitt WS Kulkarni $S$. Signaling events underlying thrombus formation. J Thromb Haemost. 2003; 1: 1602-1612. 
50. Shattil SJ, Kashiwagi H, Pampori N. Integrin signaling, the platelet paradigm Blood. 1998; $91: 2645-2657$.

51. Hymes RO. Integrins: bidirectional, allosteric signaling machines. Cell. 2002; 110:673-687.

52. Jung SM, Moroi M. Platelets interact with soluble and insoluble collagens through characteristically different reactions. J Biol Chem: 1998; 273: 14827-14837.

53. Jung SM, Moroi M. Signal-transducing mechanisms involved in activation of the platelet collagen receptor integrin $\alpha 2 \beta 1$. J Biol Chem. 2000;275:8016-8026.

54. Cruz MA, Chen J, Whitelock JL, Morales LD, Lopez JA. The platelet glycoprotein Ib - von Willebrand factor interaction activates the collagen receptor $\alpha 2 \beta 1$ to bind collagen: activation-dependent conformational change of the $\alpha 2-1$ domain. Blood. 2005; 105: 1986-1991.

55. Emsley J, King $S L$, Bergelson $\mathrm{JM}_{\mathrm{y}}$ Liddington RC. Crystal structure of the I domain from integrin $\alpha 2 \beta 1$. $\checkmark$ Biol Chem. 1997; 272: 28512-28517.

56. Inoue $O$. Suzuki Inoue $K$, Dean WL, Frampton J, Watson SP. Integrin a $2 \beta 1$ mediates outside in regullation of platelet spreading on collagen through activation of Src kinases and PLC 2 . J Cell Biol. 2003: 160: $769-780$.

57. Brass LF, Manning DR, Cichowski $K$, Abrams CS. Signaling through $G$ proteins in platelets: to the integrins and beyond. Thromb Haemost. 1997; 78: 581-589.

58. Offermanns $\mathrm{S}$, Toombs CF, Hu YH, Simon MI. Defective platelet activation in Gidiq-deficient mice. Nature. 1997; 389: 183-186.

59. Prevost $N$, Woulfe $D$, Tognolini $M$, Brass LF. Contact-dependent signaling during the late events of platelet activation. J Thromb Haemost. 2003; 1: 1613-1627.

60. Moers A, Nieswandt B, Massberg S, Wettschureck N, Gruner S, Konrad I Schulte V, Aktas B, Gratacap MP, Simon MI, Gawaz $M_{1}$ Offermanns $S$. $G_{13}$ is an essential mediator of platelet activation in hemostasis and thrombosis. Nat Med. 2003; 9: $1418-1422$.

61. Jantzen HM, Milstone DS, Gousset L, Conley PB, Mortensen RM. Impaired activation of murine platelets lacking $\mathrm{Go}_{\mathrm{i} 2}$. J Clin Invest. 2001; 108: 477-483.

62. Kauffenstein $G$, Bergmeier W, Eckly $A_{n}$ Ohimann $P$, Leon $C$, Cazenave JP, Nlieswandt $B$, Gachet $C$. The $P 2 Y_{12}$ receptor induces platelet aggregation through weak activation of the allb 33 integrin - a phosphoinositide 3-kinase-dependent mechanism. FEBS Lett. 2001; 505: 281-290.

63. Dangelmaier $\mathrm{C}$, Jin $J$, Smith JB, Kunapuli SP. Potentiation of thromboxane $A_{2}$-induced platelet secretion by $G_{i}$ signaling through the phosphoinositide-3 kinase pathway. Thromb Haemost. $2001 ; 85$ : $341-348$.

64. Jin $d_{t}$ Kunapuli SP. Coactivation of two different $G$ protein-coupled receptors is essential for ADPinduced platelet aggregation. Proc Nlatl Acad Sci U S A. 1998; 95: 8070-8074.

65. Nieswandt $B$, Schulte $V$, Zywietz $A$, Gratacap MP, Offermanns S. Costimulation of $G_{1-}$ and $G_{12} / G_{193^{-}}$ mediated signaling pathways induces integrin allbB3 activation in platelets. J Biol Chem. 2002; 277: 39493-39498.

66. Gabbeta J, Yang $X_{*}$ Kowalska MA, Sun L, Dhanasekaran N, Rao AK. Platelet signal tranisduction defect with $G a$ subunit dysfunction and diminished $G_{\alpha_{q}}$ in a patient with abnormal platelet responses. Proc Natl Acad Sci U S A. 1997; 94: 8750-8755.

67. Patel YM, Patel K, Rahman S, Smith MP, Spooner G, Sumathipala R, Mitchell M, Flynn G, Aitken A, Savidge $G$. Evidence for a role for $G o_{i 1}$ in mediating weak agonist-induced platelet aggregation in human platelets: reduced $G_{c_{i 1}}$ expression and defective $G_{i}$ signaling in the platelets of a patient with a chronic bleeding disorder. Blood. 2003; 101: 4828-4835.

68. Bevers EM, Comfurius P, Zwaal RF. Changes in membrane phospholipid distribution during platelet activation. Blochim Biophys Acta. 1983,736:57-66

69. Andersen H, Greenberg DL, Fujikawa K, Xu W, Chung DW, Davie EW. Protease-activated receptor 1 is the primary mediator of thrombin-stimulated platelet procoagulant activity. Proc Natl Acad Sci U SA 1999; 96: 11189-11193.

70. Leon $C$, Ravanat $C_{1}$ Freund $M$, Cazenave JP, Gachet $C$. Differential involvement of the $P 2 Y$, and $P 2 Y_{12}$ receptors in platelet procoagulant activity. Arterioscler Thromb Vasc Biol. 2003; 23: 1941-1947.

71. van der Meijden PE. Feijge MA, Giesen PL, Huijberts M, van Raak LP. Heemskerk. JW. Platelet P2Y, receptors enhance signalling towards procoagulant activity and thrombin generation. A study with thealthy subjects and patients at thrombotic risk. Thromb Haemost. 2005: 93: 1128-1136.

72. Hechler $B$, Eckly $A$, Ohlmann $P$, Cazenave JP, Gachet $C$. The $P 2 Y$, receptor, necessary but not sufficient to support full ADP-induced platelet aggregation, is not the target of the drug clopidogral. $\mathrm{Br} J$ Haematol. 1998; 103: 858-866.

73. Reverter JC, Beguin $S$, Kessels H, Kumar R, Hemker HC, Coller BS. Inhibition of platelet-mediated, tissue factor-induced thrombin generation by the mouse/human chimeric 7E3 antibody. Potential implications for the effect of $\mathrm{c7E} 3$ Fab treatment on acute thrombosis and "clinical restenosis". J Clin Invest. 1996; 98: 863-874. 
74. Vanschoonbeek $K$, Feijge MA, Van Kampen RJ, Kenis H. Hemker HC "Giesen PL, Heemskerk JW. Initiating and potentiating role of platelets in tissue factor-induced thrombin generation in the presence of plasma: subject-dependent variation in thrombagram characteristics. J Thromb Haemost, $2004 ; 2$ : 476-484.

75. Lopez JA, Berndt MC. The GPIb-IX-V Complex. In: Michelson AD, ed. Platelets. San Diego, USA: Academic Press, Elsevier Science: 2002: 85-104.

76. Wu $Y$, Suzuki-ynouse $K$, Satoh $K$, Asazuma $N$, Yatomi $Y$, Berndt MC, Ozaki $Y$. Role of Fc receptor gamma-chain in platelet glycoprotein Ib-mediated signaling. Blood. 2001, 97: 3836-3845.

77. Falati $S_{i}$ Edmead $C E_{\text {, Poole }}$ AW. Glycoprotein $I b-V-1 X_{i}$ a receptor for von Willebrand factor, couples physically and functionally to the Fc receptor $\gamma$-chain, Fyn, and Lyn to activate human platelets. Blood. 1999; $94: 1648-1656$.

78. Tandon NN, Kralisz U, vamieson GA. Identification of glycoprotein IV (CD36) as a primary receptor for platelet-collagen adhesion. J Bioll Chem. 1989; 264: 7576-7583.

79. Jarvis GE Atkinson BT, Snell DC, Watson SP. Distinct roles of GPVI and integrin $\alpha 2 \beta 1$ in platelet shape change and aggregation induced by different collagens. Br J Pharmacol. 2002; 137: 107-117

80. Yamamato $N$, Akamatsu $N$, Yamazaki $H$, Tanoue $K$. Normal aggregation of glycoprotein NV (CD36)deficient platelets from seven healthy Japanese donors. Br J Haematol. 1992; 81: 86-92.

81. Moog $S$, Mangin $P$, Lenain $\mathbb{N}$, Strassel $C$, Ravanat $C$, Schuhler $S$, Freund $M$, Santer $M$, Kahn $M$,

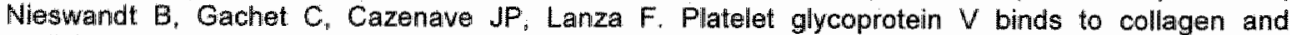
participates in platelet adhesion and aggregation. Blood. 2001; 98: 1038-1046.

82. Ni H, Ramakrishnan $V$, Ruggeri ZM, Papalia JM, Phillips DR, Wagner DD. Increased thrombogenesis and embolus formation in mice lacking glycoprotein $V$. Blood. $2001 ; 98: 368-373$.

83. Nieuwenhuis HK, Akkerman JW, Houdijk WP, Sixma JJ. Human blood platelets showing no response to collagen fail to express surface glycoprotein la. Nature. $1985 ; 318: 470-472$.

84. Nieuwenhuis HK, Sakariassen KS, Houdijk WP, Nievelstein PF. Sixma JJ. Deficiency of platelet membrame glycoprotein la associated with a decreased platelet adhesion to subendothelium: a defect in platelet spreading. Blood. 1986; 68: 692-695.

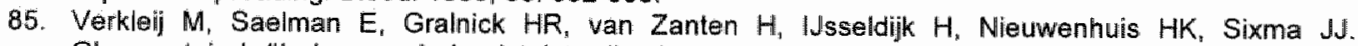
Glycoprotein la/lla has a rolle in platelet adhesion to surfaces for which it is not the receptor. Thromb Haemost. 1995; 73: 1202a (abstract).

86. Kehrel $B$, Balleisen $L_{1}$ Kokott $R_{\text {, Mesters }} \mathrm{R}_{\mathrm{s}}$ Stenzinger W, Clemetson $\mathrm{KJ}$, van de Loo J. Deficiency of intact thrombospondin and membrane glycoprotein la in platelets with defective collagen-induced aggregation and spontaneous loss of disorder. Blood. 1988; 71: 1074-1:078.

87. Handa $M$, Watanabe $K$, Kawai $Y$, Kamata $T$, Koyama $T$, Nagai $H$, lkeda $Y$. Platelet unresponsiveness to collagen: involvement of glycoprotein la-lla ( $\alpha 2 \beta 1$ integrin) deficiency associated with a myeloproliferative disorder. Thromb Haemost. 1995; 73: 521-528.

88. Sugiyama $T$, Okuma $M$, Ushikubi $F$, Sensaki $S$, Kanaji $K$, Uchino $H$. A novel platelet aggregating factor found in a patient with defective collagen-induced platelet aggreglation and autoimmune thrombocytopenila. Blood. 1987; 69: 1712-1720.

89. Takahash $H_{4}$ Moroi $M$. Antibody against platelet membrane glycoprotein $W 1$ in a patient with systemic lupus erythematosus. Am J Hematol. 2001: 67: 262-267.

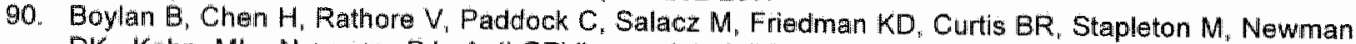
DK, Kahn ML. Newmian PJ. Anti-GPVI-associated ITP: an acquired platelet disorder caused by autoantibody-mediated clearance of the GPVI/FcR $\gamma$-chain complex from the human platelet surface. Bilood. 2004: 104: 1350-1355.

91. Moroi $M$, Jung $S M$, Okuma $M$, Shinmyozu $K$. A patient with platelets deficient in glycoprotein $V \|$ that lack both collagen-induced aggregation and adhesion. J Clin Irvest. 1989; $84: 1440-1445$.

92. Ryo $R_{v}$ Yoshida $A$, Sugano $W$, Yasunaga $M$, Nakayama $K$, Saigo $K$, Adachi $M$, Yamaguchi $N$, Okuma M. Deficiency of P62, a putative collagen receptor, in platelets from a patient with defective collageninduced platelet aggregation. Am J Hematol. 1992; 39: 25-31.

93. Arai M. Yamamoto $N$, Moroi M. Akamatsu N, Fukutake $K$, Tanoue $K$. Platelets with $10 \%$ of the normal amount af glycoprotein $V /$ have an impaired response to collegen that results in a mild bleeding tendency. Br J Haematol. 1995; 89: 124-130.

94. Nurden $P$, Jandrot-Pernus $M$, Combrie $R$, Winckler J. Arocas $V$, Lecut $C$. Pasquet JM, Kunicki $T_{v} J$ Nurden AT. Severe deficiency of glycoprotein VI in a patient with gray platelet syndrome. Blood. 2004 104: $107-114$.

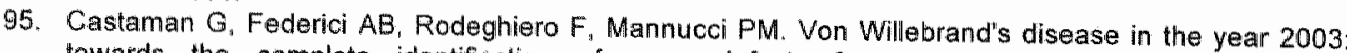
towards the complete identification of gene defects for correct diagnosis and treatment Haematologica. 2003; 88: 94-108.

96. Ramasamy I. Inherited bleeding disorders: disorders of platelet adhesion and aggregation. Crit Rev Oncol Hematol. 2004; 49:1-35. 


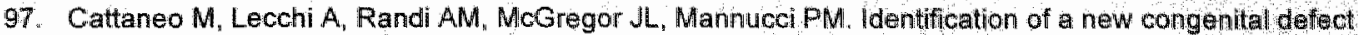
of platelet function characterized by severe impairment of platelet responses to adenosine diphosphate. Blood. 1992; 80: 2787-2796.

98. Nurden P, Savi P, Heilmann E, Bihour C, Herbert JM, Maffiand JP, Nurden A. An inherited bleeding disorder linked to a defective interaction between $A D P$ and its receptor on platelets. Its influence on glycoprotein Illb-IIla complex function. J Clin Invest. 1995: 95: 1612-1622.

99. Cattaneo $M$, Lecchi $A$, Lombardi $R_{6}$, Gachet $C$, Zighetti ML. Platelets from a patient heterozygouis for the defect of $\mathrm{P} 2 \mathrm{CYC}$ receptors for $\mathrm{ADP}$ have a secretion defect despite normal thromboxane $\mathrm{A}_{2}$ piroduction and normal granule stores: further evidence that some cases of platelet primary secretion: defect' are heterozygous for a defect of P2CYC receptors. Arterioscler Thromb Vasc Biol. 2000; 20: E101-106.

100. Shiraga $M$, Miyata $S$, Kato $H$, Kashiwagi $H$, Honda $S$, Kurata $Y$, Tomiyama $Y$, Kanakura $Y$, Impaired platelet function in a patient with $\mathrm{P} \mathrm{Y}_{12}$ deficiency caused by a mutation in the transiation initiation codon. $\|$ Thromb Haemost. $2005 ; 3: 2315-2323$.

101. Oury $C$, Lenaerts $T$, Peerlinck $K$, Vermylen $J$, Hoylaerts MF. Congenital deficiency of the phosphalipase $C$ coupled platelet $P 2 Y$, receptor leads to a mild bleeding disorder. Thromb Haemost (suppl). 1999; 82: 20.

102. Oury C, Toth Zsamboki $E$, Van Geet $C$, Thys $C$, Well L. Nillius $B$, Vermylen J, Hoylaerts MF. A natural dominant negative $P 2 X_{1}$ receptor due to deletion of a single amino acid residue. $J$ Biol Chem. 2000 ; 275: $22611-22614$.

103. Sims PJ, Wiedmer T, Esmon CT. Weiss HJ, Shattil SJ. Assemblly of the platelet prothrombinase complex is linked to vesiculation of the platelet plasma membrane. Studies in Scott syndrome: an isolated defect in platelet procoagulant activity. $₫$ Biol Chem. 1989; 264: 17049-17057.

104. Weiss HJ. Scott syndrome: a disorder of platelet coagulant activity. Semin Hematol. 1994: $31: 312-319$.

105. Toti $F_{\text {" Satta }} N$, Fressinaud $E$, Meyer D. Freyssinet JM. Scott syndrome, characterized by impaired transmembrane migration of procoagulant phosphatidylserine and hemorrhagic complications, is an inherited disorder. Blood. 1996; 87: 1409-1415.

106. Munnix $\| C$. Harmsma $M{ }_{n}$ Giddings ${ } C_{n}$ Collins $P W$, Feijge MA, Comfurius $P$, Heemskerk JW, Bevers EM. Store-mediated calcium entry in the regulation of phosphatidylserine exposure in blood cells from Scott patients. Thromb Haemost. 2003; 89; 687-695.

107. Holtkotter $O$, Nieswandt $B$, Smyth $N$, Muller $W$, Hafner $M$, Schulte $V$, Krieg $T$, Eckes $B$. Integrin $\alpha 2-$ deficient mice develop normally, are fertile but display partially defective platelet interaction with collagen. J Biol Chem. 2002; 277: 10789-10794.

108. Chen J, Diacovo TG, Grenache DG, Santoro SA, Zutter MM. The 22 integrin subunit-deficient mouse: a multifaceted phenotype including defects of branching morphogenesis and hemostasis. Am J Pathol. 2002; 161: $337-344$.

109. Fassler R, Meyer M. Consequences of lack of $\beta 1$ integrin gene expression in mice. Genes Dev. 1995; 9: $1896-1908$.

110. Potocnik AJ, Brakebusch C, Fassler R. Fetall and adult hematopoietic stem cells require in integrin function for colonizing fetal liver, spleen, and bone marrow. Immunity. 2000; 12:653-663.

111. Nieswandt $B, B r a k e b u s c h ~ C$, Bergmeler $W$, Schulte $V$, Bouvard $D$. Mokhtari Nejad $R$, Lindhout $T$, Heemskerk JW, Zirngibl $H$, Fassler R. Glycoprotein $V /$ but not $\alpha 2 \beta 1$ integrin is essential for platelet interaction with collagen. EMBO J. 2001;20:2120-2130.

112. Poole A, Gibbins JM, Turner $M$, van Vugt MJ, van de Winkel JG, Saito T, Tybulewicz VL, Watson SP. The FC receptor $\gamma$-chain and the tyrosine kinase Syk are essential for activation of mouse platelets by collagen. EMBO J. 1997; 16:2333-2341.

113. Nieswandt $B$, Bergmeier $W$, Schulte $V$, Rackebrandt $K$, Gessner JE, Zirngibl $H$. Expression and function of the mouse collagen receptor glycoprotein $\mathrm{Vl}$ is strictly dependent on its association with the FcRy chain. J Biol Chem, 2000; 275: 23998-234002.

114. Nieswandt $B$, Schulte $V$, Bergmeier $W$, Mokhtari-Nejad $R$. Rackebrandt $K_{*}$ Cazenave JP, Ohlmann $P$. Gachet $\mathrm{C}$. Zirngibl H. Long-term antithrombotic protection by in vivo depletion of platelet glycoprotein VI in mice. J Exp Med. 2001; 193: $459-469$.

115. Kato $K$, Kanaji $T$, Russell $S$, Kunicki TJ, Furihata $K$, Kanaji $S$, Marchese P, Reininger $A$, Ruggeri $Z M$, Ware J. The contribution of glycoprotein $V / l$ to stable platelet adhesion and thrombus formation illustrated by targeted gene deletion. Blood, 2003; 102: 1701-1707.

116. Lockyer S, Okuyama K, Begum S, Le S, Sun B, Watanabe T, Matsumoto $Y$, Yoshitake M, Kambayashi J. Tandon NN. GPVI-deficient mice lack collagen responses and are protected against experimentally induced pulmonary thromboembolism. Thromb Res. 2005.

117. Hodivala-Dilke $K M$, McHugh $K F$, Tsakiris DA, Rayburn $H_{1}$ Crowley $D$, Ullman-Cullere M, Ross FP, Coller BS, Teitelbaum $S$. Hynes RO. Beta3-integrin-deficient mice are a model for Glanzmann thrombasthenia showing placental defects and reduced survivall. J Clin Invest. 1999"103: 229 -238. 


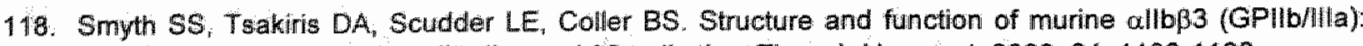
studies using monoctorial antibodies and $\beta 3$-null mice. Thromb Haemost. $2000 ; 84: 1103-1108$.

119. Smyth $S S$, Reis $E D$, Vaananen $H$, Zhang $W$, Coller BS, Variable prottection of $\beta 3$-integrin-deficient mice from thrombosis initiated by different mechanisms. Blood. 2001; 98: 1055-1062.

120. Phillps DR, Nannizzi-Alaimo L, Prasad KS. Beta3 tyrosine phosphorylation in allbß33 (platelet membrane GPllb-llla) outside in integrin sugnaling. Thromb Haemost. 2001; 86: 246-258.

121. Lav DA, DeGuzman FR, Heiser P, Ministri-Madrid K, Killeen N, Phillips DR. Integrin cytoplasmic tyrosine motff is required for outside-in oll b/33 signalling and platelet function. Nature: 1999; 401: 808-811.

122. Poujol $C$, Ware J, Nieswandt $B$, Nurden AT, Nurden $P$. Absence of GPlba is responsible for aberrant membrane development during megakaryocyte maturation: ultrastructural study using a transgenic model. Exp Hematol. 2002; 30: 352-360.

123. Kato $K$, Martinez C, Russell $S$, Nurden $P$, Nurden A, Fiering $S$, Ware $J$. Genetic deletion of mouse platelet glycoprotein Ib $\beta$ produces a Bernard-Soulier phenotype with increased $\alpha$-granule size. Blood. 2004: 104: 2339-2344

124. Kahn ML, Diacovo TG, Bainton DF, Lanza F, Trejo J, Cloughlin SR. Glycoprotein V-deficient platelets have undiminished thrombin responsiveness and do not exhibit a Bernard-Soulier phenotype. Blood. 1999; $94: 4112-4121$.

125. Ramakrishnan $V$, Reeves PS, DeGuzman $F_{x}$ Deshpande U, Ministri-Madrid $K$, DuBridge RB, Phillips DR. Increased thrombin responsiveness in platelets from mice lacking glycoprotein $V$. Proc Natl Acad Sici U S A. 1999; 96: 13336-13341.

126. Suh TT, Holmback $K$, Jensen NJ, Daugherty $C C$, Small $K$, Simon DI, Potter $S$, Degen JL. Resolution of spontaneous bleeding events but failure of pregnancy in fibrinagen-deficient mice. Genes Dev. 1995; 9: 2020-2033.

127. Denis $C$, Methia $N$, Frenette PS, Rayburn $H$, Ullman Cullere $M$, Hynes RO, Wagner DD. A mouse model of severe von Willebrand disease: defects in hemostasis and thrombosis. Proc Natl Acad Sci U S. A. 1998; 95: 9524-9529.

128. Ni H thrombus formation in arterioles of mice lacking both von Willebrand factor and fibrinagen. $J$ Clin Invest. 2000; 106: 385-392.

129. $\mathrm{Ni} H_{n}$ Yuen PS, Papalia JM. Trevithick JE, Sakai T, Fassler $R$, Hynes RO, Wagner DD. Plasma fibronectin promotes thrombus growth and stability in injured arterioles. Proc Natl Acad Soi U S A. 2003; 100: 2415-2419

130. André P, Delaney SM, LaRocca $T$, Vincent $D$, DeGuzman $F$, Jurek M, Koller $B$, Phillips DR, Conley PB. $P 2 Y_{12}$ regulates platelet adhesion/ activation, thrombus growth and thrombus stability in injured arteries. J Clin Invest. 2003; 112: 398-406.

131. Fabre JE, Nguyen MT, Latour A, Keifer JA, Audolly LP, Coffman TM, Koller BH. Decreased platelet aggregation, increased bleeding time and resistance to thrombaembolism in P2Y, -deficient mice. Nat Med. 1999; 5: 1199-1202.

132. Leon $C$. Hechler $B_{i}$ Freund $M$, Eckly $A$, Vial $C$, Ohlmann $P$, Dierich $A_{8}$ LeMeur $M_{i}$ Cazenave JP, Gachet C. Defective platelet aggregation and increased resistance to thrombosis in purinergic $P 2 Y_{1}$ receptornull mice. J Clin lnvest. 1999; 104: 1731-1737.

133. Lenain $N$, Freund $M$, Leon $C$, Cazanave $J P$, Gachet $C$. Inhibition of localized thrombosis in $P 2 Y_{1}$ deficient mice and rodents with MRS2179, a P2Y, receptor antagonist. J Thromb Haemost. 2003; 1: $1144-1149$

134. Hechler B, Lenain N, Marchese P, Vial C, Heirn W, Freund M, Cazenave JP, Cattaneo M, Ruggeri ZM, Evans $R$, Gachet $C$. A role of the fast ATP-gated $P 2 X_{4}$ cation channel in thrombosis of small arteries in vivo. J Exp Med. 2003: 198: 661-667.

135. Sakariassen KS, Aarts PA, de Groot PG, Houdijk WP, Sixma JJ. A perfusion chamber developed to investigate platelet interaction in flowing blood with human vessel wall cells, their extracellular imatrix, and purified components. J Lab Clin Med. 1983; 102: 522-535.

136. De Groot PG, Sixma JJ. Perfusion chambers. In: Michelson AD, ed. Platelets. San Diego, USA: Academic Press, Elsevier Science; 2002: 347-355.

137. oude Egbrink MGA, van Gestel MA, Broeders MD, Tangelder GJ, Heemskerk JWM, Reneman RS, Slaaf DW. Regulation of microvascular thromboembolism in vivo. Microcirculation. 2005: 12: 287-300.

138. Falati $S$, Gross $P$. Merrill-Skoloff $G_{n}$ Furie $B C$, Furie $B$. Real-time in vivo imaging of platelets, tissue factor and fibrin during arterial thrombus formation in the mouse. Nat Med. 2002; 8: 1175-1181.

139. van Gestel MA, Heemskerk JW, Slaaf DW, Heijnen WV, Sage SO, Reneman RS, oude Egbrink MG. Real-time detection of activation patterns in individual platelets during thromboembolism in vivo: differences between thrombus growth and embolus formation. J Vasc Res. 2002; 39:534-543. 
140. Goto $S$, Tamura $N$, Handa $S$, Arai $M$, Kodama $K$, Takayama $H$, Involvement of glycoprotein $W 1$ in platelet thrombus formation on both collagen and von Willebrand factor surfaces under flow conditions. Circulation. 2002, 106: 266-272.

141. Lopez JA, Andrews RK, Afshar-Kharghan V, Berndt MC Bernard-Soulier syndrome, Blood, 1998, 91 $4397-4418$.

142. Neerman-Arbez $M$. The molecular basis of inherited afibrinagenaemia. Thromb Haemost 2001,86 : $154-163$

143. Roberts HR, Stinchcombe TE, Gabriel DA. The dysfibrinogenaemias. Br J Haematol 2001; $114249-257$.

144. Hayes T. Dysfibrinogenemia and thrombosis. Anch Pathol Lab Med, 2002; $126,1387-1390$

145. Takai $T, L i M$, Sylvestre $D$, Clynes $R$, Ravetch $J V$. FCR $\gamma$-chain deletion results in pleiotrophic effector cell defects. Cell. 1994; $76: 519-529$.

146. Law DA, Nannizzl Alaimo L, Cowan KJ, Prasad KS. Ramakrishnan V. Phillips DR Signal transduction pathways for mouse platelet membrane adhesion receptors. Thromb Haemost 1999; $82.345-352$.

147. Wagner $\mathrm{DD}$, Burger PC. Platelets in intlammation and thrombosis. Arterioscler Thromb Vasc Biol. $2003 ; 23: 2131-2137$.

148. Mulryan K, Gitterman DP, Lewis CJ, Vial $C$, Leckie BJ, Cobb AL, Brown JE, Conley EC, Buell $G$ Pritchard $C_{1}$ Evans RJ. Reduced vas deferens contraction and male infertility in mice lacking $P 2 X_{1}$ receptors. Nature. 2000; 403: 86-89. 


\title{
Chapter 2
}

\section{Platelet collagen receptors and coagulation}

\section{A characteristic platelet response as possible}

\section{target of antithrombotic treatment}

\author{
Johan W. M. Heemskerk, Marijke J. E. Kuijpers, Imke C. A. Munnix and
}

Pia R. M. Siljander

Trends in Cardiovascular Medicine (2005), 15: 86-92

Reprinted with permission from Elsevier 
Collagen is a unique agonist of platelets, because it acts as an immobilized ligand which only causes platelet activation after stable adhesion. This review addresses the present understanding of how platelet interaction with collagen supports the process of thrombin generation and coagulation. Only some of the collagien-adhered platelets, lie. those showing profound changes in shape and shedding microparticles (resembling apoptotic cells), appear to contribute to the procoagulant activity of platelets. The main signaling receptor for collagen, glycoprotein VI (GPVI), plays a key role in the platelet procoagulant response during thrombus formation; this is a reason why new anti-GPVI antibodies are promising antithrombotic tools.

\subsection{Platelet activation and coagulation}

The intricate connection between platelets and coagulation was first recognized at the end of the $19^{\text {th }}$ century, when it was observed that fibrin strands co-localize to sites of platelet adhesion. The concept re-emerged about 25 years ago, when it was proved that collagen in combination with thrombin, is the most potent physiological platelet agonist in potentiation of the coagulation process by causing scrambling of phospholipids in the plasma membrane (1). Scrambling results in the surface expression of two aminophospholipids, phosphatidylserine (PS) and phosphatidyl-ethanolamine (PE), both of which are active in coagulation.

Since agents that strongly elevate cytosolic $\mathrm{Ca}^{2+}$ in platelets, such as $\mathrm{Ca}^{2+}$ ionophores (ionomycin) and $\mathrm{Ca}^{2+}$-ATPase inhibitors (thapsigargin), are even more potent than collagen in inducing phospholipid scrambling, it was envisaged that elevation in cytosolic $\mathrm{Ca}^{2+}$ must play a key role in this process (2). High cytosolic $\mathrm{Ca}^{2+}$ is considered to influence two enzymatic processes that control the scrambling process, i.e. inactivation of an aminophospholipid translocase and activation of a phospholipid scramblase (3). After a long search, candidate proteins for these activities have been proposed, but the identities of the translocase and sciramblase are still unknown (4). This PS expression greatly enhances the assembly and activity of two major coagulation factor complexes, the tenase and prothrombinase complexes, which produce lkey regulators of the coagulation process, factor Xa and thrombin, respectively. Thus. PS-expressing platelets have a potent enhancing effect on thrombin generation in plasma, where the extrinsic coagulation pathway is triggered with tissue factor. The importance of PS expression is demonstrated by the hemorrhagic episodes in patients with the Scott syndrome (5) and in dogs with similar symptoms (6), whose platelets are deficient in PS expression and microparticle formation (see bellow). In platelets from Scott patients, the diminished collagen-induced PS expression is not accompanied by reduced $\mathrm{Ca}^{2+}$ responses, indicating that the defect lies downstream of $\mathrm{Ca}^{2+}$ signaling (7).

As revilewed elsewhere, phospholipid scrambling is required but perhaps not exclusively responsible for the coagulation-supporting property of platelets $(4,8)$. For instance, platelet glycoproteins serve as binding sites for a number of coagulation factors such as 
prothrombin (9), factor $X I$ and factor $V_{\text {, }}$ of which the last is released from activated platelets themselves (10). A still pertinent question is how these protein receptors function in the regulation of platelet procoagulant activity. The debate is reopened with the finding that the elusive factor Xa receptor EPR-1 is not transcribed in cells, but that the 'EPR-1' gene encodes for a protein regulating apoptosis (11). A new, interesting possibility is that extracellular glycoprotein modification, e.g. by transglutaminases such as factor XIII, generates receptor sites. on platelets for coagulation factors (see below at COAT platelets).

Since PS-expressing platelets enhance the coagulation and, in turn, the coagulation product thrombin stimulates platelets, both processes are in a strong positive feedback loop which can have a control function in hemostasis and thrombosis (12). Thrombin generation measurements with platelets in plasma indeed demonstrate synergistic activity of (PSexpressing) platelets and the coagulant system $(12,13)$.

\subsection{Platelet adhesion to collagen stimulates procoagulant activity}

Platelet adhesion to collagen, especially to type I collagen fibers, causes PS expression and stimulates prothrombinase activity and thrombin formation after a delay of several minutes $(14,15)$. The fibrillar structure of collagen appears to be important for the procoagulant response, as platelet interaction with protease-treated soluble collagen (with an intact triple helical structure) does not lead to significant activity (16). Other platelet agonists such as ADP, acting via the $\mathrm{P} 2 Y_{12}$ receptor, and thrombin, acting particularly via the proteaseactivated receptor-1 (PAR1), can enhance the procoagulant activity of collagen-activated platelets (e.g. see (17)). Despite being strong platelet-aggregating agonists, ADP and thrombin are only weak generators of procoagulant activity by themselves, pointing to a divergence between the aggregation and procoagulant responses of platelets.

The need of platelets to adhere to collagen may explain why in suspension the combination of collagen and thrombin is a stronger procoagulant stimulus than collagen alone (3). Thrombin, for instance, enhances platelet interaction with collagen by increasing the affinity of its adhesive receptor, integrin $\alpha 2 \beta 1$ (18). On the other hand, it is proposed that the combination of collagen and thrombin induces a specific platelet reaction resulting in the formation of so-called COAT (collagen- and thrombin-activated) platelets (19). Such platelets are characterized by transglutaminase-mediated cross-linking of serotonin to platelet-derived procoagulant proteins (e.g., factor $V$ ), which bridge to fibrinogen and thrombospondin, forming a two-dimensional lattice. The precise contribution of COAT platelets to platelet-dependent coagulation is a current subject of research. 

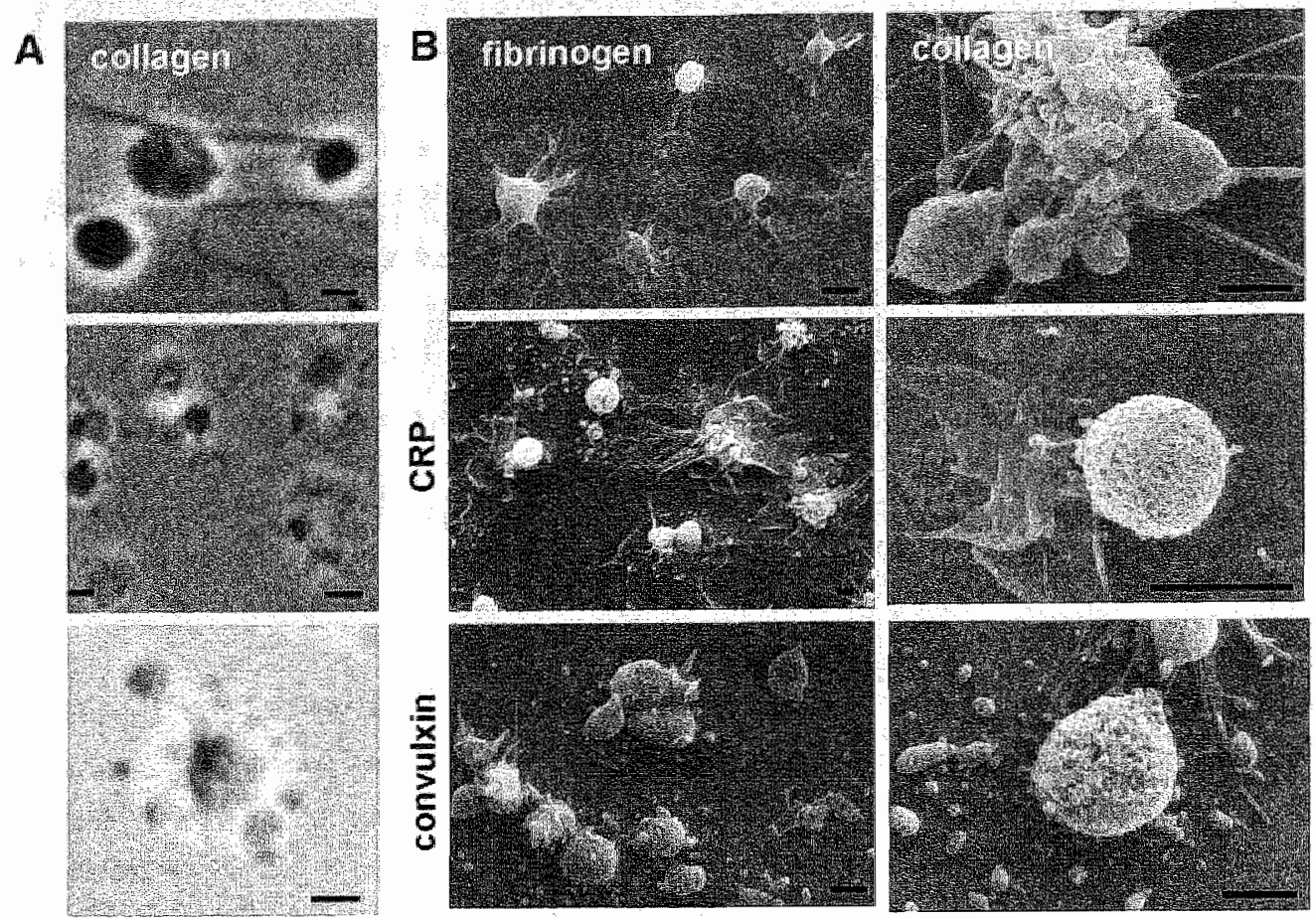

Figure. 2.1. Morphology of procioagulant platelets adhering to collagen under static conditions. Micrascopic images of human platelets adhered to fibrinogen, collagen, collagen-related peptide (CRP) or convulxin. A. Phase-contrast bright-field images; note heterogeneity of spread and blebbing morphology. B. Scanning electron microscopic images; note sponge-like structures. Bars represent $2 \mu \mathrm{m}$. Modified after Siljander ett al. (14).

\subsection{Collagen induces dramatic morphological changes in procoagulant platelets}

Platelet interaction with collagen fibers appears to lead not to a predetermined sequence of responses, but to several types of changes. In static adhesion, most collagenadhering platelets first develop pseudopods, which extend to broader lamellipods. These platelets can attract further platelets to initiate aggregate formation. However, some of the platelets (depending on the experimental conditions) suddenly transform into balloon-shaped cells with membrane blebs on their surface (Fig. 2.1). The blebbing platelets as well as the microparticles they shed express a procoagulant, PS-containing surface (14). Intravital fluorescence-microscopic observations of platelets adhering to fibrillar collagen or collagenrelated peptide (CRP) have indicated that the PS expression (detected with fluorescently labeled annexin $\mathrm{A5}$ ) is preceded by a potent and prolonged rise in cytosolic $\mathrm{Ca}^{2 *}(14,20)$. This $\mathrm{Ca}^{2+}$ signal, induced by GPVI signaling, is also a prerequisite for the dramatic morphological 


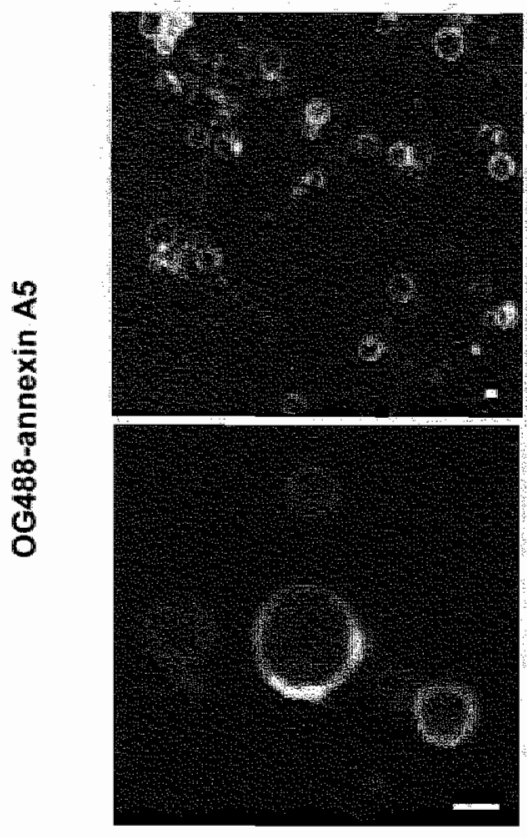

Colllagen

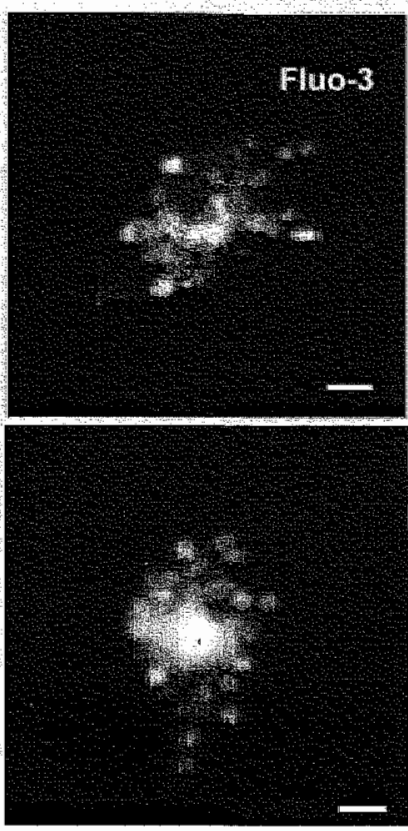

CRP
Figure 2,2 , properties of procoagulant platelets adhening 10 collagen under static conditions 1 wo-photory fluorescence mages of collagen-acherent platelels labeled with 06486 annexin A5 (staining surface exposed PS) or Fllo-3 (upper panel right indicating sevated cytosolic $\mathrm{Ca}^{2}$. Bars represent

change (Fig. 2.2). Others have similarly observed that collagen-bound platelets with high cytosolic $\mathrm{Ca}^{2+}$ respond by membrane contraction, cell fragmentation and microvesiculation (21). Such platelets were therefore designated as having SCIP (for sustained calcium-induced platelet) morphology. In many cell types, expression of PS, formation of membrane blebs and shedding of vesicles are signs of the apoptotic process. However, normall apoptosis (like in other cells of the cardiovascular system) is unlikely to occur in bleb-forming/vesiculating platelets since, for instance, the protease calpain rather than caspases controls the changes in platelet morphology (22).

During bleb formation, actin fibers become confined to the plasma membrane skeleton, implicating that degradation of cytosolic actin fibers contributes to the changed morphology of the cells (23). Protein tyrosine dephosphorylation also plays a role in bleb formation (24), as does the p38 mitogen-activated protein kinase pathway (SAPK2/3), known to be involved in actin rearrangement (14). Little more is known of the signaling prerequisites for this dramatic loss of normal platelet shape. So far, it seems that above a certain threshold of cytosolic $\mathrm{Ca}^{2+}$ concentration calpain and perhaps other proteases begin to degrade actin cytoskeletal proteins, resulting in the loss of main structural and membrane-anchoring cytoskeletal components. In scanning electron micrographs (Fig. 2.1B), the bleb-forming platelets on collagen or CRP appear as sponge-like structures (16), most likely because of the loss of lipid material by chemical fixation (25). The increase in size of blebbing platelets (balloons of about $5 \mu \mathrm{m}$ in diameter versus $2-3 \mu \mathrm{m}$ disks of resting platelets) is best explained by disappearance of the 
surface-connected canalicular system upon cytoskeleton degradation. This fits with the notion that this change in morphology is rather due to a loss of structure than to an active gain in "procoagulant" shape.

Earlier, Zwaal and colleagues already concluded that microparticle (bleb) formation is related but not the cause of phospholipid scrambling and PS expression (26). It is clear that PS expression and bleb formation are separate processes, e.g. calpain is not involved in $P S$ expression (2), but under most experimental conditions bleb-forming platelets on collagen also bind annexin A5, indicating an overlap in the regulation of these processes (4).

\subsection{Collagen induces formation of procoagulant microparticles}

Interestingly, platelets that bind to a collagen fiber, CRP or convulxin (with little surface contact) tend to develop into round, blebbing cells, whereas platelets that are spread and then stimulated via GPVI eventually fully fragment into smaller particles (Fig. 2.1) (14). Time-lapse measurements indicate that the vesiculation of retracting lamellipods of "procoagulant' platelets can occur rapidly, i.e. in a time scale of 1-3 $\min (21)$. High-resolution microscopy images further show that blebbing platelets have a translucent appearance.

Microparticles derived from collagen-adherent platelets are capable of associating with fibrin (27). As these microparticles, like the blebbing cells from which they are shed, express PS on their surface, their shedding provides a mechanism for dissemination of procoagulant activity in the circulation. This can be physiologically relevant, as (collagen/thrombin-indluced) microparticle formation is perturbed in patients with moderate bleeding disorders such as the Scott syndrome (5). Although more research is needed, there is growing evidence that the presence of platelet-derived microparticles in the circulation correlates with pathological conditions (28) . Of interest in this context is that most drugs that block the allb $\beta 3$ integrin inhibit microvesiculation, but differently affect (collagen-induced) PS expression.

\subsection{Glycoprotein $\mathrm{VI}$ as a key player in the regulation of platelet procoagulant activity during thrombus formation}

Experiments with human and mouse blood that is flown over collagen fibers have pointed out that some collagen-adherent platelets tend to develop into blebbing platelets within a developing thrombus. The experiments using blocking antibodies, inhibitors and knock-out mice, have also established that GPVI, a member of the immunoglobulin receptor family, plays a key role in the regulation of procoagulant activity during the thrombus-forming process.

Under conditions of high, arterial shear rates, platelets initially adhere to von Willebrand factor (VWF), which avidly binds to fibrillar collagen via the glycoprotein Ib-V-IX complex and subsequently via integrin $\alpha$ llb $\beta 3(29,30)$. Binding to WWF can predispose platelets 


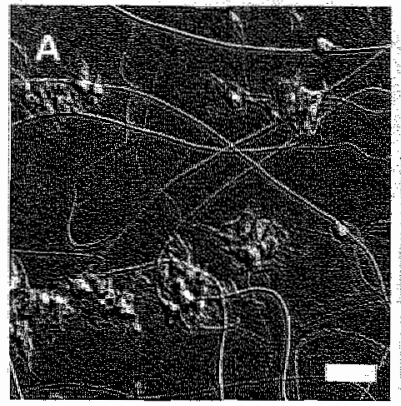

DIC

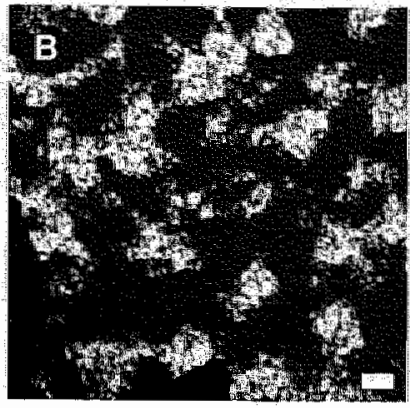

Calcein

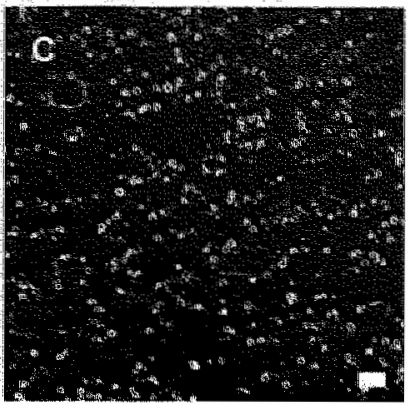

OG488 annexin A5

Figure 2.3. Thrombus formation and procoagulant activity under flow. Microscopic images of platelet thrombi formed during high-shear flow of human blood over collagen. A. Differential interference contrast image of aggregated platelets ( $4 \mathrm{~min}$ ). B. Two-photon fluorescence image after labeling with calcein ( $4 \mathrm{~min}$ ). C. Two-photon fluorescence image after labeling with $O G 488$ annexin $A 5(8 \mathrm{~min})$. Bars $=10 \mu \mathrm{m}$

to collagen-induced activation and facilitate the procoagulant response, particularly under conditions ofreduced GPVI activity (31). The subsequent order of events appears to differ from platelet to platelet both for human and mouse (32). Some platelets on collagen become rapidly activated by the main activating collagen receptor "GPVI. Subsequent signaling via GPVI involves its interaction with the Fc receptor $\gamma$-chain, activation of Src kinases, and a series of tyrosine phosphorylation events leading to activation of phospholipase $\mathrm{C}-\gamma 2$ and $\mathrm{Ca}^{2+}$ mobilization (33). In addition, the integrins $\alpha 2 \beta 1$ (collagen receptor) and $\alpha$ llb $\beta 3$ (fibrinogen and WWF receptor) assume an active conformation, which stabilizes the adhesion $(29,34)$. Autocoids like ADP and thromboxane are secreted, which activate passing platelets (35-37). However, some of the platelets, perhaps interacting with different motifs in collagen, follow a different order of events by first stably adhering to collagen via integrin $\alpha 2 \beta 1$ before showing activation responses. This heterogeneity in platelet responses may explain the apparent differences between current adhesion-activation models for human and murine platelets (32).

A further difference in responses of platelets from either species is displayed at a later stage. At first, collagen-adherent platelets trap other flowing platelets to form a growing aggregate, but after several minutes some platelets on collagen start to form blebs and expose PS (Fig. 2.3). GPVI plays a key role in both types of responses - aggregation and PS expression - as mouse platelets lacking GPVI or antibodies inhibiting mouse or human GPVI fail to form aggregates on collagen and no longer form blebs or express PS (Fig. 2.4) $(35,37)$. Absence of GPVI activity blocks $\mathrm{Ca}^{2+}$ signaling, autocrine secretion, and partially inhibits integrin activation. As expected from these findings, GPVI blockade also suppresses collageninduced prothrombinase activity (38). Nevertheless, but in agreement with the dual adhesionactivation model described above, adhesion under flow is affected variably by GPVI 

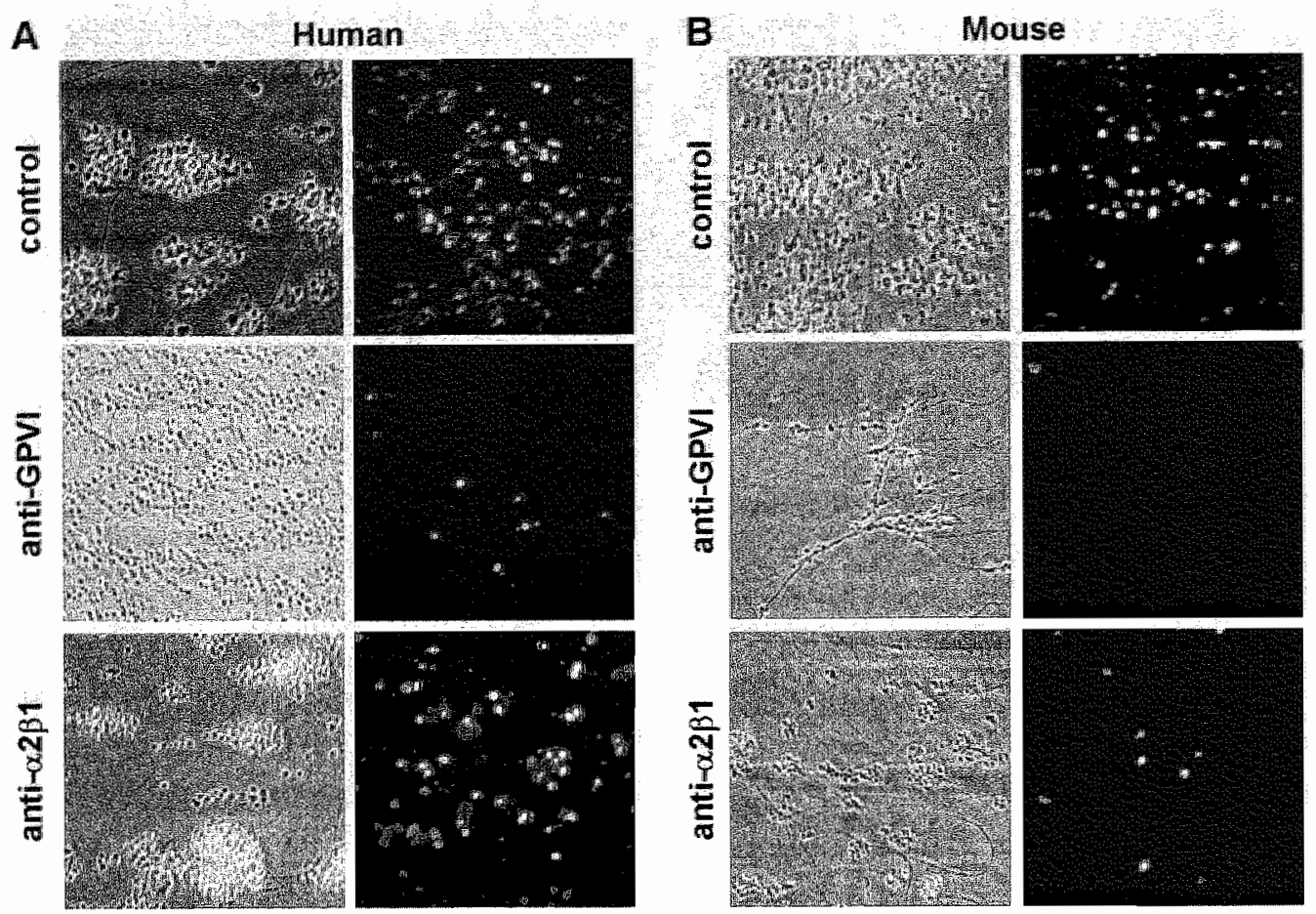

Figure 2.4. Function of collagen receptors in thrombus formation and procoagulant activity under flow. Microscopic images of human (A) and mause (B) thrombi formed during high-shear flow of blood over collagen. Blood was pretreated with anti-human or anti-mouse GPVI or $\alpha 2 \beta 1$ antibodies, as indicated. Representative images of phase-contrast $(120 \times 120 \mu \mathrm{m})$ and fluorescent-labeled annexin A5 (150 $\times 150$ $\mu \mathrm{m})$. Modified after $(35,37)$.

antagonism, probably depending on the experimental conditions $(36,37,39)$. A different situation is achieved by absence or blocking of integrin $\alpha 2 \beta 1$, which only decreases but does not abolish aggregate formation and PS expression, reducing the stability of thrombi (Fig. 2.4) $(35,37,40)$. These results agree with the proposal that GPVI and $\alpha 2 \beta 1$ determine collagen-induced platelet activation in concert, such that integrin adhesion mostly serves to amplify GPVI signaling. These results point to an interplay of GPVI and $\alpha 2 \beta 1$ in aggregation and procoagulant activity during thrombus formation, but they do not explain the observation that only some platelets develop to a 'procoagulant' shape. It is likely that differences in $\mathrm{Ca}^{2+}$ signaling explain the different fate of these platelets $(4,21)$.

Taken together, these results indicate that collagen provides a substrate on which the processes of platelet aggregation and coagulation are integrated but also separated. Especially, GPVI controls the multi-receptor interplay implicated in procoagulant activity upon thrombus formation (Fig. 2.5). 


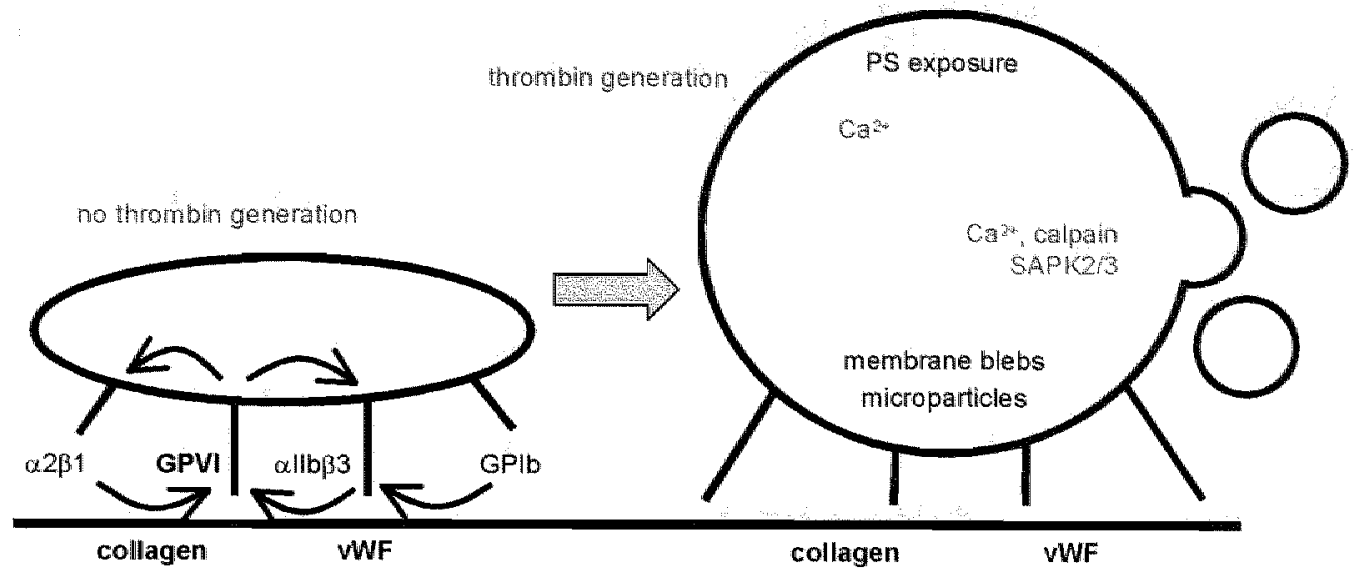

Figure 2.5. Diagram of function of collagen receptors in platelet procoagulant activity. Platelets adhere to a WWF-collagen surface via various receptors. GPVI has a central role by activating integrins, which enhance the adhesion and activation of platelets. Depending on the activation state "platelets transform into round structures with membrane blebs and shedding microparticles (increased cytosolic $\mathrm{Ca}^{2 *}$, calpain and SAPKK2/3 activation). These platelets (increased $\mathrm{Ca}^{2+}, \mathrm{PS}$ exposed) are also active in thrombin formation and coagulation.

\subsection{Collagen-induced coagulation as new target of antithrombotic therapy}

The presence of procoagulant platelets is not sufficient to induce plasma coagulation. Although in literature collagen is considered to be a trigger of the contact activation system of (intrinsic) coagulation, the current view is that for rapid onset of coagulation also tissue factor is needed. The precise localization of tissue factor in blood is still discussed. There is evidence that activated platelets themselves contain tissue factor (41), but this finding needs confirmation. On the other hand, it is clear that tissue factor is present close to all sites where (collagen-induced) procoagulant platelets are expected. For instance, tissue factor is found in the damaged wall of veins and arteries, and also within thrombi with fibrin-rich domains close to the vessel wall (42). Along with collagen, it is also found within humaln plaque tissue (43). Recent evidence indicates that thrombus formation in the macro-vasculature is primarily driven by tissue factor from the blood vessel wall (44), as opposed to (blood-borne) tissue factor from leukocytes, e.g. in contact with platelets. Together, this suggests that tissue factor and procoagulant platelets often co-localize at thrombotic sites and thus contribute synergistically to the thrombatic process.

Recent in vivo studies highlight the importance of platelet-collagen interaction and, thus, procoagulant activity in arterial thrombosis. In a variety of murine models, abolition of GPVI function suppresses thrombosis in arteries, but does not result in major bleeding $(36,45)$. Similarly, patients lacking GPV $\|$ do not suffer from a high bleeding tendency (18), but the 
number of patients is too small to estimate their thrombotic protection. Another promising finding for the usefulness of GPVI receptor blockade comes from perfusion studies, indicating that thrombus formation and PS expression on collagen-containing human atherosclerotic plaques is significantly suppressed by anti-GPVI antibodies $(43,46)$. Meanwhile, a number of novel antihuman GPVI antibodies, generated by various approaches, are available for studying the function of GPVI in thrombosis $(38,47)$. In vitro, all these antibodies avidly suppress PS expression and thrombus formation $(34,37)$ along with thrombin generation ( $P$. Siljander and $C$. Lecut, unpublished data), which are promising features for in vivo studies.

Inherently the collagen-induced procoagulant and aggregating responses via GPVI are linked to platelet adhesion to collagen that is exposed in the damaged or (ruptured) atherosclerotic vessel wall. Anti-GPVI antibodies will thus interfere at thrombus-forming and coagulant processes at sites close to the vessel wall. From a mechanistic point of view it can be anticipated that anti-GPVI treatment can suppress not only the acute assembly of thrombil on exposed collagen, but in addition the ongoing thrombus growth due to the locally generated thrombin on PS-expressing platelets. Accordingly, these novel tools may provide a locally effective antithrombotic therapy targeting adhesion-dependent platelet activation and coagulation.

\subsection{Acknowledgments}

Citations of literature are restricted due to limitations of space. We apologize for the omission of many important contributions in this field. We thank Dr. Richard Farndale for stimulating discussions and revisions, and Dr. Marc van Zandvoort for two-photon microscopy research. This work was supported by grants from the Netherlands Heart Foundation (2002B014), the Netherlands Organization for Scientific Research (902-16-276), and the British Heart Foundation (PG/02/097/14271).

\subsection{References}

1. Bevers EM, Comfurius $P$, wan Rijn JLML, Hemker HC, Zwaal RFA. Generation of prothrombinconverting activity and the exposure of phosphatidylserine at the outer surface of platelets. Eur $J$ Biochem. 1982; 122: 429-436.

2. Dachary-Prigent $J$, Pasquet $J M$, Freyssinet JM, Nurden AT. Calcium involvement in aminophospholipid exposure and microparticle formation during platelet activation: a studly using $\mathrm{Ca}^{2 *}$-ATPase inhibitors. Biachemistry. 1995; 34: 11625-11634.

3. Zwaal RFA, Schroit AJl. Pathophysiological implications of membrane phospholipid asymmetry in blood cells. Blood. 1997; 89: 1121-1132.

4. Heernskerk JWM, Bevers EM, Lindhout T. Platelet activation and blood coagulation. Thromb Haemost. 2002; 88: 186-193.

5. Sims PJ, Wiedmer T, Esmon CT, Weiss HJ, Shattil SJ. Assembly of the platelet prothrombinase complex is linked to vesiculation of the platelet plasma membrane. Studies in Scott syndrome: an isolated defect in platelet procoagulant activity. J Biol Chem. 1989; 264: 17049-17057.

6. Brooks MB, Catalfamo $\mathrm{JL}$, Brown HA, Ivanova $\mathrm{P}$, Lovaglio J. A hereditary bleeding disorder of dogs caused by a lack of platelet procoagulant activity. Blood. 2002; 99: 2434-2441. 
7. Munnix ICA, Harmsma $M$, Giddings JC, Collins PW, Felige MAH, Comfurius $P$, Haemskerth JWM, Bevers EM. Store-mediated calcium entry in the regulation of phosphatidytserine exposure in blood cells from Scott patients. Thromb Haemost. 2003; 89: 687-695.

8. Monroe DM, Hoffman M, Roberts HR. Platelets and thrombin generation. Arterioscler Thromb Vasc Bioll. 2002; 22: 1381-1389.

9. Byzova TV, Plow EF. Networking in the hemastatic system. Integrin allbb3 binds prothrombin and influences its activation. J Biol Chem. 1997; 272: 27183-27188.

10. Monkovic DD. Tracy PB. Functional characterization of human platelet-released factor $V$ and its activation by factor Xa and thrombin. J Biol Chem. 1990; 265: 17132-17140.

11. Zaman GJ, Conway EM. The elusive factor Xa receptor: failure to detect transcripts that correspond to the published sequence of EPR-1. Blood. 2000; 96: 145-148.

12. Beguin $S$, Kumar R. Thrombin, fibrin and platelets, a resonance loop in which von Willebrand factor is a necessary link. Thromb Haemost. 1997; 78: 590-594.

13. Butenas $S$, Cawthern $K M_{n}$ van't Veer $C$, DiLorenzo ME, Lock JB, Mann KG. Antiplatelet agents in tissue factor-induced blood coagulation. Blood. 2001; 97 : 2314-2322

14. Sillander $P$; Farndale RW, Feijge MAH, Comfurius $P$, Kos $S$, Bevers EM, Heemskerk JWM. Platelet adhesion enhances the glycoprotein V/-dependent procoagulant response: involvement of p38 MAP kinase and calpain. Arterioscler Thromb Vasc Biol. 2001; 21: 618-627

15. Ilveskero $S$, Siljander $P$, Lassila $R$. Procoagulant activity on platelets adhered to collagen or plasma clot. Arterioscler Thromb Vasc Biol. 2001; 21: 628-635.

16. Silljander $P$, Lassila $R$. Studies of adhesion-dependent platelet activation: distinct roles for different participating receptors can be dissociated by proteolysis of collagen. Arterioscler Thromb Vasc Biol. 1999; 19: 3033-3043.

17. Andersen $H$, Greenberg DL, Fujikawa $K_{r} \times u$ WF Chung DW, Davie EW. Protease-activated receptor 1 is the primany mediator of thrombin-stimulated platelet procoagulant activity. Proc Natl Acad Sci USA. 1999; 96: 11189-11193.

18. Jung SM, Moroi M. Activation of the platelet collagen receptor integrin $\alpha 2 \beta 1$ : its mechanism and participation in the physiological functions of platelets. Trends Cardiovasc Med. 2000; 10:285-292.

19. Dale GL, Friese P, Batar P, Hamilton SF, Reed GL, Jackson KW, Clemetson KJ, Alberio L. Stimulated platelets use serotonin to enhance their retention of procoagulant prateins on the cell surface. Nature. 2002; 415: 175-179.

20. Heemskerk JWM, Vuist WMJ, Feijge MAH, Reutelingsperger CPM, Lindhout T. Collagen but not fibrinogen surfaces induce bleb formation, exposure of phosphatidylserine and procoagulant activity of adherent platelets. Evidence for regulation by protein tyrosine kinase-dependent $\mathrm{Ca}^{2+}$ responses. Blood. 1997; 90: 2615-2625.

21. Kulkarni $S$, Jackson SP. Platelet factor XIII and calpain negatively regulate integrin allb/33 adhesive function and thrombus growth. J Biol Chem. 2004; 279: 30697-30706.

22. Wolf BB, Goldstein JC, Stennicke HR, Beere H, Amarante-Mendes GP, Salvesen GS, Green DR. Calpain functions in a caspase-independent manner to promote apoptosis-like events during platelet activation. Blood. 1999; 94: 1683-1692.

23. Fox JE, Austin CD, Boyles JK, Steffen PK. Role of the membrane skeleton in preventing the shedding of procoagulant-rich microvesicles from the platelet plasma membrane. J Cell Biol. 1990; 111: 483-493.

24. Pasquet JM, Dachary-Prigent J. Nurden AT. Microvesicle rellease is associated with extensive protein tyrosine dephosphorylation in platelets stimulated by A23187 or a mixture of thrombin and collagen. Biochem J. 1998; 333 (P\# 3): 591-599.

25. Hess MW, Siljander $P$. Procoagulant platelet balloons: evidence from cryopreparation and electron microscopy. Histochem Cell Biol. 2001; 115: 439-443.

26. Zwaal RFA, Comfurius $\mathbb{P}_{n}$ Smeets $E_{n}$ Bevers $E M$. Platelet procoagulant activity and microvesicle formation. In: Hypercoagulable States, fundamental aspects, acquired disorders "and congenital thrombophilia (Seghatchian, M J, Samama, M M and Hecker, S P, Eds). 1996.

27. Siljander $P$, Carpen $O$, Lassila R. Platelet-derived microparticles associate with fibrin during thrombosis. Blood. 1996; 87: 4651-4663.

28. Fireyssinet JM. Cellular microparticles: what are they bad or good for? J Thromb Haemost. 2003; 1 : $1655-1662$.

29. Ruggeri $Z M$, Dent $J A$, Saldivar $E$. Contribution of distinct adhesive interactions to platelet aggregation in flowing blood. Blood. 1999; 94: 172-178.

30. Wu YP. Vink T, Schiphorst M, van Zanten GH, IJsseldijk MJW, de Groot PG, Sixma JJ. Platelet thrombus formation on collagen at high shear rates is mediated by von Willebrand factor-glycoprotein Ib interaction and inhibited by von Willebrand factor-glycoprotein llb/llla interaction. Arterioscler Thromb Vasc Bial. 2000; 20: 1661-1667. 
31. Kuipers: WE, Schulte $V$, Oury $C$ Lindhout T, Broers $J$ Hoylaerts MF, Nieswandt B. Heemkerk $J$ WM. Facilitating poles of mune platelet glycoprotein lb and ollbp3 in phosphatidylserine exposure durng WWF-collagen-induced thromibus formation. I Physiol. 2004:558: $403-415$.

32. Auger JM. Kujpers MJE, Senis. YA, Watson SP, Heemskerk WWH. Adhesion of human and mouse platelets to collagen under shear: a unifying model. Faseb J. 2005; 19: 825-827.

33. Nieswand B, Watson SP. Platelet collagen interaction: is GPVI the ceintral receptor? Blood: 2003; 102: $449-461$.

34. Lecut $C_{,}$, Schoolmeester $\mathcal{A}_{*}$ Kujpers ME, Broers $J L V_{n}$ : van Zandwoort MAMJ, Vanhoorelbeke K, Deckmyn H. Jandrot-Perrus M. Heemkerk JWM. Principal role of glycopiotein Win 2931 and allbp3 activation during collagen-induced thrombus formation. Arterioscler Thromb Vasc Biol. 2004: 24: 17271733 .

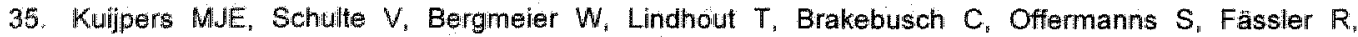
Heemskerk JWM, Wieswandt B. Complementary roles of glycoprotein $V$ and $a 2 \beta 1$ integrin in collageninduced thrombus formation in flowing whole blood ex vivo. FASEB J. 2003; 17:685-687.

36. Kato K, Kanaji T, Russell S, Kunick TJ, Furihata K, Kanaji S. Marchese P, Reininger A, Ruggeri ZM, Ware $J$ The contribution of glycoprotein $V$ to stable platelet adhesion and thrombus formation illustrated by targeted gene deletion. Blood. 2003; 102:170-1707.

37. Siljander PRM, Munnix ICA, Smethurst PA, Deckmyn H, Lindhout $T$, OuWehand WH, Famdale RW, Heemskerk WWM. Platelet receptor interplay regulates collagen-induced thrombus formation in flowing humam blood. Blood. 2004: 103: 1333-1341.

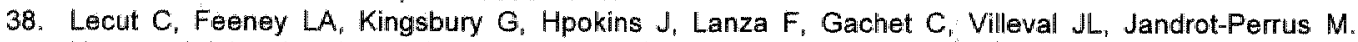
Human platelet glycoprotein $V /$ function is antagonized by monoclonal antibody-derived Fab fragments. $J$ Thromb Haemost. $2003 ; 1: 2653-2662$.

39. Nieswandt B, Brakebusch $C$, Bergmeier W, Schulte $W$, Bouvard D, Mohtarimejad R, Lindhout T, Heemskerk JWM, Zirngibl H, Fãssler R. Glycoprotein V/ but not a2 21 integrin is essentiall for platelet interartion with collagen. EMBO J. 2001; 20:2120-2130.

40. Chem H, Kahn ML. Reciprocal signaling by integrin and monintegrin receptors during collagen activation of plateliets. Mol Cell Biol. 2003; $23: 4764-4777$.

41. Engeimann $B$, Lutheir T, Möller 1. Intravascular tissue factor pathway: a model for rapid initiation of coagulation within the blood vessel. Thromb Haemost. $2003 ; 89: 3-8$.

42. Falati $S$, Gross $P$, Merrill-Skoloff $G$. Furie $B C_{1}$. Furie $B$. Real-time in vivo imaging of platelets, tissue factor and fibrin cluring arterial thrombus formation in the mouse. Nat Med. $2002 ; 10: 1175-1180$.

43. Cosemans JMEM, Kuijpers MJE, Lecut C, Loubele STBG, Heeneman S, Jandrot-Perrus M, Heemkerk JWM. Contribution of platelet glycoprotein $W$ to the thrombogenic effect of collagens in fibrous atherosclerotic plaques. Atherosclerosis. $2005 ; 181: 19-27$.

44. Day $S M$, Reeve JL. Pedersen B, Farris DM, Myeirs DD, lim M, Wakefield TW, Mackman N, Fay WP. Macrowascular thrombosis is driven by tissue factor derived primarily from the blood wessell wall. Blood. 2005; 105: 192-198.

45. Nieswandt $B$, Schulte $V$, Bergmeier W, Mokhtari-Nejad R, Rackebrandt K, Cazenave JP, Ohimann $P$, Gachet $\mathrm{C}$. Zirngibl H. Long-term antithirombotic protection by in vivo depletion of platelet glycoprotein VI in mice. J Exp Med. 2001; 193: 459-469.

46. Penz S, Reininger AJ, Brandl R, Goyal P, Rabie T, Bernlochner I, Rother E, Goetz C, Engelmann B, Smetthurst PA, Ouwehand WH. Fairndale $R$, Nieswandt $B$, Siess $W$. Human atheromatous plaques stimulate thrombus formation by activating platelet glycoprotein VI. Faseb J. 2005; 19: 898-909.

47. Smethurst PA, Joutsi-Korhonen L, O'Connor MlN, Wilson E, Jennings NS, Garmer SF, Zhang $Y$ " Knight CG, Dafforn TR, Buckle A, Jsiseldijk MJW, de Groot PG, Watkins NA, Farndale RW, Ouwehand WH. lidentification of the primary collagen-binding surface on human glycoproteill VI by site-directed mutagenesis and by a blocking phage antibody. Blood. 2004: 103: 903-911. 


\section{Chapter 3}

\section{Complementary roles of glycoprotein $\mathrm{VI}$ and $\alpha 2 \beta 1$}

\section{integrin in collagen-induced thrombus formation}

\section{in flowing whole blood ex vivo}

Marijke J. E. Kuijpers, Valerie Schulte, Wolfgang Bergmeier, Theo Lindhout, Cord Brakebusch, Stefan Offermanns, Reinhard Fässler, Johan W. M. Heemskerk and Bernhard Nieswandt

FASEB Journal (2003) 17: 685-687

Reprinted with permission 


\section{Abstract}

Platelets vigorously interact with subendothelial collagens exposed upon injury or pathological damage of a vessel wall. The collagen-bound platelets trap other platelets to form aggregates and expose phosphatidylserine (PS) required for coagulation. Both processes are implicated in the formation of vaso-occlusive thrombi. We previously demonstrated that the immunoglobulin receptor, glycoprotein VI (GPV), but not $\alpha 2 \beta 1$ integrin is essential in priming platelet-collagen interaction and subsequent aggregation. Here, we report that these receptors have a complementary function in ex vivo thrombus formation during perfusion of whole-blood over collagen. With mice deficient in GPVI or blocking antibodies, we found that GPVI was indispensable for collagen-dependent $\mathrm{Ca}^{2+}$ mobilization, exposure of PS and aggregation of platelets. Deficiency of integrin $\beta 1$ reduced the GPVI-evoked responses, but still allowed the formation of loose platelet aggregates. By using mice deficient in Go or specific thromboxane $\mathrm{A}_{2}$ and $\mathrm{ADP}$ antagionists, we show that these autocrine agents mediated aggregation, but not collagien-induced $\mathrm{Ca}^{2 *}$ mobilization or PS exposure. Collectively, these data indicate that $\alpha 2 \beta 1$ facilitates the central function of GPVI in the platelet-activation processes that lead to thrombus formation, whereas autocrine thromboxane $\mathrm{A}_{2}$ and $\mathrm{ADP}$ mainly serve to trigger aggregate formation.

\section{Introduction}

Vessel wall injury triggers sudden platelet activation and formation of a platelet plug. Subsequent coagulant activity leads to the formation of fibrin-containing thrombi, which acclude the injured vessel. Hemostasis thus starts with platelets adhering to activating components of the subendothelial matrix such as collagen. Similarly, thrombus formation, resulting from the rupture or erosion of an atherosclerotic plaque, is triggered by platelet interaction with extracellular matrix components.

Fibrous collagens are among the strongest reactive matrix components involved in platelet adhesion and activation (1). Such collagens avidly bind other proteins such as von Willebrand factor (WWF) that are implicated in stable platelet immobilization $(2,3)$. It is recognized that platelet-collagen interaction initiates a number of distinct processes that are implicated in thrombus formation. First, collagen-adherent platelets change in shape, produce pseudopods and express activated integrin $\alpha$ llb 33 , which acts as a high-affinity ligand for fibrinogen. Platelet-bound fibrinogen then serves as a binding site for flowing platelets that are trapped to form a platelet aggregate. Second, collagen increases the "activation" state of the platelets, as apparent from a rise in their cytosolic $\left[\mathrm{Ca}^{2+}\right]_{\text {in. }}$ The $\mathrm{Ca}^{2+}$ response mediates release of thromboxane $A_{2}\left(T \times A_{2}\right)$ and $A D P_{\text {" }}$ both of which act as potent autocrine agonists activating nearby platelets (4). Furthermore, the collagen-adherent platelets activate blood coagulation by 
exposing phosphatidy/serine (PS) at their surface; the procoagulant PS accomplishes the assembly of tenase and prothrombinase complexes and, thereby, stimulates the generation of thrombin by several orders of magnitude (5).

In recent years, several platelet collagen receptors have been identified. Among these, especially glycoprotein VI (GPV) and glycoprotein la-lla (integrin $\alpha 231$ ) are considered to be clinically important (6). GPVI is the main signaling collagen receptor on platelets (7). It belongs to the immunoglobulin superfamily $(8,9)$, and is non-covalently associated with the Fc receptor (FCR) $\gamma$-chain $(10,11)$. Patients lacking platelet GPVI suffer from a mild bleeding diathesis and their platelets respond poorly to collagen or collagen-related peptide $(12,43)$. The importance of the FCR $\gamma$-chain is exemplified by the fact that mice lacking this protein fall to express GPVI on their platelets and do not respond to collagen $(14,15)$. Signaling through the FoR y-chain activates phospholipase $C_{\gamma} 2$ via tyrosine kinases, causing a prolonged increase in cytosolic $\left[\mathrm{Ca}^{2+}\right]_{\mathrm{i}}(7,16)$. This $\mathrm{Ca}^{2+}$ response mediates not only exposure of procoagulant PS but also converts the platelets into blebbing cells, from which procoagulant microvesicles are shed $(16,17)$.

Unlike the role of GPVI, the role of the integrin $\alpha 2 \beta 1$ collagen receptor in platelet adhesion and activation has been controversial. Few patients lacking $\alpha 2 \beta 1$ and showing prolonged bleeding have been reported (18). Some authors found that collagen-induced adhesion and aggregation responses was greatly diminished in the absence of functional $\alpha 2 \beta 1$ $(19,20)$. Others however found only minor effects of $\alpha 2 \beta 1$ inhibition on these responses both under stasis and under flow conditions (21-24). By using $\beta 1$-null mice with a conditional inactivation of the integrin $\beta 1$ gene in megakaryocytes and thus a complete lack of integrin $\alpha 2 \beta 1$ on platelets, we recently demonstrated that integrin $\alpha 2 \beta 1$ is dispensable for both platelet adhesion and activation on fibrillar collagen (25).

Ex vivo flow studies provide an elegant tool to evaluate platelet adhesion to collagen fibrils and all subsequent processes involved in thrombus formation under physiologically relevant conditions. A current model proposes that at high wall shear rates (as in arteries) platelets initially interact wia glycoprotein Ib-V-IX (GPIb-V-IX) with WWF that is absorbed to the collagen, after which the collagen receptors accomplish irreversible adhesion $(2,3,26)$. Subsequent aggregation in such a system is caused by the soluble agonists $T \times A_{2}$ and ADP. Because mice deficient in the GTP-binding protein $\alpha$-subunit, Goq display defective platelet activation in response to $\mathrm{TXA}_{2}$ and $\mathrm{ADP}(27)$, these animals are an interesting model to study aggregate and thrombus formation under flow conditions. We have previousiy shown that these mice have normal GPVI function (28).

In the present study, we set out to resolve the current discrepancy with respect to the function of integrin $\alpha 2 \beta 1$ in collagen-dependent platelet activation by using mice with platelets deficient in either GPV/ or $\alpha 2 \beta 1$. We studied the different hemostatic processes contributing to collagen-induced thrombus formation with an ex vivo whole blood flow system and real-time 
video maging techniques. These methods allowed us to monitor shear-dependent adhesion and aggregate formation, as well as platelet activation and platelet procoagulant activity (PS exposure). We show that the integrin has a secondary yet complementary role to GPVI in all these responses. Furthermore, we demonstrate that aggregate formation, but not procoagulant activity, depends on Go stimulation by the autocrine mediators released from GPVl-stimulated platelets. These results provide novel insights into the differential roles of these platelet receptors in the hemostatic cascade. In addition, given the general importance of immunoglobulin receptors (such as GPVI) and integrins in cell biology, we infer that similar receptor interplay may also exist in other cellular systems expressing members of these two receptor families.

\section{Materials and methods}

\section{Animals}

Control NMRI mice were obtained from Charles River (Sulzfeld, Germany), while control C57BL/6 and C57BL/6 $6129 / \mathrm{Sv}$ mice were obtained from Iffa Credo (Someren, the Netherlands). C57BL/6 $\times 129 / \mathrm{Sv}$ mice carrying a floxed $\beta 1$ integrin gene, $\beta_{1}(f / / f l)(29)$ were cross-bred with mice carrying the $M x$-cre transgene $\left(\mathrm{Mx}\right.$-cre $\left.{ }^{*}\right)$. Deletion of the $\beta 1$ gene was induced in 4-5 week old $\beta 1(f / / f) / M x-c r e *$ mice by three intra-peritoneal injections with polyinoinic-polycytidylic acid at 2 -day intervals (25). The animals with a C57BL/6 $\times 129 / \mathrm{SV}$ background, were used at least two weeks after the last injection. C57BL/6 mice deficient in FCR $\gamma$-chain (30) were obtained from Taconics (Germantown, USA). To produce virtually complete GPVI-depleted animals, control mice were injected with a single dose of $100 \mu \mathrm{g}$ antiGPVI antibody JAQ1 (31). Mice deficient in Go (mixed C57BL/6 x 129/Sv background) were generated as described (27). All mice had similar platelet counts, as determined with a thrombocounter (Coulter Electronics, Luton, UK). Expression levels of integrin $\alpha 2 \beta 1$, integrin allbP3, GPIb-V-IX and GPVI were checked with antibodies directed against mouse glycoproteins using flow cytometry on a FACScalibur (Becton Dickinson, Heidelberg, Germany) (15). Mice were specific pathogen-free. Experimental protocols were approved by the Institutional Animal Care and Use Committees.

\section{Materials}

Fibrillar Horm-type collagen from equine tendon (Horm type-l) was purchased from Nycomed (Munich, Germany). Native type-I collagen fibers were extracted from bovine tendon as described (32). Nom-fibrillar "soluble" type-l collagen from rat taill (Sigma type VII) came from Sigma (St. Louis, MO), as well as apyrase, high molecular weight heparin and MRS2179. 
Annexin A5 (Apoptest) labeled with Oregon green 488 (OG488) was from Nexins Research (Hoeven, the Netherlands); fluo-3 acetoxymethyl ester was from Molecular Probes (Leiden, the Netherlands); H-Phe-Pro-Arg chloromethyl ketone (PPACK) was from Calbiochem (La Jolla, CA). AR-C69931MX, an antagonist of the $P 2 Y_{12}$ purinergic receptor, was purchased from AstraZeneca R\&D (Charnwood, UK). Sources of other chemicals are mentioned elsewhere (32).

Fab fragments of rat anti-mouse GPIb $\alpha$ antibody p0p/B and of rat anti-mouse GPVI antibody JAQ1 were generated, produced and modified as described before (15).

\section{Platelet preparation and labeling}

Mice were bled retro-orbitally, and blood (1 vol) was collected in 0.5 vol of saline containing $5 \mathrm{U} / \mathrm{ml}$ heparin and $40 \mu \mathrm{M}$ PPACK. Anticoagulated blood (1 vol) was diluted in 4-(2hydroxyethyl)-1-piperazineethanesulfonic acid (hepes) buffer pH 7.45 ( 0.5 vol) containing 137 $\mathrm{mM}$ NaCll, $5.6 \mathrm{mM}$ glucose, $5 \mathrm{mM}$ hepes, $2.7 \mathrm{mM} \mathrm{KCl}, 2 \mathrm{mM} \mathrm{MgCl}, 0.42 \mathrm{mM} \mathrm{NaH} \mathrm{PO}_{4}, 0.1 \%$ (W/V) bovine serum albumin (BSA), which was supplemented with $1 \mathrm{U} / \mathrm{m} / \mathrm{heparin}$ and $2 \mathrm{mM}$ $\mathrm{CaCl}_{2}$. The blood was used within $2 \mathrm{~h}$. Washed mouse platelets in hepes buffer, $\mathrm{pH} 7.45$ were prepared from platelet-rich plasma, as described for rat blood (33). For $\mathrm{Ca}^{2+}$ measurements, the washed platelets were incubated with $5 \mu \mathrm{M}$ fluo-3 acetoxymethyl ester in the presence of pluronic F-127 (0.2 mg/ml) and apyrase (0.1 U ADPase/ml) at room temperature for $45 \mathrm{~min}$.

\section{Flow experiments and vital imaging recording}

Adhesion experiments under flow conditions were performed with PPACK and heparin anticoagulated mouse bllood, basically as described previously (25). Rectangular coverslips (24 x $60 \mathrm{~mm}$ ) were coated with Horm-type collagen fibers $\left(12.5 \mu \mathrm{g} / \mathrm{cm}^{2}\right)$, rinsed with saline, and blocked with hepes buffer containing $1 \%$ (W/W) BSA. Where indicated, coating was with fibrillar or soluble type-1 collagens from other sources $\left(12.5 \mu \mathrm{g} / \mathrm{cm}^{2}\right)$. A coverslip was placed in a parallel-plate transparent flow chamber (slit depth of $50 \mu \mathrm{m}$ ), which was provided with polyethylene tubing (dliameter of $1 \mathrm{~mm}$ ). To prevent coagulation, chamber and tubing were prem washed with hepes buffer supplemented with $1 \mathrm{U} / \mathrm{m}$ l heparin. The blood was perfused through the flow chamber using a 1-ml syringe and a pulse-free pump (34), at high or low wall-shear rate (1000 or $150 \mathrm{~s}^{-1}$, respectively) for $4 \mathrm{~min}$. During the perfusion, high-resolution microscopic transmission and/or fluorescent fluo-3 images were recorded in real-time with a Visitech imaging system (Sunderland, UK). Digital images were captured with two parallel-placed intensiffied, charge-coupled device cameras, recording phase-contrast light and epifluorescenice (16). After $4 \mathrm{~min}$, the flow chamber was perfused with hepes buffer supplemented with $1 \mathrm{U} / \mathrm{mll}$ heparin at the same shear rate for $10 \mathrm{~min}$. Exposure of PS was detected with OG488mabelled annexin A5 $(1 \mu \mathrm{g} / \mathrm{ml})$. Phase-contrast and fluorescent images were obtained from at least nine different collagen-containing microscopic fields, which were randomly chosen. 
Where indicated, blood was incubated for $10 \mathrm{~min}$ before perfusion with $\mathrm{p} 0 \mathrm{p} / \mathrm{B}$ or JAQ1 Fab fragments $(40 \mu \mathrm{g} / \mathrm{ml})$, aspirin $(100 \mu \mathrm{M})$. MRS2179 (20 $\mu \mathrm{M})$ and/or AR-C69931MX (50 $\mu \mathrm{M})$. The same antibodies or antagonists were added to the rinse buffer. To measure changes in cytosolic $\left[\mathrm{Ca}^{2+}\right]$, fluo-3-labeled platelets (see above) from mice of the same genotype were added to the anticoagulated blood, so that about $5 \%$ of total platelets were labeled. Labeling of only a small fraction of the platelets in blood has as advantage that individual platelets can be distinguished from each other in fluorescence images, even when they are trapped in multiplatelet aggregates.

Surface area coverage from phase-contrast images was analyzed off-line using ImagePro software (Media Cybernetics, Silver Spring. MD). Data from at least 9 different microscopic images were averaged per experiment. Platelet coverage of the coverslip increased linearly around the standard perfusion time of $4 \mathrm{~min}$ at $1000 \mathrm{~s}^{-1}$. Area coverage by platelets staining with OG488-annexin A5 (9 images/experiment) was determined with Quanticell software (Visitech).

Real-time changes in fluo-3 fluorescence from single platelets, recorded during the flow experiment (5 images/second), were analyzed with Quanticell software and compared with translocation of the platelets, as deduced from the recorded images. Changes in fluo-3 fluorescence of individual platelets were converted into levels of $\left[\mathrm{Ca}^{2+}\right]$ i using a common pseudo-ratio calibration procedure (35). Normalized maximal and minimal fluorescence values

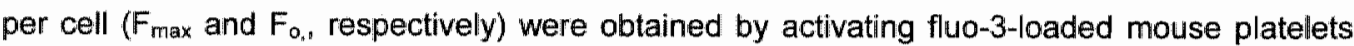
with lonomycin and thapsigargin, using the same optical and camera settings. Traces representing averaged $\mathrm{Ca}^{2+}$ responses were constructed from time-adjusted responses of 10-15 different platelets, observed during a period of at least $60 \mathrm{~s}$ ( 2 or 3 mice per experimental condition). Note that the fluo-3 images were captured during flow, and individual labeled platelets adhered and responded to the collagen surface at different time points and different sites in the microscopic field.

\section{Statistical analysis}

Data were tested on significance using the statistical package for social sciences (SPSS 8.0, Chicago, IL). Significant differences compared to control condition were evaluated with a Mann-Whitney $U$ test. 


\section{Results}

Integrin $\alpha_{2} \beta_{1}$ supports GPVI-dependent formation of stable aggregates under flow and potentiates platelet procoagulant activity

The role of collagen receptors GPVI and integrin $\alpha 2 \beta 1$ in the process of collagendependent platelet aggregation and procoagulant activity was examined in mice lacking either receptor on their platelets. Two different models for GPVI-deficiency were used. First, FicR chain-deficient mice which also lack expression of GPVI on platelets (15), and second, wildtype mice injected with the anti-GPVI antibody JAQ1. The latter treatment induces virtually complete internalization and proteolytic degradation of GPVI on circulating platelets, which results in a GPVI knockout-like phenotype for at least two weeks (31). As shown in Table 3.1, GPVI was undetectable on the platelets of either group of mice. Mice lacking integrin $\alpha 2 \beta 1$ on their platelets were generated by crossing mice carrying a floxed $\beta 1$ gene with mice expressing cre recombinase under control of an Mx promoter (29). Two weeks after injection of polyinosinicpolycytidylic acid, Mx-cre-mediated deletion was almost complete in bone marrow and platelets. Integrin $\alpha 2 \beta 1$ was undetectable on the platelets from these mice, but their GPVI level was normal (Table 3.1). Mice lacking $G a_{q}$, but expressing normal levels of platelet collagen receptors (Table 3.1) were used to determine the involvement of Gadphospholipase C $\beta$ mediated signaling implicated in $\mathrm{TXA}_{2}$-and ADP-dependent events in aggregation.

Table 3.1 Surface expression of different glycoproteins on platelets from control and modiffed mice

Mean log fluorescence $(A U) \pm S D$

\begin{tabular}{|c|c|c|c|c|c|}
\hline Glycoprotein & Control & GPVI-def & $\mathbb{F c R} \gamma-1-$ & B1-null & $\mathrm{Ga}_{\mathrm{q}} \ldots$ \\
\hline GPlla (integrin $\beta 1$ ) & $123.1 \pm 5.6$ & $122.0 \pm 7.8$ & $129.0 \pm 5.7$ & $6.6 \pm 1.1$ & $124.5 \pm 8.6$ \\
\hline GPla (integrin $\alpha 2$ ) & $63.3 \pm 6.3$ & $67.0 \pm 8.2$ & $64.3 \pm 8.0$ & $6.2 \pm 0.8^{\text {ix }}$ & $69.2 \pm 7.2$ \\
\hline GPlc" (integrin a6) & $72.8 \pm 7.9$ & $64.4 \pm 6.5$ & $68.6 \pm 8.3$ & $6.0 \pm 0.8^{*}$ & $67.4 \pm 8.6$ \\
\hline GPVI & $47.3 \pm 4.0$ & $5.8 \pm 0.7^{\star}$ & $5.1 \pm 0.5^{*}$ & $50.5 \pm 5.0$ & $48.3 \pm 4.8$ \\
\hline $\begin{array}{l}\text { GPIlb/lla } \\
\text { (integrin } \alpha / \| b \beta 3 \text { ) }\end{array}$ & $359.0 \pm 15.5$ & $368.0 \pm 14.7$ & $379.9 \pm 8.8$ & $366.0 \pm 12.0$ & $369.9 \pm 19.4$ \\
\hline GPlb-V-1X & $289.5 \pm 10.8$ & $283.9 \pm 12.4$ & $285.0 \pm 15.3$ & $290.2 \pm 11.2$ & $278.2 \pm 15.4$ \\
\hline
\end{tabular}

axpression levels were determined by flow cytometry using fluorophore-labeled monoclonal antibodies, as described previously (15). Platelets were gated by their forward scatter/side scatter characteristics. Control graup refers to platelets from NMRI mice, but similar results were obtained with control C57BL/6 and C57BL/6 $\times 129 / \mathrm{Sv}$ mice. GPVI-def indicates GPV/l-deficient mice. Results are expressed as mean log fluorescence $(A U) \pm S D$ for 6 mice per group. ${ }^{*} p<0.01$ compared to control. 

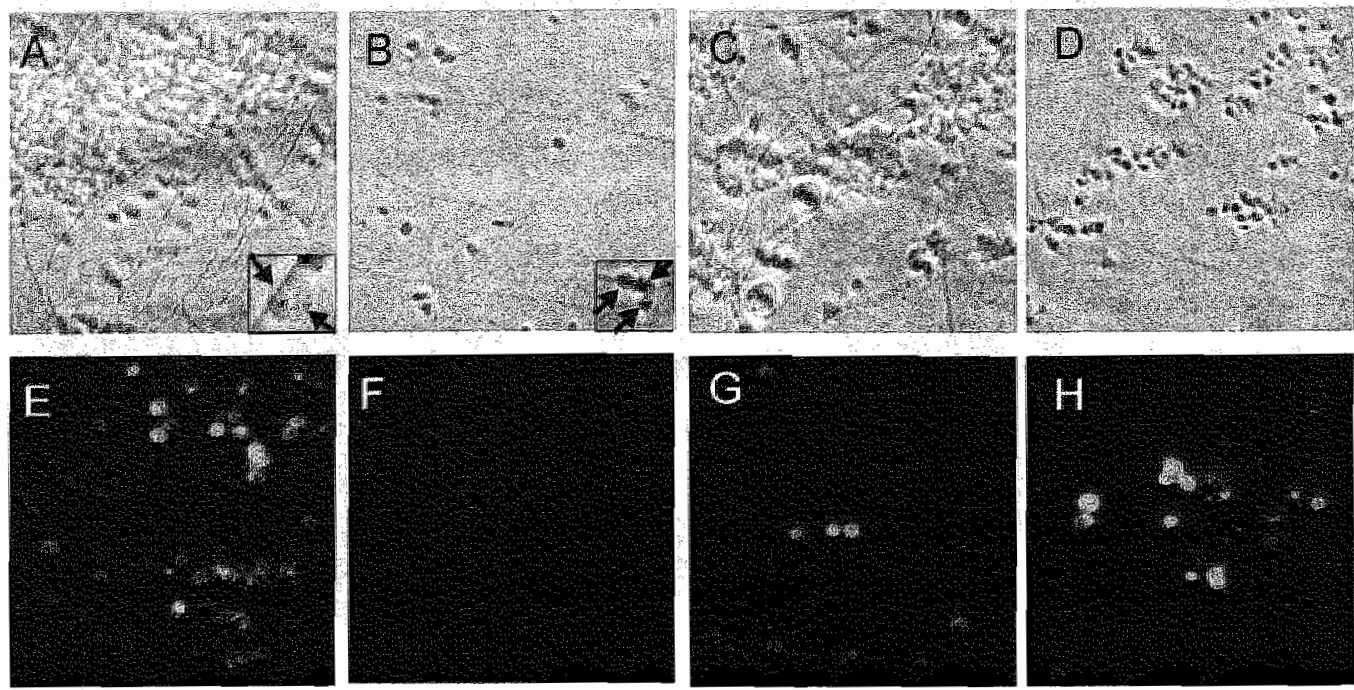

Control

$\mathrm{FCR} \gamma-1-$

B1 null

Goq $/-$

Figure 3.1. Platelets lacking GPVI, integrin $\alpha 2 \beta 1$ or $G \alpha_{-q}$ differed in collagen-mediated aggregate formation and procoagulant activity under flow conditions. (A-D) Phase-contrast microscope images after 4 min perfusion of whole mouse blood at a wall shear rate of $1000 \mathrm{~s}^{-1}$ over a collagen-coated surface (Horm type I) in a parallel plate flow chamber. Image areas are $120 \times 120 \mu \mathrm{m}$. (E-H) Fluorescence images after staining with OG488-labeled annexin $A 5_{n}$ for detecting PS-exposing platelets. Image areas are $150 \times 150 \mu \mathrm{m} .(A, E)$ NMRI controll mice; (B, F) FCR $\gamma$-chain $/$ mice; $(C, G) \beta_{1}$ null mice; $(D, H)$ Go $\alpha_{q} /$ mice. inserts are $300 \%$ magnifications of platelets at a collagen fiber; arrows indicate one blebbing platelet (A) and three unstimulated platelets (B). Data are representative for 4-9 independent experiments.

Whole blood from control mice was perfused over fibrillar (either Horm type-I or native type-I from bovine tendon) or non-fibrillar type-I collagen at a defined wall shear rate. During and after the flow video (fluorescence) microscopic images were continuously taken at the optical plane of the collagen. Blood was anticoagulated with PPACK and heparin to maintain physiological, millimolar $\mathrm{Ca}^{2+}$ and $\mathrm{Mg}^{2+}$ concentrations. At a high shear rate of $1000 \mathrm{~s}^{-1}$, platelets from control mice adhered to Horm collagen fibers and formed pseudopods within 30 s. The adhered platelets served as starting sites for large platelet aggregates that assembled within $2 \mathrm{~min}$. After about $4 \mathrm{~min}$, some collagen-attached platelets rounded off and developed into balloon-shaped, blebbing cells (Fig. 3.1A, inset). Platelet deposition and aggregate formation on collagen was independent of the genetic background of the control mice; i.e. blood from wildtype NMRI, C57BL/6 or C57BL/6 $\times 129 / \mathrm{Sv}$ mice, all with similar platelet counts, was equally reactive (see below). At a low shear rate of $150 \mathrm{~s}^{-1}$, the rate of platelet adhesion to the collagen surface and subsequent assembly of aggregates was lower than at $1000 \mathrm{~s}^{-1}$, as described before (25). 


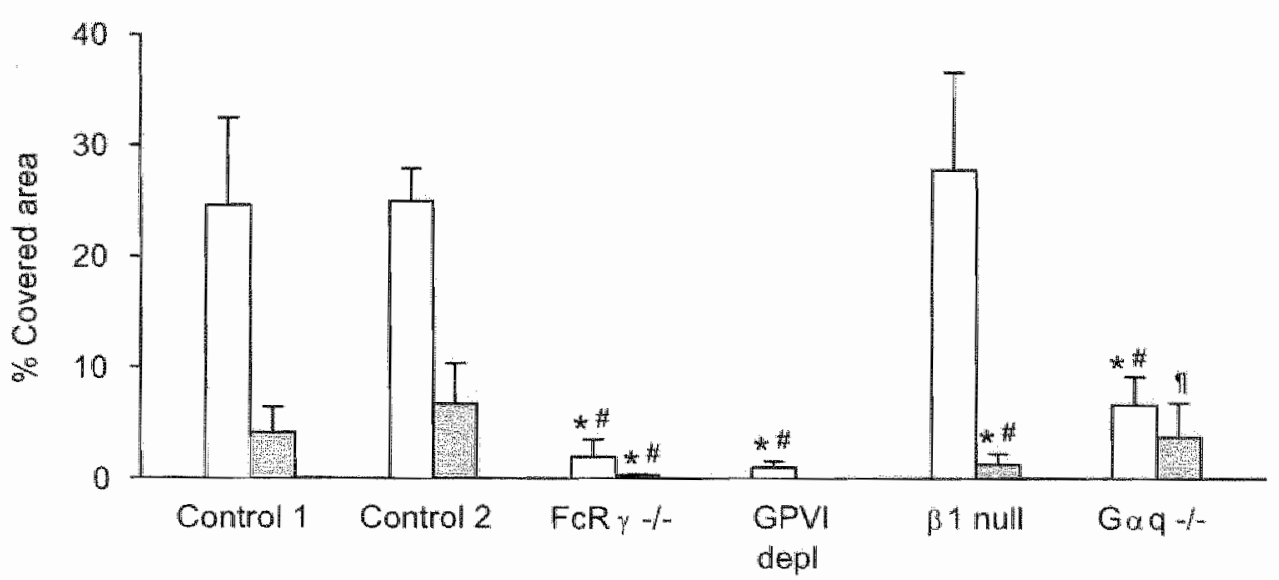

Figure 3.2. Both GPVI and integrin $\alpha 2 \beta 1$ contributed to collagen-mediated platelet procoagulant activity. Blood from different types of mice was perfused over collagen as described for Fig. 3.1. Control 1, NMRI mice; control 2, C57BL/6 $\times 129 / \mathrm{Sv}$. Data represent percentages of area coverage of all platelets (while bars) or PS-exposing platelets (gray bars) after 4 min of perfusion. Means $\pm S D(n=3-7 ; \pi n=1)$. " $p<0.05$ compared to NMRI control mice; $\# p<0,05$ compared to C57BL/6 $\times 129 / \mathrm{SV}$ control mice.

Perfusion of blood from FcR $\gamma$-chain -1 - mice at high shear stress resulted in only few platelets adhering to the Horm collagen; these did not show morphological signs of activation (Fig. 3.1B). Blood from mice depleted in GPVI by JAQ1 injection gave similar results. However, when using B1-null blood, many platelets adhered and formed aggregates (Fig. 3.1C), confirming that integrin $\alpha_{2} \beta_{1}$ is not essential for collagen-induced aggregate formation (25). Yet, the $\beta_{1}$-null aggregates consistently had a looser structure and they disintegrated more frequently later in the experiment as compared to wildtype. Also at low shear rate (150 $\mathrm{s}^{-1}$ ) and/or when native type-1 collagen was used, GPVI depletion resulted in nearly complete suppressionof platelet adhesion, whereas $\alpha 2 \beta 1$ absence prevented neither adhesion nor aggregation. However, in the latter case, again aggregates were consistently looser packed in comparison to those of control platelets.

High shear flow experiments with blood from $\mathrm{Go}$. $/$ - mice resulted in normal plateletcollagen interaction and normal pseudopod and bleb formation, but aggregates remained small and were no more than two cell layers thick (Fig. 3.1D). Because of the greatly reduced aggregate size in the absence of $\mathrm{Gaq}$, total platelet deposition was reduced by $70 \%$ as compared to the wildtype contral (Fig. 3.2).

The appearance of balloon-shaped, blebbing platelets on collagen fibers was indicative of surface exposure of procoagulant PS, a process that usually occurs simultaneously with the blebbing response (17). Indeed, after the perfusion a significant number of the control platelets was in procoagulant state, as demonstrated by their staining with OG488-Uabeled annexin A5 
(Fig. 3.1E, and quantified in Fig. 3.2). Only platelets in the focal plane of the collagen were positive for annexin A5, which demonstrates that direct contact of the cells with collagen was essential for PS exposure. This finding was confirmed by the virtually complete absence of annexin- $V$ positive cells after perfusion of blood from FCR $\gamma$-chain -1- or GPVI-depleted mice. Even the few adherent platelets of these mice did not bind annexin $A 5$, in agreement with their apparently unstimulated morphology. Strikingly, B1-null blood, despite forming platelet aggregates, showed markedly reduced annexin A5 positivity of platelets after the perfusion, as compared to the controls (Fig. 3.2). Reduced PS exposure was abserved independent of the shear rate $\left(1000\right.$ or $\left.150 \mathrm{~s}^{-1}\right)$ or type of collagen fibers. This result is in contrast to the situation with blood from $\mathrm{Ga}_{\mathrm{q}}$ /- mice, where the number of PS-exposing platelets was unchanged in spite of fairly reduced aggregate formation $\left(1000 \mathrm{~s}^{-1}\right)$. Together, these results confirm the essential role of GPVI in platelet-collagen interaction (25), but they also demonstrate that $\alpha_{2} \beta_{1}$ integrin, but not $G \alpha_{q, i}$ is required to potentiate GPVI-dependent PS exposure, i.e. procoagulant activity.

Integrin $\alpha_{2} \beta_{1}$ but not $\mathrm{G} \alpha_{q}$ contributes to sustained, GPVI-induced $\mathrm{Ca}^{2+}$ responses under flow conditions

To determine the activation state of platelets interacting with collagen under flow conditions, whole blood was spiked with fluo-3-loaded platelets derived from the same mouse type, to reach a concentration of $5 \%$ labeled platelets. This partial llabeling allowed visualization of the $\mathrm{Ca}^{2+}$ responses in individual cells even within large aggregates. Platelet labeling with fluo3 had no effect on in vitro aggregate formation (data not shown). Microscopic fluorescence images were captured at $5 \mathrm{~Hz}$ to monitor the changes in cytosolic [ $\mathrm{Ca}^{2+}$ ] of individual adherent platelets during the flow at $1000 \mathrm{~s}^{-1}$ (35). The fluo-3-labeled platelets in blood from control mice stably attached to collagen fibrils and exhibited a potent increase in $\left[\mathrm{Ca}^{2+}\right]_{\mathrm{i}}$, as shown in the averaged trace of Fig. 3.3A. Traces from most single platelets indicated one or more transient spikes in $\left[\mathrm{Ca}^{2+}\right]_{i}$ that was followed by a persistent, elevated plateau level (41/42 cells); see the single-cell trace of Fig. 3.3A. In contrast, in flow experiments with FCRy $/$-blood, the few labeled platelets that stably adhered remained low in $\left[\mathrm{Ca}^{2+}\right]$ (Fig. $3.3 \mathrm{~B}$ ), indicating that the $\mathrm{Ca}^{2+}$ signal generation was effectively abolished.

With blood from $\beta 1$-null mice, a different situation was obtained in that many platelets adhered transiently and then translocated downstream. About $90 \%$ of the labeled platelets performed such translocation (26 of 29 cells). The averaged $\mathrm{Ca}^{2+}$ response of $\beta 1$-null platelets fluctuated and was somewhat lower than the control response (Fig. $3.3 \mathrm{C}$ ). Traces from single cells showed highly spiking rises in $\left[\mathrm{Ca}^{2+}\right]$ that occurred upon contacts with collagen for more than several seconds (Fig. 3.3C). A minority of the labeled platelets displayed prolonged binding to collagen, in which case a sustained $\left[\mathrm{Ca}^{2++}\right]_{\mathrm{i}}$ rise was abserved ( 3 of 29 cells). In contrast, 

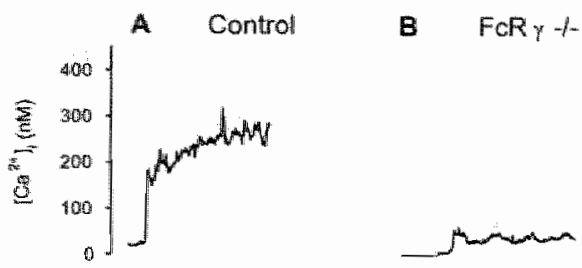

C 9 in null

arg
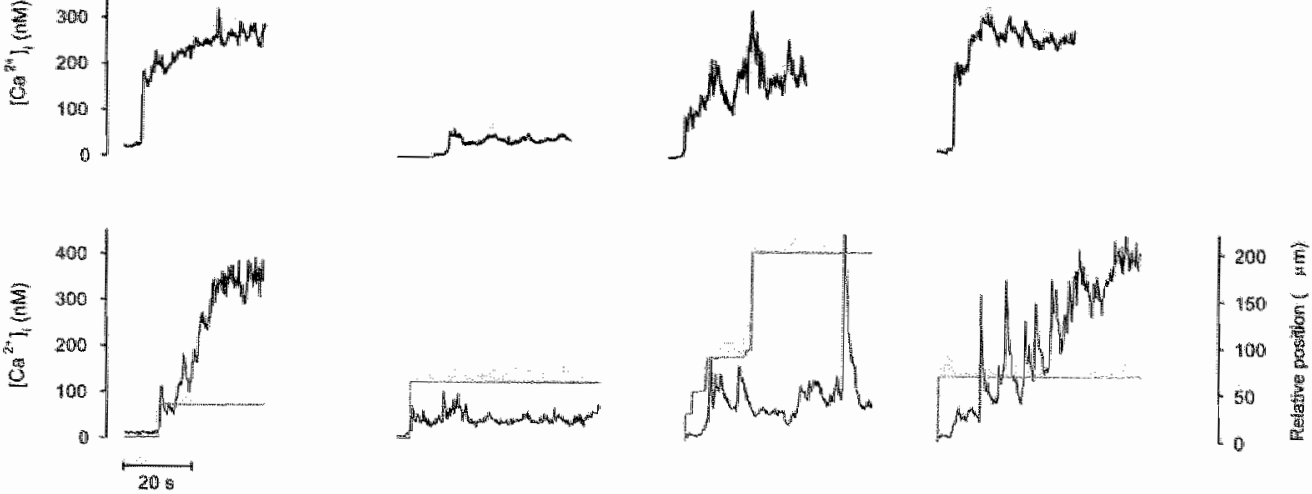

Figure 3.3. Prolonged $\mathrm{Ca}^{2+}$ responses of platelets interacting with collagen under flow required both GPVI and integrin $\alpha 2 \beta 1$. Whole blood was spiked with fluo-3-loaded platelets from the same mouse type, and perfused over a collagen surface (Horm type 1) at $1000 \mathrm{~s}^{-1}$. Upper traces show averaged changes in [Ca $\left.{ }^{2.4}\right]_{\mathrm{i}}$ of 15-20 platelets that could be observed during at least $60 \mathrm{~s} \mathrm{(2-3} \mathrm{mice} \mathrm{per} \mathrm{condition).} \mathrm{Lower} \mathrm{traces} \mathrm{show}$ $\mathrm{Ca}^{2+}$ responses of representative, single platelets (black lines) as well as their downstream translocation over the collagen surface (gray lines). Types of mice: (A) NMRI control; (B) FcR $\gamma$-chain $-/-$; (C) B1 null; (D) Gaq - $/$.

absence of $\mathrm{G} \alpha_{q}$ influenced neither stable adhesion to collagen nor the potent $\mathrm{Ca}^{2+}$ signal. The averaged $\mathrm{Ca}^{2+}$ response from $\mathrm{G} \alpha_{q}-1$ - platelets resembled that of control platelets (Fig. 3.3D); individual knock-out platelets showed a normal initial $\left[\mathrm{Ca}^{2+}\right]_{i}$ spike followed by a persistent increase (18 of 22 cells). These results demonstrate that GPVI is required for the generation of the $\mathrm{Ca}^{2+}$ signal once the platelets are deposited from the flowing blood, while integrin $\alpha_{2} \beta_{1}$ serves to facillitate and prolong GPVI-induced $\mathrm{Ca}^{2+}$ signaling. These data further show that Gor dependent stimulation of phospholipase $\mathrm{C} \beta \mathrm{is}$ not involved in the generation of this $\mathrm{Ca}^{2+}$ signal.

Secretion of $T \times A_{2}$ and ADP mediates formation of large platelet aggregates but not the primary GPVl-dependent $\mathrm{Ca}^{2+}$ responses and procoagulant activity under flow conditions

With blood from wildtype mice, we used blocking antibodies against the adhesive receptors and agents inhibiting $T \times A_{2}$ - and ADP-mediated effects to further delineate the process of shear-dependent thrombus-formation. Initial platelet adhesion and subsequent aggregate formation depended on GPIb-WWF interaction, as a Fab fragment of p0p/B blocking antibody $(40 \mu \mathrm{g} / \mathrm{ml})$, directed against mouse GPIba, almost completely inhibited these events (Fig. 3.4). The few adhering platelets, however, were activated, because they spread, formed blebs and bound annexin A5. These data are in line with the hypothesis that GPlb mediates platelet tethering under these shear-rate conditions by interacting with WWF deposited on the collagen 

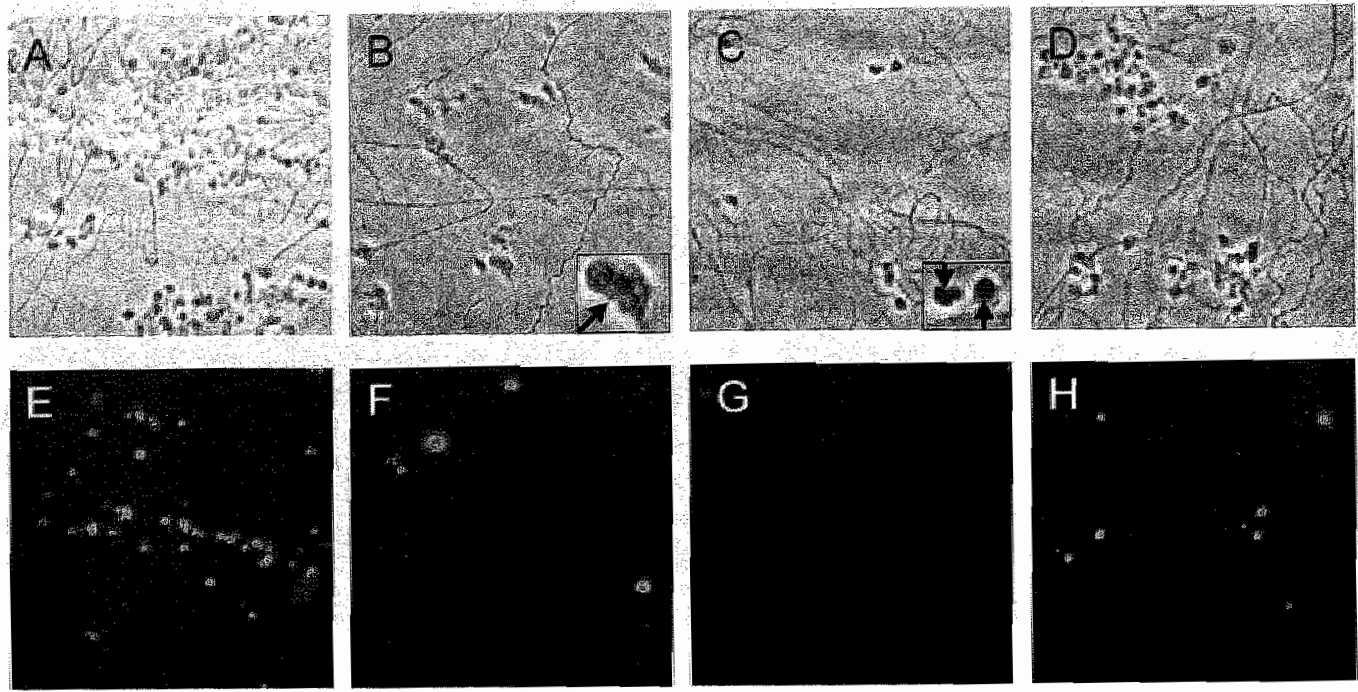

Control

pOp/B

JAQ1

Aspirin+MRS+ARC

Figure 3.4. Different effects of anti-glycoprotein antibodies and inhibitors of $T \times A_{2}$ and ADP action on platelet-collagen interaction under flow condtions. (A-D) Phase-contrast microscopic images after $4 \mathrm{~min}$ perfusion of whole blood at $1000 \mathrm{~s}^{-11}$ over a collagen-coated surface (Horm type I). Image areas are $120 \times$ $120 \mu \mathrm{m}$. (E-H) Fluorescence microscopic images after staining with OG488-labeled annexin $A 5$, for detecting PS-exposing platelets. Image areas are $150 \times 150 \mu \mathrm{m}$. Blood from C57BL/6 control mice was untreated $(A, E)$ or was incubated with the following substances for 10 min prior to perfusion: $(B, F) F a b$ fragments of $\mathrm{pOp} / \mathrm{B}$ antibody against GPIboc $(40 \mu \mathrm{g} / \mathrm{mil}) ;(C, \mathrm{G}) \mathrm{JAQ} 1$ Fab fragment against GPVI (40 $\mu \mathrm{g} / \mathrm{mll})$; (D. H) aspirin $(100 \mu \mathrm{M})$ together with MRS2179 $(20 \mu \mathrm{M})$ and AR-C69931MX $(50 \mu \mathrm{M})$. Insets are $300 \%$ magnifications of platelets at collagen; arrows point to one spreading platelet $(B)$ and two unstimulated platelets (C). Representative images from four to six experiments are shown.

fibers $(3,23)$, but they also point to unaltered GPVI- and integrin-mediated activation of those platelets that immobilized independently of GPIb.

Preincubation of wildtype blood with Fab fragments of the anti-GPVI antibody JAQ1 (40 $\mathrm{Hg} / \mathrm{ml}$ ) almost completely blocked adhesion and aggregate formation on elther Horm, native or non-fibrillar type-l collagens, as expected. The few adherent platelets "presumably binding through GPIb, showed neither morphological signs of activation nor staining with annexin A5 (Fig. 3.4). These results again confirm the pivotal role of GPVI in all collagen-induced responses. Different results were obtained with a new monoclonal rat anti-mouse antibody against integrin $\alpha 2 \beta 1, L E N 1$ (rat lgG1), which specifically blocks $\alpha 2 \beta 1$-mediated platelet adhesion to non-fibrillar collagen under steady-state conditions (V. Schulte \& B. Nieswandt, unpublished results). In high-shear experiments over Horm type-1 collagen, LEN1 (20 $\mu \mathrm{g} / \mathrm{ml})$ failed to abolish platelet adhesion and aggregate formation, but lowered the number of annexin A5-positive platelets to $21 \pm 20 \%$ (mean $\pm S D, n=4$ ) compared to the control condition. Together these results are in line with those obtained with $\beta 1$-null platelets. 

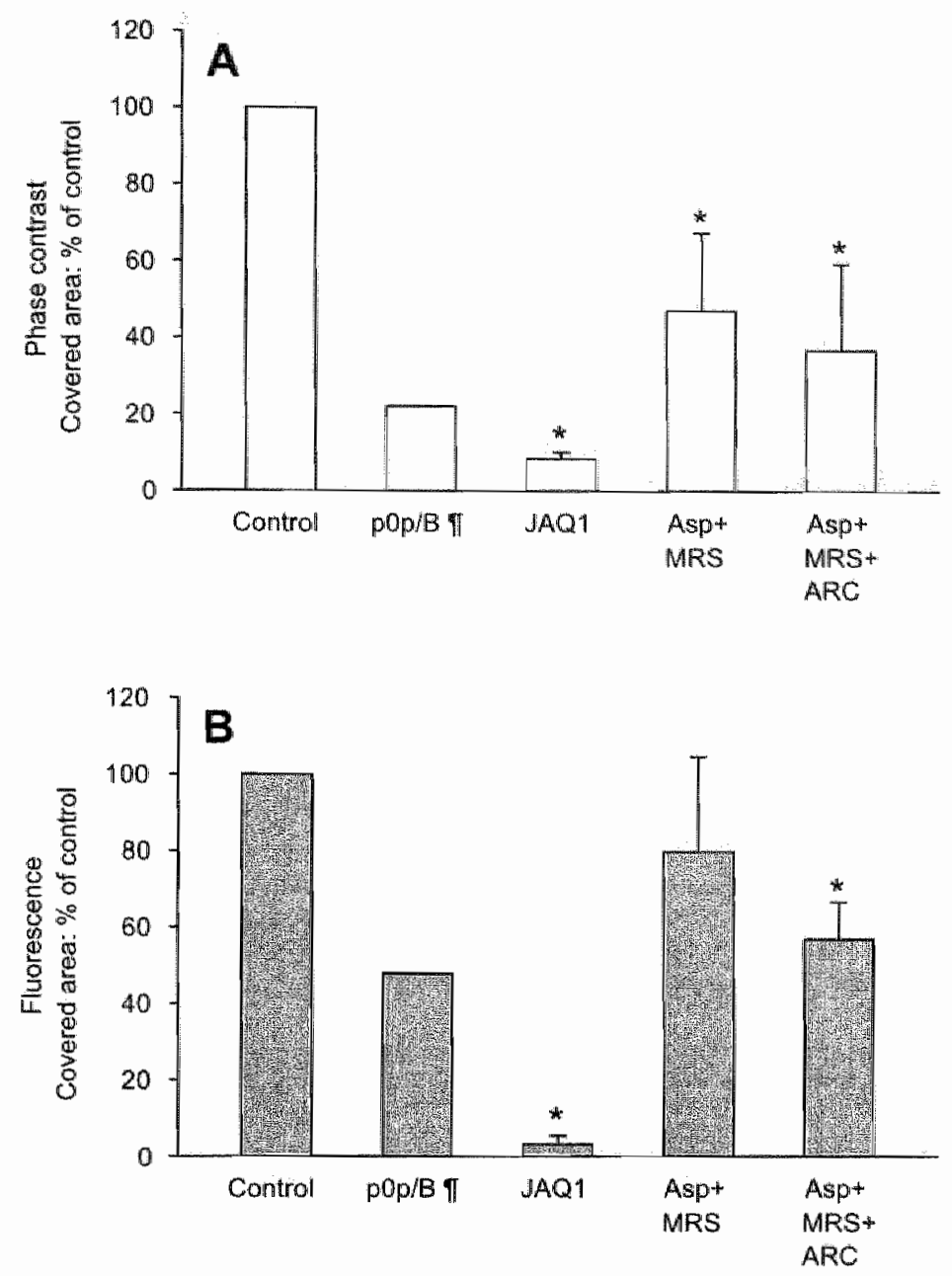

Figure 3.5. Contribution of GPVI-stimulated $T X A_{2}$ and $A D P$ secretion to collagen-mediated aggregate formation and procoagulant activity under flow conditions. Flow experiments over collagen surface were performed exactly as indicated for Fig. 3.4. Data represent percentages of area coverage of all platelets (A) or PS-exposing platelets $(B)$ after 4 min of perfusion. Mean percentages of control condition $\pm S D(n=4-11 ;$ i) $n=1) .{ }^{*} p<0.05$ compared to control.

In the absence of thrombin, le. coagulation, it is known that $\mathrm{Gq}_{q}$ mainly mediates $\mathrm{Ca}^{2+}$ and other platelet responses that are evoked by TXA and ADP through the TPa and P2Y, receptors, respectively $(27,36)$. Both $T X A_{2}$ and ADP are released from collagen-stimulated platelets and contribute to platelet aggregation in vitro (37). To mimic the effects of $G \alpha_{4}$ abolishment, we treated blood from wildtype mice with aspirin (blocking $T \times A_{2}$ formation) and added MRS2179 (a specific P2Y, antagonist). After 4 min of perfusion over Horm collagen, the treated platelets formed no more than small aggregates (Fig. 3.4); area coverage of platelets on the coverslip was half of the control condition (Fig. 3.5). Many of the collagen-adherent platelets 

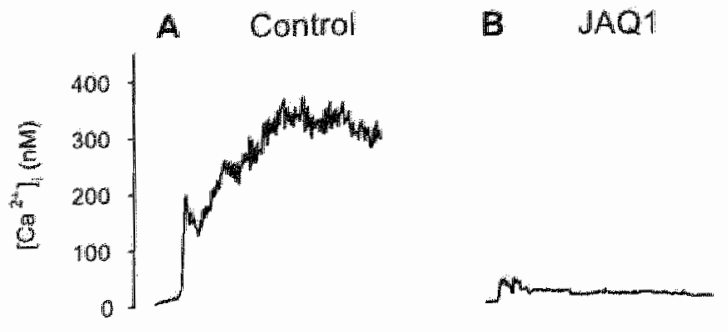

C Asp+MRS+ARC
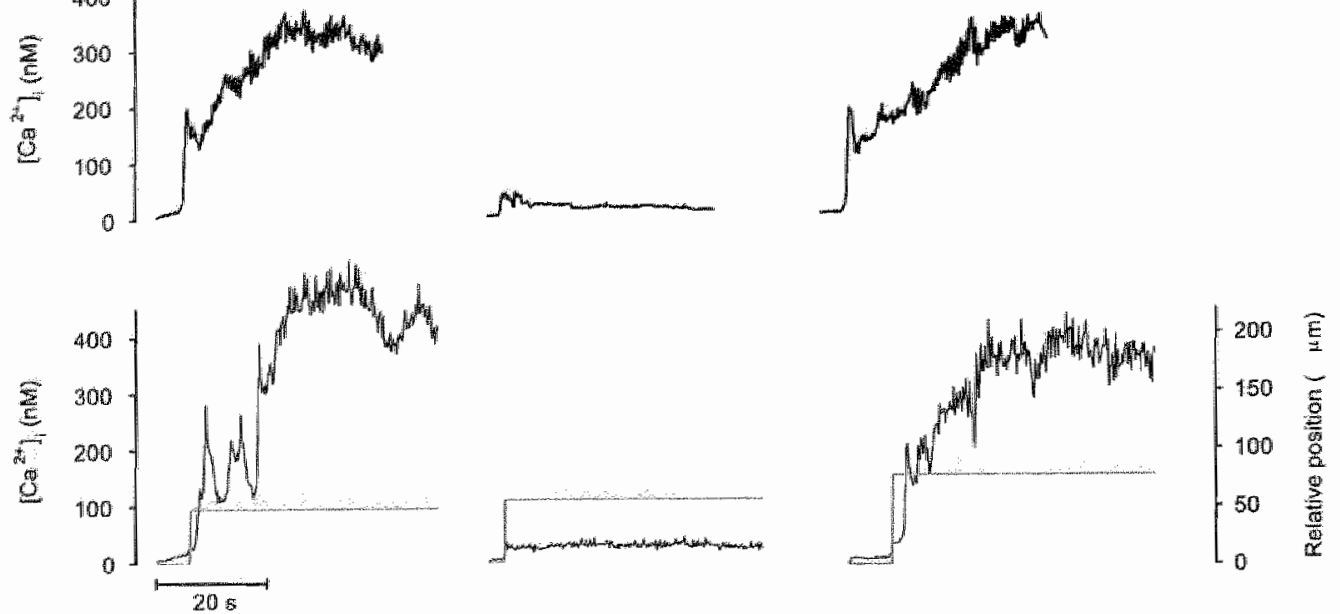

Figure 3.6. Different effects of GPVI antibody and inhibitors of $T \times A_{2}$ and $A D P$ action on $\mathrm{Ca}^{2 *}$ responses induced by collagen interaction. Whole blood from C57BL/6 control ice was spiked with fluo-3-loaded platelets from the same mouse type, and perfused over a collagen surface at $1000 \mathrm{~s}^{-1}$. Upper panels show" averaged changes in $\left[\mathrm{Ca}^{2+}\right]_{1}$ of $12-20$ platelets, which could be observed during at least $60 \mathrm{~s}$, from at least two different mice. Lower panels show representative platelets (black lines) as well as their downstream translocation over the callagen surface (gray lines). Blood was either untreated (A) or incubated for 10 min prior to perfusion with the following substances: (B) JAQ1 Fab fragment against GPVI $(40 \mu \mathrm{g} / \mathrm{ml})$; (C) aspirin $(100 \mu \mathrm{M})$ plus MRS2179 $(20 \mu \mathrm{M})$ and AR-C69931MX (50 $\mu \mathrm{M})$.

were still blebbing, and the area coverage with annexin A5-positive platelets was only slightly reduced. Treatment of the blood with aspirin alone had no influence on platelet adhesion, aggregate formation, or PS exposure (data not shown). Interestingly, concurrent inhibition of the second platelet ADP receptor, $P 2 Y_{12}$ (coupled to $G_{i}$ ), by the potent antagonist AR-C69931MX in combination with aspirin/MRS2179 still resulted in small aggregates (Fig. 3.4), but reduced the amount of annexin A5-binding platelets with about 50\% (Fig. 3.5). The decreased PS exposure by additional $P 2 Y_{12}$ blockage may point to an anticoagulant effect, which agrees with earlier demonstrated inhibitory effects of AR-C69931MX on platelet function (38).

The contribution of $\mathrm{TXA}_{2}$ and $\mathrm{ADP}$ to aggregate formation under flow conditions may depend on the type of collagen or the shear rate. To investigate this, we performed experiments with native fibrillar and non-fibrillar type I collagen as adhesive surfaces. Area coverage of platelets with these collagens was $22.5 \pm 3.7 \%$ and $14 \pm 8.5 \%$, respectively (mean $\pm S D, n=3$ ), which is in the same range as the coverage observed with Horm type-I collagen (Fig. 3.2). Preincubation with aspirin, MRS2179 and AR-C69931MX resulted in deposition of single platelets and small aggregates of no more than two cell layers thick; the coverage was lowered to $37 \pm 11 \%$ and $28 \pm 11 \%$, respectively, compared to untreated platelets $(100 \%)$. This preincubation reduced the area coverage with annexin A5-positive platelets to $60 \%$ of control. 
Similar effects of these antagonists were obtained in low-shear experiments $\left(150 \mathrm{~s}^{-1}\right)$ with Horm type-l collagen as adherent surface. Thus, the contribution of TXA2 and ADP appears to be independent of the type of collagen surface and the shear rate.

Together, these results suggest that $T \times A_{2}$ and $A D P$, both secreted from collagenactivated platelets during flow conditions, are essential for the formation of large platelet aggregates, but of moderate importance for platelet-collagen interaction and subsequent activation. This hypothesis was confirmed when we examined the contribution of $T \times A_{2} / A D P$ to the $\mathrm{Ca}^{2+}$ signal of platelets flowing over Horm collagen. As shown in Fig. 3.6 for averaged and representative single-cell $\mathrm{Ca}^{2+}$ responses, treatment of wildtype blood with aspirin, MRS2179 and AR-C69931MX did not alter the abrupt translocation of platelets or their sustained increase in $\left[\mathrm{Ca}^{2+}\right]_{\text {. }}$. This result was in sharp contrast to the situation where JAQ1 Fab fragments were added. In the latter case, the very few adherent platelets showed only minimal increases in $\left[\mathrm{Ca}^{2+}\right]$; upon adhesion (Fig. 3.6). This confirms the idea that GPVI, and not the released autocrine substances, mediates activation of the collagen-bound platelets.

\section{Discussion}

GPVl is the key receptor in platelet-collagen interaction under flow conditions but needs integrin $\alpha 2 \beta 1$ to stabilize adhesion and potentiate activation

Our data provide novel, detailed insight into the different roles of two important collagen receptors on platelets, which are both implicated in normal hemostasis and (arterial) thrombosis. We used a combination of various genetic mouse models as well as specific antibodies and drugs directed to the platelet receptors to investigate the complementary roles of GPVI and integrin $\alpha 2 \beta 1$ in a physiologically relevant test system of whole blood perfusion over collagen fibers at high shear rate. The data thereby provide a first example of interplay of immunoglobulin receptors (GPV) and integrins ( $\alpha 2 \beta 1)$ in cellular activity. Given the importance of either receptor type in cell biology, similar cross-talk may also be operative in other cellular types.

It is generally considered that, at high wall-shear rates $\left(>500 \mathrm{~s}^{-1}\right)$, initial platelet tethering to plasma-exposed collagen critically involves the interaction between GPIb and WWF deposited from plasma on collagen $(1,39)$. Recently, we provided evidence that stable plateletcollagen adhesion under these conditions is strictly dependent on active GPVI receptors (25). The GPVI-dependent adhesion, for instance, shifts the integrins $\alpha 2 \beta 1$ and $\alpha$ llb $\beta 3$ to a higher affinity state. The present paper confirms and extends the key position of GPVI as central collagen receptor on platelets. Adhesion to collagen of platelets lacking GPVI (from FcRy $/$ mice) or platelets in which GPVI activation is blocked with JAQ1 antibody is considerably 
Inhibited under conditions of high shear stress. The few GPV1-deficient or -inactivated platelets that adhere remain low in $\left[\mathrm{Ca}^{2+}\right]_{i}$, and cannot spread, collect other platelets (thus forming aggregates), or form membrane blebs and expose procoagulant PS. All these responses are essential for hemostatic plug and thrombus formation.

Using mice with $\beta 1$-deficient platelets, we previously demonstrated that $\alpha 2 \beta 1$-collagen interaction is dispensable for adhesion to collagen and for collagen-dependent aggregate formation (25). This result was confirmed in the present study. However, close examination of the aggregates formed under flow conditions revealed that, in $\beta 1$-null platelets, these were less firmly bound to the collagen and tended to disaggregate more frequently than aggregates of wildtype platelets. Similar results were obtained with the blocking anti-a2ß1 antibody LEN 1 . That integrin 2231 plays a critical role in the stabilization of platelet-collagen interactions became also evident, when $\beta 1$-null platelets were loaded with fluo-3 and their $\mathrm{Ca}^{2+*}$ responses were measured under flow conditions. Mast labeled $\beta 1$-null platelets exhibited transient periods of adhesion which were typically accompanied by short periods of spiking increases in $\left[\mathrm{Ca}^{2+}\right]$. This phenomenon coincided with a marked reduction in PS exposure of the $\beta 1$-null platelets. The latter effect is most likely related to the reduced $\mathrm{Ca}^{2+}$ responses of many of the platelets, because prolonged elevation in $\left[\mathrm{Ca}^{2+}\right]$ is required for PS exposure and bleb formation $(17,40)$. Others have reported that GPVI agonists activate $\alpha 2 \beta 1$ integrin (24). This is probably also true for the present flow experiments, because adhesion to collagen of GPVI-deficient platelets, expressing normal levels of $\alpha 2 \beta 1$, was severely impaired.

The exact role of integrin $\alpha 2 \beta 1$ in platelet-collagen interactions has been debated, which is in part related to different experimental conditions. This is exemplified by the apparent discrepancy between our study with whole mouse blood and the study by Chen and co-workers with isolated platellets from $\alpha 2$-deficient mice (41). These authors reported that $\alpha 2$-dieficiency abolishes adhesion of washed plattelets to type I collagen under either static or flow conditions. Although this approach allows precise examination of direct platelet-collagen interactions ${ }_{\text { }}$ it has clearly limitations. First, in flow experiments, red cells are needed to bring flowing platelets in close contact with the collagen surface, and WWF - which binds to collagen - is required to enhance platelet-collagen contact via GPIb and integrin allbp3 even under stasis (3). Second, Chen et al performed their experiments in the presence of millimolar $\mathrm{Mg}^{2+}$ but no added $\mathrm{Ca}^{2+}$, which greatly promotes the contribution of integrin $\alpha 2 \beta 1$-dependent adhesion (42). This situation contrasts with the physiological cationic condition with millimolar concentrations of free $\mathrm{Mg}^{2+}$ and $\mathrm{Ca}^{2+*}$ as used in the present paper.

Collectively, these data suggest that, after activation by GPVI and, possibly, released ADP (see below), the integrin serves to facilitate GPVI-dependent signaling events by stabilizing the adhesion to collagen, with as a consequence prolonged and magnified activation responses. Accordingly, both receptors have different, yet complementary and cooperative roles 
in collagen-induced thrombus formation and procoagulant activity: GPVI as an initiating and signaling receptor, and activated $\alpha_{2} \beta_{1}$ integrin as an unducible, high-affinity adhesive receptor allowing GPVI to signal.

GPV-mediated release of $T \times A_{2}$ and $A D P$ enables aggregate formation on collagen-adherent platelets

The $G \alpha_{q}$ heterotrimer is a major signaling molecule in platelet responses evoked by $T_{x A_{2}}$ and $A D P$ through the $T P_{\alpha}$ and $P 2 Y_{1}$ receptors, respectively $(36,37)$. This is best highlighted by the finding that $G \alpha_{q}$-deficient platelets display defective aggregation in response to these agonists and collagen (27). However, $G \alpha_{q}$-deficient platelets are normally activated by agonists specific for GPVI (28), suggesting that receptors other than GPVI are involved in collagen-induced platelet aggregation at least under conditions of standard aggregometry. In the current study, we found that $G \alpha_{q}$-deficient platelets normally adhered to collagen under high shear conditions, and elicited normal rises in $\left[\mathrm{Ca}^{2+}\right]_{i}$, followed by PS exposure. We thus demonstrate for the first time that $\mathrm{Go}_{q}$ is not involved in collagen-dependent adhesion or $\mathrm{Ca}^{2 *}$ and procoagulant responses of platelets. However, $G \alpha_{q}$-deficient platelets failed to form large aggregates under flow conditions; only two-layered platelet deposits could be formed on collagen. This result strongly suggests that, under normal (wildtype) conditions, collagenadherent platelets activated via GPV $\|$ produce TXA2 and/or ADP, which causes rapid trapping and aggregation of other flowing platelets, most likely through the fibrinogen receptor, integrin allop3.

Indeed, adhesion and aggregation similar to those of $G \alpha_{q}$-deficient platelets was obtained with wildtype platelets when $\mathrm{TXA}_{2}$ formation was inhibited with aspirin and the ADP receptor $P 2 Y_{1}$ was blocked using MRS2179. The combination of aspirim, MRS2179 and AR C69931MX had a partial but significant suppressive effect on the activation state of adherent platelets, as PS exposure was reduced in comparison to the control condition. This result suggests that the $P 2 Y_{12}$-evoked $G_{i}$ signaling pathway, which is blocked by AR-C69934MX but not in $G \alpha_{q}$-deficient platelets, has a potentiating effect on GPVI signaling and consequent autocrine $\alpha 2 \beta 1$ activation, i.e. stabilization of GPVI-collagen interactions.

Taken together, our data prowide novel, detailed insight into the different roles of two important receptors that are implicated in normal hemostasis as well as arterial thrombosis. They can resolve the apparent discrepancy in the literature whether integrin $\alpha 2 \beta 1$ is or is not primarily involved in platelet-collagen interaction. Platelet binding and activation via GPVI primes for integrin-mediated adhesion. Conversely, the activated intergin $\alpha 2 / 31$ (also perhaps by other agonists) stabilizes the platelets on collagen, so that GPVI can complete its signaling task. Although GPVI depletion has been shown to lead to antithrombotic protection in mice (31), these findings yet suggest that agents inhibiting $\alpha 2 \beta 1$, perhaps in combination with anti-GPVI 
effects, can be useful for platelet-directed anti-thrombotic therapies. The possible relevance of such treatment may appear from the evidence that subject-dependent variation in integrin $\alpha 2 \beta 1$ demsity on platelets influences shear-dependent platelet adhesion to collagen (43), and correlates with the GPVI content on platelets (44).

\section{Acknowledgments}

This work is supported by the Netherlands organization for scientific research, (NWO, 902-68-241) and the Deutsche Forschungsgemeinschaft (DFG, Ni556/4-1). B.N. is a Heisenberg Fellow of the DFG.

\section{References}

1. Ruggeri ZM. Platelet-vessel wall interactions in flowing blood. In: Hemostasis and Thrombosis (Colman, R. W., Hirsh, J., Marder, W. J., Clowes, A. W., George, J. N., eds.) Lippincott, Philadelphia, PA, USA. 2001:683-698.

2. Moroi M, Jung SM, Nomura $S$, Sekiguchi S, Ordinas A, Diaz-Ricart M. Analysis of the involvement of the von Willebrand factor-glycoprotein ib interaction in platelet adhesion to a collagen-coated surface under flow conditions. Blood. 1997;90:4413-4424.

3. Savage B, Almus-Jacabs F, Ruggeri ZM. Specific synergy of multiple substrate-receptor interactions in platelet thrombus formation under flow. Cell. 1998:94:657-666.

4. Turner NA, Moake $\mathrm{JL}$, Mclntire LV. Blockade of adenosine diphosphate receptors $P 2 Y_{12}$ and $P 2 Y_{1}$ is required to inhibit platelet aggregation in whole blood under flow. Blood. 2001;98:3340-3345.

5. Zwaal RFA. Schroit AJ. Pathophysiological implications of membrane phospholipid asymmetry in blood cells. Blood. 1997;89:1121-1132.

6. Moroi M, Jung SM. Platelet receptors for collagen. Thromb Haemost. 1997;78:439-444,

7. Watson SP, Asazuma N, Atkinson $B$, Berlanga $O$, Best D, Bobe R, Jarvis $G$, Marshall $S_{4}$ Snell $D_{n}$ Stafford M, Tulasne $D_{1}$, Wille $J$, Wonerow $P_{n}$ Frampton J. The role of ITAM- and ITIM-coupled receptors in platelet activation by collagen. Thromb Haemost. 2001:86:276-288.

8. Clemetson $J M$, Polgar $J$, Magenat $E$, Wells $T N$, Clemetson KJ. The platelet collagen receptor glycoproteins $V /$ is a member of the immunoglobulin superfamily closely related to $F c a R$ and the natural killer receptors. J Biol Chem. 1999;274:29019-29024.

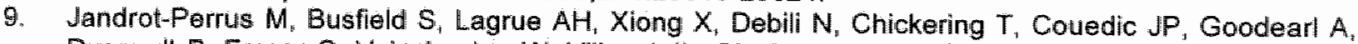
Dussault $B_{\text {, Fraser }} C$, Vainchenker $W$, Villeval JL. Cloning, characterization and functional studies of human and mouse glycoprotein VI: a platelet-specific collagen receptor from the immunoglobulin superfarmily. Blood. 2000;96:1798-1807.

10. Gibbins JM, Okuma $M$, Farndale $R$, Barnes $M$, Watson SP. Glycoprotein $V /$ is the collagen receptor in platelets which underlies tyrosine phosphorylation of the $\mathrm{Fc}$ receptor $y$-chain. FEBS Lett. $1997 ; 413: 255-259$.

11. Tsuji $M$, Ezumi $Y_{\text {" Arai }} M_{n}$ Takayama $H$. A novel association of Fc receptor $\gamma$-chain with glycoprotein $V /$ and their co-expression as a collagen receptor in human platelets. J Bial Chem. 1997;272:23528-23531.

12. Arai $M$, Yamamoto $N$, Moroi $M$, Akamatsu $N$, Fukutake $K$. Tanoue $K$. Platelets with $10 \%$ of the normal amount of glycoprotein $V /$ have an impaired response to collagen that results in a mild bleeding lendency. Br J Haematol. 1995;89:124-130.

13. Kehrel B. Wierwille $S$, Clemetson KJ, Anders $O$, Steiner $M$, Knight CG, Farndale RW, Okuma M, Barnes MJ. Glycoprotein $V \mid$ is a major collagen receptor for platelet activation: it recognizes the platelet-activating quaternary structure of collagen, whereas CD36, glycoprotein $11 \mathrm{lb}-11 \mathrm{ll}$, and von Willebrand factor do not. Blood. 1998;91:491-499.

14. Poole A, Gibbins JM, Turner M, van Vugt M.l, van de Winkel JG, Saito T, Tybulewicz VL, Watson SP. The Fc receptor $\gamma$-chain and the tyrosine kinase Syk are essential for activation of mouse platelets by
collagen. EMBO J. 1997:16:2333-2341. 
15. Nieswandt $B$, Bergmeier $W$, Schulte $V$, Rackebrandt $K$, Gessner JE, Zirngibl $H$. Expression and function of the mouse collagen receptor glycoprotein $V$ is strictly dependent on its association with the FcRy chain. J Biol Chem. 2000;275:23998-234002.

16. Heemskerk JWM, Vuist WMJ, Feijge MAH, Reutelingsperger CPM, Lindhout $T$. Collagen but not fibrinogen surfaces induce bleb formation, exposure of phosphatidylserine and procoagulant activity of adherent platelets. Evidence for regulation by protein tyrosine kinase-dependent $\mathrm{Ca}^{24}$ responses. Blood. 1997:90:2615-2625.

17. Siljander P, Farndale RW, Feijge MAH Comfurius P, Kos S, Bevers EM, Heemskerk JWM. Platelet adhesion enhances the glycoprotein V/-dependent procoagulant response: involvement of p38 MAP kinase and calpain. Arterioscler Thromb Vasc Biol. 2001:21:618-627.

18. Nieuwenhuis $K, N$. AJW, P. HW, J. SJ. Human blood platelets showing no response to collagen fail to express surface glycoprotein la. Nature. 1985;318:470-472.

19. Saelman EM, Kehrel B, Hese KM, de Groot PG, Sixma JJ, Nieuwenhuis HK. Platelet adhesion to collagen and endothelial cell matrix under flow conditions is not dependent an platelet glycoprotein IV. Blood. 1994;83:3240-3244.

20. Verkleij MW, Morton LF, Knight CG, de Groot PG, Barnes MJ, Sixma JJ. Simple collagen-like peptides support platelet adhesion under static but not under flow conditions, interaction via $\alpha 2 \beta 1$ and von Willebrand factor with specific sequences in native collagen is a requirement to resist shear forces. Blood. 1998;91:3808-3816.

21. Coller BS, Beer JH, Scudder LE, Steinberg MH. Collagen-platelet interactions: evidence for a direct interaction of collagen with platelet GPla/la and an indirect interaction with platelet GPIlb/lla mediated by adhesive proteins. Blood. 1989;74:182-192.

22. Morton LF, Peachey AR, Zijenah LS, Goodall AH, Humphries MJ, Barnes MJ. Conformationdependent platelet adhesion to collagen involving integrin $\alpha 2 \beta 1$-mediated and other mechanisms. multiple $\alpha .2 \beta 1$-recognition sites in collagen type I. Biochem J. 1994;299:791-797.

23. Savage $B$, Ginsberg $M H_{r}$ Ruggeri $Z M$. Influence of fibrillar collagen structure on the mechanisms of platelet thrombus formation under flow. Blood. 1999;94:2704-2715.

24. Moroi M, Onitsuka I, Imaizumi T, Jung SM. Involvement of activated integrin $\alpha 2 \beta 1$ in the firm adhesion of platelets onto a surface of immobilized collagen under flow conditions. Thromb Haemost. $2000 ; 83: 769-776$.

25. Nieswandt $B$, Brakebusch $C$, Bergmeier $W$, Schulte $V$, Bouvard $D$, Mohtari-Nejad $R$, Lindhout $T$, Heemskerk JWM, Zirngibl $H$, Fässler R. Glycoprotein VI but not $\alpha 2 \beta 1$ integrin is essential for platelett interaction with collagen. EMBO J. 2001;20:2120-2130.

26. Wu YP, Vink T, Schiphorst M, van Zanten GH, IJsseldijk MJW, de Groot PG, Sixma JJ. Platelet thrombus formation on collagen at high shear rates is mediated by von Willebrand factor-glycoprotein lb interaction and inhibited by von Willebrand factor-glycoprotein Ilb-llla interaction. Arterioscler Thromb Vasc Biol. 2000;20:1661-1667.

27. Offermanns $S$, Toombs $C F$, Hu $Y H$, Simon MI. Defective platelet-activation in Go $\alpha_{q}$-deficient mice. Nature. 1997:389:183-186.

28. Nieswandit $B$, Bergmeler $W$, Eckly $A$, Schulte $V$, Ohlmann $P$, Cazenave JP, Zirngibl $H$, Offermanns $S$, Gachet $C$. Evidence for cross-talk between glycoprotein $V I$ and $G_{i}$-coupled neceptors during collageninduced platielet aggregation. Blood. 2001;97:3829-3835.

29. Potocnik AJ, Brakenbusch $C$, Fässler R. Fetall and adult hematopoietic stem cells require $\beta 1$ integrin function for colonizing fetal liver, spleen, and bone marrow. Immunity. 2000,12:653-663.

30. Takai T, Li M, Sylvestre D, Clynes R, Ravetch JV. FCR $\gamma$-chain deletion results in pleilotrophic effector cell defects. Cell. 1994;76:519-529.

31. Nieswandt B, Schulte V, Bergmeier W, Mokhtari-Nejad R, Rackebrandt K, Cazenave JP, Ohlmann P. Gachet $C$, Zirngibl $H$. Long-term antithrombotic protection by in vivo depletion of plalelet glycoprotein VI in mice. $J$ Exp Med. 2001;193:459-469.

32. Heemskerk IWM, Siljander $P$, Vuist WMJ, Breikers $G$, Reutelingsperger CPM, Barnes MJ, Knight $C G$, Lassila $R$, Farndale RW. Function of glycoprotein $V \mid$ and integrin $\alpha_{2} \beta \beta_{1}$ in the procoagulant response of single, collagen-adherent platelets. Thromb Haemost. 1999;81:78-92.

33. Heemskerk JWM, Feijge MAH. Sage SO, Walter $U$. lndirect regulation of $\mathrm{Ca}^{2+}$ entry by cAMP. dependent and CGMP-dependent protein kinases and phospholipase $\mathrm{C}$ in rat platelets. Eur J Biochem. 1994:223:543-551.

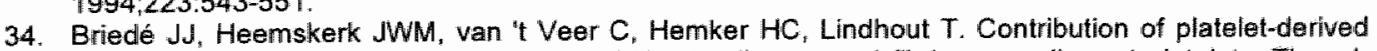
factor $\mathrm{Va}$ to thrombin generation on immobilized collagen- and fibrinogen-adherent platelets. Thromb Haemost. 2001;85:509-513.

35. Heemskerk JWM, Willems GM, Rook MB, Sage SO. Ragged spiking in free calcium in ADP-stimulated platelets: regulation of puff-like calcium signal in vitro and ex vivo. J Physiol. 2001;535:625-635. 
36. Hechler $B$, Léon $C$, Vial $C$, Vigne $P$. Frelin $C$, Cazenave JP, Gachet $C$. The $P 2 Y$, receptor is necessany for adenositwe 5i-diphosphate-induced platelet aggregation. Blood. 1998;92:152-159.

37. Jin J, Kunapoli SP. Coactivation of two different 6 protein-coupled receptors is essential for ADPinduced platelet aggregation. Proc Natl Acad Sci USA. 1998;95:8070-8074.

38. Storey RF, Sanderson $H M$, White $A E_{n}$ May $J A_{x}$ Cameron $K E$, Heptinstall $S$. The central role of the $P(2 T)$ receptor in amplification of human platelet activation, aggregation, secretion and procoagulant activity. Br J Haematol. 2000;110:925-934.

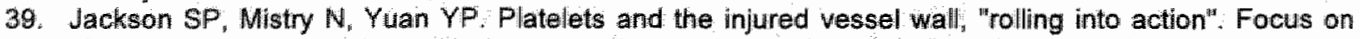
glycoprotein $\| \mathrm{b} / \mathrm{N} / \mathrm{X}$ and the platelet cytoskeleton. Trends Cardiovasc Med. 2000;10:192-197.

40. Pasquet JM, Quek $L$, Stevens $C$, Bobe $R$, Huber $M$, Duronio $V$, Krystal $G$, Watson $S P$. Phosphatidylinositoll $3,4,5$-trisphosphate regulates $\mathrm{Ca}^{2+}$ entry via Btk in platelets and megakaryocytes without increasing phospholipase C activity. EMBO J. 2000;19:2793-2802.

41. Chen J, Diacovo TG, Grenache DG, Santoro SA, Zutter MM. The $\alpha 2$ integrin subunit-deficient mouse: a multifaceted phenotype including defects of branching morphogenesis and hemostasis. Am J Pathol. $2002,161: 337-344$.

42. Heemskerk. JWM, Bevers EM " Lindhout T. Platelet activation and blood coagulation. Thromb Haemost. 2002;88:186-193.

43. Roest $M$, Sixmal JJ, Wu YP, IJsseldijk MJ, Tempelman M, Slootweg PJ, de Groot PG, van Zanten GH. Platelet adhesion to collagen in healthy volunteers is influenced by variation of both $\alpha 2 \beta 1$ density and von Willebrand factor. Blood. 2000;96:1433-1437.

44. Furilhata $\mathrm{K}$, Clemetson $\mathrm{KJ}$, Deguchi $\mathrm{H}$, Kunicki $\mathrm{TJ}$. Variation in human platelet glycoprotein $\mathrm{VI}$ content modulates glycoprotein VI-specific prothrombinase activity. Arterioscler Thromb Vasc Bioll. $2001 ; 21: 1857-1863$. 


\section{Chapter 4}

\section{Role of integrin $\alpha 2 \beta 1$ in thrombus stabilization}

\section{and embolization}

Marijke J. E. Kuijpers, M., Sabine Grüner, Imke C. A. Munnix, Miroslava Pozgajova, Jocelyn Auger, Beate Eckes, Bernhard Nieswandt and Johan W. M. Heemskerk

Submitted for publication 


\section{Abstract}

Upon vessel wall damage, platelets interact with exposed collagen via two receptors, glycoprotein (GP)VI and $\alpha 2 \beta 1$ integrin. In contrast to the established platelet-activating role of GPVI, the function of $\alpha 2 \beta 1$ in thrombus formation has remained unclear. We report that using a murine thrombosis model, induced by extracellular matrix exposure, in arteries from $\alpha 2-$ null mice smaller thrombi were formed with more embolization compared to the vessels from wildtype mice. In vitro, perfusion of blood from a.2-null mice over collagen also resulted in formation of thrombi that were smaller and looser in appearance than those obtained with wildtype blood, regardless of the shear rate (low/high) and the presence of coagulation. Twophoton laser scanning microscopy showed that under flow the absence of $\alpha 2 \beta 1$ reduced fibrinogen binding to platelets and lowered exposure of procoagulant phosphatidylserine. In platelet-rich plasma from $\alpha 2$-null mice, thrombin generation in response to tissule factor and collagen was delayed and reduced. Because also thromboxane $A_{2}$ release from platelets was reduced in the absence of $\alpha .2 \beta 1$, blood from $\alpha 2$-null mice was co-perfused with thromboxane $A_{2}$ analogue U46619 over collagen. This led to normalization of the thrombus size. In vivo, application of the thromboxane analogue abrogated the frequent embolization of $\alpha 2$-null thrombi. Together, these novel data indicate that $\alpha 2 \beta 1$ has a moderate but qualitatively important effect to stabilize thrombi by enhancement of the following GPV/l-dependent mechanisms: (i) release of thromboxane $A_{2}$, (ii) activation of $\alpha$ llb $\beta 3$ leading to irreversible aggregation, and (iii) phosphatidylserine exposure leading to generation of thrombin and fibrin clots. The increased embolization in the absence of $\alpha 2 \beta 1$ argues against use of $\alpha 2 \beta 1$ integrin inhibitors for antithrombotic therapy.

\section{Introduction}

Vascular damage triggers platelet adhesion and aggregation at the exposed extracellular matrix, leading to thrombus formation and cessation of bleeding. In vivo studies with a variety of murine thrombosis models have shown that the low-affinity platelet collagen receptor, glycoprotein VI (GPVI) is required for thrombus formation on injured arteries $(1,2)$. In addition, integrins on the platelet surface ".e. the fibrinogen receptor allb $\beta 3$ and the collagen receptor $\alpha 2 \beta 1$, are involved in stable platelet adhesion to the damaged vessel wall. Both integrins can be activated via inside-out signaling by a conformational switch mechanism, which shifts the extracellular domain to a higher affinity state with increased ligand interaction (3-5).

Whereas the role of activated $\alpha$ llb $\beta 3$ in platelet aggregation is well-established, the precise function of $\alpha 2 \beta 1$ in platelet-collagen interaction is still debated. About twenty years ago, it was reported that two patients with deficiency in $\alpha 2 \beta 1$ experienced greatly prolonged bleeding times (6-8). However, later it was questioned whether these clinical symptoms were related to 
the proposed platelet defect (9). Further interest in the $\alpha 2 \beta 1$ integrin came from the observation that its level on platelets can vary up to 10-fold in association with the C807T genetic polymorphism of $\alpha 2$ (10). Since 1986, many investigations have been carried out to determine whether absence or blocking of $\alpha 2 \beta 1$ may protect from thrombosis. Therefore, mice have been generated with conditional $\beta 1$-integrin deficiency (1) or lacking the $\alpha 2$-integrin (11). These mice had normal tail bleeding times and unaltered thrombosis tendency (12). However, in a different strain of $\alpha 2$-deficient mice (13), arterial thrombosis tendency was reported to be diminished (14).

In vitro whole blood perfusion studies at high shear have indicated that platelets which are adhering to collagen and von Willebrand factor (WWF) are activated by interplay of the lowaffinity collagen receptor GPVI with integrin $\alpha 2 \beta 1(15,16)$. Again the precise role of $\alpha 2 \beta 1$ is debated, as some in vitro studies show that platelets from $\alpha 2$-null mice are reduced in adhesion on collagen (13), while other studies with $\alpha 2-$ and $\beta 1$-null mice point to normal adhesion and aggregate formation under flow (17). Recent insight, however, indicates that both collagen receptors have additive effects on platelet adhesion $(18,19)$, likely by two mechanisms of stable platelet adhesion, one via $\alpha 2 \beta 1$ and one via GPVI, both of which are conserved in mouse and man. Earlier, we have proposed that the facilitating and consolidating role of $\alpha 2 \beta 1$ explains why aggregates are less compact in the absence of $\alpha 2 \beta 1$ (17).

In the present study, we hypothesized that $\alpha 2 \beta 1$ has a role in thrombus stabilization on collagen rather than in mediating thrombus formation per se. We used intravital and two-photon fluorescence microscopy to determine thrombus growth and stability both in vivo, at sites of vascular injury, and in vitro, on collagen/vWF surfaces under conditions of flow and coagulation. The data reveal that $\alpha 2$-null mice have a subtle but clinically relevant phenotype, in which unstable thrombi tend to shed from the adhesive surface as emboli, due to three mechanisms: reduced thromboxane formation, reduced platelet aggregation, and diminished coagulant activity.

\subsection{Materials and Methods}

\section{Animals}

Mice deficient in the $\alpha 2$-integrin subunit were produced and checked for absence of the integrin on platelets, as described (11). Both mutant and wildtype control animals were on a $129 / \mathrm{Sv} \times \mathrm{C} 57 \mathrm{BL} / 6$ genetic background. Animals were used at the age of $4-5$ weeks for intravital experiments, and at 12-16 weeks for perfusion and thrombin generation experiments. The local Animal Care and Use Committees approved the studies. 
Materials

Fibrillar type-1 collagen (Horm) was purchased from Nycomed (Munich, Germany). Annexin A5 labeled with fluorescein isothiocyanate (FITC) came from Nexins Research (Hoeven, The Netherlands). OG488-conjugated fibrinogen and annexin A5 labeled with Alexa fluor 647 (AF647) were from Molecular Probes (Leiden. The Netheriands). 5-carboxyfluorescein diacetate (DCF) succinimidyl ester was from Invitrogen (Karlsruhe, Germany). Monoclonal antibody against the $\alpha 2$-integrin subunit, SAMG4, was from Emfret Analytics (Würburg. Germany). Recombinant tissue factor came from Dade (Düdingen, Switzerland); Z-Gly-Gly-Arg aminomethyl coumarin (Z-GGR-AMC) from Bachem (Bubendorf, Switzerland); H-Phe-Pro-Arg chloromethyl ketone (PPACK) from Calbiochem (La Jolla, CA) and FeCls from Merck (Darmstadi, Germany). Ketamine and xylazine were from Eurovet (Bladel, the Netherlands). Other materials were obtained from Sigma (St. Louis, MO).

\section{Preparation of platelets for intravital microscopy}

Mouse blood ( 1 vol) was drawn from the retro-orbital plexus and collected into 0.5 vol 5 $\mathrm{mM}$ Hepes buffer $\mathrm{pH} 7.14$ containing $20 \mathrm{U} / \mathrm{ml}$ heparin. Blood was centrifuged at $250 \mathrm{~g}$ for 5 minutes, and platelet-rich plasma (PRP) was gently transferred to a fresh tube. After labeling with DCF ( $5 \mu \mathrm{g} / \mathrm{ml}$ for 2 minutes), platelets were centrifuged at $2000 \mathrm{~g}$ for 10 minutes. The pellet was resuspended in phosphate-buffered saline (PBS) and platelet concentration was adjusted to a final concentration of $200 \times 10^{6}$ platelets $/ 250 \mu \mathrm{l}(12)$.

Animal preparation, intravital microscopy and thrombus formation in vivo

Four- to 5-week old mice were anesthetized by intraperitoneal injection of 2,2,2tribromoethanol and $2-$ methyl-2-butanol $(0.15 \mathrm{ml} / 10 \mathrm{~g}$ of body weight from $2.5 \%$ solution). A mouse was positioned on a plastic petridish, and a segment of the ileum was exteriorized through a right side abdominal incision. The mesentery was spread out on the petridish and kept wet with a buffered Tyrode's solution (130 $\mathrm{mM} \mathrm{NaCl}, 5.6 \mathrm{mM} \mathrm{KCl}, 2.2 \mathrm{mM} \mathrm{CaCl}, 0.56 \mathrm{mM}$ $\mathrm{MgCl}_{2}, 11 \mathrm{mM}$ glucose, $13 \mathrm{mM}$ sucrose, $25 \mathrm{mM} \mathrm{NaHCO}$ and $1.2 \mathrm{mM} \mathrm{NaH} \mathrm{PO}_{4} ; \mathrm{pH}$ 7.35) supplemented with $1 \mu \mathrm{g} / \mathrm{ml}$ isoprenaline. The exteriorized ileum was kept moist with overlying wet gauze. Fluorescent platelets $\left(200 \times 10^{6} / 250 \mu l\right)$ were infused through the retro-orbital plexus.

Vessel wall damage was induced as described (20). Briefly, $\mathrm{FeCl}_{3}(30 \mu /, 500 \mathrm{mM})$ was topically applied on selected mesenteric vessels. Wildtype arterioles (diameter $66 \pm 7 \mu \mathrm{m}, \mathrm{n}=15$ ) and $\alpha 2$-null arterioles (diameter $93 \pm 5 \mu \mathrm{m}, \mathrm{n}=20$, mean \pm SEM) each constricted by $15-20 \%$ upon application of $\mathrm{FeCl}_{3}$, while venular diameters (wildtype $155 \pm 14 \mu \mathrm{m}, \mathrm{n}=15$; $\alpha 2$-null $182 \pm$ $10 \mu \mathrm{m}, \mathrm{n}=19$ ) did not change. Prior to and following vascular injury, fluorescent platelets in mesenteric vessels were visualized in vivo by video microscopy using a Zeiss Axiovert 200 
inverted microscope, equipped with 10*(0.25 Numerical Aperture) and $20 \times(0.40$ NA) objective lenses (Zeiss, Göttingen, Germany) and a 100-W HBO mercury lamp for epi-illumination. Platelet adhesion and thrombus formation were observed for at least 10 minutes and recorded on videotape (Panasonic AG-7355, Matsushida Electric, Osaka, Japan). Recorded images corresponded to $410 \times 308 \mu \mathrm{m}$. Per vessel the following parameters were determined off-line: (i) time to first platelet-vessel wall interaction (tethering), (ii) time to first stable platelet adhesion (i.e. fixed adhesion for at least 30 seconds). (iii) number of thrombi in the recorded vessel segment, (iv) height of thrombi ( $\geq 10 \mu \mathrm{m}$ in the same segment) at 2,5 and 10 minutes after $\mathrm{FeCl}_{3}$ application, measured perpendicular to the vessel wall and expressed as percentage of wessel diameter, and ( $v$ ) number of emboli during 10 minutes. Thrombus height was measured relative to the local vessel diameter, as described (21). If separate thrombi were detected, the cumulative thrombus height was calculated as summation of the short thrombus axes, perpendicular to the vessel wall. Heights of individual thrombi were categorized as $<25 \%$, between $25-50 \%$, or $\geq 50 \%$ of vessel diameter.

\section{Thrombus formation on collagen under flow}

Thrombus formation was measured in flow chamber experiments in which mouse blood was perfused over a collagen surface as described (17). Briefly, an area of $5 \times 5 \mathrm{~mm}$ in the centre of a glass coverslip was coated with fibrillar Horm type-I collagen $(50 \mu \mathrm{g} / \mathrm{ml}$ for 20 minutes at $37^{\circ} \mathrm{C}$ ), blocked with Hepes buffer pH 7.45 containing $137 \mathrm{mM} \mathrm{NaCl}, 5.6 \mathrm{mM}$ glucase, $5 \mathrm{mM}$ Hepes $_{\pi} 2.7 \mathrm{mM} \mathrm{KCl}, 2 \mathrm{mM} \mathrm{MgCl}_{2}, 0.42 \mathrm{mM} \mathrm{NaH} \mathrm{NOO}_{4}$ and $1 \%(\mathrm{w} / \mathrm{v})$ bovine serum allbumin (BSA), and then placed in a parallel plate flow chamber (slit depth $50 \mu \mathrm{m}$ ). Blood was incubated for 10 minutes with various inhibitors and/or fluorescent probes, placed in a syringe and perfused over the coverslip at a shear rate of $150-1000 \mathrm{~s}^{-1}$ for 4 minutes. Thereafter, the coverslip was perfused with Hepes buffer pH 7.45 containing $137 \mathrm{mM} \mathrm{NaCl}, 5.6 \mathrm{mM}$ glucose, 5 $\mathrm{mM}$ Hepes, $2.7 \mathrm{mM} \mathrm{KCl}, 2 \mathrm{mM} \mathrm{MgCl}, 0.42 \mathrm{mM} \mathrm{NaH} \mathrm{PO}_{4}, 0.1 \%$ (w/v) BSA with $2 \mathrm{mM} \mathrm{CaCl} 2$ and $1 \mathrm{U} / \mathrm{ml}$ heparin plus fluorescently labeled annexin A5 $(0.5 \mu \mathrm{g} / \mathrm{ml})$ for 4 minutes. Phase contrast images and non-confocal fluorescence images of adherent platelets were recorded using a two camera system (15).

For flow experiments without coagulation, blood collected on PPACK/heparin was used. For experiments in the presence of coagulation, citrated blood was mixed during perfusion with $10 \%$ volume of $20 \mathrm{pM}$ tissue factor in $200 \mathrm{mM} \mathrm{CaCl}$ upon entry in the flow chamber. This flow protocol allows thrombin generation at millimolar free $\mathrm{Mg}^{2 *}$ and $\mathrm{Ca}^{2+}$ concentrations (22). Platelet surface coverage of images was analyzed using ImagePro software (Media Cybernetics, Silver Spring, MD) for phase contrast images and Quanticell software (Visitech, Sunderland, UK) for fluorescent annexin A5 images. At least 10 different fields of view were averaged per experiment (no image processing). 
Two-photon laser scanining microscopy

For two-photon laser scanning microscopy (TPLSM), coverslips with thrombi were observed with a Bio-Rad 2100 multiphoton system (23). Excitation was by a Spectra-Physics Tsunami Ti:Sapphire laser, tuned and mode-locked at $800 \mathrm{~nm}$; producing pullses of 100 fs wide (repetition rate $82 \mathrm{MHz}$ ). Excitation at $647 \mathrm{~nm}$ was by a parallel-placed red diode laser. Fluorescence was detected using appropriate wavelength filters. Thrombi in flow chambers, double labeled with OG488-fibrinogen and AF647-annexin A5, were scanmed at the end of perfusions. Optical sections were recorded in Kalman filtering mode; no further image processing was performed.

\section{Thrombin generation measurements}

Mouse PRP and platelet-poor plasma (PPP) collected on citrate were used to measure thrombin generation with the thrombogram method (24), which was adapted for murine plasma. Briefly, normalized PRP $\left(1.5 \times 10^{8}\right.$ platelets $\left./ \mathrm{ml}\right)$ was preincubated with inhibitors for 10 minutes, followed by 10 minutes stimulation with collagen $(5 \mu \mathrm{g} / \mathrm{ml})$. Subsequentlly, $40 \mu l$ of PRP was added to a 96-well plate, containing per well $10 \mu \mathrm{l}$ tissue factor $(6 \mathrm{pM})$ in buffer $\mathrm{A}(20 \mathrm{mM}$ Hepes, $140 \mathrm{mM} \mathrm{NaCl}$ and $5 \mathrm{mg} / \mathrm{ml} \mathrm{BSA}, \mathrm{pH} 7.35$ ). Final tissue factor concentration was $1 \mathrm{pM}$, at which thrombin formation depends on the presence of platelet-expressed phosphatidylserine (PS). Thrombin formation was started by adding $10 \mu \mathrm{ll}$ of $\mathrm{CaCl}_{2}(16.6 \mathrm{mM})$ and Z-GGR-AMC (2.5 $\mathrm{mM}$ ) in buffer $\mathrm{A}$. Changes in fluorescence were continuously measured at $37^{\circ} \mathrm{C}$ with a Fluoroscan Ascent well-plate reader (Thermolab Systems, Helsinki). First-derivative curves of accumulation of fluorescence were generated as described (25). Curves were not processed for $\alpha_{2}$-macroglobulin correction, as this parameter in murine blood is unknown; calibrations were with human thrombin. Assays were run in duplicates or triplicates.

\section{Thromboxane $A_{2}$ measurements}

Citrated PRP was prepared as described for thrombin generation measurements and activated with collagen in the presence and absence of SAM.G4. Then. PRP was centrifuged at $22,000 \mathrm{~g}$ and plasma was stored at $-80^{\circ} \mathrm{C}$. Thromboxane $\mathrm{B}_{2,}$, the stable breakdown product of thromboxane $\mathrm{A}_{2}$, was measured with a competitive enzyme immunoassay (Cayman, Ann Arbor, Mi). Samples were difuted to the optimal detection range, and were analyzed in duplicate according to the manufacturer's instructions. Thromboxane $\mathrm{B}_{2}$ concentrations were calculated from calibration curves. 


\section{Statistical analysis}

Data are given as means \pm SEM. Differences between experimental groups were tested with the non-parametric Mann-Whitney $U$ test, using the statistical package for social sciences (SPSS 11.0). Level of significance was set at $5 \%$.

\section{Results}

Mice deficient in $\alpha 2$-integrin show subtle changes in anterial thrombus formation in vivo

Injury of the mesenteric arterioles and venules of anesthetized mice was induced by topical application of $\mathrm{FeCl}_{3}$. This free radical-forming compound causes disruption of endothelial cells (26), resulting in collagen exposure in the sub-endothelial

matrix (27). Before vascular injury, DCF-labeled platelets were injected into the mice. During and after $\mathrm{FeCl}_{3}$ application, dynamic pllatelet accumulation in arterioles and venules was measured in vivo by fluorescence microscopy. In damaged arterioles, platelets adhered stable after $53 \pm 21$ seconds in wildtype and after $99 \pm 36$ seconds in $\alpha 2$-null mice (mean $\pm S E M, n=$ 11-13 " $p=0.18$ ). In most arterioles of either animal type, thrombi were formed which gradually increased in size (Fig. 4.1). After 10 minutes, thrombi were present in $73 \%$ of wildtype arterioles and in $60 \%$ of $\alpha 2$-null arterioles (Table 4.1), indicating that the thrombotic process persisted in the absence of the integrin. In most willtype and knockout venules, pllatellets adhered almost instantly after $\mathrm{FeCl}_{3}$ application, and assembled together to form often occlusive thrombil within 10 minutes (Fig. 4.1).

Continuous recording of the thrombus-forming process indicated that a significant proportion of the fluorescent thrombi in $\alpha 2$-null arterioles was unstable, meaning that the aggregates moved to downstream sites after seconds or minutes (Fig. 4.2). This instability was rare in vessels from wildtype animals. Quantitation showed that significantly more thrombi were shed as emboli in arterioles from $\alpha 2$-null mice than in vessels from wildtype mice (Fig. 4.2B).

Table 4.1: Percentage of vessels with thrombi and number of thrombi per arteriole and venule from wildtype and $\alpha 2$-null mice at 2,5 and 10 minutes after $\mathrm{FeCl}_{3}$ application. Data are means ( $\left.n=15-20\right)$.

\begin{tabular}{lccccccc} 
& \multicolumn{3}{c}{ Wilditype } & \multicolumn{2}{c}{ a2-null } \\
\hline Arterioles with thrombi $(\%)$ & $2 \mathrm{~min}$ & $5 \mathrm{~min}$ & $10 \mathrm{~min}$ & $2 \mathrm{~min}$ & 5 min & $10 \mathrm{~min}$ \\
Venules with thrombi $(\%)$ & 47 & 67 & 73 & 50 & 50 & 60 \\
Mean number of thrombi per arteriole & 4.6 & 4.7 & 4.9 & 5.0 & 8.1 & 6.0 \\
Mean number of thrombi per venule & 10.2 & 13.5 & 14.3 & 7.3 & 12.1 & 12.3 \\
\hline
\end{tabular}


Anteriole
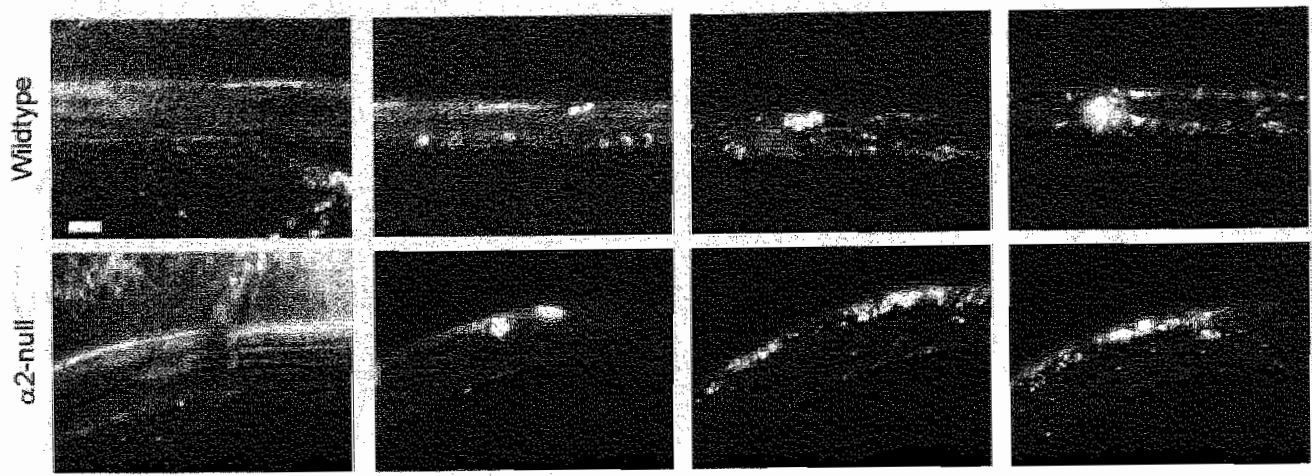

Verule

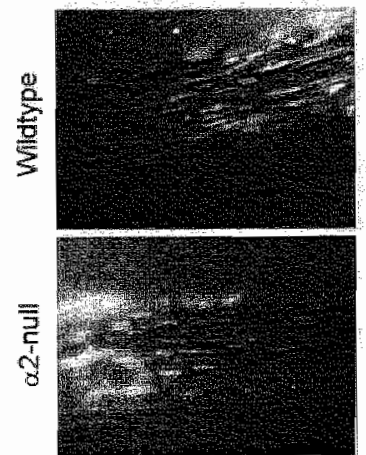

baseline
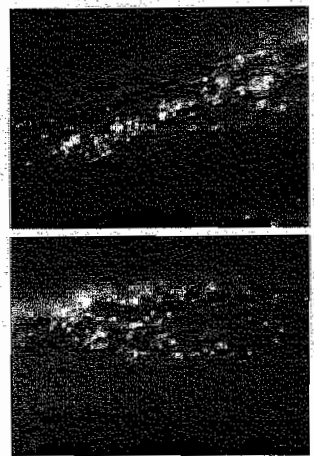

$2 \mathrm{~min}$
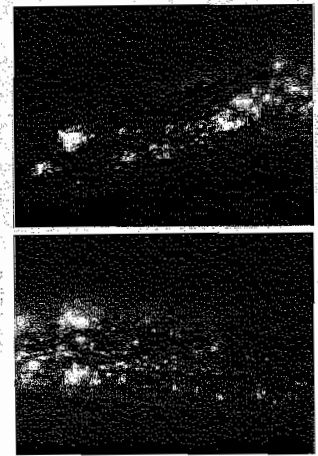

$5 \min$
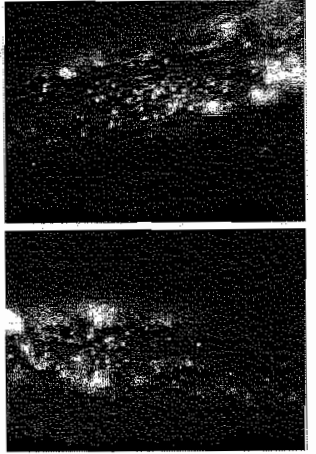

$10 \mathrm{~min}$

Figure 4.1. Thrombus formation in arterioles and venules from $\alpha 2$-null mice. Damage of adjacent mesenteric arterioles and venules was induced by topical application of $\mathrm{FeCl}_{3}$ at $\mathrm{t}=0$ seconds (baseline). Flworescence images of aggregating DCF-labeled platelets in representative arterioles (upper panels) and venules (lower panels) at 2, 5 and 10 minutes after $\mathrm{FeCl}_{3}$ application. Bar represents $50 \mu \mathrm{m}$.

The cumulative height of thrombi (measured as \% of vessel diameter) increased similarly in time for arterioles from wildtype and a2-null mice (Fig. 4.3A). Typically, when the height of individual thrombi was compared, arterioles from knockout animals had a much larger fraction of small $(<25 \%)$ thrombi (Fig. 4.3B). While in vessels from wildtype mice the average number of thrombi did not change during the measurement time of 10 minutes, in a2-null mice it peaked at 5 minutes and then decreased due to embolization (Table 4.1). Thus, in this vivo thrombosis model, $\alpha 2 \beta 1$ appears to have a subtle but consistent role in the dynamics of thrombus. formation, by stabilizing platelet adhesion and consolidating the formed thrombi.

\section{Application of U46619 stabilizes thrombi in arteriales from a2-null mice}

We hypothesized that the absence of $\alpha 2 \beta 1$ may cause platelets to release less secondary mediators such as thromboxane $A_{z}$, which may affect both thrombus size and 


\section{A}

a.2-null arteriole
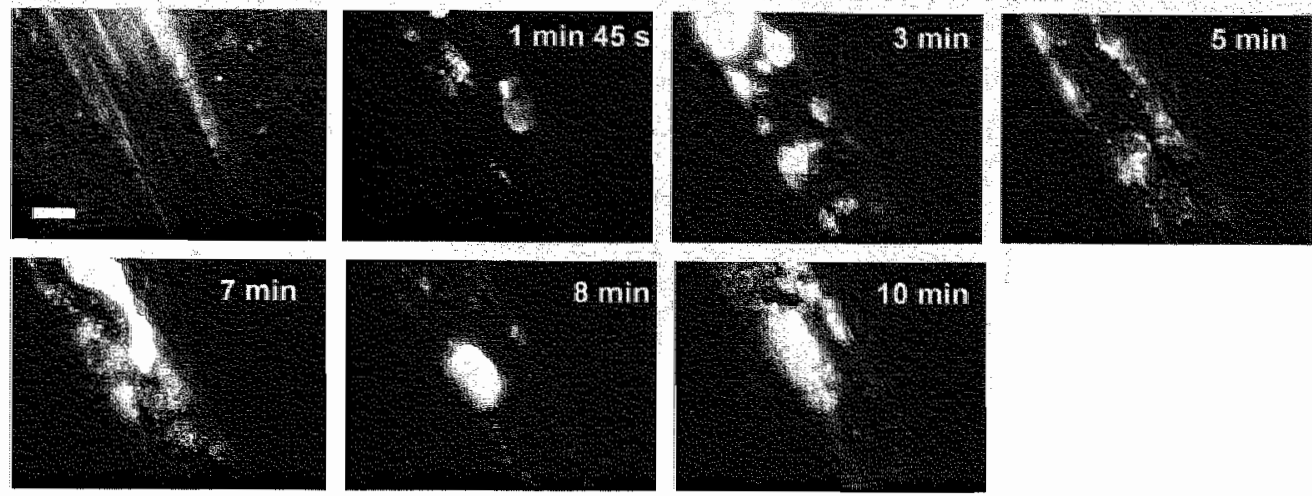

B

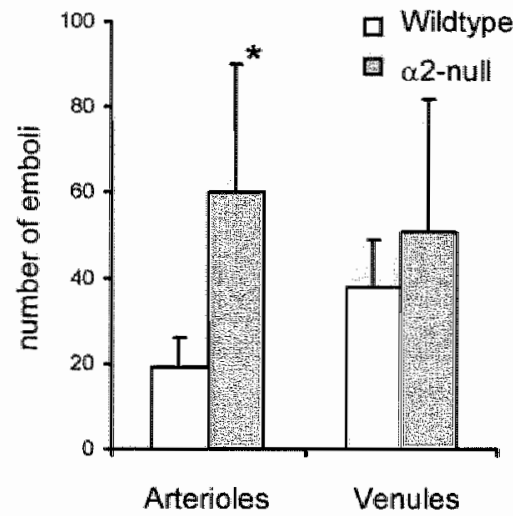

Figure 4.2. Decreased thrombus stability in arterioles and venules from a2-null mice. Damage of adjacent mesenteric arterioles and venules was induced by topical application of $\mathrm{FeCl}_{3}$ at $t=0$ seconds (baseline). (A) Fluorescence images of appearance and disappearance (embolization) of thrombi formed in an arteriole of an a2-null mouse. Arrows indicate direction of flow; bar represents $50 \mu \mathrm{m}$. For dynamic images see supplemented videos. (B) Number of emboli produced in 10 minutes per vessel segment (means $\pm S E M$, $n=4-9) .{ }^{*} p=0.08$.

stability. Indeed, we found that inhibition of a2B1 resulted in a reduced thromboxane $B_{2}$ production with $31 \pm 6 \%$ in collagen-stimulated PRP (mean $\pm \mathrm{SEM}, n=6, p=0.002$ ). Tó investigate whether reduced thromboxane formation could restrict the size and stability of thrombi in vivo, a solution of $\mathrm{U} 46619(30 \mu \mathrm{l}$ of $100 \mu \mathrm{M})$ was topically applied on the mesentery of willdype and a2-null mice at 6 minutes after $\mathrm{FeCl}_{3}$ application, a time point when thrombus formation was fully active. Both in wildtype and $\alpha 2$-null arterioles - the latter with much stronger embolization tendency - this intervention stopped embolization, while it continued in control arterioles (Fig. 4.4A). Quantitative analysis of all data indicated that embolus formation was greatly reduced after U46619 application in 22 -null arterioles (Fig. 4.4B). 


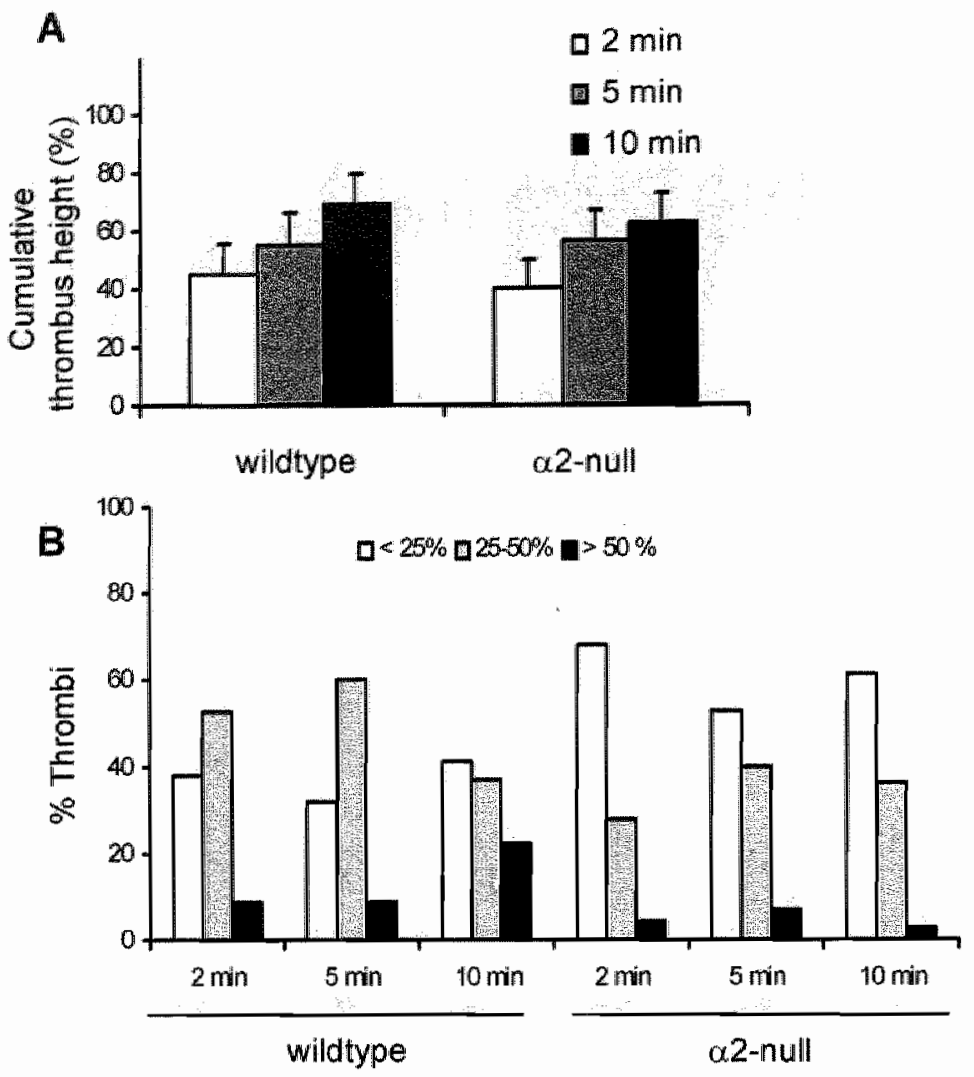

Figure 4.3. Smaller thrombi in arterioles from a2-null mice. Damage of adjacent mesenteric arterioles and venules was induced by topical application of $\mathrm{FeCl}_{3}$ at $\mathrm{t}=0$ seconds (baseline). (A) Cumulative thrombus height at 2,5 and 10 minutes after $\mathrm{FeCl}_{3}$ application (expressed as $\%$ of vessell diameter). Data are mean \pm SEM $(n=11-13)$. (B) Number of thrombi per vessell measured at 2,5 and 10 minutes after $\mathrm{FeCl}_{3}$ application. Thrombi were categorized as $<25 \%$, between 25 and $50 \%$, and $>50 \%$ of vessel diameter.

Reduced thrombus formation and platelet activity on collagen in flowing blood from a2-null mice

Knowing that the process of thrombus formation in the damaged arterioles is driven by collagen exposure, thrombin generation and coagulation $(27,28)$, we investigated how integrin $\alpha 2 \beta 1$ contributes to collagen-dependent thrombus formation under conditions of shear and coagulation. First, PPACK/heparin-anticoagulated blood from wildtype and $\alpha 2$-null mice was perfused over collagen at a shear rate of $1000 \mathrm{~s}^{-1}$, i.e. representative of that found in arterioles (17). As observed before, platelets from $\alpha 2$-null mice formed smaller sized, round-shaped aggregates (Fig. 4.5A). When compared to perfusion with wildtype blood, adhered $\alpha 2$-null platelets showed $49 \%$ reduced staining with FITC-annexin A5, indicative for diminished PS exposure (Fig. 4.5A, B). Interestingly, during flow $6.8 \pm 3.9$ emboli were shed from $\alpha 2$-null 

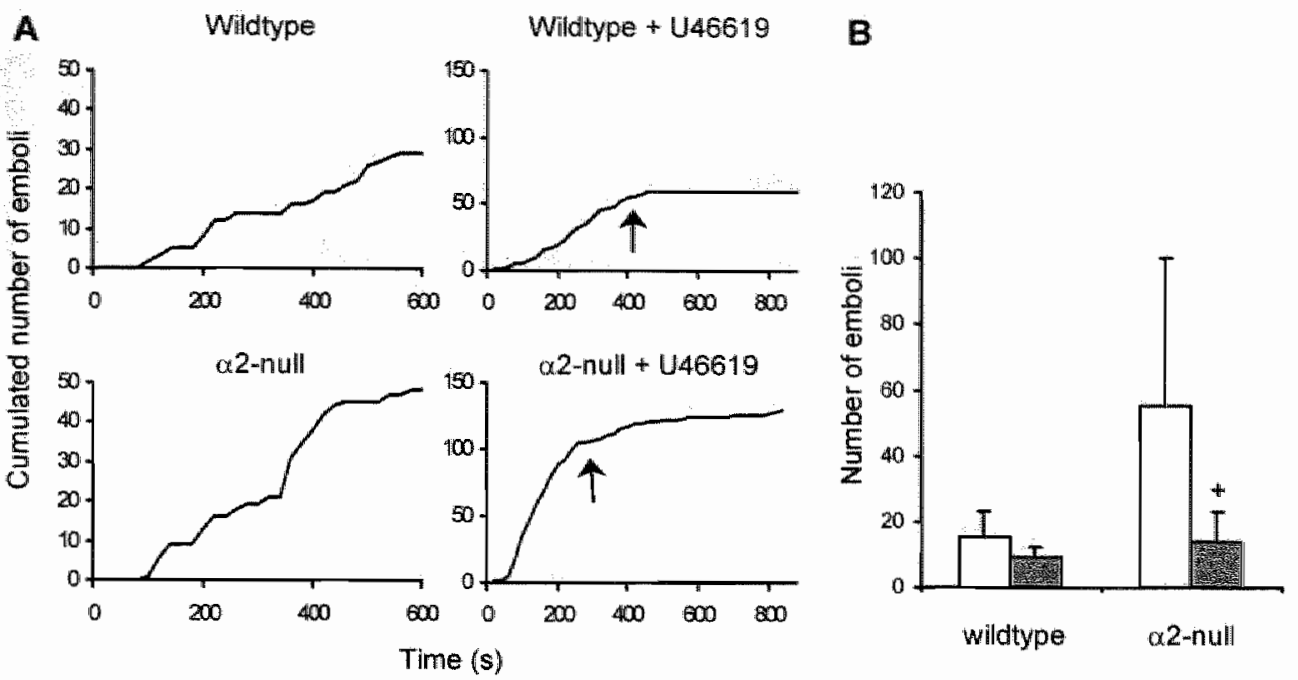

Figure 4.4. Effect of U46619 application on thrombus formation in vivo. Damage of adjacent mesenteric arterioles and venules was induced by $\mathrm{FeCl}_{3}$ at $\mathrm{t}=0$ seconds (baseline). $U 46619$ or vehicle was topically applied $\left(30 \mu \mathrm{l}\right.$ of $100 \mu \mathrm{M}$ ) at about 6 minutes after $\mathrm{FeCl}_{3}$ application. (A) Left panels: cumulative number of emboli in a wildtype and $\alpha 2$-null arteriole with many emboli, right pane/s." cessation of embolization after $\cup 46619$ application (arrow) at embolizing wildtype and a2-null arterioles. (B) Quantification of embolus production before (white bars) and after (grey bars) U46619 application; data are means \pm SEM.

aggregates compared to $0.8 \pm 0.8$ emboli in wildtype blood (mean $\pm S E M, n=4-6, p=0.046$ ), indicating that thrombus stability was also compromised in vitro. When a2-null blood was perfused at a low shear rate of $150 \mathrm{~s}^{-1}$, representative of that found in venules, this resulted in reduced aggregate formation and in less PS exposure of platelets (Fig. 4.5C).

To determine the contribution of coagulation, citrated blood was co-perfused with tissue factor/ $\mathrm{CaCl}_{2}$ during flow over collagen $\left(1000 \mathrm{~s}^{-1}\right)$. With wildtype blood, this resulted in formation of platelet-fibrin clots. Using bload from a2-null mice, aggregate-containing clots were still formed but were again smaller in size, while PS exposure was decreased compared to wildtype (Fig. 4.5A, D). Similar results were obtained when wildtype blood was preincubated with the anti- $\alpha 2$ antibody, SAM.G4 (data not shown).

Absence of integrin $\alpha 2 \beta 1$ may lead to diminished activation of integrim $\alpha$ lllb $\beta 3$, restricting the size of thrombi in a2-null blood. To investigate this, fluorescently labeled fibrinogen in combination with annexin $A 5$ was added to the blood prior to perfusion. The thrombotic process was visualized using the high resolution power of TPLSM. In thrombi from $\alpha 2$-null blood less fibrinogen staining was present, pointing to reduced activation of $\alpha$ llb $\beta 3$ (Fig. 4.6). Interestingly, the annexin A5 labeling did not co-localize with fibrinogen labeling, but restricted to single, collagen-bound platelets around the aggregates. This heterogeneity within thrombi was not influenced by the presence or absence of $\alpha 2 \beta 1$, indicating it is not controlled by this integrin. 
A
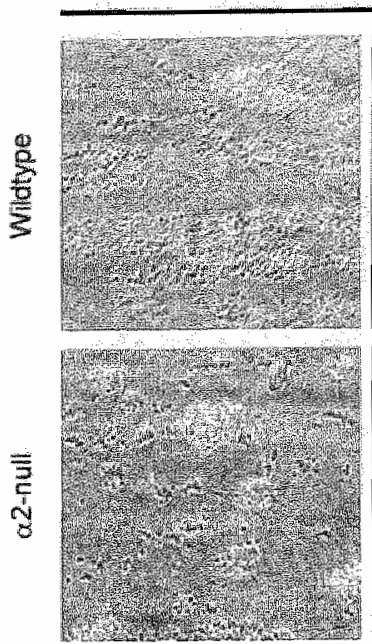

$\mathrm{B}$

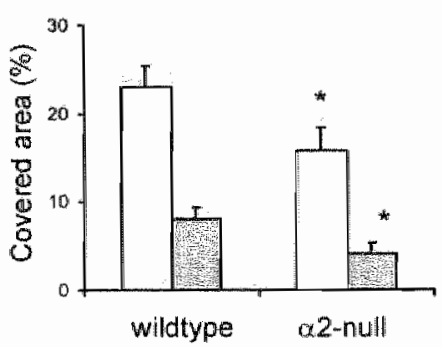

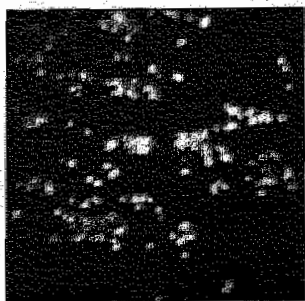

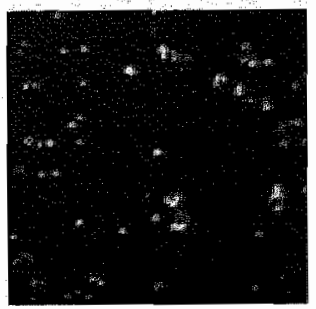

C

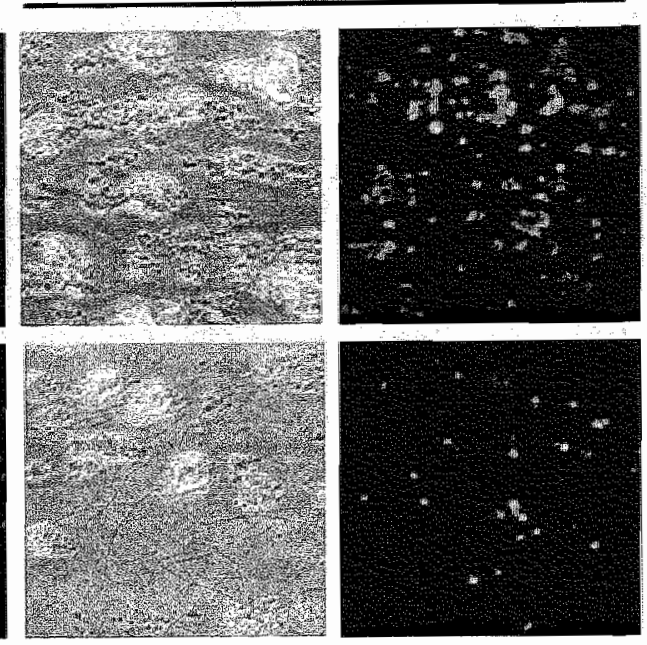

D
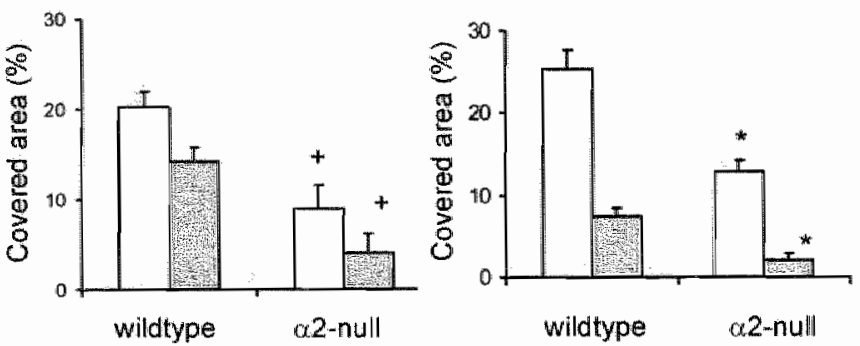

Figure 4.5. Reduced thrombus formation in flowing blood from a 2 null mice in the absence or presence of coagulation. (A) PPACK/heparin-anticoagulated blood was perfused over a collagen surface or citratted blood was perfused over collagen together with tissue factor $(2 \mathrm{pM}, \mathrm{f} . \mathrm{c}$.) and $\mathrm{CaCll} 2$ (20 $\mathrm{mM})$ to allow coagulation. Perfusion time was 4 minutes at a shear rate of $1000 \mathrm{~s}^{-1}$, followed by 4 minutes wash with buffer in the presence of fluorescently labeled annexin A5 $(0.5 \mathrm{\mu g} / \mathrm{ml})$. First column: representative phasecontrast images after buffer perfusion without coagulation; second column: images of FITC-amnexin As fluorescence without coggulation; thind column. representative phase contrast images after buffer perfusion with coagulation; founth column: images of FlTC-innexim A5 fluarescence with coagulation. Phase-Contrast $(120 \times 420 \mu \mathrm{m})$ and fluorescence $(150 \times 150 \mu \mathrm{m})$ images are representative of $5-12$ experiments. (B-D) Percentages of area coverage of all platelets (phase contrast; white bars) or PS-xposing platelets (annexin A5-FITC, grey bars) after 4 minutes of perfusion in the absence of coagulation at shear rates of $1000 \mathrm{~s}^{-1}(\mathrm{~B})$ or $150 \mathrm{~s}^{-1}$ (C) or in the presence of coagulation at $1000 \mathrm{~s}^{-1}$ (D). Data are means $\pm S E M, * p \leq 0.05,+p=0.06$

In these flow studies, the reduced thrombus formation and $\alpha$ llb $\beta 3$ activation may be also mediated by impaired autocrine release of thromboxane $A_{2}$. To investigate this, PPACK/heparin-anticoagulated blood was co-perfused with a solution of U46619. With both wildtype and a2-null blood, this resulted in an about 2-fold increased platelet deposition, whereas typically PS exposure did not increase (Fig. 4.7). Similar results were obtained with U46619 co-perfusion using wildtype blood that was preincubated with anti- $\alpha 2$ antibody (data not 
wildtype

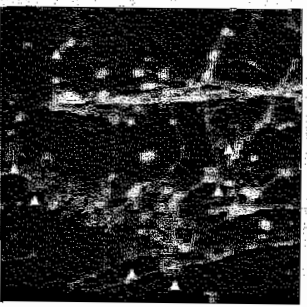

a.2-null

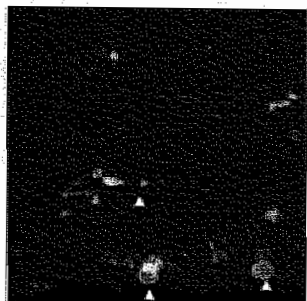

Figure 4:6. Reduced fibrinogen binding in flowing blood from a2-null mice PPACK/heparinanticoagulatted blood was perfused over a collagen surface as described for Fig. 4.5. Prior to perfusion OG488-fibrinagen $(0.25 \mathrm{mg} / \mathrm{ml})$ and $A F / 647$-annexin A5 $(0.5 \mu \mathrm{g} / \mathrm{ml})$ were added to the blood. TPLSM images were taken of OG488-fibrinogen and AF647annexin $A 5$ (indicated by $\Delta$ ) fluorescence $(77 \times 77 \mu \mathrm{m})$.
A

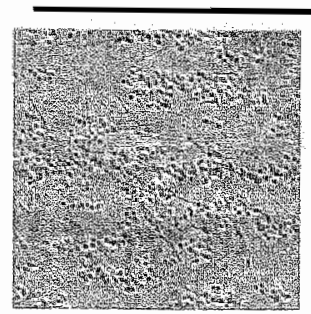

No U46619 coinfusion

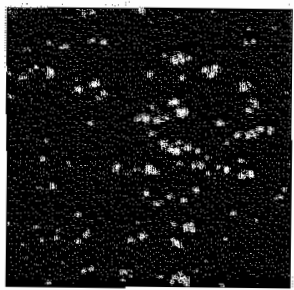

B

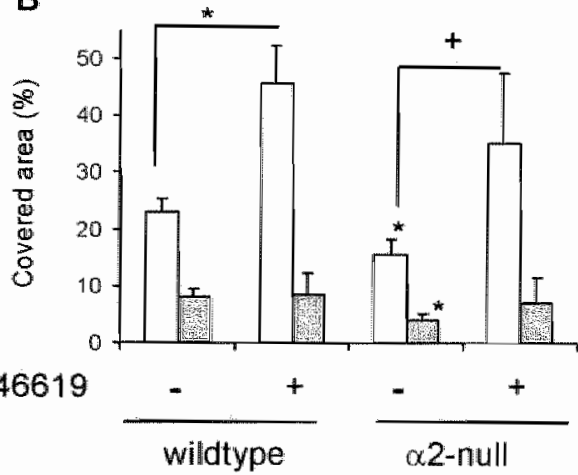

With U46619 coinfusion

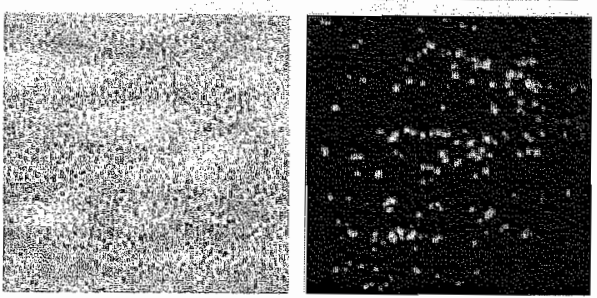

Figure 4.7. Effect of U46619 co-infusion on thrombus formation in flowing whole blood from wildtype and a2-null mice. PPACKJheparin-anticoagulated wildtype blood was perfused over collagen for 4 minutens at a shear rate of $1000 \mathrm{~s}^{-1}$, as indicated for Fig. 4.5. Thromboxane $A_{2}$ analogue $U 46619(1 \mu \mathrm{M}$, f.c.) was coinfused where indicated. (A) Representative phase-contrast (panels 1 and $3,120 \times 120 \mu \mathrm{m}$ ) and FITCannexin $A 5$ (panels 2 and $4,150 \times 150 \mu \mathrm{m}$ ) images after buffer perfusion. Images are representative of 6-10 experiments. (B) Percentages of area coverage of all platelets (phase contrast, white bars) or PS exposing platelets (FITC-annexin A5, grey bars) perfused for 4 minutes at $1000 \mathrm{~s}-1$ with or without U46619 $\mathrm{co}$ infusion. Data are means \pm SEM $(n=3-10),{ }^{*} p \leq 0.05_{n}$ * $p<0.06$.

shown). Thus, insufficient thromboxane $A_{2}$ production can explain reduced thrombus formation in the absence of $\alpha 2 \beta 1$. 
A

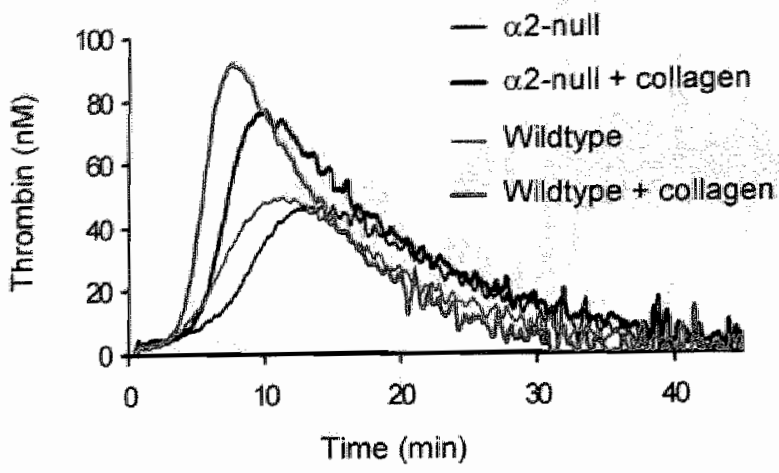

B

C
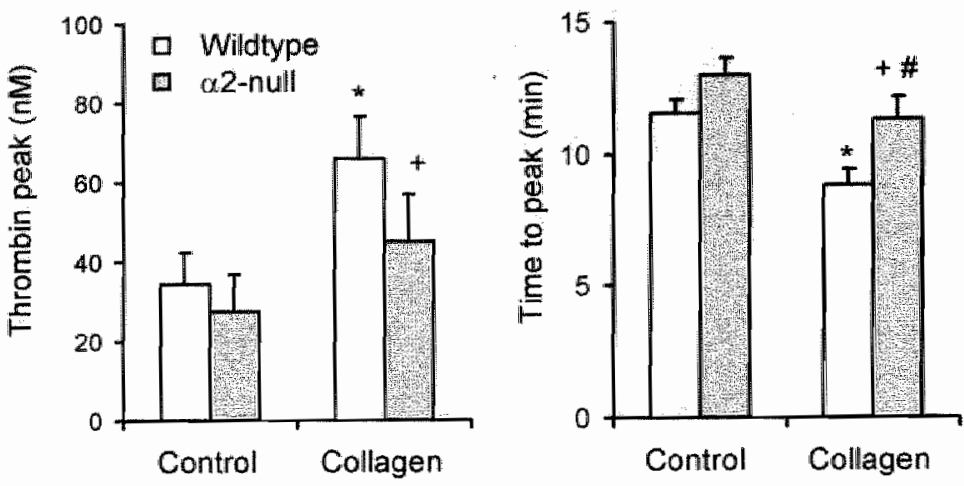

Figure 4.8. Contribution of $\alpha 2 \beta 1$ to collagen-mediated thrombin generation in PRP Mouse PRP was preincubated with vehicle (control) or $5 \mu \mathrm{g} / \mathrm{ml}$ collagen for 10 minutes, after which coagulation was initiated with $1 \mathrm{pM}$ tissue factor (f.c.) and $16.6 \mathrm{mM} \mathrm{CaCl}$. (A) Representative thrombin generation curves of wildtype and a2-null mice in the presence or absence of collagen. (B) Effect of collagen on thrombin peak height, (means \pm SEM, n=3-4). (C) Effect of collagen on time to peak. Collagen compared to control: * $p \leq 0.05,+p<0.08$; a2-nult compared to wiltype: $p \leq 0.05$

\section{Diminished collagen-enhanced thrombin generation in PRP in the absence of $\alpha 2 \beta 1$}

The results of reduced PS exposure point to a role of $\alpha 2 \beta 1$ in collagen-induced platelet procoagulant activity. This was directly measured in thrombin generation experiments with PRP. Upon triggering with tissue factor/ $/ \mathrm{CaCl}_{2}$, collagen enhanced the thrombin-forming process in PRP from wildtype and knockout mice (Fig. 4.8A). However, in $\alpha 2$-null PRP this collagen effect was smaller (Fig. 4.8B), and the time to maximal thrombin generation was delayed (Fig. 4.8C). Preincubation of wildtype PRP with $\alpha 2$ antibody SAM.G4 resulted in similar changes (data not shown). These results indicate that $\alpha 2 \beta 1$ supports and enhances the platelet function in thrombin generation and, thus, promotes the coagulation process. 


\section{Discussion}

In this report, we investigated the function of $\alpha 2 \beta 1$ in collagen-induced thrombus stability and growth. In an in vivo model where thrombosis was induced by exposure of the collagen-containing extracellular matrix, thrombi in $\alpha 2$-null arterioles were smaller in size than in wildtype arterioles, and had a significantly increased tendency to detach from the vessel and form emboli. In agreement with this, the in vitro flow experiments indicate that $\alpha 2 \beta 1$ has a role in the consolidation of thrombi, although the integrin is dispensable for thrombus formation as such. The integrin $\alpha 2 \beta 1$ appears to be involved in release of autocrine mediators, integrin activation and procoagulant activity. These are all platelet reactions known to be triggered primarily by GPVI $(15,17,29)$, and thus point to support of GPVI activity via $\alpha 2 \beta 1$. Importantly. we now describe that $\alpha 2 \beta 1$ retains this effect in the presence of flow and (tissue factor-induced) thrombin generation and coagulation. This knowledge is particularly relevant, since thrombin and fibrin play a significant role in the current (M. Kuijpers, submitted, (26)) and other thrombosis models (30). Accordingly, in the in vivo situation, $\alpha 2 \beta 1$ can regulate thrombus size and stability via a number of pathways: enhanced release of autocrine agents, increased $\alpha / 1 \mathrm{~b} / 33$ activation, and enhanced procoagulant activity of collagen-bound platelets, resulting in fibrin deposition.

The absence of the integrin $\alpha 2$-subunit from the currently used $\alpha 2$-null mice was confirmed by flow cytometry and the levels of $\beta 1$ were reduced by $30 \%$ (see also (11)). The expression levels of other glycoproteins were not altered in mutant platelets. In mice with a conditional B1-deficiency, dependent on Cre-mediated excision (1), we observed the appearance of loose platelet aggregates on the collagen surface (17). In the present study, we see that $\alpha 2 \beta 1$-deficient aggregates are intrinsically less stable structures, with increased tendency to embolize. Such instability might also explain the partially reduced aggregate formation - especially at high shear - seen with blood from another strain of $\alpha 2$-deficient mice (19).

The moderate effect of $\alpha 2$ deficiency sharply contrasted to the strongly delayed and reduced thrombus formation of GPVI-deficient platelets in the same thrombosis model (27). In various collagen-induced thrombosis models $\alpha 2$-deficiency did not result in impaired thrombus formation $(12,14,31)$. However, in some of these models, a moderate delay in the thrombotic process has been observed (14), which may be compatible with the presently detected thrombus instability. The present continuous recordings of the thrombotic process in response to vascular damage point to a subtle but important function of $\alpha 2 \beta 1$ : the integrin appears to determine the growth rate and stabilization of the thrombi, rather than to trigger the thrombotic process as such. Keeping in mind that platelets may react differently when encountered with a different stimulus " differences between the two a2-deficient mouse strains may be only minimal. 
The $\alpha 2 \beta 1$ integrin has a moderate but qualitatively impontant effect to stabilize thrombi and reduce embolization, most likely by enhancement of GPVI-dependent mechanisms.

The reduced thromboxane $A_{2}$ formation provides a mechanistic explanation for earlier studies with a2-null mice, which showed a delay in collagen-induced aggregation in the absence of the integrin (11). We found that the thromboxane $A_{2}$ analogue $U 46619$ could normalize the thrombus-forming process in az-deficient mice in vivo and under flow in vitro. Application of this compound increased platelet aggregation in vitro and immediately stopped the embolizing process in arterioles in vivo. Noteworthy, the platelet TP receptors for thromboxane $A_{2}$ couple to $G_{q}$ and $G_{12 / 13_{1}}$ both of which signaling proteins have been implicated in the formation of stable murine thrombi $(32-34)$. Since 446619 can induce activation of $\alpha 2 \beta 1$ (5) and allbp3 $3(35)$, our results provide additional support to the conclusion that $\alpha 2 \beta 1$ plays a role in shear-resistant platelet adhesion particularly under conditions of weak integrin activation (31). Furthermore, thromboxane release mediates ADP secretion (36), implicating that absence of $\alpha 2 \beta 1$ will indirectly suppress ADP-evoked allbB3 activation and platelet aggregation. Together with reduced physical contact with collagen in the absence of $\alpha 2 \beta 1$, this can enforce the detachment of formed thrombi.

An important question is why such a thrombus-destabilizing effect is not observed with aspirin, which completely suppresses thromboxane formation. One explanation is that aspirin will affect the activation of all platelets and not only those that adhere to collagen, thus leading to an overall reduced capability of the platelets to aggregate. Further, it should be considered that $\alpha 2 \beta 1$ is not the only platelet protein regulating thrombus stability. Increased platelet-platelet interaction is achieved, e.g. via ADP receptors (21,37), CD40L (38), ephrins (39), SLAM (40), and also fibronectin (41).

In summary, the present study reveals that (platelets from) a2-null mice have a subtle but clinically relevant phenotype upon vascular damage, in which unstable thrombi have an increased tendency to embolization, likely due to three mechanisms: reduced release of autocrine mediators, reduced platelet activation and lower coagullation activity. This thrombusstabilizing role of $2.2 \beta 1$ is likely to be relevant for the clinic, as antithrombotic therapy directed against $\alpha 2 \beta 1$ might be beneficial in reducing the size of thrombi, but also lead to an undesired effect of increased embolization.

\section{Acknowledgements:}

This work was supported by grants from the Netherlands Heart Foundation 2002-B014 and the Netherlands Organization for Scientific Research 902-16-276. 


\section{References}

1. Nieswandt B, Brakebusch $C$. Bergmeier $W$, Schulte $V$, Bouvard $D$, Mokhtari Nejad $R$, Lindhout $T$, Heemskerk $\mathrm{JW}$, Zirngibl $\mathrm{H}$. Fassler R. Glycoprotein VI but not $\alpha 2 \beta 1$ integrin is essential for platelet interaction with collagen. EMBO J. 2001; 20: 2120-2130.

2. Nieswandt $B$, Schulte $W$, Bergmeier $W$, Mokhtari-Nejad $R_{8}$ Rackebrandt $K_{\text {, }}$ Cazenave JP, Ohimann $P$, Gachet $\mathrm{C}_{\|}$Zirngibl $\mathrm{H}$. Lang-term antithrombotic protection by in vivo depletion of platelet glycoprotein VI in mice. J Exp Med. 2001; 193: 459-469.

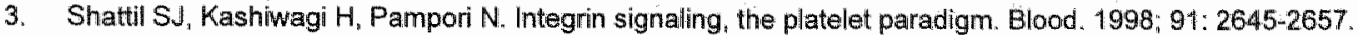

4. Jing SM, Moroi M. Signal-transducing mechanisms involved in activation of the platelet collagen receptor integrin $\alpha 231$. J Biol Chem. 2000; 275: 8016-8026.

5. Schoolmeester $A$, Vanhoorelbeke $K$, Katsutani $S$, Depraetere $H$, Feys HB. Heemskerk JM, Hoylaerts $M F_{n}$ Deckmyn $H$. Monoclonal antibody $\mid A C-1$ is specific for activated $\alpha 2 \beta 1$ and binds to amino acids 199 to 201 of the integrin $\alpha 2$ l-domain. Blood. 2004; 104:390-396.

6. Nieuwenhuis HK, Akkerman JW, Houdijk WP, Sixma JJ. Human blood platelets showing mo response to collagen fail to express surface glycoprotein la. Nature. $1985 ; 318: 470-472$

7. Nieuwenhuis HK, Sakariassen KS, Houdijk WP, Nievelstein PF, Sixma JJ. Deficlency of platelet membrane glycoprotein la associated with a decreased platelet adhesion to subendothelium: a defect in platelet spreading. Blood. 1986; 68: 692-695.

8. Kehrel $B_{1}$ Balleisen $L$, Kokott $R$, Mesters $R$, Stenzinger $W$, Clemetson $K J$, van de Loo J. Deficiency of intact thrombospondin and membrane glycoprotein la in platelets with defective collagen-induced aggregation and spontaneous loss of disorder. Blood. 1988; 71: 1074-1078.

9. Nieswandt B, Watson SP. Platelet collagen interaction: is GPVI the central receptor? Blood. 2003; 102 : 449-461.

10. Kunicki Tu Kritzik $M$ Annis DS, Nugent DJ. Hereditary variation in platelet integrin a.2\$1 density is associated with two silent polymorphisms in the a2 gene coding sequence. Blood. 1997; 89: 1939-1943.

11. Holtkotter $O$, Nieswandt $B$, Smyth $N$, Muller $W_{4}$, Hafner $M$, Schulte $V_{1}$ Krieg $T$, Eckes B. Integrin a2deficient mice develop normally, are fertile, but display partially defective platelet interaction with collagen. J Bial Chem. 2002; 277: 10789-10794.

12. Grüner $S$, Prostredna $M$, Schulte $V$, Krieg $T$, Eckes B, Brakebusch $C$, Nieswandt $B$. Multiple integrinligand interactions synergize in shear-resistant platelet adhesion at sittes of arterial injury in vivo. Blood. 2003; 102: 4021-2027.

13. Chen J, Diacovo TG, Grenache DG, Santoro SA, Zutter MM. The $\alpha 2$-integrin subunit-deficient mouse: a multifaceted phenotype including defects of branching morphogenesis and hemostasis. Am J Pathol. 2002; 161: 337-344.

14. He L, Pappan LK, Grenache DG, Li Z, Tollefsen DM, Santoro SA, Zutter MM. The contributions of the $\alpha 2 \beta 1$ integrin to vascular thrombosis in vivo. Blood. 2003; 102: 3652-3657.

15. Siljander PR, Munnix ICA, Smethurst PA, Deckmyn $H$, Lindhout $T$, Ouwehand $W H$, Farndale RW, Heemskerk JWM. Platelet receptor interplay regulates collagen-induced thrombus formation in flowing human blood. Blood. 2004; 103: 1333-1341.

16. Chen $H$, Kahn ML. Reciprocal signaling by integrin and nonintegrin receptors during collagen activation of platelets. Mol Cell Biol. 2003; 23: 4764-4777.

17. Kuijpers MJE Schulte $V$, Bergmeier $W$, Lindhout $T$, Brakebusch $C$, Offermanns $S$, Fassier $R_{1}$ Heemskerk JWM, Nieswandt B. Complementary roles of glycoprotein $V /$ and $a 2 \beta 1$ integrin in collageninduced thrombus formation in flowing whole blood ex vivo. Faseb J. 2003; 17: 685-687.

18. Auger JM, Kuijpers MJ, Senis YA, Watson SP, Heemskerk JW. Adhesion of human and mouse platelets to collagen under shear: a unifying model. Faseb J. 2005; 19: 825-827.

19. Sarratt KL, Chen $H_{1}$ Zutter MM, Santoro SA, Hammer DA, Kahn ML. GPVI and $\alpha 2 \beta 1$ play independent critical roles during platelet adhesion and aggregate formation to collagen under flow. Bloodi. 2005; 106: $1268-1277$.

20. Denis $C$, Methia $N$, Frenette PS, Rayburn $H$, Ullman Cullere $M$, Hynes RO, Wagner DD. A mouse model of severe von Willebrand disease: defects in hemostasis and thrombosis. Proc Natl Acad Sci U S A. 1998; 95: 9524-9529.

21. Van Gestel MA, Heemskerk JWM, Slaaf DW, Heijnen WV Reneman RS, Oude Egbrink MGA. In vivo blockade of platelet $A D P$ receptor $P 2 Y_{12}$ reduces embolus and thrombus formation but not thrombus stability. Arterioscler Thromb Vasc Biol. 2003; 23: 518-523.

22. Kuijpers MJE, Nieuwenhuys CM. Feijge MAH, Kloots W. Giesen PL, Jerling JC, oude Egbrinlk MGA, Heemskerk JWM. Regulation of tissue factor-induced coagulation and platelet aggregation in flowing whole blood. Thromb Haemast. 2005; 93: 97-105. 


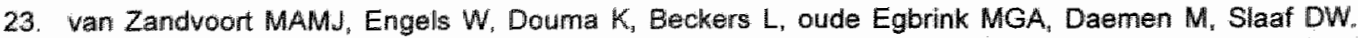
Two-photon microscopy for imaging of the (atherosclerotic) vascular wall: a proof of concept study. $J$ Vasc Res. 2004: 41:54-63.

24. Hemker HC, Giesen $P$, Al Dieri $R$, Regnault $V$, de Smedt $E$, Wagenvoord $R$, Lecompte $T$, Beguin $S$. Calibrated automated thrombin generation measurement in clotting plasma. Pathophysial Haemost Thromb. 2003; 33: 4-15.

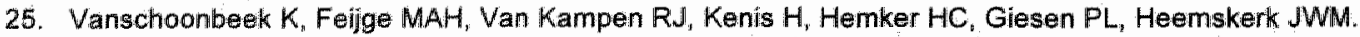
Initiating and potentiating role of platelets in tissue factor-induced thrombin generation in the presence of plasma: subject-dependent wariation in thrombogram characteristics. $J$ Thromb Haemost. $2004 ; 2$ : 476-484.

26. Ni H, Ramakrishnan $V$, Ruggeri $Z M$, Papalia JM, Phillips $D R$, Wagner DD. Increased thrombogenesis and embolus formation in mice lacking glycoprotein V. Blood. 2001; 98: 368-373.

27. Munnix ICA, Strehl A, Kuijpers MJE, Auger JM, van der Meijden PEJ, van Zandvoort MAM, oude Egbrink MGA, Nieswandt B, Heemskerk JWM. The glycoprotein VI-phospholipase C 2 signaling pathway controls collagen-and tissue factor-induced thrombus formation in vitro and in vivo. Atheroscl Thromb Vasc Biol. 2005; in press.

28. $\mathrm{Ni} \mathrm{H}$, Denis $\mathrm{CV}$, Subbarao S, Degen $\mathrm{JL}$, Sato TN, Hynes RO, Wagner DD. Persistence of platelet thrombus formation in arterioles of mice lacking both won Willebrand factor and fibrinogen. $\mathrm{J} C \mathrm{Clin}$ Invest. 2000; 106: 385-392.

29. Lecut $C_{*}$ Schoolmeester A, Kuijpers MJE, Broers JL" Van Zandvoort MAM, Vanhoorelbeke $K$, Deckmyn $H_{4}$, Jandrot-Perrus $M$, Heemskerk JW. Principal role of glycoprotein $V I$ in $\alpha 2 \beta 1$ and $\alpha / b \beta 3$ activation during collagen-induced thrombus formation. Arterioscler Thromb Vasc Biol. 2004; 24 : 17271733.

30. Falati S, Gross P, Merrill-Skoloff G, Furie BC, Furie B. Real-time in vivo imaging of platelets, tiissue factor and fibrin during arterial thrombus formation in the mouse. Nat Med. 2002; 8: 1175-1181.

31. Grüner S, Prostredna M, Aktas B, Moers A, Schulte V, Krieg T, Offermanns S, Eckes B, Nieswandit B. Anti-glycoprotein VI treatment severely compromises hemostasis in mice with reduced $\alpha 2 \beta 1$ levels or concomitant aspirin therapy. Circulation. 2004; 110: 2946-2951.

32. Offermanns S, Toombs CF, Hu YH, Simon MI. Defective platelet activation in Gaq-deficient mice. Nature. 1997; 389: 183-186.

33. Moers $A_{1}$ Nieswandt $B$. Massberg $S$, Wettschureck $N$, Grüner $S$, Konrad I, Schulte $V$, Aktas $B$, Gratacap MP, Simon MI, Gawaz M, Offermanns $S . G_{13}$ is an essential mediator of platelet activation in hemostasis and thrombosis. Nat Med. 2003; 9: 1418-1422.

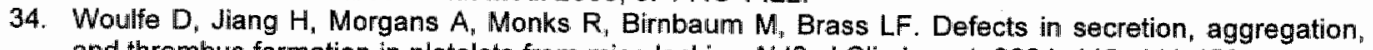
and thrombus formation in platelets from mice lacking Akt2. J Clin Invest. 2004; 113: 441-450.

35. Nieswandt $B$, Schulte $V_{n}$ Zywietz A, Gratacap MP, Offermanns S. Costimulation of $G_{i-}$ and $G_{12} / G_{13^{-}}$ mediated signaling pathways induces integrin allb/33 activation in platelets. J Biol Chem. 2002; 277: 39493-39498

36. Paul BZ, Jin J, Kunapuli SP. Molecular mechanism of thromboxane $A_{2}$-induced platelet aggregation. Essential role for p2t(ac) and alpha(2a) receptors. J Biol Chem. 1999; 274: 29108-29114.

37. André $P$, Delaney $S M$, LaRocca $T$, Vincent $D$, DeGuzman $F$, Jurek $M$, Koller $B$, Phillips DR, Conley PB. P2Y regullates platelet adhesion/ activation, thrombus growth, and thrombus stability in injured arteries. J Clin invest. 2003; 112: 398-406.

38. André $P$, Prasad KS, Denis CV. He M, Papalia JM, Hynes RO, Phillips DR, Wagner DD. CD4OL stabilizes arterial thrombi by a $\beta 3$ integrin-dependent mechanism. Nat Med. 2002; 8: 247-252.

39. Prevost N, Woulfe DS, Jiang $H$, Stalker TJ, Marchese P, Ruggeri ZM, Brass LF. Eph kinases and ephrins support thrombus growth and stability by regulating integrin outside-in signaling in platelets. Proc Natl Acad Sci U S A. 2005; 102: 9820-9825.

40. Nanda N, Andre P, Bao M, Clauser K, Deguzman F, Howie D, Conley PB, Terhorst $C$, Phillips DR. Platelet aggregation induces platelet aggregate stability via SLAM family receptor signaling. Blood.
2005.106:3028-3034.

41. Ni H, Yuen PS, Papalia JM, Trevithick JE, Sakai T, Fassler R, Hynes RO, Wagner DD. Plasma fibronectin promotes thrombus growth and stability in injured anterioles. Proc Natl Acad Sci U S A.
$2003 ; 100: 2415-2419$. 


\section{Chapter 5}

\section{Facilitating roles of murine platelet glycoprotein}

\section{Ib and $\alpha$ llb $\beta 3$ in phosphatidylserine exposure}

\section{during vWF-collagen-induced thrombus formation}

Mariijke J. E. Kuijpers, Valerie Schulte, Cécile Oury, Theo Lindhout, Jos Broers, Marc F. Hoylaerts, Bernhard Nieswandt and Johan W. M. Heemskerk

Joumal of Physiology (2004) 558: 403-41.5

Reprinted with permission 


\section{Abstract}

Vessel wall damage exposes collagen fibres, to which platelets adhere directly via the collagen receptors glycoprotein (GP) 1 and integrin $\alpha 2 \beta 1$, and indirectly by collagen-bound won Willebrand factor (WWF) via GPlb-V- $\mathrm{X}$ and integrin allb 33 receptor complexes. Platelet-collagen interaction under shear stimulates thrombus formation in two ways, by integrin-dependent formation of platelet aggregates and by surface exposure of procoagulant phosphatidylserine (PS). GPVI is involved in both processes complemented by a.231. In mouse blood flowing over collagen, we investigated the additional role of platelet-vWF binding via GPlb and $\alpha$ lllb 33 . Inhibition of GPIb as well as blocking of WWF binding to collagen reduced stable platelett adhesion at high shear rate. This was accompanied by delayed platelet $\mathrm{Ca}^{2+}$ responses and reduced PS exposure, while micro-aggregates were still formed. Inhibition of integrin $\alpha$ lib $\beta 3$ with JON/A antibody, which blocks allbB3 binding to both WWF and fibrinogen, reduced PS exposure and aggregate formation. The JON/A effects were not enhanced by combined blocking of GPIbWWF binding, suggesting a function for allb 33 downstream of GPIb. Typically, with blood from FCR $\gamma$-chain +1 - mice, expressing $50 \%$ of normal platelet GPVI levels, GPIb blockage almost completely abolished platelet adhesion and PS exposure. Together, these data indicate that, under physiological conditions of flow, both adhesive receptors, GPIb and ollb 33 , facilitate GPVl-mediated PS expasure by stabilising platelet binding to collagen. Hence, these glycoproteins have an assistant procoagulant role in collagen-dependent thrombus formation, which is most prominent at reduced GPVI activity and is independent of thrombin.

\section{Introduction}

Collagen fibres, exposed upon vessel wall damage, are strongly platelet-adhesive. Binding of platelets to collagen triggers a chain of activating events and leads to the assembly of platelet aggregates and the formation of fibrin-containing thrombi. The thrombus-forming reaction is essential in haemostasis, but detrimental in the progression of atherothrombosis and plaque rupture. This process of thrombus formation has widely been studied in vitro, using flow chambers where whole blood is perfused over a collagen-containing surface at (patho)physiological shear conditions, even in the absence of coagulation. From this work, it has appeared that multiple receptors are involved in the interaction of platelets with collagen.

Collagen rapidly adsorbs von Willebrand factor (VWF), which is present in plasma as a multimeric protein (1). WWF acts as a bridging molecule in platelet-collagen interactions, since it can bind to both collagen and the receptor complexes, glycoprotein (GP)/b-V-HX and integrin all $\mathrm{b} \beta 3$, through its $A 3, A 1$ and $C$ t domains, respectively. High shear stress induces conformational changes of WWF, which result in a reversible interaction with GPIb (2). This reduces the velocity of platelets flowing over collagen-bound WWF and results in transient 
attachment to the collagen surface (3). Subsequent, irreversible binding to WWF is mediated by the alibß3 integrin. This integrin also needs conformational changes for ligand interaction (inside-out signalling), which can be achieved e.g. by WWF-GPIb binding $(4,5)$ or following stimulation of the ADP, thromboxane $A_{2}$ or collagen receptors $(6,7)$. Both GPIb and $\alpha$ llibB3 also mediate WWF/fibrinogen dependent platelet aggregate formation under shear $(7,8)$.

Direct platelet-collagen contact is established by the collagen receptors, GPVI and integrin $\alpha 2 \beta 1$ (8-10). GPVI acts as a major signalling receptor, while $\alpha 2 \beta 1$ is required for stable adhesion to collagen. Ligand-induced clustering of GPVI results in its non-covalent association with the $\mathrm{FC}$ receptor ( $\mathrm{FCR}$ ) $\gamma$-chain, which leads to signalling via tyrosine-phosphorylation $(11,12)$. As a result, phospholipase $C_{\gamma} 2$ becomes phosphorylated and activated, which causes a prolonged increase in cytosolic $\left[\mathrm{Ca}^{2+}\right]_{\mathrm{i}}(13)$. This $\mathrm{Ca}^{2+}$ response contributes to the release of feedback agonists such as ADP and thromboxame $A_{2}$, which sustain platelet aggregate formation.

Previous in vivo and in vitro flow studies with mice have indicated that the $\alpha 2 \beta 1$ integrin is dispensable for platelet-collagen adhesion and subsequent thrombus formation $(14,15)$. Using mice deficient in $\alpha 2 \beta 1$ or GPVI, it was furthermore shown that under high, arterial shear conditions this integrin enhances GPVI signalling and, thereby, stabilises the platelet aggregates on collagen (16). This has led to a model of interplay between the collagen receptors, in which the $\alpha 2 \beta 1$ integrin supported by release products functions to enhance GPVIinduced platelet activation. Such a model is now proposed by several groups $(10,17-19)$, although it is still unclear to what extent the synergistic effect of $\alpha 2 \beta 1$ on GPVI is due to intracellular signaling by the integrin itself $(9,20)$ or to stabilization of collagen-GPVI contact by an activated integrin form.

Apart from aggregate formation, platelet-collagen interaction stimulates the coagulation process. Collagen or collagen-related peptide provake, in a $\mathrm{Ca}^{2+}$ dependent way, exposure of phosphatidylserine (PS) at the platelet outer membrane surface $(21,22)$. The availability of PS greatly potentiates the conversion of prothrombin into coagulant thrombin and, thus, enhances thrombin generation (23-25). PS exposure is one of the early platelet responses in sheardependent thrombus formation upon perfusion of human or murine blood over WWF/collagen $(16,19)$. In both species, it is a consequence of GPVI activity, while $\alpha .2 \beta 1$ mainly potentiates the GPVI effect. There is evidence, mostly from experiments with coagulating plasma, that GPIb. allbB3 and also WWF have discrete functions in stimulating platelet-dependent thrombin generation $(26,27)$. However, whether these factors also contribute to the PS-exposing. procoagulant response of platelets interacting with WWF/collagen is still unresolved.

Since platelet-collagen interaction under high shear is dependent on WWF, GPIb and allbß3, we focused here on the contribution of these proteins in the generation of the platelet procoagulant response under flow conditions. Using real-time video imaging techniques, we 
show that at high shear rates GPIb and WWF - and downstream of it allbp3 - enhance GPVImediated PS exposure, especially under conditions of reduced GPVI expression and activity. This nowel procoagulant effect of GPIb is independent of thrombin action and is additionall to its function in platelet aggregation. It is likely to be of physiological relevance, given the large variation in GPVI expresision between humans. As $\alpha 2 p 1$ also stimulates GPVI activity our results reveal receptor interplay in the regulation of platelet procoagulant activity that is not limited to collagen receptors, but extends to the GPIb-V-llX complex.

\section{Methods}

Animals

Pathogen-free C57BL/6 mice were obtained from Charles River (Maastricht, The Netherlands); mice deficient in FCR $\gamma$-chain (28) were obtained from Taconics (Germantown, NY, USA). Heterozygous FcR $\gamma$-chain deficient mice were generated by crossing wildtype mice with homozygous deficient mice of C57BL/6 background (14). Reduced expression of both GPVI and FCR $\gamma$-chain was checked at the protein level by Western blots, and by flow cytometric measurement of surface expression of GPVI, as described (29). Experimental protocols were ethically approved by the animal care and use committee of the University of Maastricht.

\section{Materials}

Fab fragments of rat anti-mouse antibodies were produced and modified in our laboratories (30). This concerned pOp/B antibody, which binds to the WWF binding site on GPIba; and JON/A antibody, which selectively binds to activated integrin allbB3 and inhibits integrin interaction with both WWF and fibrinogen. Polyclonal rabbit anti-human WWF antibody, cross-reacting with mouse WWF, was obtained from Dako (Glostrup, Denmark), and FITClabeled goat anti-rabbit IgG (GAR-FITC) was from Southern Biotech (Birmingham, AL, USA).

Fibrillar Horm collagen from equine tendon (Horm type-1) was purchased from Nycomed (Munich. Germany). Apyrase, high molecular weight heparin and MRS2179, an antagonist of the $\mathrm{P} 2 Y_{1}$ purinergic receptor, came from Sigma (St. Louis, MO, USA). Annexin V (annexin A5) labeled with fluorescein isothiocyanate (FITC) was from Nexins Research (Hoeven, The Netherlands); calcein and Fluo-3 acetoxymethyl esters, Pluronic F-127, and phalloidin labeled with Texas red $X$ were from Molecular Probes (Leiden, the Netherlands); $H$ Phe-Pro-Arg chioromethyl ketone (PPACK) was from Calbiochem (La Jolla, CA, USA). ARC69931MX, an antagonist of the $P 2 Y_{12}$ purinergic receptor, was kindly provided by AstraZeneca 
R\&D (Charnwood, UK). Recombinant saratin was produced in the yeast Hansenula polymorpha, as described (31). Sources of other chemicals are mentioned elsewhere (32).

\section{Platelet preparation and labeling}

Under full anesthesia, mice were bled retro-orbitally and sacrificed by cervical dislocation. The blood (1 volume) was collected in 0.5 volumes of saline cantaining 5 units ml $^{-1}$ heparin and $40 \mu \mathrm{M}$ PPACK. Anticoagulated blood (1 volume) was diluted in Hepes buffer $\mathrm{pH}$ 7.45 (0.5 volumes) containing $137 \mathrm{mM} \mathrm{NaCl}, 5.6 \mathrm{mM}$ glucose, $5 \mathrm{mM}$ Hepes, $2.7 \mathrm{mM} \mathrm{KCl}, 2 \mathrm{mM}$ $\mathrm{MgCl}_{2}, 2 \mathrm{mM} \mathrm{CaCl}, 0.42 \mathrm{mM} \mathrm{NaH} \mathrm{PO}_{4}, 0.1 \%$ (w/v) bovine serum albumin (BSA), which was supplemented with 1 unit/ml heparin. The blood was used within $2 \mathrm{~h}$. Where indicated, blood was incubated with $2.5 \mu \mathrm{M}$ calcein acetoxymethyl ester for $30 \mathrm{~min}$, as described (14).

Washed murine platelets in Hepes buffer $\mathrm{pH} 7.45$ were prepared from platelet-rich plasma, as described for rat blood (33). For $\mathrm{Ca}^{2+}$ measurements, washed platelets were incubated with Fluo-3 acetoxymethyl ester $(5 \mu \mathrm{M})$ in the presence of Pluronic $\mathrm{F}-127(0.2 \mathrm{mg} / \mathrm{ml})$ and apyrase (0.1 units ADPase $/ \mathrm{ml})$ at room temperature for $45 \mathrm{~min}$.

\section{Real-time video imaging}

Adhesion experiments under flow conditions were performed with mouse blood anticoagulated with PPACK and heparin, basically as described earlier (14). Briefly, coverslips $(24 \times 60 \mathrm{~mm})$ were partly coated with Horm collagen type I fibers $\left(1.25 \mathrm{mg} / 50 \mathrm{~mm}^{2}\right)$, rinsed with saline, and blocked with Hepes buffer containing $1 \%(w / v)$ BSA. Coverslips were placed in a parallel-plate transparent flow chamber (slit depth of $50 \mu \mathrm{m}$ ), which was connected by polyethylene tubing (diameter $1 \mathrm{~mm}$ ), and mounted on an inverted Nikon (Tokyo, Japan) micrascope. To prevent coagulation, chamber and tubing were pre-washed with Hepes buffer containing 1 unit/ml heparin. Blood was perfused through the flow chamber using a $1 \mathrm{ml}$ syringe and a pulse-free pump, at the desired shear rate (1000 or $1500 \mathrm{~s}^{-1}$ ) for $4 \mathrm{~min}$. During perfusion, high-resolution microscopic images of transmission or fluorescence (Fluo-3 or calcein) were recorded in real-time with a Visitech imaging system (Sunderland, UK). Digital images were captured with two parallel-placed intensified, CCD cameras, recording infrared $(0.3 \mathrm{~Hz})$ and epifluorescence $(5 \mathrm{~Hz}$ ) light at desired wavelengths (21). After perfusion, the flow chamber was rinsed with Hepes buffer supplemented with 1 unit/ml heparin at the desired shear rate. Exposure of PS was detected with FITC-labeled annexin A5 $(0.5 \mu \mathrm{g} / \mathrm{ml})$ added to the rinse buffer.

Where indicated, blood was incubated for $10 \mathrm{~min}$ prior to perfusion with a saturating concentration of $\mathrm{p} 0 \mathrm{p} / \mathrm{B}$ or JON/A Fab fragment $(40 \mu \mathrm{g} / \mathrm{ml})$, saratin $(10 \mu \mathrm{g} / \mathrm{ml})$ or MRS2179 $(20$ HM) plus AR-C69931MX (50 $\mathrm{MM})$. These antagonists were also added to the rinse buffer. To measure changes in cytosolic $\left[\mathrm{Ca}^{2+}\right]_{\text {in }}$ Fluo-3-labelled platelets from mice of the same genotype 
were added to the anticoagulated blood, so that 5-10\% of total platelets were labeled. Labeling a small fraction of the platelets in blood had the advantage that individual, collagen-bound platelets could be distinguished from each other even when trapped in multi-platelet aggregates.

Real-time changes in Fluo-3 fluorescence from single platelets, recorded during the flow experiment, were analyzed with Quanticell software. Changes in Fluo-3 fluorescence of individual platelets were converted into levels of $\left[\mathrm{Ca}^{2+}\right]$ using a pseudo-ratio calibration procedure, exactly as described (34). Traces representing averaged $\mathrm{Ca}^{2+}$ responses were constructed from time-adjusted responses of at least 13 single platelets that could be observed for at least $60 \mathrm{~s}$ (2-4 mice per condition).

\section{Confocal fluorescence microscopy}

Immediately after perfusion, collagen-coated coverslips with aggregates were removed from the flow chamber, fixed with $2 \%$ formaldehyde during $15 \mathrm{~min}$, and rinsed with tap water. Further procedures were performed in a humid chamber at room temperature. The samples were first blocked with $15 \%$ (w/v) BSA in phosphate-buffered saline (PBS) for 30 min. Samples were then incubated with rabbit anti-human WWF antibody $(10 \mu \mathrm{g} / \mathrm{mi})$ for one $\mathrm{h}$, washed in PBS 3 times for $5 \mathrm{~min}$, and stained with GAR-FITC $(10 \mu \mathrm{g} / \mathrm{ml})$ for one $h$. Samples were counterstained for actin to stain all platelets. After a triple wash in PBS and permeabilisation with $0.005 \%$ SDS in PBS for 10 min "they were blocked with $1 \%$ BSA in PBS. The samples were then incubated with Texas red-labeled phalloidin ( 3 units $/ \mathrm{ml}$ ) in blocking buffer for $1 \mathrm{~h}$ and, after another wash, they were mounted in 9 volumes of glycerol plus 1 volume of $0.2 \mathrm{M}$ Tris$\mathrm{HCl}_{1} \quad 0.02 \% \mathrm{NaN}_{3}$ with $2 \%$ 1,4-diazabicyclo(2,2,2)-octane (Dabco), pH 8.0. Double stained aggregates were observed with a BioRad MRC-600 confocal scanning laser microscope (BioRad, Richmond, CA USA) equipped with a krypton/argon mixed gas laser and a red diode laser (Ion Laser Technology. Salt Lake City, UT, USA) with two separate wavelengths for excitation of fluorescein $(488 \mathrm{~nm})$ and Texas red $X(568 \mathrm{~nm})$.

Image analysis

Data were compared off-line from at least nine different randamly chosen, microscopic images, taken at the coilagen surface. Platelet deposition was determined from phase-contrast images, as described before (16). Area coverage by platelets staining with calcein or FITCannexin A5 fluorescence was determined with Quanticell software (Visitech). Procoagulant area was corrected for fluorescent glare in the optics by comparison of camera images in fluorescence and transmission modes. 


\section{Statistical analysis}

Data were tested on significance using the statistical package for social sciences (SPSS 11.0, Chicago, IL, USA). Significant differences compared to control condition were evaluated with a Mann-Whitney $U$ test.

\section{Results}

Roles of GPIb and VWF in PS exposure of platelets adhering to collagen under shear

Whole blood from wildtype mice, anticoagulated with PPACK/heparin, was used to investigate the contribution of GP\|b-WWF interaction to platelet deposition on collagen and subsequent PS exposure. The blood was perfused over immobilized type-I collagen at an intermediate, arterial wall shear rate $\left(1000 \mathrm{~s}^{-1}\right)$ to achieve GPlb dependency (16). Video microscopy showed that most wildtype platelets firmly adhered to the collagen fibers. Part of these platelets assembled to platelet aggregates, while others remained single and transformed

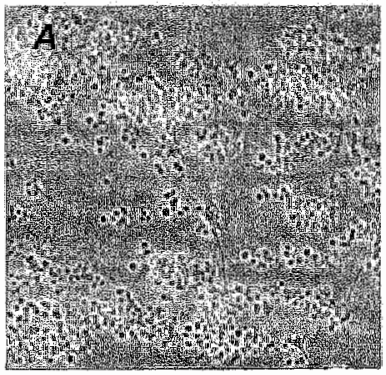

Control

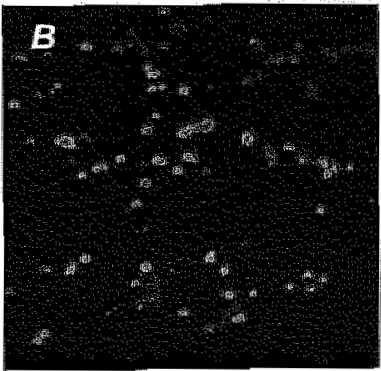

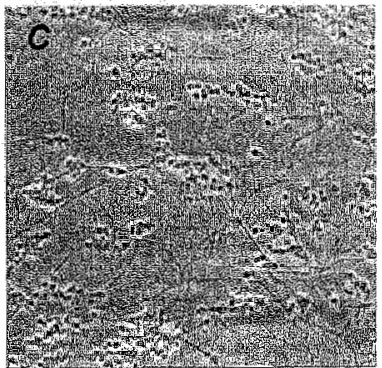

p0p/B

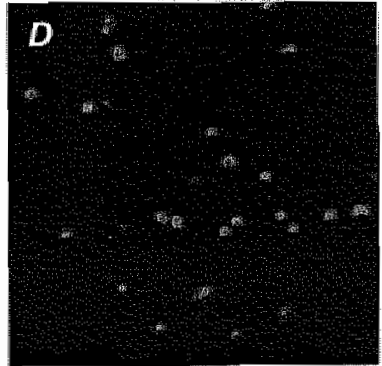

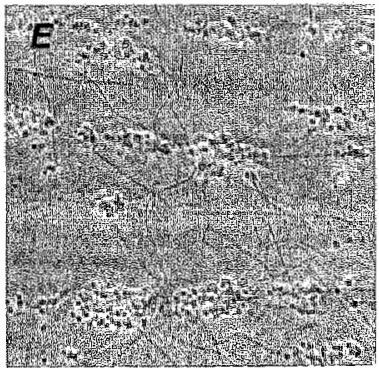

\section{Saratin}

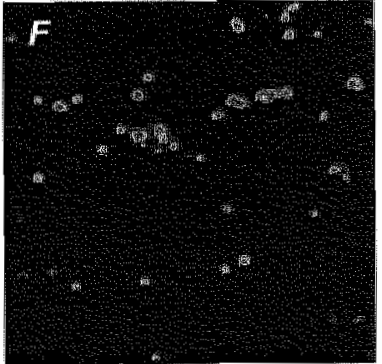

Figure 5.1. Effect of blocking GPlb on platelet deposition and PS exposure upon flow over WWF/collagen. Whole blood from C57BL/6 wildtype mice was perfused over type I collagen at a wall shear rate of $1000 \mathrm{~s}^{4}$. $A, C, E$, phase-contrast microscopic images $(120 \times 120 \mu \mathrm{m})$ after $4 \mathrm{~min}$ of perfusion. $B, D, F$, fiuore-scence images $(150 \times 150 \mu \mathrm{m})$ after staining with FITC-labeled annexin $A 5$. $A$ and $B_{\text {u }}$ untreated control blood. $C$ and $D$, blood pre-treated with $40 \mu \mathrm{g} / \mathrm{ml}$ anti-GPIb pOp/B Fab fragment (10 min). E and $F$, blood pre-treated with $10 \mu \mathrm{g} / \mathrm{ml}$ saratin $(10 \mathrm{~min})$. 
$41000 \mathrm{s:}^{-3}$

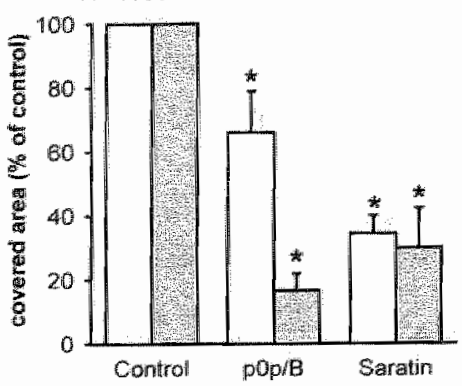

$15005^{-1}$

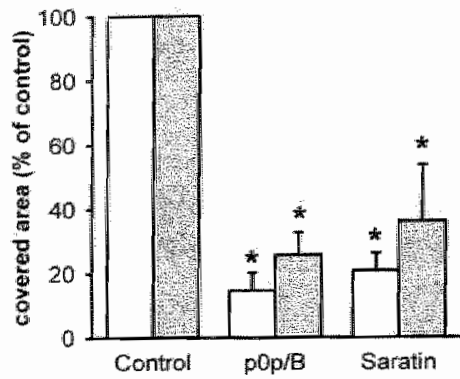

Figure 5.2. Roles of GPlb and shear stress in platelet deposition and PS exposure. Whole blood from wildtype mice was perfused over collagen for $4 \mathrm{~min}$ at a shear rate of 1000 or $1500 \mathrm{~s}^{-1}$. Effect of pretreatment with pop/B Fab $(40 \mu \mathrm{g} / \mathrm{ml})$ or saratin $(10 \mu \mathrm{g} / \mathrm{ml})$ on area coverage of all platelets (white bars) and PS-exposing platelets (gray bars). Data are percentages of control condition at indicated shear rate (mean \pm S.E. $M_{n} n=6-20 \% . \mid p<0.05$ compared to control.

into round, blebbing structures. The latter morphological change is an undicator for PS exposure and procoagulant activity $(16,22)$. The deposition of platelets, measured as surface area coverage, increased about linearly for at least 6 min. After 4 min perfusion, $25 \pm 2 \%$ (mean \pm S.E.M., $n=32$ ) of the surface was covered with platelets (Fig. 5.1A). A similar, linear increase in platelet deposition was observed, when blood containing calcein-labeled platelets was perfused over the collagen surface (data not shown, but see (14)). Staining with FITC-labeled annexin A5 showed that, at the 4-min end point, a considerable proportion of single, collagen-binding platelets had exposed PS, with an area coverage with fluorescence of $9 \pm 1 \%(\mathrm{n}=20)$ (Fig. 5.1B). Experiments where FITC-annexin A5 was added to the blood indicated that PS exposure of deposited platelets started after a lag time of $2 \mathrm{~min}$ and then increased continuously up to 10 $\min$.

To block GPIb-VWF interaction, wildtype blood was pre-incubated with a saturating concentration of anti-GPlba pOp/B Fab fragment $(40 \mu \mathrm{g} / \mathrm{mi})$, which specifically abolishes the GPIb binding to mouse WWF (30). This treatment led to increased translocation velocity of platelets over the collagen surface and to diminished stable adhesion, while micro-aggregates were still formed (Fig. $5.1 \mathrm{C}$ ). Platelet deposition was reduced by pop/B to $66 \pm 13 \%(\mathrm{n}=5$ ) of the control condition. The number of single, PS-exposing platelets (Fig. 5.1D) was more strongly reduced to about $20 \%(\mathrm{p}=0.02)$ of control (Fig. 5.2A). As an alternative way to eliminate the contribution of WWF, blood was treated with $10 \mu \mathrm{g} / \mathrm{ml}$ saratin, a leech protein which blocks WWF binding to collagen (31). Again, platelets were moving over the collagen surface and made fewer stable contacts (Fig. 5.1E). With some of the platelets still forming aggregates, the total area coverage was $34 \pm 6 \%(n=11)$ of controll. The number of PS-exposing platelets (Fig. 5.1F) was similarly reduced to $30 \pm 13 \%$ of control (Fig. 5.2A). 


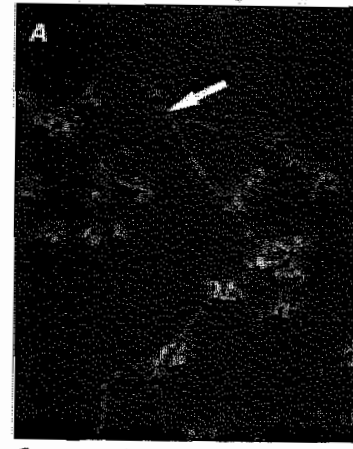

Control

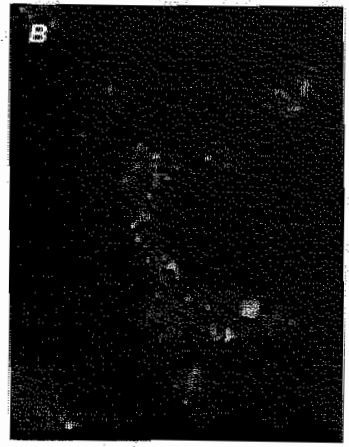

Saratin
Figure 5.3. Effect of saratin on WWF binding to collagen and platelets. Blood from wildtype mice was perfused over collagen in the absence (A) or presence (B) of saratin $(10$ $\mu \mathrm{g} / \mathrm{mil})$ at $1000 \mathrm{~s}^{-1}$ for $4 \mathrm{~min}$. Representative confocal fituorescence ïmages are given after fixation with $2 \%$ formaldehyde and staining for WWF and actin. Micrographs show contours of platelets (actin) and deposited UWF as brighter punctuated spots; arrow indicates WWF covered collagen fiber. Image sizes are $20 *$ $25 \mu \mathrm{m}$.

To achieve higher GPIb dependency, additional experiments were performed at a higher shear rate of $1500 \mathrm{~s}^{-1}$. In this case, blocking GPlb with $\mathrm{p} 0 \mathrm{p} / \mathrm{B}$ further reduced area coverage of platelets to $15 \pm 6 \%$ and of annexin A5-binding platelets to $26 \pm 7 \%$ of the control (Fig. 5.2B). Similarly, the presence of saratin decreased the coverage by platelets to $21 \pm 5 \%$ and by annexin A5 fluorescence to $36 \pm 17 \%$ of control. Thus, inhibition of the GPIb-VWF interaction by GPIb blocking (pOp/B) or absence of WWF (saratin) caused a substantial but incomplete reduction in platelet deposition and PS exposure at shear rates up to $1500 \mathrm{~s}^{-1}$.

The similarities in effects of $\mathrm{pOp} / \mathrm{B}$ and saratin treatment suggested that GPIb interaction with collagen-bound WWF could control PS exposure by allowing stable platelet adhesion. To confirm this, platelets on collagen-coated coverslips were stained post-perfusion for VWF and then counterstained with phalloidin to visualize actin filaments. In the control situation, confocal microscopy showed bright WWF staining on the collagen fibers as well as on platelet aggregates, where it appeared as clustered spots (Fig. 5.3A). With saratin present, the collagen fibers no longer stained for WWF, whereas the platelets in aggregates had unaitered WWF staining (Fig.5.3B).

Role of GPIb in $\mathrm{Ca}^{2+}$ responses of platelets adhering to WWF-collagen

The activation state of platelets interacting with VWF/collagen was investigated by adding $10 \%$ Fluo-3 labeled murine platelets to the blood. This labeling of platelets did not influence collagen-induced aggregate formation in vitro, as measured by aggregometry «data not shown). Under control conditions of flow $\left(1000 \mathrm{~s}^{-1}\right)$, the large majority of Fluo-3 labeled platelets stably attached to collagen fibrils. The platelets showed a potent and prolonged $\mathrm{Ca}^{2+}$ response (Fig. 5.4A), as is required for PS exposure (21). Traces from single platelets indicated a rapid, prolonged rise in $\left[\mathrm{Ca}^{24}\right]$, that was occasionally preceded by one high spike in $\left[\mathrm{Ca}^{2+}\right]$ (Fig. 5.4B). As we have shown before, this $\mathrm{Ca}^{2+}$ signal under flow conditions is almost completely dependent on GPVI signaling, with minute, spiking $\left[\mathrm{Ca}^{2+}\right]_{i}$ increases remaining in the absence of GPVI (16). 

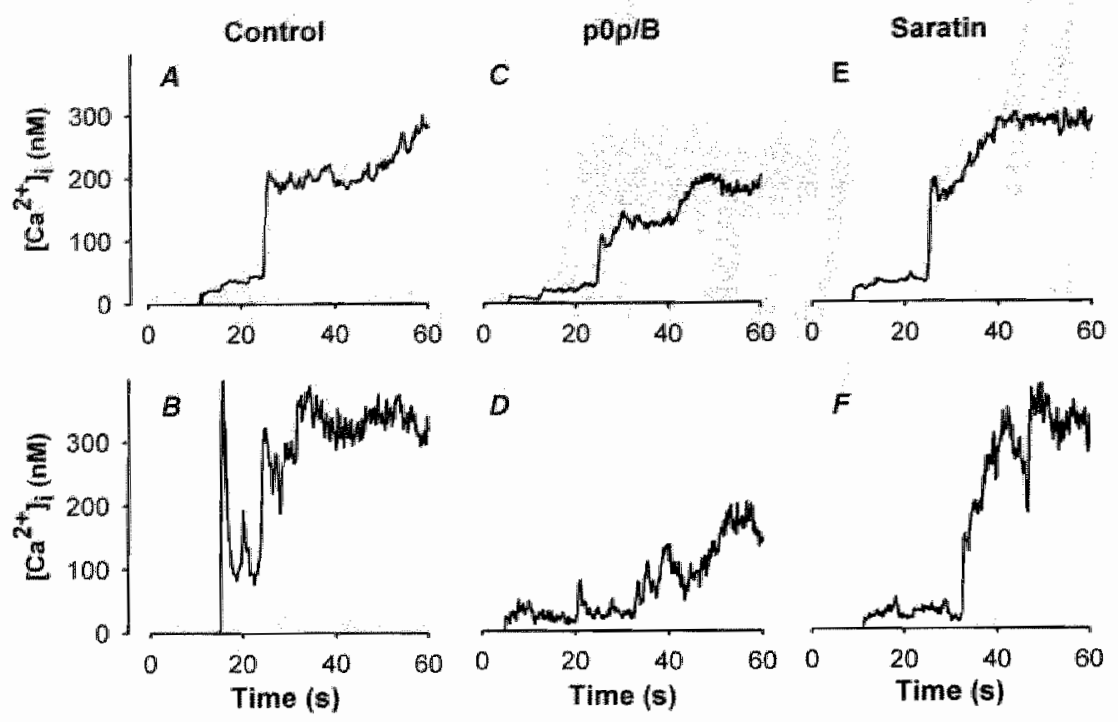

Figure 5.4. Potentiating role of $\mathrm{GPIb}$ in $\mathrm{Ca}^{2+}$ response of collagen-adhering platelets under shear. Whole blood was supplemented with 10\% Fluo-3-loaded platelets, and perfused over collagen as indicated for Fig. 5.1. Upper paneis show averaged changes in $\left[\mathrm{Ca}^{24}\right]$ of $13-32$ platelets, observed during at least $60 \mathrm{~s}$, from at least two different mice. Lower panels show changes in $\left[\mathrm{Ca}^{24}\right]$ of represen-tative single platelets. Blood was either untreated $(A, B)$ or incubated for $10 \mathrm{~min}$ prior to perfusion with $40 \mu \mathrm{g} / \mathrm{ml} \mathrm{pOp} / \mathrm{B} F \mathrm{Fab}\left(C_{t}, D\right)$ or 10 $\mu \mathrm{g} / \mathrm{m}$ l saratin $(E, F)$.

When the blood was treated with anti-GPlb pop/B, many of the Fluo-3 labeled platelets moved over the surface before stopping. Once adhered, the $\mathrm{Ca}^{2+}$ signals of many of the pop/Btreated platelets were reduced in comparison to the control (Fig. 5.4C, D). Individual cells often showed a series of $\mathrm{Ca}^{2+}$ spikes before reaching a maximal level, which was on average reduced by $35 \%(n=13-26$ platelets, $p=0.02$ unpaired, measured after $60 \mathrm{~s}$ ). Treatment of the blood with saratin caused similar but not identical effects. Again, many of the Fluo-3 labeled platelets moved over the surface before adhering stably. The $\mathrm{Ca}^{2+}$ responses of these platelets were typically delayed (Fig. 5.4E, F). The median lag time (time measured from first collagen contact until $\left[\mathrm{Ca}^{2+}\right]$ rise) was notably increased from 9 to $13 \mathrm{~s}$ compared to control platelets. Maximal $\left[\mathrm{Ca}^{2+}\right]$ rises after the delay were unchanged with saratin. These data indicated that the blocking of GPlb and absence of WWF delayed and destabilized platelet-collagen contact and subsequent signaling. This points to a stimulating role of GPIb and WWF in GPVI-induced $\mathrm{Ca}^{2+}$ signaling. Since PS exposure relies on a persistent $\left[\mathrm{Ca}^{2+}\right]_{i}$ rise, the reduced or delayed $\mathrm{Ca}^{2+}$ signall with pOp/B or saratin can explain the lower PS exposure under these flow conditions (see Fig. 5.2A). 

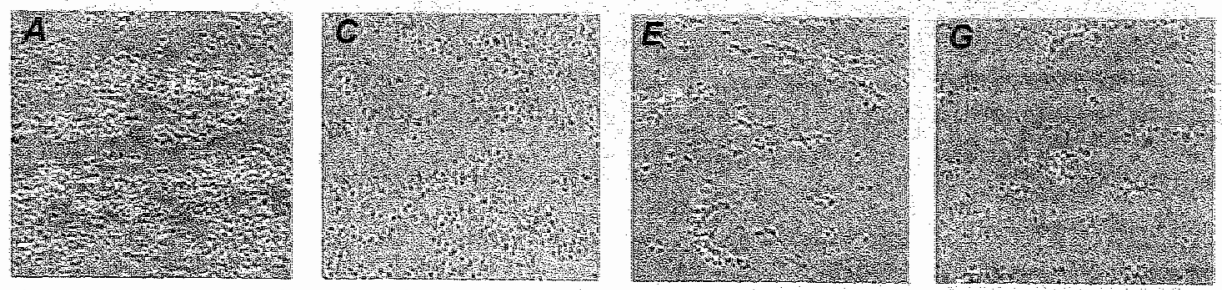

\section{Control}

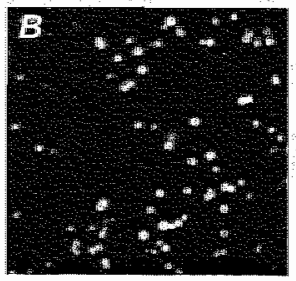

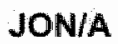

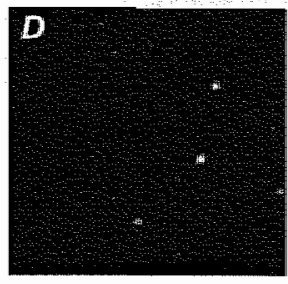

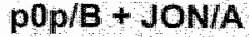

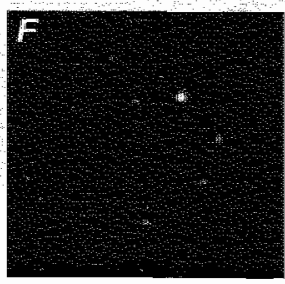

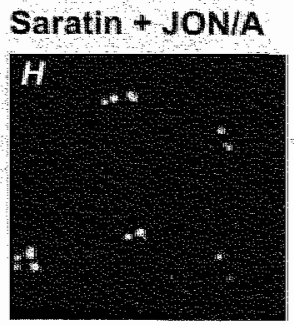

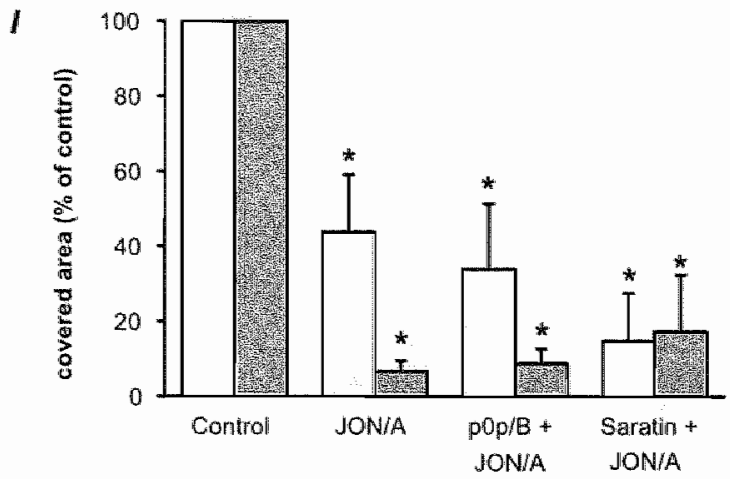

Figure 5.5. Role of integrin $\alpha / l b \beta 3$ in platelet deposition and PS exposure. Whale blood from wildtype mice was perfused over type I collagen as indicated for Fig. 5.1. Upper panels: representative phase contrast images $(120 \times 120 \mu \mathrm{m})$ after $4 \mathrm{~min}$ of perfusion. Lower panels: fluorescence images $(150 \times 150 \mu \mathrm{m})$ after staining with FITC-labeled annexin A.5. Blood was untreated $(A, B)$, or treated with $40 \mu \mathrm{g} / \mathrm{ml}$ anti-allb 33 JON/A Fab fragment alone (C, D), with JON/A plus $40 \mu \mathrm{g} / \mathrm{mll} \mathrm{pOp} / \mathrm{B}$ Fab fragment $(E, F)$, or with $10 \mu \mathrm{g} / \mathrm{ml}$ saratin $(G, H) 10$ min prior to perfusion. 1. Surface area coverage of all platelets (white bars) and PS. exposing platelets (gray bars) of conditions described in panels A-H. Data are given as percentages of control condition (mean values $\pm S . E . M ., n=3-11$ ). ${ }^{*} p<0.05$ comprared to control.

\section{Role of integrin allb $\beta 3$ and GPIb in PS exposure of platelets adhering to WWF-collagen}

Stable adhesion to WWF requires platelet interaction with both GPIb-V-IX and activated integrin allbB3 $(5,35-37)$. To interfere with the contribution of allbB3, the murine blood was incubated with Fab fragments $(40 \mu \mathrm{g} / \mathrm{ml})$ of JON/A, which is a unique, recently characterized antibody that blocks allb 33 binding sites for WWF and fibrinogen $(38,39)$. This is in contrast to anti-aggregatory peptide inhibitors of $\alpha / \mathrm{lb \beta} 3$, which only react with the fibrinogen binding site. Upon perfusion of blood in the presence of JON/A, platelets adhered to $\mathrm{WWF} /$ collagen as single cells or two-layered micro-aggregates (Fig. 5.5A-D). Surface coverage with platelets was 
reduced to $44 \pm 15 \%(n=7)$ of control (Fig. 5.51). PS exposure of platelets on callagen was greatly lowered to $7 \pm 3 \%$ of control. In comparison, when effects of autocrine ADP were blocked with the $\mathrm{P}_{2} \mathrm{Y}_{1}$ and $\mathrm{P} 2 \mathrm{Y}_{12}$ receptor antagonists, MRS2179 (20 $\left.\mu \mathrm{M}\right)$ and AR-C69931MX $(50 \mu \mathrm{M})$, respectively, this gave a similar decrease in platelet deposition (area coverage with platelets to $48 \pm 9 \%$ of control; not shown), but less strong decrease in PS exposure ( $38 \pm 17 \%$ of control).

To test whether the inhibitory effects of JON/A were dependent on GPIb and WWF. combined treatments were carried out with either pOp/B or saratin (Fig. 5.5E-H). The addition of p0p/B did not further reduce platelet deposition nor PS exposure in comparison to JON/A alone (Fig. 5.51). Perfusion with saratin plus JON/A resulted in a somewhat lower platelet deposition, and an unchanged reduction in PS exposing platelets. These data suggest that GPIb and integrin allb 33 influenced platelet activation at least in part via a common route involving WWF.Increased role of GPIb in PS exposure at reduced expression of GPVI

Since GPVI activity is a limiting factor in collagen-dependent platelet activation and aggregation (18), the effect of GPIb inhibition was also examined under conditions of reduced GPVI expression. Therefore, blood was used from mice which were partially or completely deficient in FCR $\gamma$-chain. As expected, homozygous deficiency resulted in undetectable levels of both FCR $\gamma$-chain and GPVI on platelets, whille heterozygous deficiency gave $50 \%$ reduction of both proteins (Table 5.1). Expression levels of GPIb-V-IX and $\alpha / l b \beta 3$ were unchanged in these animals. When blood from heterozygous mice was perfused over WWF/collagen (1000 $\mathrm{s}^{-}$ $\left.{ }^{1}\right)$,platelet deposition was about linear with time. In a typical experiment, the increase in surface area coverage was $2.3 \% / \mathrm{min}\left(R^{2}=0.44\right)$ in comparison to $5.5 \% / \mathrm{min}\left(R^{2}=0.93\right)$ for willdtype blood. At the 4-min endpoint $t$ this resulted in an about $42 \%$ lower platelet adherence for the FcR $\gamma$ chain $+/$-mice (Fig. 5.6A-D). Exposure of PS was also about $40 \%$ reduced in comparison to

Table 5.1. Surface expression of different glycoproteins on platelets from wildtype and FcR $\gamma$-chain deficient mice

\begin{tabular}{|c|c|c|c|}
\hline Glycoprotein(s) & Wildtype & $\mathrm{FeR} y+1-$ & FoR $\gamma-1-$ \\
\hline GPVI & $48.3 \pm 8.7$ & $27.2 \pm 9.3^{*}$ & $6.4 \pm 1.9^{*}$ \\
\hline GPlla $(\beta 1)$ & $135.6 \pm 11.2$ & $131.7 \pm 13.1$ & $133.3 \pm 12.8$ \\
\hline GPla $(\alpha 2)$ & $47.2 \pm 8.5$ & $45.5 \pm 7.3$ & $44.8 \pm 7.9$ \\
\hline GP\|llb/llla (allb/33) & $395.8 \pm 30.4$ & $416.2 \pm 32.5$ & $399.4 \pm 33.7$ \\
\hline GPV & $187.2 \pm 19.3$ & $179.4 \pm \| 6.7$ & $185.1 \pm 20.5$ \\
\hline CD9 & $532.3 \pm 38.2$ & $535.7 \pm 41.4$ & $528.7 \pm 35.6$ \\
\hline
\end{tabular}

Expression Hevels were determined by flow cytometry using fluorophore-labeled monoclonal antibodies, as described (54). Platelets were gated by their forward scatter/side scatter characteristics. Results are expressed as mean log fluorescence (arbitrary units) \pm S.D. for 6 mice per group. ${ }^{*} P<0.01$ compared to wildtype. 


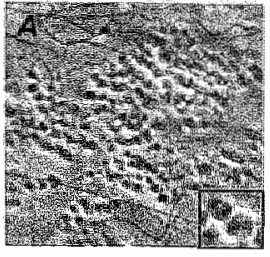

Control

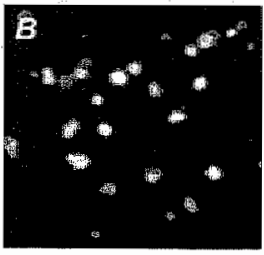

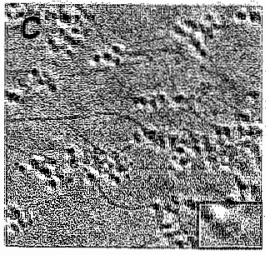

FcR $y+1$ -

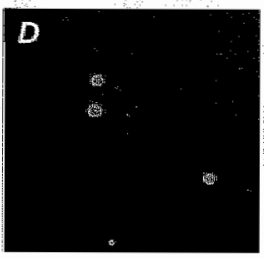

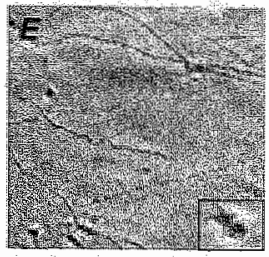

FcR $+/-+$ pop/B

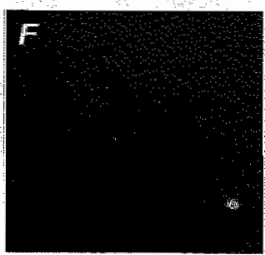

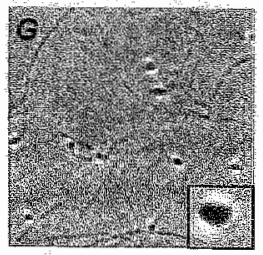

FaR $y$

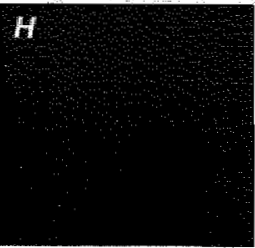

$l$

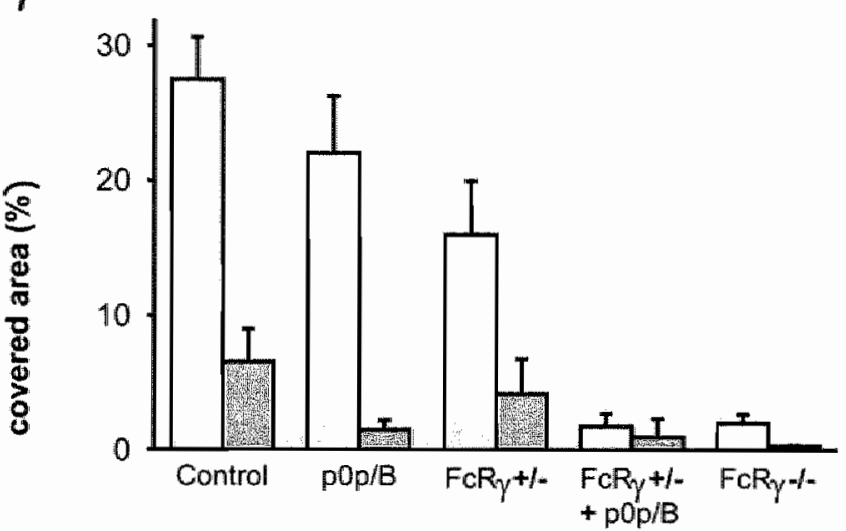

Figure 5.6. Increased role of GPIb in platelet deposition and PS exposure upon reduced expression of GPVI. lood from wildtype, FCR $\gamma$-chain $+/$ and $/$ - mice was perfused over collagen (see Fig. 5.1. Wildtype and FCR $\gamma$-chain $+/$ blood were pre-incubated with $40 \mu \mathrm{g} / \mathrm{ml} \mathrm{pOp} / \mathrm{B}$ Fab as indicated. Upper panels: representative phase-contrast images $(48 \times 48 \mu \mathrm{m})$ after $4 \mathrm{~min}$ perfusion. Inserts are $200 \%$ magnifications showing platelet morphology. Lower panels: fluorescence images $(150 \times 150 \mu \mathrm{m})$ after staining with FiTClabeled annexin A5. (1) Surface area coverage of all platelets (white bars) and PS-exposing platelets (gray bars). Data are mean values \pm S.E.M. $(n=3-5)$.

wildtype (Fig. 5.6I). Strikingly, blockage of GPlb with pop/B fragments in the heterozygous blood nearly completely abolished stable platelet adhesion, while PS-exposing platelets were hardly detectable (Fig. 5.6E-F). In agreement with earlier results $(14,16)$, perfusion of blood from homozygous FCR $y$-chain $/$ - mice under these conditions resulted in diminished platelet adhesion to the collagen. During flow, most FCR $\gamma$-chain $/$ - platelets adhered only transiently to the surface (putatively via GPIb) and then moved on. After $4 \mathrm{~min}$, a limited number of stably adherent platelets was detected (Fig. $5.6 \mathrm{G}-\mathrm{H}$ ), interestingly especially att sites of higher density of collagen fibers. These platelets neither showed morphological signs of activation nor exposed PS, confirming the essential role of GPVI in these platelet responses. 


\section{Discussion}

In this study with mouse blood, we have evaluated the contribution of GPIb and collagen-bound WWF to shear-dependent platelet adhesion and procoagulant activity during thrombus formation. The results extend earlier work, demonstrating that GPVI has a conditional role in platelet-collagen interaction and subsequent activation both ex vivo $(14,16)$ and in denuded artery in vivo (40). In the present study we find that, at high shear rates up to $1500 \mathrm{~s}^{-1}$ (mimicking those at the arterial wall), GPIb interaction with WWF deposited on collagen enhances irreversible platelet binding and GPVI-induced PS exposure, along with stimulation of

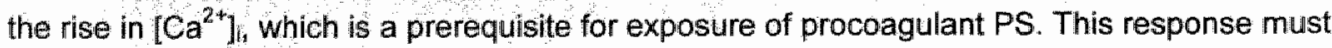
be regulated separately from platelet aggregate formation, as the PS exposing cells are usually not found in aggregates. Importantly, at reduced levels of GPVI we find that the procoagulant response is highly dependent on GPIb. Inhibitor studies indicate that allb $\beta 3$, which also binds to VWF, has an overlapping role with GPlb, underlining the important adhesive function of this integrin, which is mostly considered subordinate to its function in platelet aggregation. As exposed PS potently enhances thrombin generation, in platelet-collagen interaction either of the two adhesive glycoproteins appears to potentiate the two haemostatic processes contributing to thrombus formation: aggregate formation and coagulant activity.

Human and murine WWF and GPIb-V-IX play an initial role in tethering and adhesion to collagen under high shear flow conditions, and thereby mediate platelet aggregate formation on collagen $(8,36,41)$. In addition, both WWF and the GPIb-V-IX complex are involved in thrombin generation and coagulation, perhaps because of the binding to multiple coagulation proteins, including factor VIII, factor $X I$, thrombin and fibrin $(26,27,42,43)$. Here, we report on a procoagulant effect of VWF and GPIb, i.e. PS exposure, linked to collagen receptor stimulation, which is independent of the formation of thrombin. Whether WWF and GPIb may also contribute to platelet PS exposure in coagulating plasma is still unknown. However, recent data indicate that GPIb can stimulate thrombin formation (in the absence of collagen) in a shear-dependent way (27). It is thus conceivable that the function of GPIb in thrombin formation also involves a shear-dependent stimulation of PS exposure, similarly as we report here for platelet-collagen interaction.

The data with anti-GPIb pOp/B Fab fragment or saratin (which prevents vWF binding to collagen) show that platelets can still bind to collagen in the absence of WWF-GPIb interaction up to a shear rate of $1500 \mathrm{~s}^{-1}$. Others have described that GPIb, in the absence of WWF, is still free to bind thrombospondin, which also mediates platelet adhesion under flow (44). Thus, GPIb can still have a role at intermediate shear rates independently of collagen-bound WWF. However, we find that residual, VWF-independent adhesion is mostly due to GPVI or integrin $\alpha 2 \beta 1$, as it is abolished in the absence of functional collagen receptors $(M$. Kuijpers, unpublished results, 2003). On the other hand "pop/B or saratin treatment did lead to a 
decreased deposition of platelets (Fig. 1), and in a reduced or delayed $\mathrm{Ca}^{2 \cdot+}$ response and PS exposure (Fig. 5.4). This could indicate that the GPIb-dependent spiking elevations in [Ca ${ }^{2+}$ ] reported in platelets binding to immobilized WWF $(5,45,46)$ also contribute to the $\mathrm{Ca}^{2+}$ signal in the presence of collagen. We have earlier shown that collagen-induced $\mathrm{Ca}^{2+}$ signaling in murine platelets is almost completely dependent on the presence of the GPVIFCR $\gamma$-chain complex, with minute spiking $\left[\mathrm{Ca}^{2 *}\right]$ increases remaining in $\mathrm{FCR}_{\gamma} /$ platelets $(16)$, which might be the result of WWF-GPIb interaction. Accordingly, GPVI must be responsible for the majority of the $\mathrm{Ca}^{2+}$ signal, while GPIb has only a small contribution. Taken together, this points to an enhancement of GPVI signaling by GPIb/WWF, by direct signaling and/or allowing full engagement of the GPVI receptors.

The Fab fragment JON/A bllocks binding of the allbB3 to fibrinogen and WWF (39), and thus provides a unique tool to study the role of this integrin in adhesion and aggregation. Incubation with JON/A resulted in stronger inhibition of platelet deposition and PS exposure than inhibition of ADP function by receptor antagonists. This confirms the concept that $\alpha$ llb $\beta 3$ is involved in stable adhesion to this surface (35). Furthermore, combined blockage of GPIb and integrin $\alpha$ llb $\beta 3$ did not further reduce platelet activation in comparison to $\alpha / l b \beta 3$ inhibition alone. This places the function of integrin $\alpha \mathrm{lb} \beta 3$ downstream of GPIb, which is in good agreement with the current model of WWF-platelet interaction. This model presumes initial shear-dependent tethering via GPIb-V-IX, subsequent stable adhesion and enhanced signaling via activated integrin $\alpha$ llb $\beta 3(5,35)$. This is also in line with in vivo findings with mice that platelet adhesion to the vessel wall involves multiple integrin-ligand interactions, none of which are essential by themselves (39), and that $\beta 3$-deficiency results in defective stable platelet adhesion to the vessel wall (47).

For mice with reduced levels of GPVI/FCR $\gamma$-chain it is demonstrated that, under static conditions, neither platelet adhesion to immobilized collagen nor protein tyrosine phosphorylation induced by collagen is affected compared to wildtype (29). Here we show" with mice expressing half of the normal GPVI/FCR $y$-chain levels, that under flow conditions both platelet adhesion on collagen and platelet activation - as apparent from PS exposure - are reduced by about $50 \%$. This indicates that the level of GPVI expression determines (and is a limiting factor for) signaling under shear. This conclusion is in agreement with the findings that collagen-induced $\mathrm{Ca}^{2+}$ responses of murine platelets are dependent on the GPVI expression level (48). Similarly, in human, partial blockage of GPVI has been shown to suppress aggregate formation and PS exposure under flow (19). Thus, the regulatory function of this collagen receptor in platelet activation and procoagulant activity appears to be conserved between species..

Interestingly, in FCR $\gamma$-chain heterozygous mice, expressing normal GPIb and $\alpha$ llb $\beta 3$ levels on platelets, the blockage of GPIb caused almost complete abolition of stable platelet 
adhesion and PS exposure under shear (Fig. 6). This indicates that GPlb plays a more prominent role in platelet-collagen interaction at reduced levels of GPVIFCR $y$-chain. Apparently, there is some redundancy in GPIb and GPVI receptor function. It is likely to be of physiological relevance, given the large variation in GPVI expression between humans (48-50). As also $\alpha 2 \beta 1$ stimulates GPVI activity, the present results point to receptor interplay in the regulation of platelet procoagulant activity that is not restricted to collagen receptors, but extends to the GPIb-V-IX complex.

Earlier it has been proposed that the FCR $\gamma$-chain mediates GPlb-induced platelet activation $(51,52)$. However, our data do not support this concept, as we find that partial knockout of the $\gamma$-chain enhances the GPlb functioning. On the other hand, our findings are fully in line with those of Mangin et al. (2003), who propose that in mice GPib signaling to $\mathrm{Ca}^{2+}$ flux and filopod extension relies on Src kinases via a pathway distinct from FCR $y$-chain derived signaling.

Perfusion of blood from homazygous FcR $y$-chain deficient mice resulted in only few adhering platelets, especially at sites where the collagen density was relatively high (Fig. 6). This is in apparent contrast to recent findings with GPVI knockout mice, where full adhesion to collagen was detected under flow conditions (53). The difference with the present data is likely explained by differences in methodology (collagen surface, anticoagulant, mepacrine labeling. etc.). Preliminary data in our laboratory indicate that the few GPVI/FcR $\gamma-/$ - platelets adhere in a GPIb/a2/1-dependent way (unpublished results). This is similar to the situation with human platelets, where it also has been shown that $\alpha 2 \beta 1$ is adhesive in the absence of GPVI signaling (19).

In summary, the current data, together with the earlier established role of integrin $\alpha 2 \beta 1$ $(10,14,16)$, confirm that murine GPVI is the primary trigger of activation in platelet-collagen interaction under shear. In addition it is shown that GPVII is facilitated by GPIb-V-IX in addition to integrins $\alpha 2 \beta 1$ and $\alpha \mathrm{llb} \beta 3$. Platelet adhesion and subsequent activation evolves as a series of multimreceptor events with redundancy, facilitation and mutual interactions, rather than as a linear process. Specificaliy, concerning the procoagulant platelet reaction, both GP\|b and $\alpha / \mathrm{lb} \beta 3$ appear to control PS exposure under these shear conditions, likely by enhancing GPVIdependent activation. The finding that these adhesive receptors in concert with GPV! have a procoagulant role in collagen-dependent thrombus formation indicates that interplay does not only accur between the collagen receptors, but also extends to the GPIb-V-IX complex. 


\section{References}

1. Novak $L$, Deckmyn $H$, Damjanovich $S$, Harsfalvi J. Shear-dependent morphology of von Willebrand factor bound to immobilized collagen. Blood. 2002,99:2070-2076.

2. Huizinga EG. Tsuji $S$, Romijn RAP, Schiphorst ME, de Groot PG, Sixma JJ, Gros P. Structures of glycoprotein $\mid \mathrm{b} \alpha$ and its complex with von Willebrand factor A1 domain. Science. 2002;297:1176-1179.

3. Savage $B$, Saldivar $E$, Ruggeri ZM. Initiation of platelet adhesion by arrest onto fibrinogen or translocation on von Willebrand factor. Cell. 1996;84:289-297.

4. Arya M, Lopez JA, Romo GM, Cruz MA, Kasiner-Friede A, Shattil SJ, Anvari B. Glycoprotein Ib-IXmediated activation of integrin allbß3: effects of receptor clustering and von Willebrand factor adhesion. J Thromb Haemost. 2003;1:1150-1157.

5. Nesbitt WS, Kulkarni $S$, Giuliano S, Goncalves I, Dopheide SM, Yap CL, Harper IS, Salem HH Jackson SP. Distinct glycoprotein $\mathrm{Ib} / \mathrm{N} / \mathrm{X}$ and integrin olllb $\beta 3$-dependent calcium signalls cooperatively regulate platelet adhesion under flow. J Biol Chem. 2002;277:2965-2972.

6. Jung $S M$, Moroi M. Platelet collagen receptor integrin $\alpha 2 \beta 1$ activation involves differential participation of ADP-receptor subtypes $P 2 Y_{1}$ and $P 2 Y_{12}$ but not intracellular calcium change. Eur $\mathrm{J}$ Biochem. 2001;:268:3513-35:22.

7. Shattil SJ, Ginsberg MH. Integrin signaling in vascular biology. J Clin Invest. 1997; 100:1-5.

8. Savage $B$, Sixma JJ, Ruggeri ZM. Functional self-association of von Willebrand factor during platelet adhesion under flow. Proc Natl Acad Sci USA. 2002;99:425-430.

9. Jung $S M$, Moroil $M$. Activation of the platelet collagen receptor integrin $\alpha 2 \beta 1$. Trends Cardiovasc Med. 2000;10:285-292.

10. Nieswandt B, Watson SP. Platelet collagen interaction: is GPVI the central receptor? Blood... 2003;102:449-461.

11. Gibbins JM, Okuma $M$, Farndale $R$, Barnes $M$, Watson SP. Glycoprotein $V I$ is the collagen receptor in platelets which underlies tyrosine phosphorylation of the $\mathrm{Fc}$ receptor r-chain. FEBS Lett. 1997;413:255-259.

12. Tsuji M, Ezumi $Y$, Arai M, Takayama $H$. A novel association of Fc receptor $\gamma$-chain with glycoprotein $V \|$ and their co-expression as a collagen receptor in human platelets. J Biol Chem. 1997;272;23528-23531.

13. Watson SP, Asazuma $N$, Atkinson $B$, Berlanga $O$, Best $D$, Bobe $R$, Jarvis $G$, Marshall $S$, Snell $D_{n}$ Stafford $M$, Tulasne $D$, Wilde $J$, Wonerow $P$, Frampton $J$. The role of $\| T A M-$ and $\|T\| M$-coupled receptors in platelet activation by collagen. Thromb Haemost. $2001 ; 86: 276-288$.

14. Nieswandt $B$, Brakebusch $C$, Bergmeier $W$, Schulte $V$, Bouvard $D$, Mokhtari-Nejad $R_{\text {, Lindhout }}{ }_{\text {, }}$ Heemskerk JWM, Zirngibl $H$, Fässler R. Glycoprotein V/ but not $\alpha 1 \beta 2$ integrin is essential for platelelt interaction with collagen. EMBO J. 2001;20:2120-2130.

15. Nieswandt $B$, Schulte $V$, Bergmeier $W$, Mokhtari-Nejad R, Rackebrandt $K$, Cazenave JP, Ohlmann $P$, Gachet $C$, Zirngibl H. Long-term antithrambotic protection by in vivo depletion of platelet glycoprotein $V /$ in mice. J Exp Med. 2001;193:459-469.

16. Kuijpers $M J_{\text {, Schulte }} V$, Bergmeier $W$, Lindhout $T$, Brakebusch $C$, Offermanns $S$, Fässler $R_{*}$ Heemskerk JWM, Nieswandt B. Complementary roles of glycoprotein $V_{1}$ and $\alpha_{+} \beta_{2}$ integrin in callageninduced thrombus formation in flowing whole blood ex vivo. FASEB J. 2003;17:685-687.

17. Atkinson BT, Jarvis GE, Watson SP. Activation of GPVI by collagen is regulated by a $1 \beta 2$ and secondary mediators. J Thromb Haemost. 2003;1:1278-1287.

18. Chen $\mathrm{H}$, Kahn ML. Reciprocal signaling by integrin and nonintegrin receptors during collagen activation of platelets. Mol Cell Biol. 2003;23:4764-4777.

19. Siljander PR, Munnix IC, Smethurst PA, Deckmyn $H$, Lindhout $T$, Ouwehand WH, Farndale RW, Heemskerk. $J W$. Platelet receptor interplay regulates collagen-induced thrombus formation in flowing human blood. Blood. 2004;203:1333-1341.

20. Inoue $O$, Suzuki-Inoue $K$, Deaan $W L$, Frampton J, Watson SP. Integrin $\alpha 2 \beta 1$ mediates outside in regulation of platelet spreading on collagen through activation of Src kinases and PLCY2. J Cell Biol. 2003"160:769-780.

21. Heemskerk JWM, Vuist WMJ, Feijge MAH, Reutelingsperger CPM, Lindhout $T$. Collagen but not fibrinogen surfaces induce bleb formation, exposure of phosphatidylserine, and procoagulant activity of adherent platelets. Blood. 1997;90:2615-2625.

22. Siljander P, Farndale RW, Feijge MAH, Comfurius $P$, Kos S, Bevers EM, Heemskerk JWM. Platelet adhesion enhances the glycoprotein Vl-dependent procoagulant response: Involvement of p38 MAP kinase and calpain. Arterioscler Thromb Vasc Biol. 2001;21:618-627.

23. Bevers EM, Comfurius $P$, van Rijn لJLML, Hemker HC, Zwaal RFA. Generation of prothrombinconverting activity and the exposure of phosphatidylserine at the outer surface of platellets. Eur d Biochem. 1982;122:429-436 
24. Béguin $S$, Kumar $R$. Thrombin, fibrin and platelets, a resonance loop in which von Willebrand factor is a necessary link. Thromb Haemost. 1997;78:590-594.

25. Heemskerk JWM, Bevers EM, Lindhout T. Platelet activation and blood coagulation. Thromb Haemost: 2002;88:186-193.

26. Beguin $S$, Kumar $R$, Keularts I, Seligsohn $U$, Coller BS, Hemker HC. Fibrin-dependent platelet procoagulant activity requires GPIb receptors and von Willebrand factor. Blood. 1999;93:564-570.

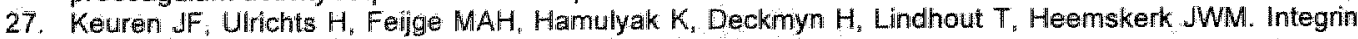
allbB3 and shear-dependent action of glycoprotein lba stimulate platelet-dependent thrombin formation in stirred plasma. $\mathrm{J}$ Lab Clin Med. 2003:141:350-358.

28. Takai T, Li M Syivestre D, Clynes $R_{i}$, Ravetch JV. FcRy chain deletion results in pleiotrophic effector cell defects. Cell. 1994;76:519-529.

29. Snell DC, Schulte V, Jarvis GE, Arase K, Sakurai D, Saito T, Watson SP. Nieswandt B. Differential effects of reduced glycoprotein VI levels on activation of murine platelets by glycoprotein VI ligands. Biochem J. 2002;368:293-300.

30. Bergmeier $W$, Rackebrandt $K$, Schroder $W$, Zirngibl $H$, Nieswandt $B$. Structural and functional characterization of the mouse von Willebrand factor receptor GPIb-lX with novel monoclonall antibodies. Blood. 2000;95:886-893.

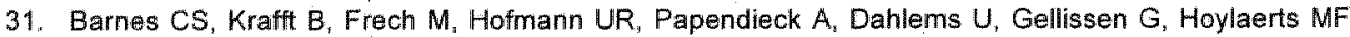
Production and characterization of saratin adhesion to collagen. Semin Thromb Hemost. 2001;27:337-348.

32. Heemskerk JWM, Siljander $P$, Vuist WMJ, Breikers $G$, Reutelingsperger $C P M$, Barnes $M J$, Knight $C G$, Lassila R, Farndale RW. Function of glycoprotein $\mathrm{Vl}$ and integrin $\alpha 2 \beta 31$ in the procoagulant response of single, collagen-adherent platelets. Thromb Haemost. 1999:81: 78-92.

33. Heemskerk JWM, Feijge MAH, Sage SO, Walter U. Indirect regulation of $\mathrm{Ca}^{2+}$ entry by cAMPdependent and CGMP-dependent protein kinases and phospholipase $\mathrm{C}$ in rat platelets. Eur $\mathrm{J}$ Biochem. $1994: 223: 543-551$.

34. Heernskerk JWM, Willems GM, Rook MB, Sage SO. Ragged spiking of free calcium in ADP-stimullated human platelets: regulation of puff-like calcium signals in vitro and ex vivo. J Physiol. 2001;535:625-635.

35. Savage B, Almus-Jacobs F, Ruggeri ZM. Specific synergy of multiple substrate-receptor interactions in platelet thrombus formation under flow. Cell. 1998;94:657-666.

36. Wu YP, Vink T, Schiphorst M, van Zanten GH, MJ I, de Groot PG, Sixma JJ. Platelet thrombus formation on collagen at high shear rates is mediated by von Willebrand factor-glycoprotein lb interaction and inhibited by won Willebrand factor-glycoprotein Ilb/lla interaction. Arterioscler Thromb Vasc Biol. 2000;20:1661-1667.

37. Patel D. Vaananen $H$, Jirouskova M, Hoffmann T. Badian $C$, Coller BS. Dynamics of GPIlb/llamediated platelet-platelet interactions in platelet adhesion/thrombus formation on collagen in vitro as revealed by videomicroscopy. Blood. 2003;101:929-936.

38. Bergmeier $W$, Schulte $V$, Brockhoff $G$, Bier $U$, Zirngibl $H$, Nieswandt B. Flow cytometric detection off

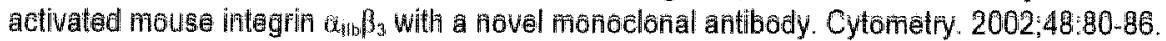

39. Gruner $S$, Prostredna $M$, Schulte $V$, Krieg T, Eckes $B$, Brakebusch $C$, Nieswandt $B$. Multiple integrinligand interactions synergize in shear-resistant platelet adhesion at sites of arterial injury in vivo. Blood. 2003:102:4021-4027.

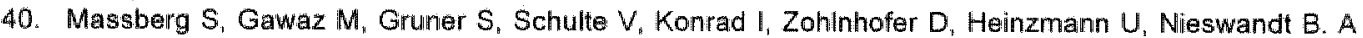
crucial role of glycoprotein $\mathrm{W} /$ for platelet recruitment to the injured arterial wall in wivo. J Exp Med. 2003;197:41-49.

41. Goto $S$. Tamura $N$, Handa $S$, Arai $M$, Kodama $K_{n}$ Takayama $H$. Involvement of glycoprotein $V / l$ in platelet thrombus formation on both collagen and von Willebrand factor surfaces under flow conditions. Circulation. 2002;106:266-272.

42. Baird TR, Walsh PN. The interaction of factor Xla with activated platelets but not endathellal cells promotes the activation of factor $\| X$ in the consolidation phase of blood coagulation. $J$ Biol Chem. $2002 ; 277: 38462-38467$.

43. Andrews RK, Gardineir EE, Shen $Y$, Whisstock JC, Berndt MC. Glycoprotein Ib-IX-V. Int J Biochem Cell Biol. 2003;3:1170-1174.

44. Jurk K, Clemetson KJ, de Groot PG, Brodde MF, Steiner M, Savion N, Varon D, Sixma Jل, van Aken $\mathrm{H}$, Kehrel BE. Thrombospondin-1 mediates platelet adhesion at high shear via glycoprotein $\mathrm{lb}(\mathrm{GPI})$ : an alternative/backup mechanism to won Willebrand factor. FASEB J. 2003;17:1490-1492.

45. Mazzucato M. Pradella P, Cozzi MR, De Marco L. Ruggeri ZM. Sequential cytoplasmic calcium signals in a 2-stage platelet activation process induced by the glycoprotein lba mechanoreceptor. Blood. 2002, 100:2793-2800. 
46. Mangin $P$, Yuan $Y$, Goncalves I. Eckly $A_{1}$ Freund $M$, Cazenave JP, Gachet $C$, Jackson SP. Lanza F Signaling role for phospholipase $\mathrm{C}_{2} 2$ in platelet glycoprotein $\mathrm{lba}$ calcium flux and cytoskeletal reorglanization. J Biol Chem. 2003;278:32880-3:2891.

47. Wagner DD, Burger PC. Platelets in inflammation and thrombosis Arterioscler Thromb Vasc Biol. $2003 ; 23: 2131-2137$

48. Chen $H$, Locke D, Liu $Y$, Liu $C$, Kahn ML. The platelet receptor GPVI mediates both adhesion and signaling responses to collagen in a receptor density-diependent fashion. J Biol Chem. 2002;277:30113019.

49. Best D, Senis YA, Jarvis GE, Eagleton HJ, Roberts DJ, Saito T, Jung SM, Moroi M, Harrison P, Green FR, Watson SP. GPVI levels in platelets: relationship to platelet function at high shear. Blood. 2003;102:2811-2818.

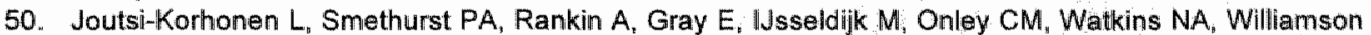
$L M$, Goodall $A H_{r}$ de Groot PG, Farndale RW, Ouwehand WH. The low-frequency allele of the platelet collagen signaling receptor glycoprotein $\mathrm{V}$ is associated with reduced functionall responses and expression. Blood. 2003;101:4372-4379.

51. Falati $S$, Edmead CE, Poole AW. Glycoprotein Ib-V-1X, a receptor for von Willebrand factor, couples physically and functionally to the $\mathrm{Fc}$ receptor $\gamma$-chain, fym, and lyn to activate human platelets. Blood. $1999 ; 94: 1648-1656$.

52. Canobbio I. Bertoni $A$, Lova $P$, Paganini $S$, Hirsch $\mathbb{E}$, Sinigaglia $F$, Balduini $C$, Torti $M$. Platelet activation by von Willebrand factor requires coordinated signaling through thromboxane $A_{2}$ and FoyllA receptor. J Biol Chem. 2001:276:26022-26029.

53. Kato $K$, Kanaji $T$, Russell $S$, Kunicki TJ, Furihata $K$, Kanaji $S$, Marchese $P$, Reininger $A$, Ruggeri ZM, Ware J. The contribution of glycoprotein $\mathrm{VI}$ to stable platelet adhesion and thrombus formation illustrated by targeted gene deletion. Bllood. 2003;102:170-1707.

54. Nieswandt $B$, Bergmeier $W$, Schulte $V$, Rackebrandt $K$, Gessner JE, Zirngibl $H$. Expression and function of the mouse collagen receptor glycoprotein $\mathrm{V} /$ is strictly dependent on its association with the FcRy chain. J Biol Chem. 2000;275:23998-234002. 


\section{Chapter 6}

\section{Regulation of tissue factor-induced coagulation}

\section{and platelet aggregation in flowing whole blood}

Marijke J.E. Kuijpers, Cécile M.A. Nieuwenhuys, Marion A.H. Feijge, Willem Kloots, Peter L.A.

Giesen, Johann C. Jerling, Mirjam G.A. oude Egbrink, Johan W.M. Heemskerk

Thrombosis and Haemostasis (2005) 93: 97-105

Reprinted with permission 


\section{Abstract}

Photochemically induced thrombosis (a thrombin-dependent process) was measured in rats treated with moderate doses of anticoagulants, but appeared to be unchanged. We considered the possibility that platelet-inhibiting agents which allso indirectly inhibit coagullation, would act as more potent antithrombotic agents. Inhibitors used as such were prostaglandin $E_{1}$ $\left(P E_{1}\right)$, which elevates cyclic AMP levels, and the P2Y 12 ADP-receptor antagonist, ARC69931MX. Effects of these agents were investigated in an ex vivo model system, in which whole blood under coagulant conditions was perfused over fibrinogen at defined wall shear rate. Perfusion of blood (rat or human) in the presence of tissue factor resulted in deposition of activated platelets and subsequent aggregate formation, along with exposure of procoagulant phosphatidylserine (PS) on the platelet surface and formation of fibrin fibers. In the presence of $P G E_{1}$ aggregation was completely inhibited, but platelet adhesion and PS exposure were onlly party reduced, while fibrin formation was hardly affected. Treatment with AR-C69931MX caused similar, but less complete effects. These results indicate that in tissue factor-triggered blood under conditions of flow: (i) the platelet procoagulant response is independent of aggregate formation; (ii) the platelet-inhibiting effect of PGE 1 and AR-C69931MX is sufficient to suppress aggregation, but not platelet adhesion and coagulation. These platelet inhibitors thus maintain their aggregation-inhibiting effect at sites of thrombin formation.

\section{Introduction}

Hemostasis involves formation of a vaso-occlusive platelet plug and coagulation of blood plasma. Although usually studied separately, it is known that platelet activation and the formation of thrombin in the coagulation cascade are mutually dependent processes. The extrinsic coagulation pathway is initiated by tissue factor (TF), either blood-borne or exposed at the surface of a damaged vessel wall (1). Thrombin, once formed from prothrombin, has multiple ampilfying effects. It facilitates its own generation by activating the coagulation factors V, VIII, and XI. Thrombin converts fibrinogen into fibrin and, furthermore, stimulates platelets to change shape and assemble into aggregates and fibrin-containing thrombi.

Platelets, in turn, support and maintain the coagulation process in different ways. They bind coagulation factors like prothrombin and factor $X 1(2,3)$, and they secrete coagulation factors when stimulated by agonists that induce rises in cytosolic $\left[\mathrm{Ca}^{2+}\right]_{i}$. Activated platelets also expose procoagulant phosphatidylserine (PS) at their outer membrane surface $(4,5)$, which serves as a site for the assembly and activation of tenase and prothrombinase complexes, forming factor $\mathrm{Xa}$ and thrombin, respectively (6-8). Exposed $P S$ thereby is the main binding site on platelets for the $y$-carboxyglutamate-containing enzymes, factor IXa and factor Xa $(8,9)$. The significance of PS exposure becomes apparent in patients suffering from the Scott syndrome, a 
rare bleeding disorder in which platelets are partly deficient in PS exposure upon activation $(10,11)$.

Platelet-rich plasma (PRP) triggered with TF enters a potent reinforcement loop of thrombin generation, fibrin formation and platelet activation (12,13). In such a plasma system, platelet-dependent thrombin generation can be suppressed by antibodies against the platelletadhesive receptors, integrin allbB3 (fibrinogen receptor) and glycoprotein Ib/lXN (von Willebrand factor receptor) $(14,15)$. Simillarly, thrombin generation is reduced in the PRP from patients with Glanzmann"s thrombasthenia (deficient in allb $\beta 3$ ) or von Willebrand disease (deficient in von Willebrand factor) $(12,15)$. Together, this suggests that the mutual interaction of platelets and coagulation is of physiological importance in hemostasis, and that these glycoproteins herein play an important role.

A number of platelet inhibitors can also suppress thrombin generation and coagulation in platelet-containing plasma. Particularly active in this respect are cyclic AMP elevating agonists, such as prostaglandin $E_{1}\left(P G E_{1}\right)$, and $P 2 Y_{12}$ receptors antagonists like AR-C69931MX $(12,16,17)$. The latter receptor comprises the pharmacological target of clopidogrel and ticlopidine, and contributes to ADP-mediated platelet aggregation (18-22). As these compounds also downregulate integrin $\alpha / \| b \beta 3$ activation and platelet aggregation, it is possible that their effects on thrombin generation are via regulation of integrin activation.

The rat is a widely used laboratory animal to study thrombosis in vivo. Photochemical injury of the rat femoral artery is an established model for thrombosis with limitedly invasive effect, which relies on endothelial damage and subsequent initiation of coagulation and platelet activation $(23,24)$. In earlier in vitro studies with platelet-containing plasma, we have established that, also in rat, thrombin generation triggered by the TF pathway relies on the activation of platelets and the coagulation system $(25,26)$. If this interaction of platelets and coagulation is of (patho)physiological relevance, it is expected that thrombin inhibitors would be effective in such a thrambasis model.

In the present paper we studied the effect of thrombin inhibition on photochemically induced thrombosis tendency in this animal model. To this end, rats were subjected to moderate treatment with heparin or warfarin. The inability of these anticoagulants to influence the thrombotic process prompted us to investigate the effects of the anti-platelet agents, PGE, and AR-C69931MX, which indirectly affect coagulation via their platelet-inhibiting activity. To mimic physiological conditions, we studied the effects of these agents in whole blood triggered with tissue factor on the formation of platelet-fibrin thrombi under conditions of flow and coagulation. 


\section{Methods}

\section{Materials}

H-Phe-Pro-Arg chloromethyl ketone (PPACK) was from Calbiochem (La Jolla, CA, USA). Bovine fibrinogen, bowine serum albumin (BSA), MRS 2179, $\mathrm{PGE}_{\|}$, rat thrombin, rose bengal and unfractionated heparin and were from Sigma (St. Louis, MO, USA). Recombinant human TF was from Dade (Dudingen, Switzerland); Oregon green 488 (OG488)-labeled and unlabeled annexin A5 (annexin V) from Nexins Research (Hoeven, The Netherlands); benzyloxycarbonyl Gly-Gly-Arg 7-amido-4-methyl-coumarin (Z-GGR-AMC) and Gly-Pro-Arg-Pro (GPRP) from Bachem (Bubendorf, Switzerland); Fluo-3 acetoxymethyl ester and human OG488-fibrinogen from Molecular Probes (Leiden. The Netherlands). Collagen ('Horm' type I) was from Nycomed (Munich, Germany). Warfarin (coumarin) was bought from Dupont Merck and heparin (enoxaparin) from Rhone-Poulenc Rorer. FITC-labeled monoclonal antibody PAC1, against the activated human allbB3 was obtained from Becton and Dickinson. AR-C69931MX was kindly provided by AstraZeneca R\&D (Charnwood, UK), Other materials were from sources described before (25).

\section{Animals}

Forty eight male Wistar rats (Charles River, Sulzfeld, Germany) were used for the intervention study. Of these, 24 rats were subjected to photochemically induced thrombosis; 24 other rats were used for ex vivo measurements. In each cohort, 3 groups of 8 rats (selected at random) were formed. The animals were subjected to one of the following interventions: none (control group), heparin (2 mg/kg enoxaparin, subcutaneous injection at 49,25 and $1 \mathrm{~h}$ before experiment), or warfarin $(0.3 \mathrm{mg} / \mathrm{kg}$, intravenous injection at $24 \mathrm{~h}$ before experiment). Subsequent experiments were carried out with blood from adult Wistar rats. The animals were anesthetized by intra-peritoneal injection with Nembutall ( $50 \mathrm{mg} / \mathrm{kg}$ body weight) and subjected to abdominal aortic puncture. Animals were sacrificed after blood collection $(10-12 \mathrm{ml})$. The studies were approved by the institutional animal care committees (Unilever Research Vlaardingen and University of Maastricht).

\section{In wivo thrombus formation}

Rats were subjected to a standard protocol for measurement of photochemically induced thrombosis (27). Briefly, the rats were anaesthetized with ketamine and domitor (intramuscular, 40 and $500 \mathrm{mg} / \mathrm{kg}$ body weight, respectively), and fixed on a heating pad at $36^{\circ} \mathrm{C}$. The femoral artery and vein were separated from surrounding tissue, and a catheter was inserted through the jugular vein. An ultrasound flow probe was placed against the femorall 
artery" to measure blood flow. Green light $(540 \mathrm{~nm}$ ) from a xenon lamp was led through an optical fiber positioned at $5 \mathrm{~mm}$ from a part of the femoral artery proximal to the flow probe. Light was switched on after stable flow for $3 \mathrm{~min} ; 1 \mathrm{~min}$ later, rose bengal (10 $\mathrm{mg} / \mathrm{kg}$ ) was infused over a period of $1.5 \mathrm{~min}$; at $4 \mathrm{~min}$ after rose bengal infusion the light was switched off. Blood flow was recorded during $30 \mathrm{~min}$. In this model, endothelial injury and thrombosis are caused by free radical formation via a photochemical reaction between rose bengal and green light (23). Thrombus formation was evaluated by measuring the time to vascular occlusion and the area under the curve of blood flow, calculated over $30 \mathrm{~min}$. The latter gives an indication of the overall blood flow response during the whole measurement period (27).

\section{Collection and preparation of rat and human blood}

For most experiments, rat blood was collected into 0.1 vol of $129 \mathrm{mM}$ trisodium citrate. Blood was used as such, or centrifuged to obtain platelet-rich plasma (PRP) and platelet-free plasma (PFP) (26). To prepare Fluo-3-labeled platelets, blood was collected into 0.2 vol of 183 $\mathrm{mM}$ glucose, $80 \mathrm{mM}$ trisodium acetate and $52 \mathrm{mM}$ citric acid. Washed platelets $\left(5 \times 10^{8} / \mathrm{ml}\right)$ were loaded with $5 \mu \mathrm{M}$ Fluo-3 acetoxymethyl ester in the presence of $0.5 \mathrm{~g} / \mathrm{l}$ Pluronic $\mathrm{F}-127$ for 45 min (room temperature). Platelets were suspended at $1 \times 10^{9} / \mathrm{ml}$ in Hepes buffer $\mathrm{pH} 7.45$ (in mM: $\mathrm{NaCl} 136$, glucose 5.6, Hepes 5, $\mathrm{KCl} 2.7, \mathrm{MgCl}_{2} 2, \mathrm{NaH}_{2} \mathrm{PO}_{4}, 0.42$, and $0.1 \% \mathrm{BSA}$ ), and readded to citrate-anticoagulated blood from the same animal to give a fraction of $2 \%$ labeled platellets.

Human blood was collected from healthy volunteers into 0.1 vol of $129 \mathrm{mM}$ trisodium citrate. For some experiments PRP and (defibrinated) PFP were prepared, as described elsewhere (15).

\section{Coagulation factors and platelet aggregation}

In rat PFP, prothrombin time, and activity of fibrinogen, prothrombin, factors $\mathrm{VII}$ and antithrombin were measured as previously described and the anticoagulant effect of heparin in rat plasma was quantified from the anti-thrombin activity (26). Platelet aggregation in citrated whole blood was measured as change in impedance, while stirring at $37^{\circ} \mathrm{C}$ in a Chronolog whole blood aggregometer (Chronolog Corporation. Havertown. PA, USA) (28). Platellet aggregation in recalcified PRP under coagulant conditions was measured by turbidometry with/without $2 \mathrm{mM}$ GPRP in siliconized cuvettes, while stirring at $37^{\circ} \mathrm{C}$. 


\section{Thrombin generation}

Thrombin generation was measured in freshly obtained rat or human PRP using lowaffinity fluorescent substrate, Z-GGR-AMC $(0.42 \mu \mathrm{M})$, following the procedure described for human plasma (29). PRP $\left(1,0 \times 10^{8}\right.$ platelets/m, f.c.) was triggered with $0.5-2 \mathrm{pM}$ TF and 16.7 $\mathrm{mM} \mathrm{CaCl}_{2}$ in 96 -well microtitre plates $\left(37^{\circ} \mathrm{C}\right)$. Fluorescence from cleaved amidomethyl coumarin was followed in time, and first-derivative curves were constructed. The curves were converted to nanomolar thrombin by using internal calibrator (26).

\section{Perfusion of whole blood under coagulant conditions}

Rat or human wholle blood was perfused over a glass surface covered with fibrinogen, which is an adhesive protein abundantly present in plasma and involved in platelet-platelet contact. Immobilized fibrinogen, as an excellent starting point for fibrin fiber formation, was used for the detection of initial stages of coagulation. Fibrinogen-coated coverslips were blocked with Hepes buffer $\mathrm{pH} 7.45$ containing $2 \%(w / v)$ BSA (5). The coverslips were mounted in a transparent, parallel-plate flow chamber (9). The chamber (flow-cell volume of $60 \mu l)$ was connected, via siliconized plastic tubes and a three-way adapter, to plastic syringes placed in two pulse-free perfusion pumps (Harvard Apparatus, South Natick, MA, USA). Pump 1 contained a syringe filled with blood (normal perfusion rate of $27 \mathrm{ml} / \mathrm{h}$ ). Pump 2 contained a syringe with $200 \mathrm{mM} \mathrm{CaCl}_{2}, 153 \mathrm{mM} \mathrm{NaCl}$ and $20 \mathrm{pM} \mathrm{TF}$ (perfusion rate $3 \mathrm{ml} / \mathrm{h}^{1}$ ). Together, these pumps produced a flow rate of $30 \mathrm{ml} / \mathrm{h}$, resulting in a wall shear rate at the flow chamber surface of $250 \mathrm{~s}^{-1}$. Other experiments were carried out at $1500 \mathrm{~s}^{-4}$ by increasing the rate of pumping. Experiments were stopped before occlusion of the flow chamber by clotting. Rinsing was at the same flow rate using heparinized Hepes buffer $\mathrm{pH} 7.45$ containing, as indicated, 2 $\mathrm{mM} \mathrm{CaCl}_{2}$ and $0.5 \mu \mathrm{g} / \mathrm{OOG} 488$-annexin $\mathrm{A} 5$.

Phase-contrast and fluorescence images were taken from the perfusion chamber, placed on the stage of an inverted microscope (Nikon Diaphot 200. Tokyo, Japan). Intensified, charge-coupled device cameras were connected to the microscope via a beam splitter (5). Digital images were obtained with a recording system controlled by Quanticell software (Visitech, Sunderland "UK). Excitation and emission wavelengths were $485 \pm 11$ and $530 \pm 15$ nm, respectively.

Changes in Fluo-3 fluorescence from single platelets were converted into pseudo-ratio values and converted into nanomolar concentration of cytosolic $\left[\mathrm{Ca}^{2+}\right]_{\mathrm{i}}$ as described (30). Fluorescence and phase-contrast transmission images (10 microscopic fields per experiment) were analyzed on coverage by platelets or label using Quanticell and ImagePro software, respectively (9). 


\section{Statistics}

Differences between intervention groups and the control group were analyzed with the Dunnet's test (mean square error) taking into account all values obtained. Effects of antagonists were compared to control condition with a Mann-Whitney U-test (SPSS, Chicago, IL, USA). Data are mean values \pm SEM .

\section{Results}

Effect of moderate anticoagulation treatment on in vivo thrombosis tendency in rats

Thrombus formation involves platelet activation and coagulation, which are mutually stimulatory processes, both in human and rat $(13,26)$. To study the importance of this interaction, we used a limitedly invasive thrombosis model in rats, which relies on photochemically induced exposure of tissue factor (TF) and subsequent activation of coagulation and platellets $(23,31)$. In a standardized way, thrombus formation was induced in the femoral artery by infusion of rose bengal and controlled illumination with green light (27). To achieve moderate anticoagulation, the rats were injected at $1-2$ days before the experiment with intermediate doses of heparin (enoxaparin, a low molecular-weight heparin increasing the activity of antithrombin) or warfarin (inhibiting the synthesis of vitamin K-dependent prothrombin, factors VII, $I X$ and $X$ and proteins $C$ and S). As shown in Table 6.1, intervention with heparin or

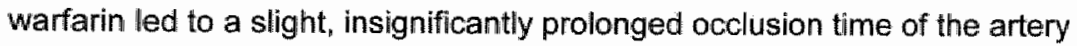

The efficacy of the treatments was verified using blood samples from rats that were similarly treated, but not used for thrombosis induction. Thrombin generation was measured in citrated PRP, triggered with $\mathrm{TF} / \mathrm{CaCl}_{2}$, using the thrombogram method. The endogenous thrombin potential (ETP, area-under-the-curve) was substantially decreased by heparin and warfarin treatment with $87 \%$ and $52.5 \%$, respectively (Table 6.1 ). Platelet aggregation, measured in anticoagulated whole blood was not significantly changed. After heparin treatment, levels of coagulation factors in plasma were unaltered, whereas increased antithrombin activity was detected. After warfarin treatment, levels of the vitamin $\mathrm{K}$-dependent coagulation factors prothrombin and factor VII were reduced by 40-60\%. This was accompanied by a prolonged prothrombin time, indicative of delayed coagulation. Taken together, these moderate anticoagulant treatments led to a marked suppression in thrombin generation which, apparently, was not sufficient to significantly reduce the in vivo thrombosis tendency.

Earlier studies with human PRP showed that the platelet-inhibiting agents, PGE, (which elevates cyclic AMP) and AR-C69931MX (which specifically blocks P2Y 12 receptors for ADP), caused a substantial decrease in thrombin generation $(12,16)$, which was similar in size as detected in the rats subjected to the anticoagulant interventions. This raised the question of 
Table 6.1 Effect of heparin or warfarin intervention on thrombosis tendency and hemostatic parameters in rat. Control

Heparin

Wartarin

Thrombosis tendency

- time to occlusian (min)

$17.4 \pm 3.6$

$19.7 \pm 3.5$

$21.5 \pm 3.1$

- area under flow curve (AU")

$1160 \pm 241$

$1293 \pm 1.28$

$1361 \pm 213$

Thrombin generation in PRP

- time to peak (min)

$8.63 \pm 0.25$

$22.4 \pm 0.78^{* *}$

$10.2 \pm 0.65$

- peak height (AU)

$36.6 \pm 1.3$

$3.62 \pm 1.4^{\text {int }}$

$18.3 \pm 4.2^{* *}$

- $\operatorname{ETP}(A U \times \min )$

$186 \pm 8.3$

$23.6 \pm 8.9^{* *}$

$88.4 \pm 23^{\star \star}$

Whole blood aggregation (\% aggregation/min)

Prothrombin time (\% of pool)

Fibrinogen (g/ll)

Prothrombin ( $\%$ of pool)

Factor VII (\% of pool)

Antithrombin ( $\%$ of pool)

Thrombin inhibiting activity (/mol/s)
$39.7 \pm 4.2$

$99.1 \pm 1.7$

$2.19 \pm 0.04$

$96.9 \pm 2.1$

$95.6 \pm 5.5$

$107 \pm 2.5$

n.d.
$3 \pi .4 \pm 4.8$

$98.6 \pm 2.1$

$2.27 \pm 0.06$

$91.4 \pm 2.0$

$85.5 \pm 3.2$

$106 \pm 2.8$

$53009 \pm 3000$
$31.1 \pm 7.5$

$75.4 \pm 8.6^{*}$

$2.27 \pm 0.07$

$54.5 \pm 7.6^{\star \star}$

$36.6 \pm 9.6^{\text {*did }}$

$105 \pm 3.1$

n.d.

Animals were untreated (control) or subjected to intervention with heparin (2 mg/ $/ \mathrm{kg}$ enoxaparin, injection at 49,25 and $1 \mathrm{~h}$ before measurement) or warfarin $(0.3 \mathrm{mg} / \mathrm{kg}$, injection at $24 \mathrm{~h}$ before measurement). Thrombosis tendency was measured in the femoral antery following rose bengall injection and photochemical induction. Other rats were subjected to the same interventions, and blood was taken on citrate to determine: thrombin generation in PRP (triggered with $16.7 \mathrm{mM} \mathrm{CaCl} z$ and $1 \mathrm{pM} \mathrm{TF}$ ), giving time to thrombin peak, thrombin peak theilght and endogenous thrombin potential (ETP); whole blood aggregation (1 $\mu \mathrm{g} / \mathrm{ml}$ collagen): prothrombin time; individual coagulation factors (data as percentages of rat pool plasma). Mean \pm SEM $(n=8) ;{ }^{*} p<0.01$ and *** $p<0.001$ compared to control. "AU, arbitrary units: $n . d$., not determined.

possible advantages of such agents, which combine antiplatelet with indirect anticoagulant activity in comparison to moderate anticoagulant treatment. We investigated this under a variety of physiologically relevant conditions.

In vitro effects of platelet inhibitors on thrombin generation and aggregation in rat plasma

First we determined the effects of PGE and AR-C69931MX in coagulating rat PRP in the absence of flow. In recalcified PRP, addition of TF ( 2 pM) greatly accelerated the generation of thrombin (Fig. 6.1A). We verified that this thrombin generation was almost completely abclished by preincubation with a saturating dose of heparin (reducing the ETP by $>95 \%$ ). Furthermore, thrombin generation fully relied on activated platelets " because it was abolished 


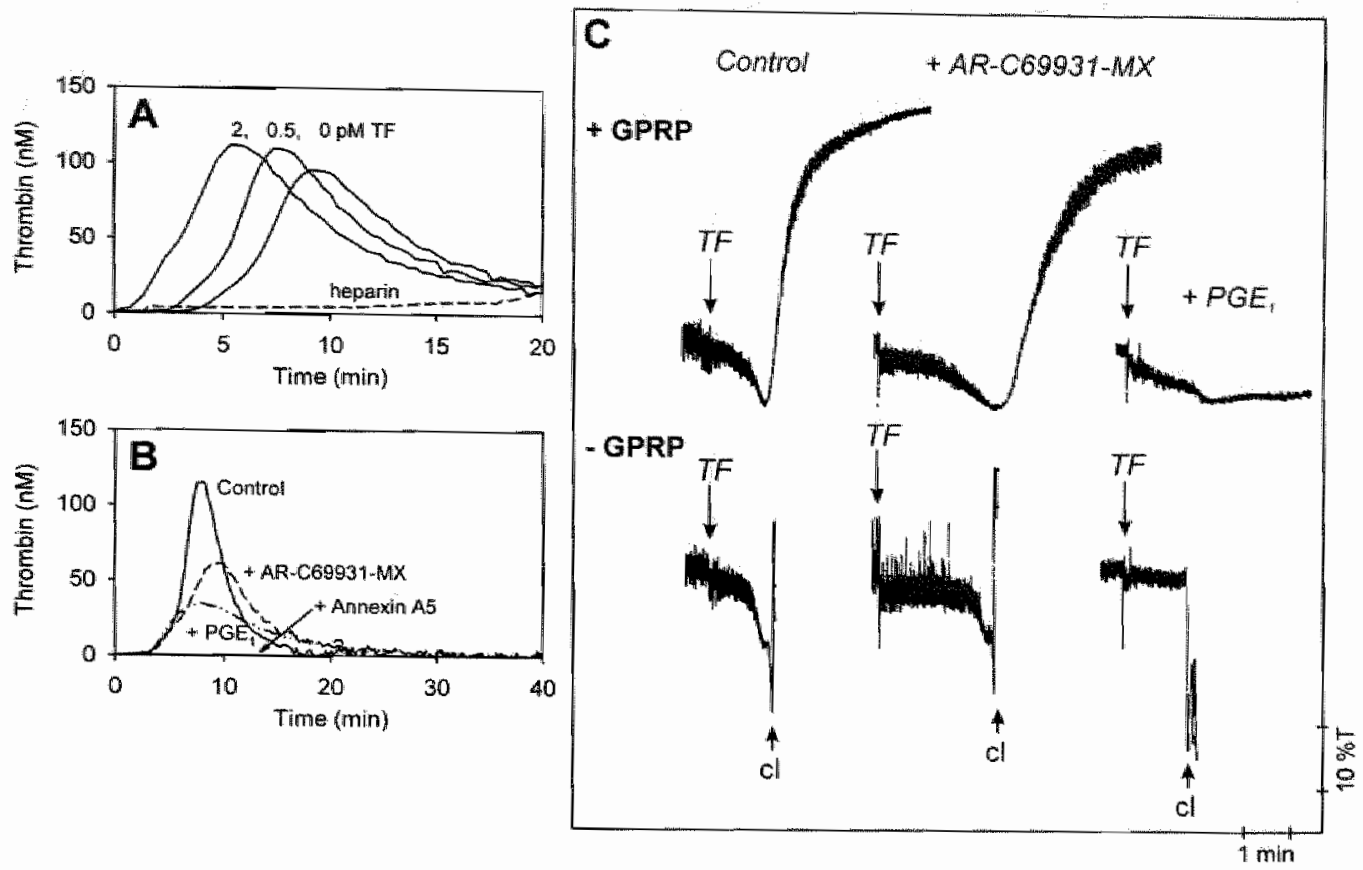

Figure 6.1. Effect of $P G E_{1}$ and $A R-C 69931 M X$ on thrombin generation and aggregation in PRP triggered with tissue factor. (A) Thrombin generation was measured in citrated rat PRP triggered with 0-2 pM TF and $16.7 \mathrm{mM} \mathrm{CaCl}_{2}$. Heparin $(0.05 \mathrm{U} / \mathrm{ml})$ was present where indicated. (B) Effect of $\mathrm{PGE}_{1}(10 \mu \mathrm{M})$. ARC69931 MX $\left(10 \mu \mathrm{mol}^{-1}\right)$ or annexin $\mathrm{A5}\left(30 \mu \mathrm{g} \mathrm{mL}^{-1}\right)$ an thrombin generation with TF (2 pmol L-1) and $\mathrm{CaCl}_{2}$. (C) Effect of $P G E_{1}$ or AR-C69931MX (each 10 $\mu \mathrm{M}$ ) on turbidity change in PRP triggered with TF (2 pM) and $\mathrm{CaCl}_{2}$ under stirring conditions. Experiments were performed in the presence or absence of GPRP ( $2 \mathrm{mM}$ ): $\mathrm{cll}=$ formation of clot. Traces are representative for 5-7 experiments.

When PFP instead of PRP was used (data not shown), and it was fully blocked in the presence of $30 \mu \mathrm{g} / \mathrm{ml}$ PS-scavenging annexin A5 (peak height $1.6 \pm 0.5 \%$ of control, Fig. 6.1B).

Preincubation of rat PRP with $10 \mu \mathrm{M} \mathrm{PGE}_{9}$ resulted in greatly reduced but not abrogated thrombin formation with a thrombin peak height of $28.0 \pm 8.6 \% \quad(n=5, p<0.05)$ compared to control (Fig. 6.1B). Typically, this peak was reached at an earlier time point, i.e. 2.1 $\pm 0.5 \mathrm{~min}$ earlier than in the control condition. Preincubation of rat PRP with $10 \mu M A R-$ C69931MX gave a smaller reduction in peak height to $53.9 \pm 3.1 \%(n=5, p<0.05)$; the peak was now delayed with $3.1 \pm 1.0 \mathrm{~min}$ compared to control. The effects of PGE did not add up: combined preincubation gave a peak height of $22.0 \pm 4.3 \%$ of control. Furthermore, the AR-C69931MX effect was not influenced by addition of $20 \mu \mathrm{M}$ MRS 2179 (an antagonist of the second platelet ADP receptor, $P 2 Y_{1}$ ), giving a peak height of $61.7 \pm 3.5 \%$ of control. This indicates that, similarly as reported for human platelets (17), the procoagulant effect of $A D P$ is mediated by $P 2 Y_{12}$ receptors. 


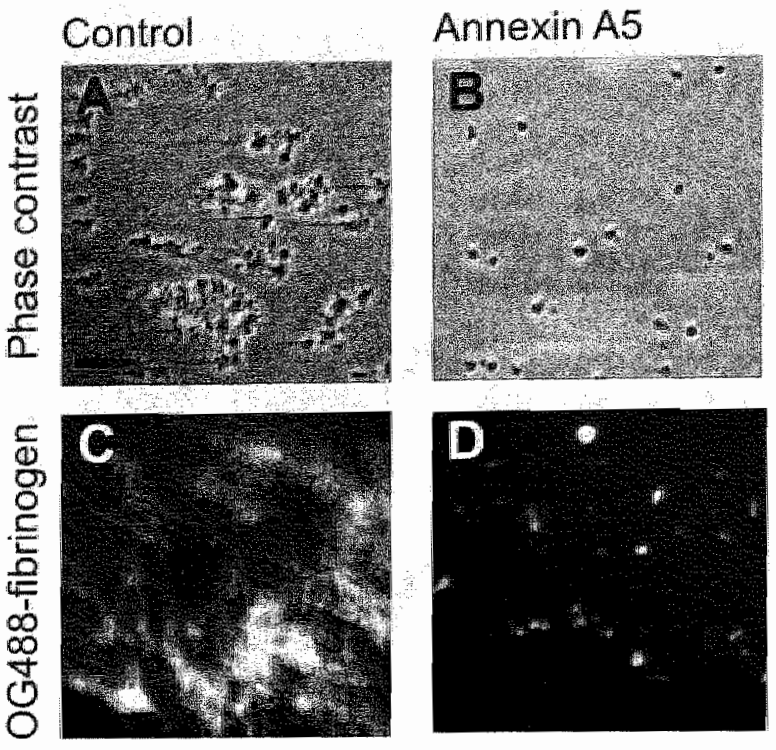

Figure 6.2. Effect of annexin $A 5$ on thrombus and fibrin formation in flowing blood triggered with tissue factor: Citrated rat blood containing $0.2 \mathrm{mg} / \mathrm{ml}$ OG488-fibrinogen was perfused during 5 min over a fibrinogen surface at a shear rate of $250 \mathrm{~s}^{-1}$. During perfusion coagulation was triggered with $2 \mathrm{pM}$ TF and $16.7 \mathrm{mM} \mathrm{CaCl}$. Blood was pretreated with a high dose of $30 \mu \mathrm{g} / \mathrm{ml}$ unlabeled annexin $\mathrm{A} 5$, where indicated. Shown are representative phase-contrast $\left(A_{n} B\right)$ and fluorescent images $(C, D)$, captured after 8 min $(n=3)$. Bar $=10 \mu \mathrm{m}$.

The efficacy of AR-C69931MX and PGE in inhibiting platelets under conditions of thrombin generation was evaluated by turbidometry. Triggering of citrated PRP with $\mathrm{TF} / \mathrm{CaCl}_{2}$ presence of GPRP, the shape change in response to $T F / \mathrm{CaCl}_{2}$ was followed by rapid aggregation of platelets. Preincubation with AR-C69931MX delayed both shape change and aggregation, as was observed in the presence of GPRP (Fig. 6.1C). Preincubation with PGE, further delayed shape change and completely inhibited aggregation. Thus, in TF-triggered rat PRP, both compounds had an aggregation-delaying effect in addition to their inhibiting effect on thrombin generation.

\section{Effects of platelet inhibitors on thrombus formation and caagulation in rat blood under flow}

To study the effects of platelet inhibitors under conditions of flow and coagulation, whole rat blood was triggered with $\mathrm{TF} / \mathrm{CaCl}_{2}$ and perfused over a fibrinogen surface at a moderately low wall-shear rate of $250 \mathrm{~s}^{-4}$. Perfusion of blood with $\mathrm{CaCl}_{2}$ plus $2 \mathrm{pM}$ TF resulted in early platelet deposition and formation of fibrin fibers, which started after about 2 min. Platelets later assembled into aggregates, leading to $29.7 \pm 2.6 \%(n=12)$ of the fibrinogen surface area covered with multi-layered thrombi after 5 min of flow (Fig. 6.2A). At a more advanced stage (7$8 \mathrm{~min})$, the chamber became occluded by large fibrin-platelet thrombi. Addition to the blood of $30 \mu \mathrm{g} / \mathrm{ml}$ annexin A5 (chelating exposed PS), completely abolished aggregate formation, while 

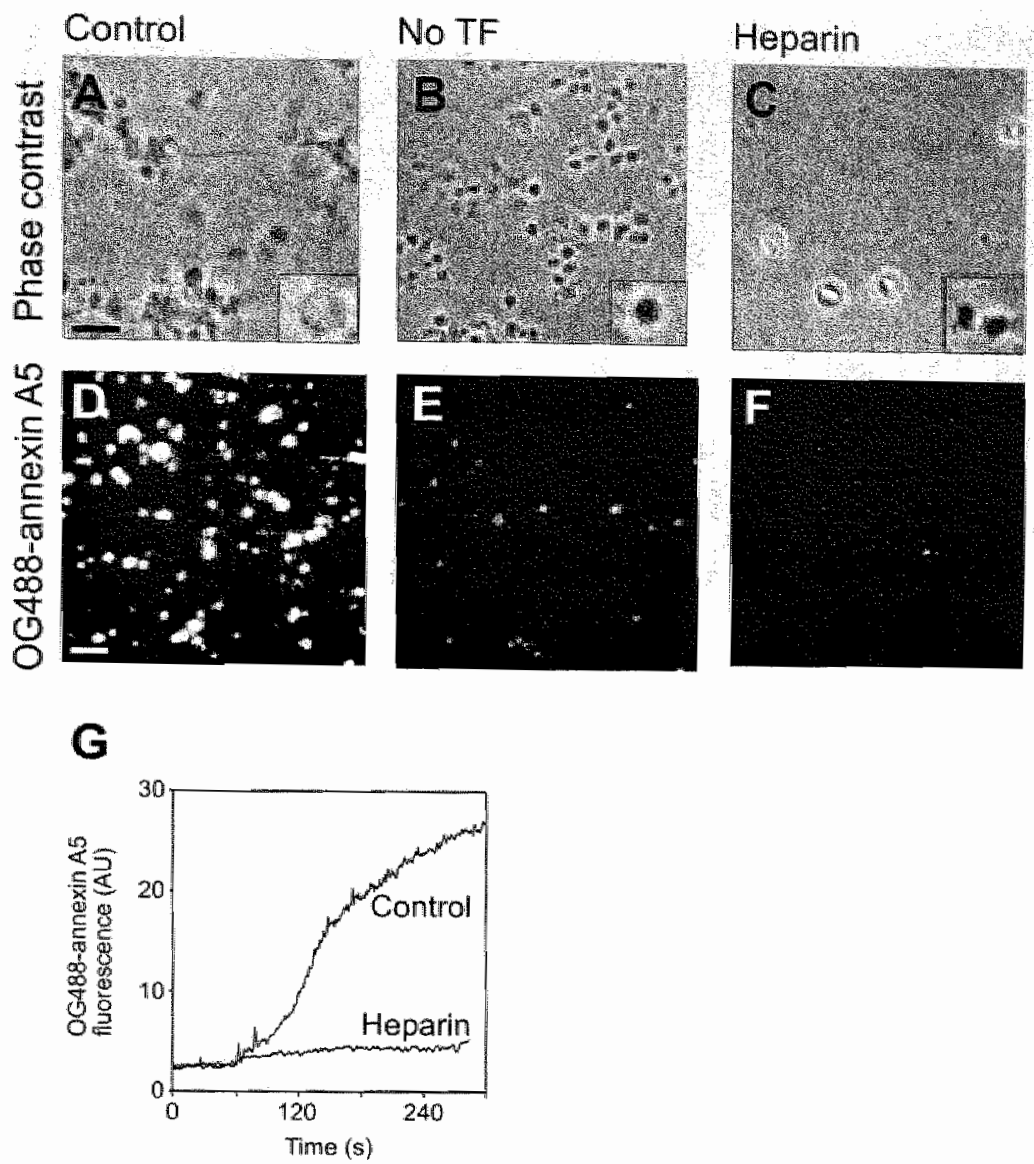

Figure 6.3. Contribution of thrombin to thrombus formation and PS exposure in tissue factor-triggered, flowing blood. Citrated rat blood was perfused during 5 min over a fibrinogen surface at a shear rate of 250 $\mathrm{s}^{-3}$. During perfusion, coagulation was triggered with $2 \mathrm{pM} \mathrm{TF}$ and $16.7 \mathrm{mM} \mathrm{CaCl}(\mathrm{A}, \mathrm{D}) ;$ with $16.7 \mathrm{mM}$ $\mathrm{CaCl}_{2}$ alone $(\mathrm{B}, \mathrm{E})$; or with $\mathrm{TF} / \mathrm{CaCl}_{2}$ and $0.05 \mathrm{U} / \mathrm{mi}$ heparin $(\mathrm{C}, \mathrm{F})$. Representative images are presented. which were taken after $5 \mathrm{~min}(\mathrm{n}=4-10$ experiments). (A-C) Phase-contrast images; (D-F) fluorescence irmages after staining post-perfusion with $0.5 \mu \mathrm{g} / \mathrm{ml}$ OG488-annexin A.5. (G) Accumulation of fiugrescence at fibrinogen surface during perfusion of blood, labeled with $0.5 \mu \mathrm{g} / \mathrm{m}$ OG488-annexin A5, triggered with $\mathrm{TF} / \mathrm{CaCl}_{2 .}$. Heparin $(0.05 \mathrm{U} / \mathrm{ml})$ was present as indicated. Bar $=10 \mu \mathrm{m}$; inserts show $2 \%$ magnifications.

only few platelets adhered (Fig. 6.2B). That annexin A5 acted as an anticoagulant was confirmed by experiments where OG488-fibrinogen was added. In the control condition, networks of OG488-labeled fibrin and platelets were observed after perfusion (Fig. 6.2C). With annexin A5 present, fluorescent fibers remained absent and only few single platelets displayed fibrinogen labeling (Fig. 6.2D). This indicated that the formation of aggregates and fibrin during flow relied on PS exposure and subsequent thrombin formation, putatively on activated platelets.

Further flow experiments confirmed that platelet activation and aggregate formation were enhanced by TF. Perfusion of blood without TF resulted in a delayed adhesion of mostly 


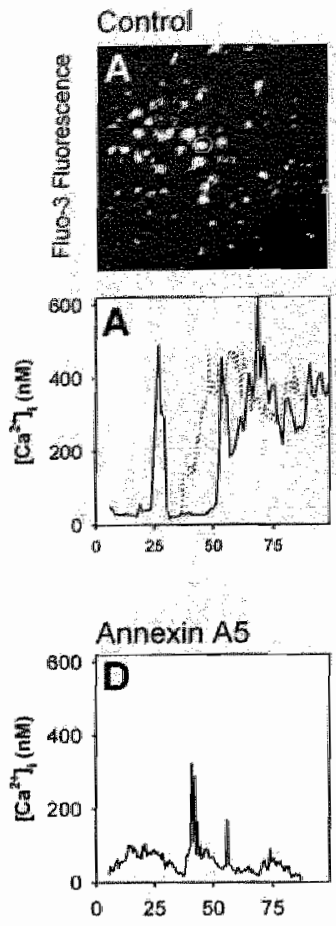

\section{no TF}
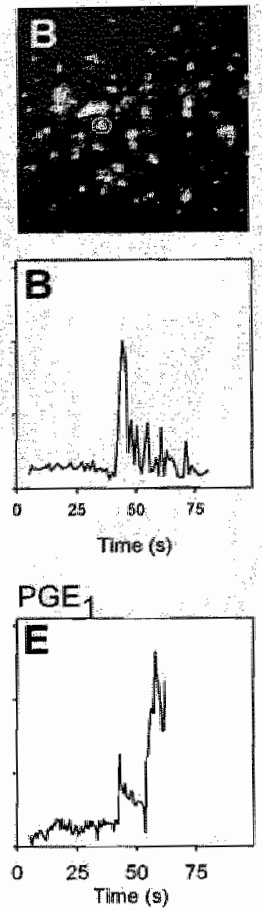

Heparin
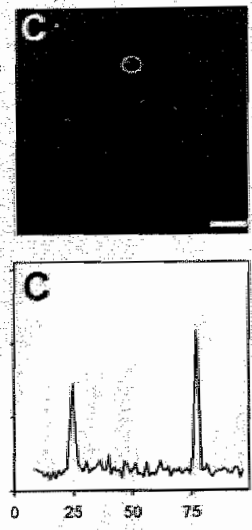

AR-C69931-MX

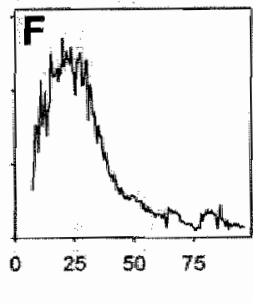

Figure 6.4. Platelet $\mathrm{Ca}^{2 *}$ responses in flowing blood triggered with tissue factor. Citrated rat blcod containing $2 \%$ Fluo-3 loaded platelets from the same animal was triggered with $\mathrm{TF} / \mathrm{CaCl}_{2}$ during perfusion (see Fig. 6.3). Rises in $\left[\mathrm{Ca}^{2+}\right]$ in single adherent platelets were determined after about $3 \mathrm{~min}$ of flow. Coagulation was triggered during perfusion with $2 \mathrm{pM} \mathrm{TF}$ and $16.7 \mathrm{mM} \mathrm{CaCl}$. (A) Contral condition, (B) triggering without TF. Further, pretreatment of the blood with $0.05 \mathrm{U} / \mathrm{ml}$ heparin (C), $30 \mu \mathrm{g} / \mathrm{ml}$ annexin A5 (D), $10 \mu M \mathrm{PGE}_{1}(\mathrm{E})_{\text {, }}$ or $10 \mu \mathrm{M}$ AR-C69931MX (F). Single-platellet $\mathrm{Ca}^{2+}$ responses are representative for those of $16-45$ cells.

individual platelets. First traces of fibrin fibers did not appear before 5 min of flow (Fig. 6.3B). To show that the TF-induced process relied on thrombin formation, a saturating dose of heparin was added, which indeed completely abolished platelet deposition and fibrin formation during the experimental time (Fig. 6.3C). The activation state of adhered platelets was verified by poststaining with OG488-annexin A5 to detect PS-exposing platelets (Fig 6.3D-F). The few adherent platelets hardly exposed PS in the presence of heparin. When OG488-annexin A5 label was added to the flowing blood $(0.5 \mu \mathrm{g} / \mathrm{ml}$, a low dose not influencing coagulation), it could be verified that heparin prevented the appearance of PS-exposing platelets during the whole flow experiment (Fig. 6.3G).

To monitor the changes in activation state of platelets during adhesion, blood was supplemented with $2 \%$ Fluo-3 loaded platelets from the same animal. Upon perfusion with $\mathrm{TF} / \mathrm{CaC} \|_{2}$, adherent fluorescent platelets displayed a prolonged increase in $\left[\mathrm{Ca}^{2+}\right]_{\mathfrak{l}}$, starting at 
A
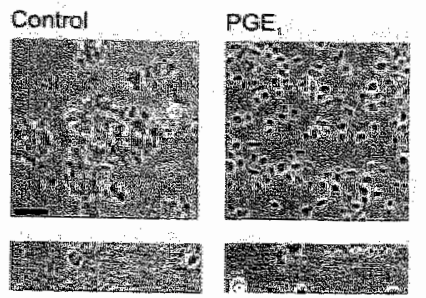

AR.C69931 MX

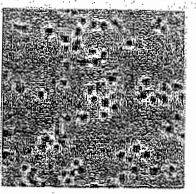

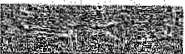

B

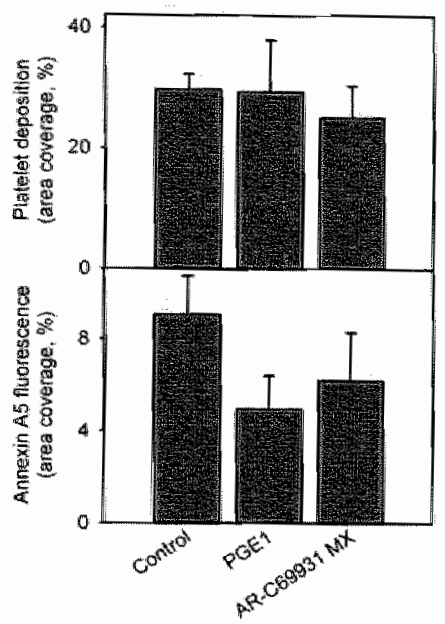

Figure 6.5. Effects of $P G E_{1}$ and $A R$ C69931MX on thrombus formation and platelet activation in flowing rat blood triggered with tissue factor. Flow experiments were carried out in the presence of $\mathrm{TF} / \mathrm{CaCl}_{2}$, as described for Fig. 6.3. Rat blood was pretreated with $\mathrm{PGE}_{1}$ or AR-C69931MX, each $10 \mu \mathrm{M}$ as indicated. (A) Representative phase-contrast images taken after $5 \mathrm{~min}$ of perfusion. Upper panels: images taken slightly above the coverslip surface; lower panels: images of fibrin fibers at the focal piane of the surface (bar $=10 \mu \mathrm{m}$ ). (B) Surface area coverage with platelets or OG488-annexin A5 fluorescence after $5 \mathrm{~min}$ of perfusion. Mean \pm SEM ( $n=4-6$ experiments).
A

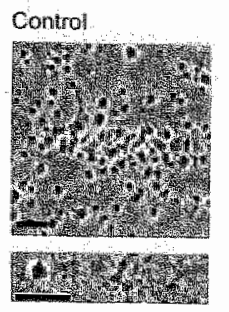

B

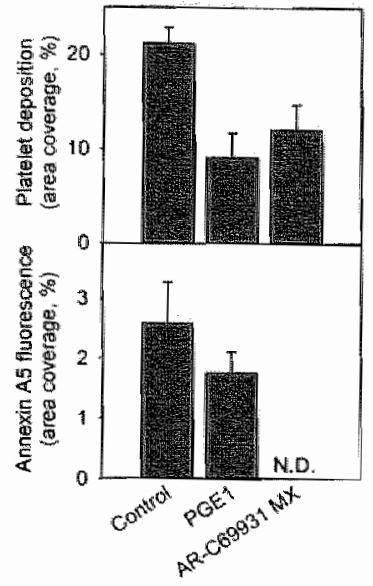

FGE,
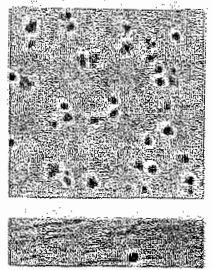

AR-C6993! MX

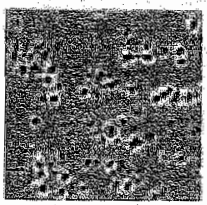

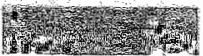

C

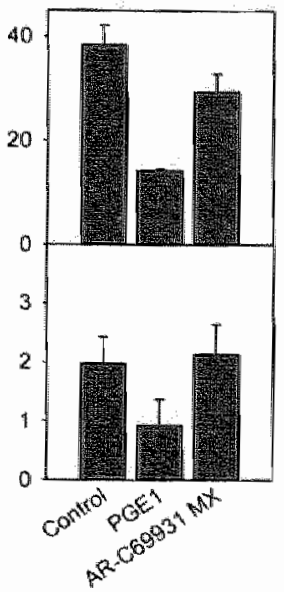

Figure 6.6. Effects of $P G E_{1}$ and $A R-C 69931 M X$ on thrombus formation and platelet activation in flowing human blood triggered with tissue factor. Flow experiments were carried out in the presence of $\mathrm{TF} / \mathrm{CaCl}_{2,}$ as indicated for Fig. 6.3. Human blood was pretreated with $10 \mu \mathrm{M} \mathrm{PGE}_{1}$ or $10 \mu \mathrm{MAR}$-C69931MX, as indicated. (A) Representative phase-contrast images and (B) surface area coverage after 6 min of perfusion at a shear rate of $250 \mathrm{~s}^{-1}$ (N.D. not determined). Upper panels: images taken slightly above the coverslip surface; lower panels: irnages of fibrin fibers at the focal plane of the surface (bar $=10$ um). Surface area coverage is given with platelets or OG48B-annexin A5 fluorescence (staineid postm perfusion). (C) surface area coverage after $4 \mathrm{~min}$ of perfusion at $1500 \mathrm{~s}^{-1}$. MeantSEM (n=2-3 experiments).

the moment of adhesion or after a short lag-time (Fig. 6.4A). This pointed to a high activation state of the cells. In the absence of $\mathrm{TF}_{1}\left[\mathrm{Ca}^{2+}\right]_{1}$ in adherent platelets initially remained low. However, after 5 min of flow, most cells responded by series of spiking rises in $\left[\mathrm{Ca}^{2+}\right]_{i}$ (Fig. $6.4 B$ ). Further control experiments indicated that with heparin or annexin A5 present (at concentrations completely blocking thrombin generation), platelets remained low in [Ca $\left.{ }^{2 *}\right]_{i}$ except for incidental spikes (Fig. 6.4C,D). The majority of the $\mathrm{Ca}^{2+}$ responses thus were 
secondary to generation of thrombin. Together, these data indicate that under flow the TF/CaCl2 activated, PS-exposing platelets and subsequent thrombin generation. Indeed without coagulation (heparin) or procoagulant platelets (annexin A5), thrombus formation was absent.

Effects of the platelet inhibitors PGE, and AR-C69931MX were studied in this flow model in the presence of TF-triggered coagulation. Pretreatment of blood with $P G E_{1}(10 \mu M)$ resulted in deposition of mostly single platelets (Fig. 6.5A). Fibrin fibers were still formed. in comparison to the contral condition, area coverage by platelets was not reduced after 5 min of flow (Fig. 6.5B). PGE influenced the activation state of adhered platelets: the $\mathrm{Ca}^{2 *}$ responses showed a cansistent lag-time (Fig. 6.4E) and the surface coverage with PS-exposing platelets was about halved (Fig. 6.5B). Nevertheless, platelets gradually spread over the surface and some formed lebs, which are morphologic indications for (delayed) activation. When blood was pretreated with AR-C69931MX $(10 \mu \mathrm{M})$, similar effects were seen as with PGE: platelets mostly adhered as single cells, but sometimes assembled into micro-aggregates and fibrim was still formed (Fig. 6.5A). Furthermore, the AR-C69931MX treatment reduced PS exposure (Fig. $6.5 \mathrm{~B}$ ) and gave transient $\mathrm{Ca}^{2+}$ responses (Fig. 6.4F). This indicated that both agents effectively suppressed platelet aggregate formation under flow, but only partially inhibited the activation state of the deposited platelets in terms of $\left[\mathrm{Ca}^{2+}\right]_{j}$ elevation and PS exposure.

\section{Effects of platelet inhibitors on thrombus formation and coagulation in human blood under flow}

To investigate the relevance of these findings for the human system, we performed a similar set of flow experiments with human blood under conditions of coagulation at a shear rate of $250 \mathrm{~s}^{-1}$. The onset of stable platelet adhesion and the formation of platelet aggregates and fibrin fibers was relatively slow when $\mathrm{TF} / \mathrm{CaCl}_{2}$-triggered human blood was perfused over fibrinogen in comparison to rat blood. After several min of perfusion, the human platelets adhered and became activated so that, after $6 \mathrm{~min}$, aggregated platelets had covered $21 \pm 2 \%$ $(n=3)$ of the fibrinogen surface (Fig. 6.6A). After staining for PS exposure with labeled annexin $A 5,2.6 \pm 0.7 \%$ of the surface was covered with fluorescent platelets, which was lower than seen with rat blood. Control experiments showed that heparin addition (at a concentration abrogating thrombin generation), as with rat blood, completely inhibited platelet aggregation and PS exposure as well as fibrin formation; only few single platelets adhered. In the presence of PGE $(10 \mu \mathrm{M})$, aggregate formation was completely prevented. However, with human blood, many single platelets adhered, which had an activated shape and spread over the surface; fibrin fibers were still formed. Surface coverage of OG488-annexin A5 fluorescence was only partly reduced by $30 \%$ compared to the control (Fig. 6.6B), similar as seen with rat platelets.

When the flow experiments were performed at a higher (arterial) shear rate of $1500 \mathrm{~s}^{-1}$, essentially the same effects of PGE, treatment were obtained (Fig. 6.6C). Inhibition of the ADP 
receptor $\mathrm{P} 2 Y_{12}$ by AR-C69931MX (10 $\mathrm{MM}$ ) resulted in similar, but less potent effects: reduced aggregate formation and still fibrin formation and PS exposure. Under static conditions, using

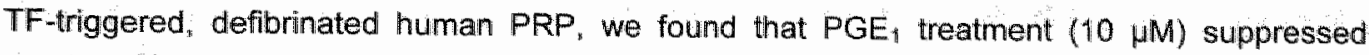
integrin allbB3 activation with $83 \%$ (platelet binding of FITC-labeled PAC1, an antibody against activated allb 33 , as measured by flow cytometry). while thrombin was still formed (peaking at $40 \mathrm{nM}$ ). Assuming that $P \mathrm{FE}_{\mathrm{y}}$ has the same effect under flow, we can conclude that a substantial but incomplete suppression of integrin activation can abolish platelet aggregation, but still allow platelet adhesion to fibrinogen. Taken together, these data show that in flowing, coagulating blood from rat and human, either inhibitor suppressed platelet aggregation, but no more than delayed formation of thrombin and fibrin, or PS exposure on activated platelets.

\section{Discussion}

Photochemically induced thrombus formation is considered to be a sensitive method to detect hypocoagulant conditions in laboratory animals, e.g. as induced by dietary fish oil (27). Surprisingly, using this thrombosis model in rats, we did not find effects of moderate anticoagulant treatment, with either heparin (inactivating factor $\mathrm{Xa}$ and thrombin) or warfarin (reducing levels of vitamin K-dependent coagulation factors). Nevertheless, this treatment caused major reduction in thrombin generation, when measured ex vivo in tissue factortriggered PRP. Because these results suggested that the mere down-regulation of coagulant activity is insufficient to reduce thrombosis tendency, we further explored the effects of two antiplatelet agents which, in addition, are known to reduce thrombin generation.

First, $P G E_{1}$ was used, which causes EP/IP receptor-mediated, $G_{\mathbb{S}}$-dependent elevation in cyclic AMP in platelets, resulting in down-regulation of $\mathrm{Ca}^{2+4}$ responses, inactivation of $\alpha$ llb $\beta 3$ integrin, and inhibition of platelet aggregation (32-34). Second, AR-C69931MX was used to block the $P 2 Y_{12}$ receptor $(21,22)$. This ADP receptor, coupled to $G_{i}$, contributes to $A D P$ mediated platelet aggregation as well as thrombin generation $(17,18,20)$. In human PRP, the reducing effects of these agents on thrombin generation are due to inhibition of appearance of procoagulant PS at the platelet surface (16). We thus assessed the effects of PGE, and ARC69931MX on procoagulant activity of rat platelets by performing static thrombin generation experiments with PRP and, more physiologically, ex vivo flow experiments with coagulating whole blood. In both sets of experiments, the extrinsic coagulation pathway was triggered with TF. Most flow studies were performed at relatively low shear rate $\left(250 \mathrm{~s}^{-1}\right)$, as thrombin is considered to play a prominent role under this condition.

Perfusion of whole rat blood over a fibrinogen surface upon simultaneous triggering with TF/CaCl 2 allowed detection of initial and late coagulant effects: platelet adhesion and activation, PS exposure, fibrin formation and platelet aggregation. Adhered platelets showed high, prolonged $\mathrm{Ca}^{2+}$ responses that were accompanied by bleb formation and surface exposure 
of procoagulant PS. These platelet responses were thrombin-mediated, as they were absent in control experiments with heparin. Labeling experiments with OG488-annexin A5 showed a good correlation between the appearance of PS-exposing (blebbing) platelets and fibrin. Blocking experiments with high annexin A5 demonstrated that the exposed PS is critical for the formation of thrombin and fibrin, proving that procoagulant platelets play a key role in this process. The above experiments thereby illustrate that the positive feedback loop, in which initial thrombin formation stimulates platelet aggregate formation and exposure of coagulation-stimulating $P S_{\text {. }}$. is also operative under conditions of flow.

We note that in the initial in vivo experiments heparin and warfarin were used at moderate concentrations to partially suppress thrombin generation. On the other hand, in the flow experiments with whole blood, heparin was applied in vitro at maximally effective dose, sufficient to completely block thrombin/fibrin formation, to verify that the observed platelet responses were thrombin-dependent. However, as in vivo also the vessel wall plays a regulatory role in thrombus formation, the apparent inability of anticoagulants to influence in viwo thrombosis can also be due to the presence of activating substances at the (damaged) vessel wall.

The flow results obtained with platelet inhibitors under conditions of TF-triggered coagulation are unexpected. In both rat and human blood, PGE prevents the formation of platelet aggregates in flowing blood (Figs. 6.5-6.6\%, even until occlusion of the flow chamber by massive fibrin deposition. AR-C69931MX has a similar, though more moderate effect. In agreement with the notion that $P G E_{1}$ and $A R-C 69931 M X$ considerably but incompletely inhibit PS-dependent thrombin generation under stasis in PRP from rat (Fig. 6.1B) and human (16). these agents also only partially reduce PS exposure and fibrin formation in flowing blood (Figs. 6.5-6.6). Consistent with these results " other authors have described that $\mathrm{PGE}_{1}$ delays fibrin clot formation in TF-triggered whole blood under static conditions (35). Overall, we can conclude that $\mathrm{PGE}$, and $\mathrm{AR}-\mathrm{C} 69931 \mathrm{MX}$ inhibit the various aspects of coagulation-induced platelet activation in a different way. They extensively reduce integrin activation, but only delay $\mathrm{Ca}^{2+}$ signaling and PS exposure in response of the thrombin that is formed upon coagulation. That platelets deposited from PGE - and AR-C69931MX-treated blood are in an activated state is also apparent from their changes in morphology, i.e. spreading over the surface and forming blebs. The final result is abolished (with $P G_{1}$ ) or suppressed (with AR-C69931MX) platelet

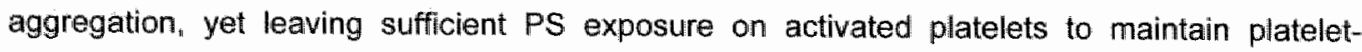
dependent coagulation (thrombin and clot formation). Both rat and human platelets behave similarly in the presence of $\mathrm{PGE}_{1}$ or AR-C69931MX under coagulant conditions. Yet, subtle differences are observed between the rat and human systems, as in human blood deposition of platelets is reduced in the presence of $P G E_{1}$ or AR-C69931MX, while in rat blood this remains 
unchanged. This can be explained, for instance, by the higher platelet count of rat blood and different levels of adhesive receptors on the platelets from this species.

The present results thus indicate that platelet aggregation is more sensitive to platelet inthibitors such as PGE than PS exposure and subsequent formation of thrombin and fibrin. In agreement with this, others have observed that prostaglandin-induced down-regulation of integrin allb $\beta 3$ activation is of longer duration than the platelet $\mathrm{Ca}^{2+}$ signal (34). Our findings, using whole blood in which coagulation is triggered with TF/CaCl 2 under flow conditions, are a clear indication that this differential regulation of plateiet responses is of physiological relevance.

Interestingly, for the human system, we find that treatment of TF-triggered blood with $P G E_{1}$ gives reduced platelet aggregation with only partial reduction of PS exposure upon perfusions at low and high shear rates of 250 and $1500 \mathrm{~s}^{-1}$, respectively. This finding is of potentiall clinical interest. For many years, patients with peripheral arterial obstructive disease are being treated by intravenous administration of $P \mathrm{PE}_{1}$ (alprostadil). The mechanism for the therapeutic efficacy is not fully clear yet; moderate increases in blood flow have been measured as well as reduced expression of endothelial activation markers and increased production of pro-angiogenic factors (36-38). The present results suggest that part of the beneficial effect of alprostadil can lay in a reduction of aggregate and thrombus formation under conditions where coagulation is still sufficiently active. If this proves to be true, it argues for the use of inhibitors which suppress both platelets and thrombin generation as antithrombotic agents. These positive effects of substances with anti-aggregatory as well as anti-coagulatory properties thus need to be taken further in future human studies.

\section{Acknowledgments}

We thank E. Haddeman and dr. C. Kroner for participation in various stages of this work. Support was obtained from the Netherlands Foundation for Scientific Research (902-68241) and AstraZeneca R\&D. 


\section{References}

1. Giesen $P L_{\text {, }}$ Rauch $U$, Bohmann $B$, Kling $D$, Roque $M$, Fallon JT, Badimon JJ, Himber J, Riederer $M A_{*}$ Nemerson $Y$. Blood-borne tissue factor: another view of thrombosis. Proc Natt Acad Sci U S A. $199986: 2311-2315$

2. Plow EF, Cierniewski CS, Xiao Z, Haas TA, Byzova TV. Alphallbbetal 3 and its antagonism at the new millennium. Thromb Haemost. 2001;86:34-40.

3. Walsh PN. Roles of platelets and factor $X \mid$ in the initiation of blood coagulation by thrombin. Thromb Haemost. $2001 ; 86: 75-82$.

4. Smeets EF, Heemskerk JW, Comfurius P, Bevers EM, Zwaal RF. Thapsigargin amplifies the platelet procoagulant response caused by thrombin. Thromb Haemost. 1993;70:1024-1029.

5. Heemskerk JW, Vuist WM, Feijge MA, Reutelingsperger CP. Lindhout T. Collagen but not tibrinogen surfaces induce bleb formation, exposure of phosphatidylserine, and procoagulant activity of adherent platelets: evidence for regulation by protein tyrosine kinase-dependent Ca2t responses. Blood. $1997: 90: 2615-2625$

6. Bevers EM, Comfurius P, van Rijn JL, Hemker HC, Zwaal RF, Generation of prothrombin-converting activity and the exposure of phosphatidylserine at the outer surface of platelets. Eur $\mathrm{J}$ Biochem. $1982 ; 122 ; 429-436$.

7. Swords NA, Manin KG. The assembly of the prothrombinase complex on adherent platelets. Arterioscler Thromb. 1993;13:1602-1612.

8. Zwaal RFA, Schroit AJ. Pathophysiological implications of membrane phospholipid asymmetry in blood cells. Blood. 1997;89:1121-1132.

9. Briede $\mathrm{J} J$, Heemskerk $\mathrm{JW}$, van't Veer $\mathrm{C}_{1}$, Hemker $\mathrm{HC}$, Lindhoult $\mathrm{T}$. Contribution of platelet-derived factor $V a$ to thrombin generation on immobilized collagen- and fibrinogen-adherent platelets. Thromb Haemost. 2001:85:509-513.

10. Rosing $J$, Bevers EM, Comfurius $P$, Hemker $H C$, van Dieijen $G$, Weiss $H J_{1}$, Zwaal RF. Impaired factor $X$ and prothrombin activation associated with decreased phospholipid exposure in platelets from a patient with a bleeding disorder. Blood. 1985;65:1557-1561.

11. Weiss HJ. Scott syndrome: a disorder of platelet coagulant activity. Semin Hematol. 1994;31:312-319.

12. Reverter JC, Béguin $\mathrm{S}$, Kessels $\mathrm{H}$, Kumar R, Hemker HC, Coller BS. Inhibition of platelet-mediated, tissue-factor-induced thrombin generation by the mouse/human chimeric $7 E 3$ antibody. Potential implications for the effect of c7E3 Fab treatment on acute thrombosis and "climicall restenosis'. J Clin Invest. 1996;98:863-874.

13. Beguin $S$, Kumar $R$. Thrombin, fibrin and platelets: a resonance loop in which von Willebrand factor is a necessary link. Thromb Haemost. 1997;78:590-594.

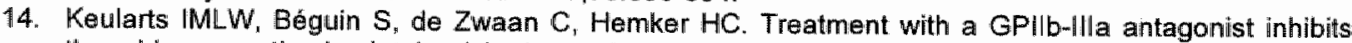
thrombin generation in platelet-rich plasma from patients. Thromb Haemost. 1998;80:370-371.

15. Béguin $S$, Kumar $R$, Keularts I, Seligsonn U, Coller BS, Hemker HC. Fibrin-dependent platelet procoagulant activity requires. GPIb receptors and von Willebrand factor. Blood. 1999:93:564-570.

16. Vanschoonbeek $K$, Feijge MA, Van Kampen RJ, Kenis H. Hemker HG, Giesen PL, Heemskerk JW. Initiating and potentiating role of platelels in tissue factor-induced thrombin generation in the presence of plasma: subject-dependent variation in thrombogram characteristics. J Thromb Haemost. $2004 ; 2 ; 476-484$

17. Leon $C$, Ravanat $C$, Freund $M$, Cazenave JP. Gachet $C$. Differential involvement of the P2Y1 and P2Y12 receptor in platelet procoagulant activity. Arterioscler Thromb Vasc Biol. 2003;23:1941-1947.

18. Danial JL, Dangermaier C, Jin J. Ashby B, Smith JB, Kunapuli SP. Molecular basis for ADP-induced platelet activation. I: evidence for three distinct ADP receptors on human platelets. J Biol Chem. $1998 ; 273: 2024-2029$.

19. Hechler B, Eckly A. Ohlmann P, Cazenave JP, Gachet C. The P2Y1 receptor, necessary but not sufficient to support full ADP-induced platelet aggregation, is not the target of the drug clopidogrel. $\mathrm{Br} J$ Haematol. 1998;103:858 866.

20. Herault JP, Dol $F$, Gaich $C$, Bernat $A$, Herbert JM. Effect of clopidogrel on thrombin generation in platelet-rich plasma in the rat. Thrombosis and Haemostasis. 1999;81:957-960.

21. Ingall $A H$, Dixon J. Bailey $A$, Coombs ME, Cox D, Mclnally Jl, Hunt SF, Kindon ND, Teobald BJ, Willis $P A$, Humphries $R G$, Leff $P$. Clegg JA, Smith JA, Tomlinson $W$. Antagonists of the platelet $P 2 T$ receptor: a novel approach to antithrombotic therapy. J Med Chem. 1999;42:213-220.

22. Hollopeter $G$, Jantzen $H M$, Vincent $D$, Li G, England L, Ramakrishnan $V$, Yang RB, Nurden $P$, Nurden A, Julius D, Conley PB. Identification of the platelet ADP receptor targeted by antithrombotic drugs. Nature. 2001; $409: 202-208$. 
23. Matsuno $H$, Uematsu T, Nagashima S, Nakashima M. Photochemically induced thrombosis model in rat femoral artery and evaluation of effects of heparin and tissue-type plasminogen activator with use of this model. J Pharmacol Methods. 1991;25:303-317.

24. Inamo $J_{n}$ Belougne $E_{n}$ Doutremepuich $C$. Importance of photo activation of rose bengal for platelet activation in experimental models of photochemically induced thrombosis. Thromb Res. 1996;83:229-235.

25. Nieuwenhuys CM, Beguin S, Offermans RF, Emeis JJ, Hornstra G. Heemskerk JW. Hypocoagulant and lipid-lowering effects of dietary $n-3$ polyunsaturated fatty acids with unchanged platelet activation in rats. Arterioscler Thromb Vasc Bioll. 1998;18:1480-1489.

26. Nieuwenhuys $C M$. Feijge MA, Beguin $S$, Heemskerk JW. Monitoring hypocoagulant conditions in rat plasma: factors determining the endogenous thrombin potential of tissue factor-activated plasma. Thromb Haemost. 2000;84:1045-1051.

27. Jerling $J C_{n}$ Curiel-Martos $A$, Kroner $C_{n}$ Kloots $W$. Fish oil inhibits photochemically induced thrombosis in the guinea pig in a dose dependent manner. Thromb Res. 2003;111:11-17.

28. Nieuwenhuys $C M_{r}$ Hornstra $G$. The effects of purified eicosapentaenoic and docosahexaenoic acids on arterial thrombosis tendency and platelet function in rats. Biochim Blophys Acta. 1998;1390:313-322.

29. Hemker $H C$, Giesen PLA, Ramjee $M$, Wagenvoord $R$, Béguin $S$. The thrombogram: monitoring thrombin generation in platelet rich plasma. Thrombosis and Haemostasis. 2000;83:589-591.

30. Heemskerk JW Willems GM, Rook MB, Sage SO. Ragged spiking of free calcium in ADP-stimulated human platelets: regulation of puff-like calcium signals in vitro and ex vivo. J Physiol. 2001,535:625-635.

31. Fungaloi $P$, Waterman $P$, Nigri $G$, Statius-van Eps $R$, Sluiter $W$, van Urk $H$, LaMuraglia $G$. Photochemically modulated endothelial cell thrombogenicity via the thrombomodulin-tissue factor pathways. Photochem Photobiol. 2003;78:475-480.

32. Heemskerk JWM, Feijge MAH, Sage SO, Walter U. Indirect regulation of Ca ${ }^{2+}$ entry by CAMPdependent and cGMP-dependent protein kinases and phospholipase $\mathrm{C}$ in rat platelets. Eur J Biochem. $1994: 223: 543-551$.

33. Keularts IM, van Gorp RM, Feijge MA, Vuist WM, Heemskerk JW. alpha(2A)-adrenergic receptor stimulation potentiates calcium release in platelets by modulating CAMP levels. J Bioll chem. 2000;275:1763-1772.

34. Van Willigen $G$, Akkerman JWN. Regulation of glycoprotein Ilb/llla exposure on platelets stimulated with alpha-thrombin. Blood. 1992;79:82-90.

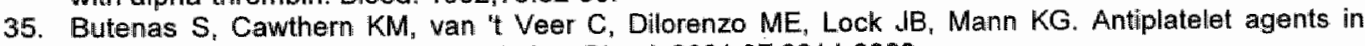
tissue factor-induced bload coagulation. Blood. 2001;97:2314-2322

36. Gianetti $J$, De Caterina $M$, De Cristofaro $T$, Ungaro $B$, Guercio $R D$, De Caterina $R$. Intravenous prostaglandin E1 reduces soluble vascular cell adhesion molecule-1 in peripheral arterial obstructive disease. Am Heart J. 2001;142:733-739.

37. Weiss $T$, Fischer D, Hausmann D, Weiss $C$. Endothelial function in patients with peripheral vascular disease: influence of prostaglandin E1. Prostaglandins Leukot Essent Fatty Acids. 2002;67:277-281.

38. Makino $H$, Aoki M, Hashiya $N$, Yamasaki $K$, Hiraoka $K$, Shimizu $H$, Azuma J, Kurinami $H$, Ogihara $T$, Morishita $R$. Increase in peripheral blood flow by intravenous administration of prostaglandin $E 1$ in patients with peripheral arterial disease, accompanied by up-regulation of hepatocyte growth factor. Hypertens Res. 2004;27:85-91. 


\section{Chapter 7}

\section{Platelet-dependent coagulation regulates arterial}

\section{and venous thrombus formation in vivo}

Marijke J. E. Kuijpers, Imke C. A. Munnix, Judith M. E. M. Cosemans, Chris P.M. Reutelingsperger, Mirjam G. A. oude Egbrink and Johan W.M. Heemskerk

Submitted for publication 


\section{Abstract}

The interactions between plateles activation and coagulation have extensively been studied in vitro, but not in vivo. The present study investigated the contribution of pracoagulant platelets to thrombin generation and thrombus formation in a mouse model of arterial and venous thrombosis, where vascular darnage was induced by $\mathrm{FeCl}_{3}$. in either vessell type, thrombus formation appeared to be triggered by tissue factor-factor VII(a) interaction and collagen exposure. Moderate thrombin inhibition or platelet inhibition suppressed arterial thrombus formation. while high thrombin inhibition or combination with platelet inhibition was necessary to suppress thrombosis in veins. Thrombus formation in either vessel type was characterized by the presence of PS (PS)-exposing platelets, detected with fluorescently labeled annexin A5. Shielding of exposed PS by injected annexin A5 completely abolished the formation of arterial and venous thrombi, while mutant M1234-annexin A5 was ineffective. Thus, in this thrombosis model, initiation occurs by tissue factor and collagen exposure, followed by propagation of thrombin generation by PS-exposing platelets. The latter appears to be a key regulatory process in veins and arteries. Platelet-dependent thrombin generation, which is most active in venous thrombus formation, may constitute a clinically relevant target to reduce thrombosis.

\section{Introduction}

Undesired thrombus formation both in veins and arteries can be life-threatening. The current understanding is that activated platelets on one side and the coagulation system on the ather side contribute in different ways to pathological thrombosis in veins and arteries. Thrombi formed in the venous system are mastly rich in fibrin and trapped red cells, though relatively poor in platelets. This is in paradox with the fact that thrombin is one of the most potent platelet agonists $(1,2)$, which implicates that platelets must become activated at sites of thrombin generation in veins. On the other hand, arterial thrombosis is associated with undesired platelet activation; thus, "white" thrombi formed in atherothrombotic arteries are rich in aggregated platelets, although fibrin is detectable here as well. In clinicall practice, anticoagulant drugs such as heparins and active-site thrombin inhibitors are preferentially used to reduce venous thromboembolism, while platelet inhibition is preferred in case of arterial thrombosis. In recent years, however. there is increasing interest in combination therapy of anticoagulant and antiplatelet drugs (3). This urges for better knowledge of the interaction mechanisms of platelet activation and coagulation in vivo.

In vitro studies on the regulation of thrombin generation in platelet rich plasma (PRP) have clearly shown that platelet inhibition, e.g. with cAMP-elevating agents or integrin $\alpha$ llb $\beta 3$ antagonists, have an anticoagulant effect by slowing down the formation of thrombin and fibrin 
$(4,5)$. Although there is strong evidence that (activated) platelets stimulate the coagulation process $(6,7)$, the mechanism behind this effect is still disputed partly because in vivo evidence is lacking. Studies in vitro have pointed to specific binding of coagulation factors (prothrombin and factors $V, X$ and $X I)$ to platelet integrins and other receptor proteins $\left(8_{n}, 9\right)$. There is also evidence that tissue factor (TF) binding to platelet aggregates and thrombi can stimulate the coagulation process $(10,11)$. Another proposed mechanism concerns the exposure of procoagulant phasphatidylserine (PS) at the outer surface of activated platelets. In vitro, PS serves as a site for the assembly of coagulation factor complexes, which greatly enhance thrombin generation and, hence, coagulation (12,13). Platelet interaction with immobilized collagen is a strong trigger of this procoagulant response $(14,15)$, while platelet stimulation via the thrombin receptors is less effective (16). How important these processes, such as TF accumulation and PS exposure, are in pathological thrombus formation in vivo is completely unclear.

The present work was directed to resolve this question. We studied the procoagulant function and mechanism of pllatelets in an established murine thrombosis model of $\mathrm{FeCl}_{3}$ induced vascular damage, known to be sensitive to platelet inhibition as well as anticoagulant activity $(2,17-19)$. The data show that PS exposure plays a prominent role in the thrombotic process in both veins and arteries. In either vessel type, procoagulant platellets in part activated by collagen, together with triggering of the TF pathway appear to mediate local thrombin generation and fibrin formation. These findings suggest that the platelet procoagulant response may constitute an attractive novel target for antithrombotic therapies.

\section{Materials and methods}

Animals

C57BL/6 mice of 4-5 weeks old (11-21 g) or 12 weeks old $(20-25 \mathrm{~g})$ of either sex were obtained from Charles River (Maastricht, the Netherlands). Mice deficient in FoRy-chain were from Taconics (Germantown, NY. USA) (20). Experiments were approved by the local animal care and use committee.

\section{Materials}

Fibrillar Horm collagen from equine tendon (Horm type-1) was purchased from Nycomed Pharma GmbH (Munich, Germany). Unfractionated heparin (ISH 1), prostaglandin $E_{1}$ and rhodamin 6G were from Sigma (St. Louis, MO, USA). Annexin A5, unlabeled and labeled with fluorescein isothiocyanate (FITC), and M1234-annexin A5 were from Nexins Research (Hoeven, the Netherlands); acridine red came from Chroma (Stuttgart, Germany). Recombinant 
human tissue lactor was from Dade (Düdingen, Switserland); Z-Gly-Gly-Arg aminomethyl coumarin (Z-GGR-AMC) and Gly-Pro-Arg-Pro (GPRP, Pefablock) were from Bachem (Bubendorf, Switzerland), FeCl 3 was from Merck (Darmstadt, Germany). Hematoxylin and eosin came from Kinipath (Duiven, the Netherlands). Ketamine and Xylazine were from Eurovet (Bladel, the Netherlands). Transfected cells expressing CDNA encoding for the annexin A5 mutant M1234 were provided by Dr. F. Russo-Marie (Bionexins-Pharmaceuticals, France). Melagatran was kindly provided by Dr. M. Elg (AstraZeneca, Mölndal, Sweden). Mouse tissue factor, anti-mouse tissue factor antibody and mouse factor Vllai (active site-inhibited seven, ASIS) (21) were kindly provided by Dr. P. Tijburg (Novo Nordisk, Bagsvæerd, Denmark).

\section{Perfusion of whole blood under coagulant conditions}

Mice were bled retro-orbitally under full anaesthesia by subcutaneous injection of 0.1 $\mathrm{mg} / \mathrm{g}$ body weight (bw) ketamine and $0.02 \mathrm{mg} / \mathrm{g}$ bw xylazine. Blood ( 9 volumes) was collected in 1 volume of citrate $(0,129 \mathrm{M})$. Anticoagulated blood (1 volume) was diluted with Hepes buffer $\mathrm{pH}$ 7.45 ( 0.5 volume) containing $137 \mathrm{mM} \mathrm{NaCl}, 5.6 \mathrm{mM}$ glucose, $5 \mathrm{mM} \mathrm{Hepes,} 2.7 \mathrm{mM} \mathrm{KCl}, 2 \mathrm{mM}$ $\mathrm{MgCl}_{2}, 2 \mathrm{mM} \mathrm{CaCl}, 0.42 \mathrm{mM} \mathrm{NaH} \mathrm{PO}_{4}, 0.1 \%$ (w/w) bovine serum albumin (BSA). Adhesion experiments under coagulant flow conditions were performed, as described earlier (22). Briefly, coverslips ( $24 \times 60 \mathrm{~mm}$ ) were coated with Horm collagen type I fibers $\left(50 \mu \mathrm{g} / 50 \mathrm{~mm}^{2}\right.$ ), rinsed with saline, and blocked with Hepes buffer $\mathrm{pH} 7.45$ containing $1 \%$ (w/v) BSA. Coverslips were placed in a parallel-plate transparent flow chamber (slit depth $50 \mu \mathrm{m}$ ) and mounted on an inverted Nikon microscope. The chamber was connected via a three-way siliconized polyethylene plastic tube (diameter $1 \mathrm{~mm}$ ) to plastic $1 \mathrm{ml}$ syringes placed in two pulse-free perfusion pumps (Harvard Apparatus). Pump 1 contained a syringe filled with blood (normall perfusion rate of $4.5 \mathrm{ml} / \mathrm{h}$ ); pump 2 contained a syringe with $200 \mathrm{mM} \mathrm{CaCl}$ and $20 \mathrm{pM}$ TF in Hepes buffer pH 7.45 (perfusion rate $0.45 \mathrm{ml} / \mathrm{h}$ ). Together, these pumps produced a wall shear rate at the flow chamber surface of $1000 \mathrm{~s}^{-1}$. Where indicated, blood was labeled with $0.5 \mu \mathrm{g} / \mathrm{ml}$ FITC-annexin A5 before perfusion. During perfusion, high-resolution microscopic images of transmission or fluorescence were recorded in real-time with a Visitech imaging system (Sunderland, UK). Per experiment, at least 10 representative images were captured with two parallel-placed intensified, CCD cameras, recording infrared $(0.3 \mathrm{~Hz})$ and epifluorescence $(0.5$ $\mathrm{Hz}$ ) light (14). Excitation and emission wavelengths were $485 \pm 11$ and $530 \pm 15 \mathrm{~nm}$, respectively. Platelet surface coverage of images was analyzed using ImagePro software (Media Cybernetics, Silver Spring. MD) for phase contrast images and Quanticell software (Visitech, Sunderland, UK) for fluorescent annexin A5 images. 


\section{Animal preparation and intravital microscopy}

Four to 5-week old mice were anesthetized by subcutaneous injection of $0.1 \mathrm{mg} / \mathrm{g}$ body weight (bw) ketamine and $0.02 \mathrm{mg} / \mathrm{g}$ bw xylazine. Anesthesia was maintained by continuous infusion of ketamine $(0.07 \mathrm{mg} / \mathrm{g} / \mathrm{h})$ through a subcutaneous polyethylene (PE)-10 catheter in the neck. Pharmacologicall agents were administered intravenously through a PE-10 catheter in the tail vein. Dehydration during the experiment was prevented by a subcutaneous bolus injection of saline $(1.5 \mathrm{ml})$. Body temperature was kept at $37^{\circ} \mathrm{C}$ using an infrared heating lamp "controlled by a thermo-analyzer system connected to a rectal probe.

A segment of the ileum was exteriorized through a right side abdominal incision. The mesentery was spread over a siliconized glass plate mounted on an electrically heated table $\left(37^{\circ} \mathrm{C}\right)$ of a Leitz intravital microscope, and continuously superfused with a buffered Tyrode's solution (130 mM NaCl, $5.6 \mathrm{mM} \mathrm{KCl}, 2.2 \mathrm{mM} \mathrm{CaCl}, 0.56 \mathrm{mM} \mathrm{MgCl}, 11.1 \mathrm{mM}$ glucose, 13.1 $\mathrm{mM}$ sucrose, $25 \mathrm{mM} \mathrm{NaHCO}_{3}$ and $1.2 \mathrm{mM} \mathrm{NaH}_{2} \mathrm{PO}_{4} ; \mathrm{pH} 7.35$ at $37^{\circ} \mathrm{C}$ ) supplemented with 1 $\mu \mathrm{g} / \mathrm{ml}$ isoprenaline and saturated with $95 \% \mathrm{~N}_{2}$ and $5 \% \mathrm{CO}_{2}$. The exteriorized ileum was kept moist with overlying wet gauze. Mesenteric tissue was visualized by intravital microscopy, using an LL25 objective lens (numerical aperture 0.35) and a CCD camera (Hamamatsu) as described previously (23).

Where indicated, (fluorescently labeled) compounds were injected (bolus, $100 \mu$ ) via the tail vein catheter, either immediately before or after application of $\mathrm{FeCl}_{3}$. Controll mice received the same volume of saline (vehicle). High-resolution fluorescence images were observed by epi-illumination with a Xenon lamp, using an SW50 objective (numerical aperture 1.0), a sensitive, high-resolution fluorescence imaging system and an intensified CCD camera (Photonic Sciences), as described (23).

\section{Thrombus formation in vivo}

After selection of a fat-free mesenteric arteriole with a proximate venule superfusion with Tyrode's buffer was stopped, and the remaining fluid was carefully removed from the mesentery. Vessel wall damage was induced by topical application of $\mathrm{FeCl}_{3}(30 \mu l, 500 \mathrm{mM})$, which never caused bleeding. Arterioles constricted by $19 \%$ upon application of $\mathrm{FeCl}_{3}$, while venular diameters did not change (Table 7.1). After $\mathrm{FeCl}_{3}$ application, vessels were observed for $600 \mathrm{~s}$, either under trans-illumination by bright-field microscopy and/or under epi-illumination by fluorescence microscopy. For each vessel, the following parameters were quantified from video recordings off-line: lag time to first observation of thrombus formation, thrombus height perpendicular to the vessel wall (expressed relative to local vessell diameter) at 2, 5 and 10 min after $\mathrm{FeCl}_{3}$ application, and time to occlusion. Where indicated, acridine red $(30 \mu \| \mathrm{lof} 5 \mathrm{mg} / \mathrm{ml})$ was injected intravenousily for higher resolution fluorescence imaging of labeled thrombi. After 
intravital microscopy , blood was drawn from the mice by retro-orbital puncture and collected into citrate $(0.129 \mathrm{M})$. Isolated plasmas were frozen at $-80^{\circ} \mathrm{C}$.

To determine wall shear rates (WSR) in representative mesenteric arterioles and venules, two mice were injected with rhodamin $6 \mathrm{G}(30 \mu \mathrm{l}$ of $1 \mathrm{mg} / \mathrm{ml}$ solution, intravenous) for labeling of circulating leukocytes. Fluorescence microscopy was applied to quantify centerline blood flow velocities in 8 arterioles and 8 venules, using the fastest passing leukocyte as a marker (24). WSR were calculated according to the Newtonian definition: WSR $=8 \times$ (mean velocity / vessel diameter $)$, where mean velocity represents the centerline velocity / $1.6(25)$. The resulting WSR represent least estimates of the actual WSR (26).

\section{Thrombin Generation Measurements}

Murine platelet poor plasma (PPP) or platellet rich plasma (PRP) was prepared from blood from 12 week old mice as described (27). Thrombin generation was measured using the thrombogram method (28), adapted for murine plasma. Briefly, normalized PRP (1.5 $\times 10^{8}$ platelets/ml) or PPP (supplemented with $4.0 \mu \mathrm{M}$ vesicles of phosphatidylserine phasphatidylcholine: phosphatidylethanolamine $=1: 3: 1$ ) was preincubated with inhibitors for $10 \mathrm{~min}$ at room temperature, as indicated. Subsequently, $40 \mu 1$ of PRP or PPP was added to a 96-well plate, containing per well $10 \mu \mathrm{TF}$ (6 pM) in Hepes buffer $(20 \mathrm{mM} \mathrm{Hepes,} 140 \mathrm{mM} \mathrm{NaCl}$, $5 \mathrm{mg} / \mathrm{ml}$ bovine serum albumin, $\mathrm{pH} 7.35$ ). TF was diluted to a concentration (1 pM) at which thrombin formation depended on the presence of platelet expressed PS. Thrombin formation was started by adding $10 \mu \mathrm{l}$ of $\mathrm{CaCl}_{2}(16.6 \mathrm{mM})$ and Z-GGR-AMC $(2.5 \mathrm{mM})$ in Hepes buffer. Fluorescence was continuously measured in time at $37^{\circ} \mathrm{C}$ with a Fluoroscan Ascent well-plate reader (Thermolab Systems). First-derivative curves of accumulation of fluorescence were generated as described (29), but were not processed for $\alpha_{2}$-macroglobulin correction, as the activity of $\alpha_{2}$-macroglobulin-bound thrombin in murine blood is unknown. Assays were run in duplicates or triplicates" calibrations were performed with human thrombin.

Immunohistochemical staining

After intravital experimentation, intestine with attached mesentery was collected from mice for histology. Subsequently, the removed tissues were fixed in freshly dissolved paraformaldehyde ( $1 \%$ in phosphate buffered saline) at $4^{\circ} \mathrm{C}$ for $24 \mathrm{~h}$, routinelly processed and embedded in paraffin. Sections of $4 \mu \mathrm{m}$ were cut and stained with hematoxylin and eosin.

\section{Statistical analysis}

Data from in vivo experiments displayed nonsymmetrical distribution and are presented as median values with interquartile ranges. Data from in vitro flow chamber and thrombin 
generation experiments are presented as mean \pm SEM. Differences between experimental groups were tested with the non-parametric Mann-Whitney $U$ test, using the statistical package for social sciences (SPSS 11.0). Level of significance was set at $5 \%$.

\section{Results}

Tissue factor-induced thrombin formation and collagen contribute to platelet phosphatidy/serine exposure in flowing blood

To evaluate the importance of the interaction between platelet activation and coagullation in thrombus formation, perfusion studies were performed with mouse blood, which was recalcified and activated with a low dose of TF (2 pM), directly before entering a collagencontaining flow chamber (shear rate $1000 \mathrm{~s}^{-1}$ ). This resulted in early platelet deposition. subsequent aggregate formation and appearance of fibrin fibers after a lagtime of $2-3$ minutes. At a more advanced stage (7-8 minutes), the chamber became occluded by large fibrin-platelet thrombi with trapped red cells (Fig. 7.1A). The activation state of adhered platelets was monitored by labeling blood with FITC-annexin A5 $10.5 \mu \mathrm{g} / \mathrm{ml}$, a low dose not influencing
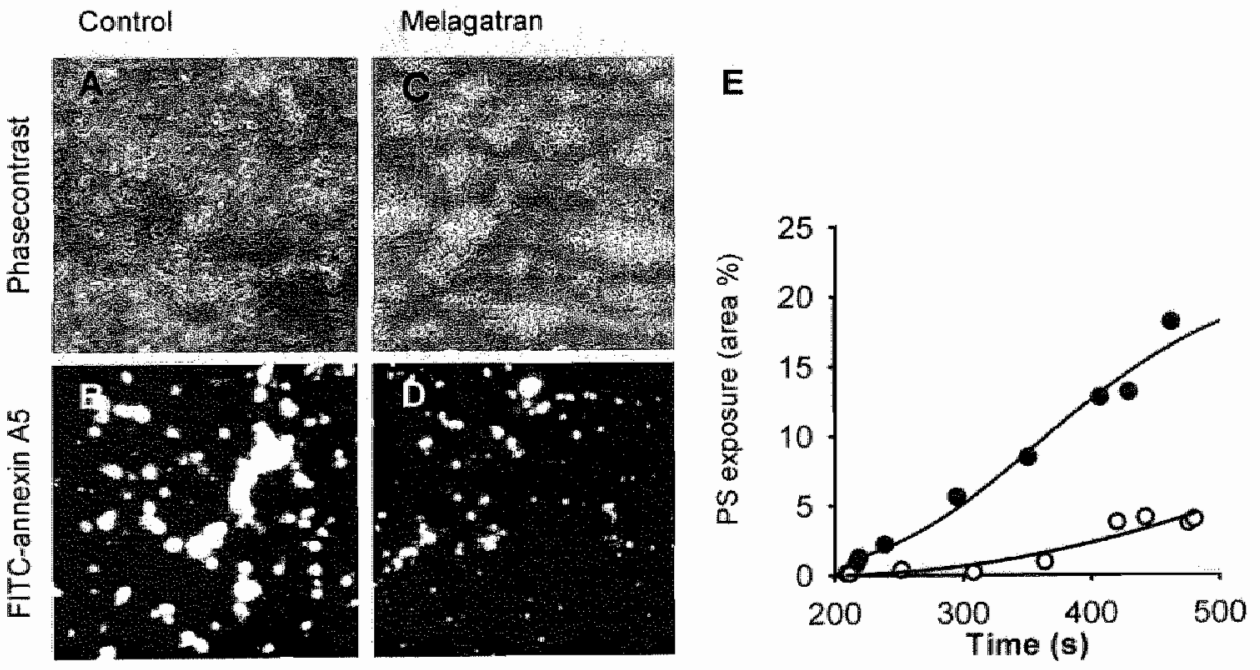

Figure 7.1. Contribution af coagulation to thrombus formation and platelet phosphatidylserine exposure in flowing blood triggered by tissue factor and collagen. Citrated mouse blood was perfused for 4 minutes over a collagen surface at a shear rate of $1000 \mathrm{~s}^{-1}$. During perfusion, coagulation was triggered with $2 \mathrm{pM}$ tissue factor and $20 \mathrm{mM} \mathrm{CaCl}$ (resulting in about $2 \mathrm{mM}$ free $\mathrm{Ca}^{2 *}$ ) in the absence $\left(A_{,} B\right.$ ) or presence of 5 $\mu g / m$ melagattran (C. D). Representative phase contrast images $(A, C)$ and fluorescence images ( $B$, $D$; labeled phosphatidylserine-exposing platelets) are given, taken after 4 minutes of perfusion of blood and 4 minutes wash with $0.5 \mu \mathrm{g} / \mathrm{ml}$ FITC-annexin A5 $(\mathrm{n}=3)$. (E) Accumulation of fluorescence at the collagen surfiace during perfusion of bload prelabeled with $0.5 \mu \mathrm{g} / \mathrm{ml}$ FITC-annexin A5 and triggered with tissue factori $\mathrm{CaCl}_{2}$. Control condition $(\cdot), 5 \mu \mathrm{g} / \mathrm{ml}$ melagatran $(0)$. 

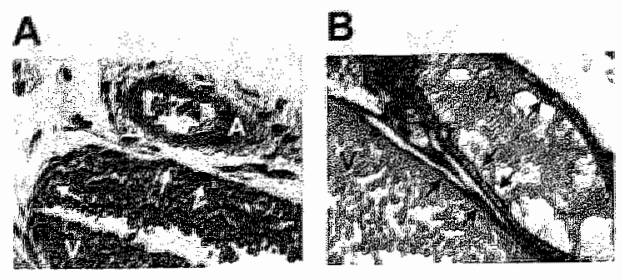

Figure 7.2. FeCla application results in endothellial denudation of mesenteric arterioles and venules. (A) Control and (B) FeCly-treated paraffin sections of mesenteric arterioles (a) and venules (v) were stained with hematoxylin and eosin. Nuclei of endothelial cells stained strongly in untreated vessels (A) indicated by the arrows, while almost no endothelial cells were seen after $\mathrm{FeCl}_{3}$ treatment (B). Note that vessels and thrombi were not fixed prior to removal from the mouise.

coagulation) to detect PS-exposing platelets. After 8 minutes, many collagen-adherent and aggregated platellets exposed PS, covering about $20 \%$ of the surface area (Fig. 7.1B). Perfusion was also performed in the presence of melagatran $(5 \mu \mathrm{g} / \mathrm{ml})$, a high affinity, active-site thrombin inhibitor (30). In this case, aggregate formation still occurred, but fibrin fibers were absent, as were occlusive thrombi containing red cells (Fig. 7.1C). In this case, only the collagen-bound platelets exposed PS, covering $5 \%$ of the surface area (Fig. 7.1D). Quantitative analysis indicated that melagatran significantly but incompletely reduced the appearance of PS-exposing platelets during the whole flow experiment (Fig. 7.1E). In the absence of collagen, aggregates or PS-exposing platelets were not formed in this time interval (not shown). These results with melagatran resemble earlier flow data obtained with wildtype murine blood anticaagulated with PPACK/heparin (27). Together, these data indicate that, under these in vitro flow conditions, platelet-collagen interaction and activation of the TF pathway synergize in generating procoagulant platelets and stable platelet-fibrin thrombi.

\section{Tissue factor and collagen trigger thrombus formation in arterioles and venules}

Using an established mouse model of arterial and venous thrombus formation, intravascular thrombi were generated by topical application of $\mathrm{FeCl}_{3}$ on adjacent arterioles and venules in a mesenteric intestinal loop of anesthetized mice. This model of vascular damage is known to rely on local free radical formation (31). $\mathrm{FeCl}_{3}$ application resulted in almost complete disruption and denudation of the endothelial cells and full exposure of the sub-endothelial matrix, as demonstrated by hematoxylin/eosin stained paraffin sections of the mesenteric tissue (Fig. 7.2).

Intravital microscopic trans-illumination images indicated that, in venules, $\mathrm{FeCl}_{3}$ induced local accumulation of platelets into large thrombi within a few seconds, while in arterioles this process started only after a lagtime of several minutes (Fig. 7.3A). However, thrombus build-up was more rapid in arterioles than in venules; at 10 min after $\mathrm{FeCl}_{3}$ application the incidence of total occlusion was comparable for arterioles $(33 \%)$ and venules (42\%) (Table 7.1). Median wall shear rates were $1336 \mathrm{~s}^{-1}$ in arterioles and $285 \mathrm{~s}^{-1}$ in venules. Some mice were injected intravenously with acridine red, which labels platelets and leukocytes in vivo, to confirm the more rapid onset of thrombus formation in venules compared to arterioles, using a sensitive fluorescence vildeo imaging approach (23). Again, application of $\mathrm{FeCl}_{3}$ caused rapid 
A
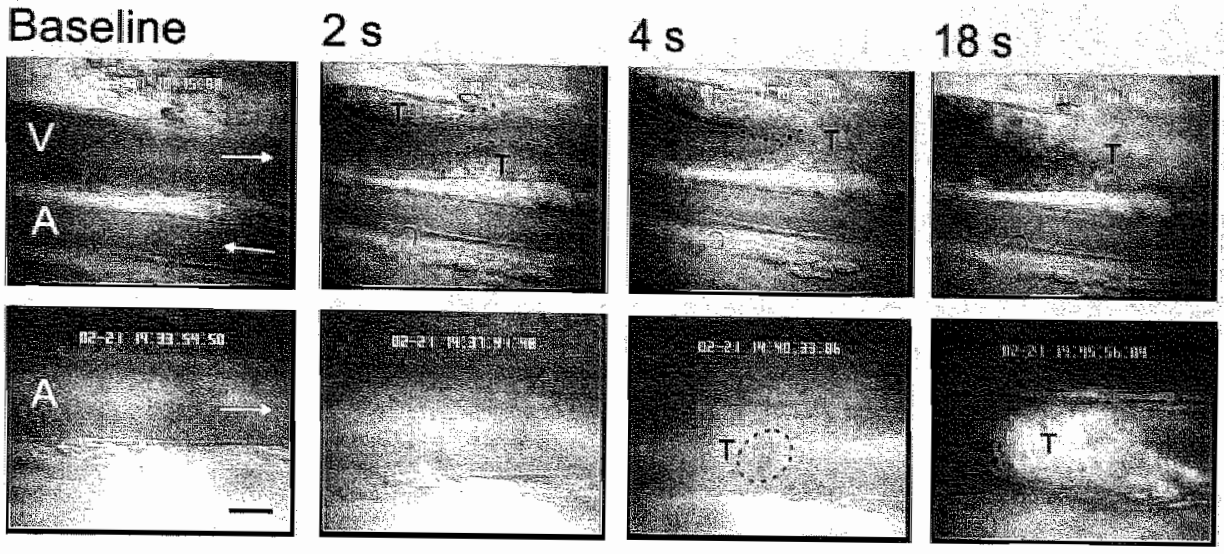

Baseline

$2 \min$

5 min

$10 \mathrm{~min}$

B
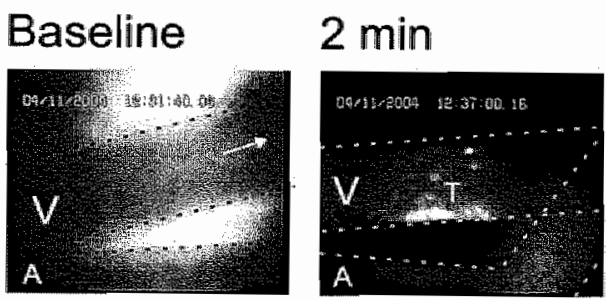

\section{$10 \mathrm{~min}$}
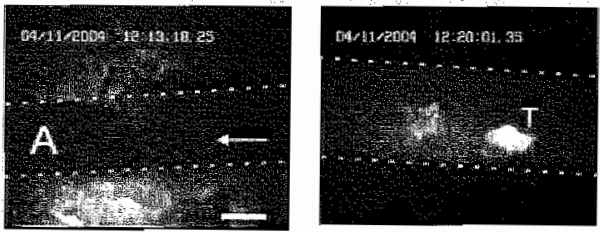

Baseline

$5 \mathrm{~min}$
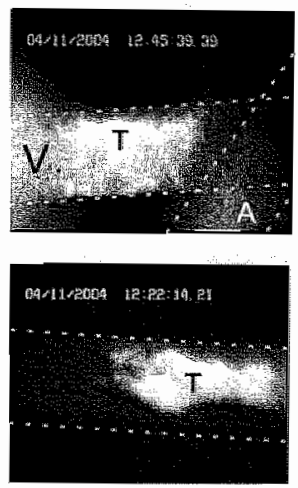

$10 \mathrm{~min}$

Figure 7.3. Frogression of thrombus formation in arterioles and venules. Damage of adjacent mesenteric arterioles and venules was induced by topical application of $\mathrm{FeCl}_{3}$ at $\mathrm{t}=0$ sec (baseline). (A) Transillumination images of thrombus formation in venule ( $V_{\text {; }}$ upper panels) and arteriole ( $A_{i}$ lower panels). Dotted lines indicate contours of a thrombus (T). (B) Fluorescence images of thrombus formation with platelets labeled with acridine red in venule (upper panels) and arteriole (lower panels); dotted lines indicate vessel wall. Arrows indicate direction of flow; bars represent $50 \mu \mathrm{m}$.

accumulation of fluorescently labeled platelets in venules, and in arterioles platelet deposition was delayed (Fig. 7.3B). Topical application of the hydrophilic molecule acridine red, which has a similar molecular weight as $\mathrm{FeCl}_{3}$ (about $300 \mathrm{Da}$ ), on the mesenteric vessels resulted in almost simultaneous appearance of the fluorescent dye in arterioles and venules (data not 
Table 71. Control parameters of arterioles and venules from wildtype mice before and after $\mathrm{FeCl}_{3}$ application

\begin{tabular}{lcc}
\hline & Arterioles & Venules \\
\hline $\begin{array}{l}\text { Number of vessels (mice) } \\
\text { Vessel diameter before FeCl }(j \mathrm{~m})\end{array}$ & $30(23)$ & $20(16)$ \\
Wall shear rate (s) & $70(60-80)$ & $110(80-130)^{*}$ \\
After application of FeCls: & $1336(906-1400)$ & $285(219-434)^{*}$ \\
constriction $(\%$ of diameter) & & $0(0-10)^{*}$ \\
occlusion during 10 min (\% of vessels) & $19(8-30)$ & 42 \\
occlusion time of occluded vessels (s) & 33 & $361(113-392)^{+}$ \\
\hline
\end{tabular}

Data are median values (and interquartile ranges). Wall shear rate was determined in 8 vessels. * $p \leq 0.05$; ${ }^{+} p=0.08$ as compared to arterioles.

A

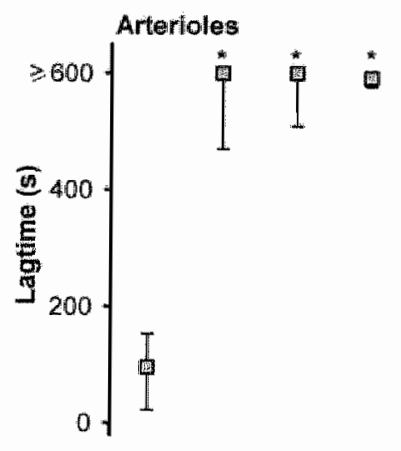

$\mathbf{B}$

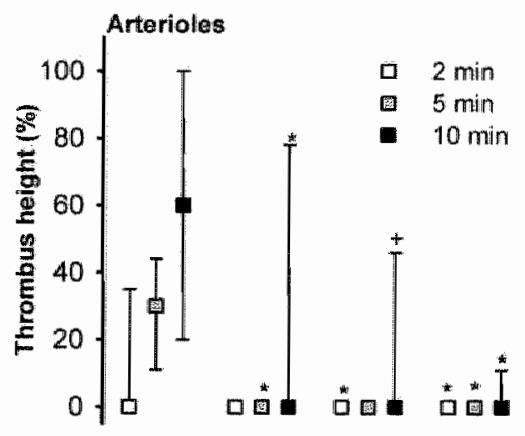

Figure 7.4. Effects of tissue factor and factor VIla inhibition and GPV/ deficiency on thrombus formation in arterioles and venules in vivo. Wildtype mice were treated systemically with vehicle (controly, $3 \mu \mathrm{g} / \mathrm{g}$ bw antimouse tissue factor antibody (anti-mTF) or $10 \mu \mathrm{g} / \mathrm{g}$ bw factor Vllai (FVllai). Mesenteric vessels of wildtype and $\mathrm{FcR}$-chain $/$ mice were damaged by topical application of $\mathrm{FeCl}_{3}$. (A) Lagtime to thrombus formation after $\mathrm{FeCl}_{3}$ application. (B) Thrombus height measured at 2, 5 and 10 min after $\mathrm{FeCl}_{3}$ application (\% of vessel diameter). Data are median values with interquartile ranges $(n=6-12)^{*} p \leq 0.05$ as compared to conitrol; ${ }^{*} p \leq 0.1$ compared to control. 
A
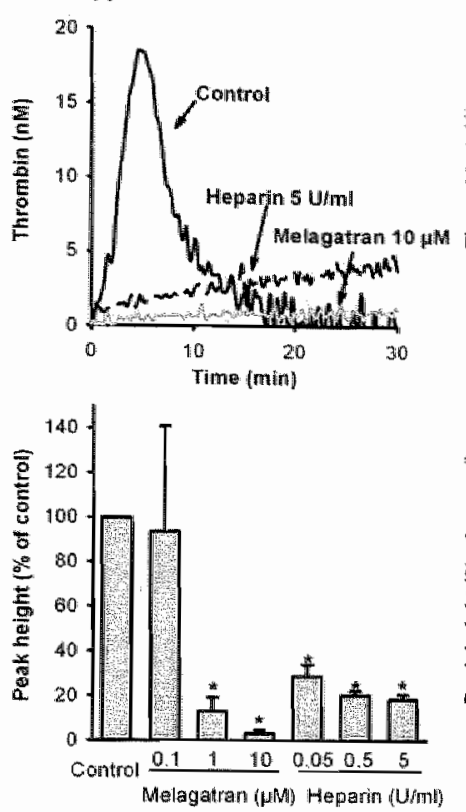

$B$
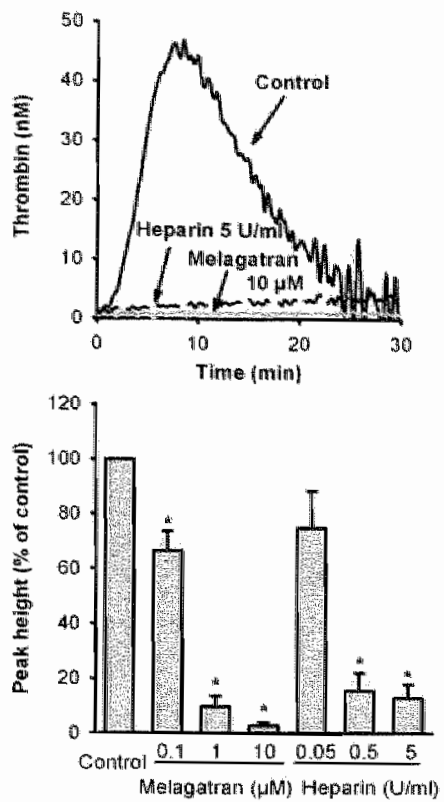

Figure 7.5. Effects of melagatran and heparin on tissue factor-triggered thrombin generation in vitro. (A) Citrated PPP. supplemented with $4 \mu \mathrm{M}$ phospholipids, or (B) PRP containing $1.5 \times 10^{8}$ platelets $/ \mathrm{ml}$ was incubatted with $0.1-10 \mu \mathrm{M}$ melagatran or $0.05-5 \mathrm{U} / \mathrm{ml}$ heparin. Thrombin generation was determined after activation with $1 \mathrm{pM}\left(f_{.} c\right.$.) tissue factor and $16.6 \mathrm{mM} \mathrm{CaCl}$ by measuring fluarescence accumulation from cleaved Z-GGR-AMC. Upper panels show representative thrombograms for 3 independent experiments: lower panels show effects on thrombin peak height relative to control condition without thrombin inhibitor (mean $\pm \mathrm{SEM}, \mathrm{n}=3-5$ ). * $\mathrm{p} \leq 0.05$ as compared to control.

shown). This suggests that the wall of either vessel type is similarly permeable for such small molecules.

To determine the involvement of TF in this thrombosis model, we inhibited TF activity or, alternatively, its ligand factor $\mathrm{V} \| l(\mathrm{a})$ in wildtype mice. Intravenous administration of $3 \mu \mathrm{g} / \mathrm{g} \mathrm{bw}$ anti-murine TF antibody significantly delayed and reduced the thrombotic process in both arterioles and venules (Figure 7.4). Injection of $10 \mu \mathrm{g} / \mathrm{g}$ bw mouse active site-inhibited factor $\mathrm{V} / \mathrm{I}$ (factor VIlai) had a similar inhibitory effect. In vitro experiments showed that thrombin generation in mouse plasma was completely blocked with anti-TF antibody or factor Vllai leach $20 \mu \mathrm{g} / \mathrm{ml}$, not shown). Similarly, in plasma samples taken from mice injected with factor Vllai, thrombin generation was delayed and reduced to $6.8 \pm 2.4 \%$ of control level. Thus TF$_{\|}$, probably present in the extracellular matrix, had an initiating role in the thrombus-forming process in arterioles and venules by interaction with factor VII(a). Other experiments showed that platelet interaction with exposed collagen also contributed in this mouse modiel. Mice deficient in the FcR $y$-chain, which do mot express the activating collagen receptor GPVI on platelets (32), showed a delayed and significantly reduced thrombus build-up in arterioles and venules (Figure 7.4 ). Injection of 
A
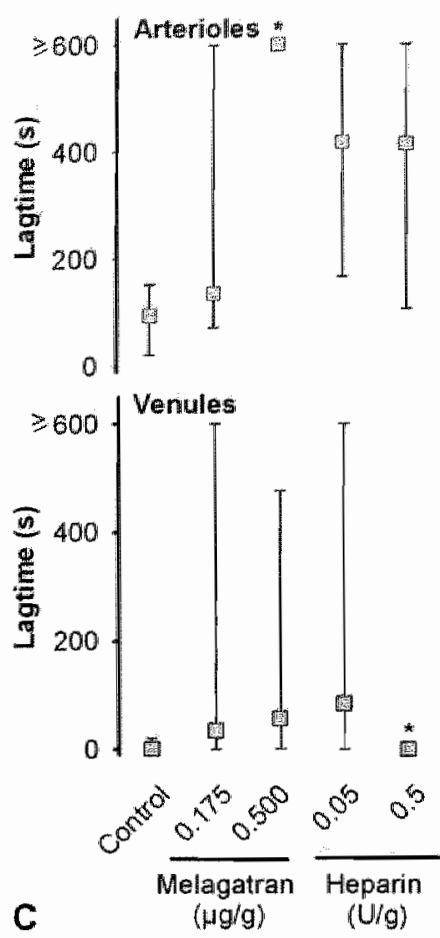

B

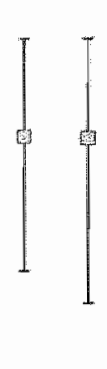

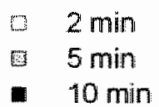
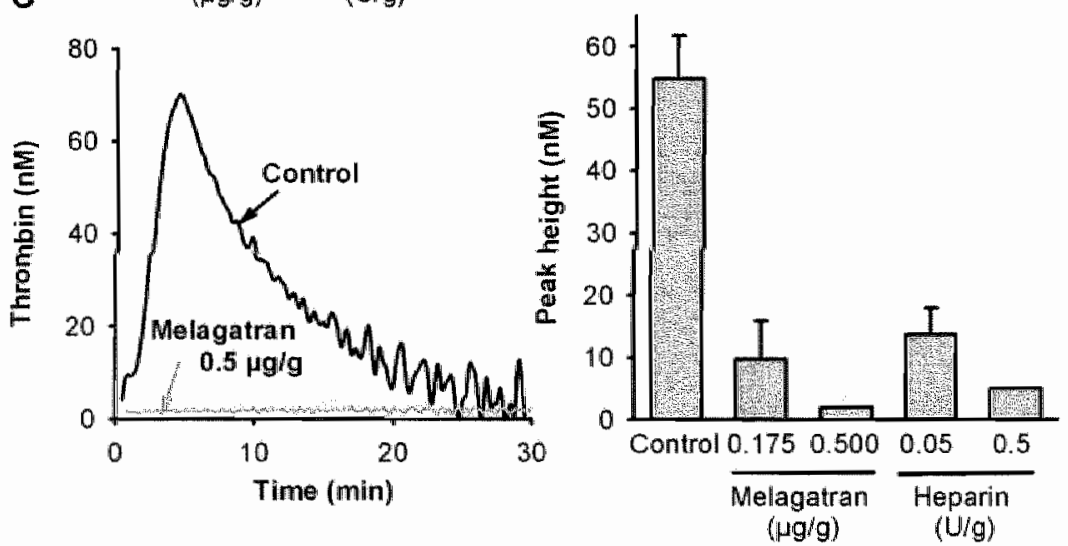

Figure 7.6. Effects of melagatran and heparin on thrombus formation in arterioles and venules in vivo. Mice were treated systemically with vehicle (control), $0.175-0.500 \mu \mathrm{g} / \mathrm{g}$ bw melagatran or $0.05-0.5 \mathrm{U} / \mathrm{g}$ bw heparin. Mesenteric vessels were damaged by topical application of $\mathrm{FeCl}_{3}$. (A) Lagtime to thrombus formation after $\mathrm{FeCl}_{3}$ application. (B) Thrombus height measured at 2, 5 and 10 min after $\mathrm{FeCl}_{3}$ application (\% of vessel diameter). Data are median values with interquartile ranges $(n=6-9)$. ${ }^{*} p \leq 0.05$ as compared to control. (C) Effect of in vivo infusion of melagatran or heparin on thrombin generation in PPP. supplemented with $4 \mu \mathrm{M}$ phospholipids. PPP was prepared from blood collected at the end of in viwo measurements. Left panel shows representative thrombograms; Right panel shows bar graph of measured thrombin peak height (mean \pm SEM; $n=1-9$ ). 
mice with the inhibitory anti-GPVI antibody JAQ1 gave similar results (33). Thuls, in this model, both activation of coagulation by exposed TF/factor VI(a) and platelet activation by collagen appear to initiate the thrombotic process.

\section{Thrombin inhibition differently affects thrombus formation in damaged arterioles and venules.}

Before intravenous administration into mice, the efficacy of two thrombin inhibitors in murine plasma was tested in thrombin generation measurements using the thrombogram method. The high-affinity, active-site thrombin inhibitor melagatran was used (30), as well as unfractionated heparin, which acts indirectly by enhancing the antithrombin-mediated inactivation of thrombin and factor Xa (34). Each compound substantially reduced thrombin generation in murine plasma activated with TF bath in the presence of procoagulant phospholipids (Fig. 7.5A) and in the presence of platelets (Fig. 7.5B). Effects on peak height of thrombin generation curves (maximal levels) were measured, which parameter is proportional to the maximal rate of thrombin generation (35). Dose-response experiments indicated a $50 \%$ reduction in maximal thrombin levels in the presence of phospholipids at about $0.5 \mu \mathrm{M}$ melagatran and $<0.05 \mathrm{U} / \mathrm{ml}$ heparin. In the presence of platelets, the reducing effect of melagatran on thrombin peak height was similar. However, a six-fold higher dose of heparin $(0.2$ $\mathrm{U} / \mathrm{ml}$ ) was needed for $50 \%$ inhibition; this difference is prabably due to an activating effect of heparin on platelets (36). Typically, considerable (nanomolar) concentrations of thrombin were still generated, with both phospholipids and platelets, at high heparin $(5 \mathrm{U} / \mathrm{ml})$ but not high melagatran (10 $\mu \mathrm{M}$ ) doses (Fig. 7.5, lower panels).

Mice were injected with a moderate dose of melagatran or heparin to give about threefold prollongation in clotting time (as determined in vitro), and used to study thrombus formation in vivo; higher doses were used as well. In comparison to vehicle controls, injection of 0.175 $\mu \mathrm{g} / \mathrm{g}$ bw melagatran did not influence the lagtime to thrombus formation in arterioles (Fig. 7.6A), but thrombus height was significantly reduced (Fig. 7.6B). After intravenous administration of a three-fold higher melagatran dose $(0.5 \mu \mathrm{g} / \mathrm{g} \mathrm{bw})$, the arterialar lagtime to thrombus formation was prolonged ( $>600 \mathrm{~s}, \mathrm{p}=0.05, \mathrm{Fig} .7 .6 \mathrm{~A}$ ), while thrombus build-up was again greatly reduced (Fig. 7.6B). Venular thrombus formation was inhibited only by the higher dose of melagatran (Fig. 7.6A, B). None of the arterioles and venules accluded within $10 \mathrm{~min}$ with the moderate and high dose of melagatran. At the end of the experiments, plasma samples were taken and used for thrombin generation measurements. As indicated in $\mathrm{Fig} .7 .6 \mathrm{C}$, thrombin peak height was diminished to $18 \%$ and $4 \%$ of control, respectively, after administration of these melagatran doses. 


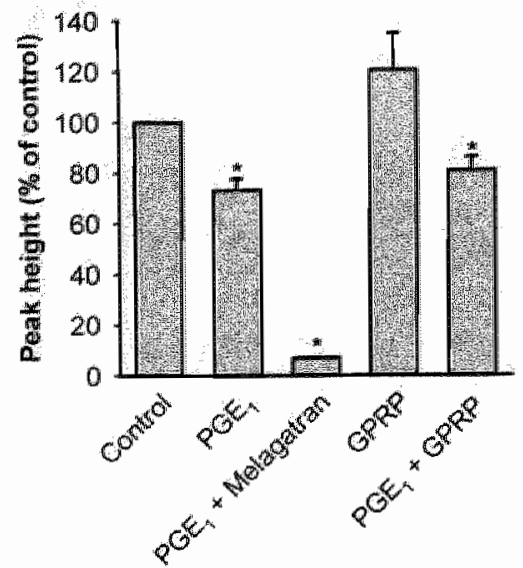

Figure 7.7. Effects of melagatran, PGE and GPRP on tissue factor-triggered thrombin generation in vitro. Thrombin generation was measured in mouse PRP with the thrombogram method, as described fiar Fig. 7.5. PRP was pretreated for 10 min with prostaglandin $E_{\uparrow}\left(P G E_{1}, 10 \mu M\right)$, $P G E_{1}$ plus melagatran (1. $\mu M)_{1}$ GPRP $(1 \mathrm{mg} / \mathrm{ml})$, or PGE, plus GPRP, as indicated. Presented is the effect on thrombin peak height as \% of control condition (mean $\pm S E M$ ). ${ }^{*} p \leq 0.05$ as compared to control.

In mice injected with $0.05 \mathrm{U} / \mathrm{g}$ bw heparin, thrombus formation was only influenced in arterioles (Fig. 7.6A, B). Injection of the higher heparin dose $(0.5 \mathrm{U} / \mathrm{g}$ bw) similarly reduced this process in arterioles, but - intriguingly - led to increased thrombus formation in venules (Fig. 7.6B). Thrombin generation, measured in plasma samples taken from mice treated with moderate or high heparin, showed an incomplete reduction in peak height to $25 \%$ and $9 \%$ of contral, respectively (Fig. $7.6 \mathrm{C}$ ). Together, these data stress the importance of thrombin generation and coagulation in this mouse thrombosis model and furthermore show that stronger inhibition of the thrombin-generating process is required to affect venular compared to arteriolar thrombus formation.

\section{Additive effect of platelet and thrombin inhibitors on venous thrombus formation}

To inhibit platelet activation the cAMP-elevating agent prostaglandin $E_{\|}\left(P E_{1}\right)$ was used. In isclated mouse PRP, $10 \mu \mathrm{M} \mathrm{PGE}$, substantially reduced platelet aggregation (not shown) and platelet-dependent thrombin generation (Fig. 7.7, peak height reduced to $73 \pm 5 \%$, $P=0.003)$. This corresponds to results obtained with human PRP $(4,29)$. In vivo treatment of mice with $0.4 \mathrm{mg} / \mathrm{g}$ bw PGE, (giving a plasma concentration of about $10 \mu \mathrm{M}$ ) significantly delayed and reduced thrombus formation in arterioles, but not in venules (Fig. 7.8).

Administration of $\mathrm{PGE}_{1}(0.4 \mathrm{mg} / \mathrm{g}$ bw) together with the lower dose of melagatran $(0.175 \mu \mathrm{g} / \mathrm{g} \mathrm{bw})$ resulted in significant retardation and reduction of the thrombotic process, not only in arterioles, but also in venules (Fig. 7.8). Thus, in venules, this combined administration was more effective than that of $\mathrm{PGE}_{1}$ or moderate melagatran alone. Platelet inhibition by $\mathrm{PGE}_{1}$ or moderate thrombin inhibition by melagatran was sufficient to inhibit arterial thrombus formation, but the combined action was needed for reducing venous thrombosis. 
A
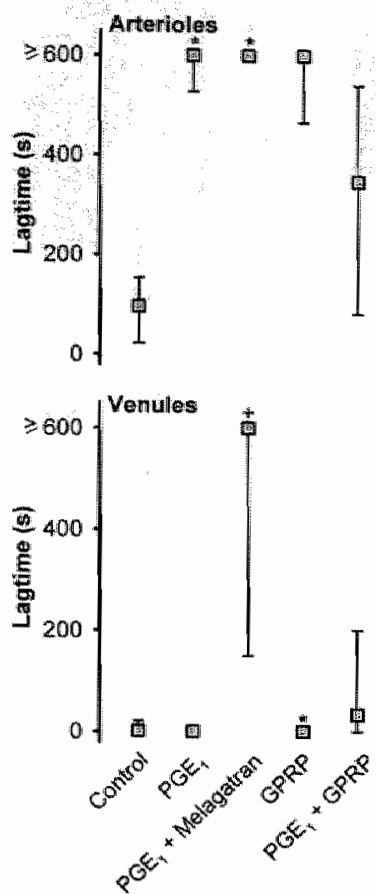

$\mathbf{B}$
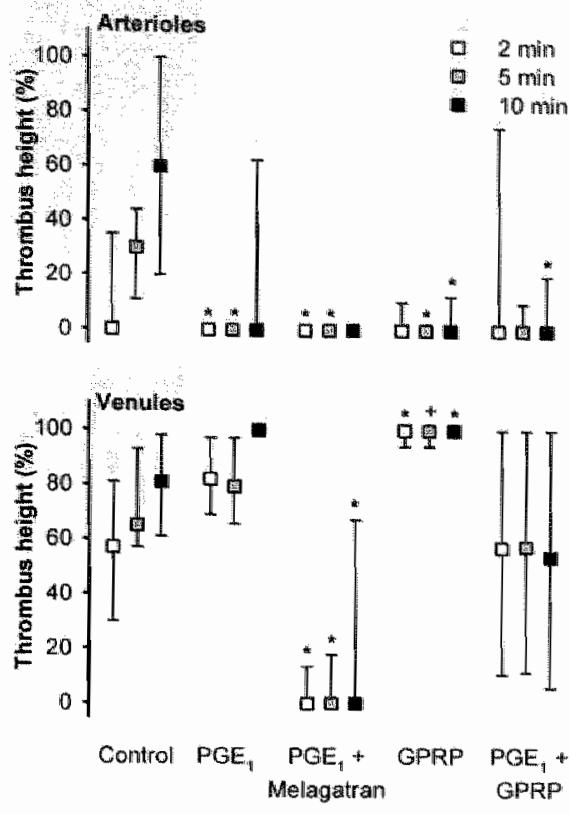

Figure 7.8. Effects of melagatran, $P G E_{1}$ and GPRP on thrombus formation in arterioles and venules in vivo. Mice were treated intravenously with vehicle (control) or with: $0.4 \mathrm{mg} / \mathrm{g}$ bw prostaglandin $E_{1}\left(\mathrm{PGE}_{1}\right), \mathrm{PGE}_{1}$ plus $0.175 \mu \mathrm{g} / \mathrm{g}$ bw melagatran, $135 \mu \mathrm{g} / \mathrm{g}$ bw GPRP or PGE, plus GPRP. Mesenteric arterioles and venules were damaged by topical application of $\mathrm{FeCl}_{3}$. (A) Lagtime to thrombus formation after $\mathrm{FeCl}_{3}$ application. (B) Thrombus height measured at 2,5 and $10 \mathrm{~min}$ after $\mathrm{FeCl}_{3}$ application (\% of vessel diameter). Data are median values with interquartile ranges $(n=4-9)$. ${ }^{*} p \leq 0.05 ;{ }^{+} p \leq 0.07$ as compared to control.

\section{Inhibition of fibrin formation in arterial and venous thrombus formation}

Fibrin fibers can bind thrombin and protect it from inactivation (37). We considered the possibility that the capture of thrombin by abundant fibrin formation is responsible for the relative resistance of venular thrombi to thrombin antagonism. This was investigated with GPRP, a peptide which blocks the polymerization of fibrin monomers. In vitro experiments indicated that GPRP (1 $\mathrm{mg} / \mathrm{ml}$ ) abolished the formation of fibrin clots (not shown), but was of only little effect on platelet-dependent thrombin generation (Fig. 7.7). Mice were subsequently infused with $135 \mu \mathrm{g} / \mathrm{g}$ bw GPRP, resulting in a plasma concentration of about $1 \mathrm{mg} / \mathrm{ml}$. Surprisingly, the infused GPRP greatly delayed thrombus formation in arterioles, but enhanced this process in venules (Fig. 7.8). With GPRP, only one of the arterioles, but $75 \%$ of the venules occluded within 10 minutes. No extra effect was reached in either vessel type by combined infusion of GPRP and PGE facilitates the action of thrombin in venules, possibly by limiting thrombin diffusion. 


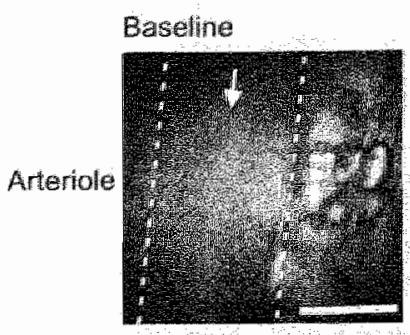

5 mint

$10 \mathrm{~min}$
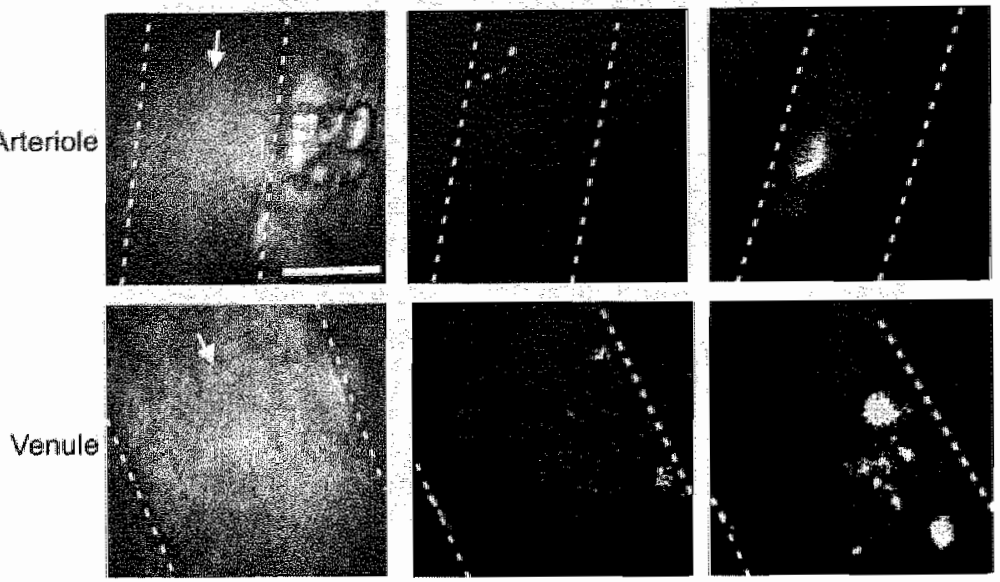

Figure 7.9. Detection of phosphatidyllserine exposure in arterial and venous thrombi formed in vivo. Vessel wall damage was induced by topical $\mathrm{FeCl}$ application, directly after which FITC-labeled annexin $\mathrm{A5}$ (0.16 $\mu \mathrm{g} / \mathrm{g}$ bw) was infused intravenously. Trans-illumination images were taken at baseline; fluorescence images were taken alt 5 and $10 \mathrm{~min}$ after FeCl, application. Dotted lines indicate vessel wall, arrows indicate direction of flow; bar represents $50 \mathrm{um}$

Thrombus formation in arterioles and venules relies on exposure of procoagulant phosphatidylserine by platelets

To investigate whether procoagulant platelets play a role in the thrombin-dependent thrombus-forming process, mice were injected with a tracer amount of FITC-labelled annexin A5, which detects cell surface-exposed PS, after the onset of $\mathrm{FeCl}_{3}$-induced thrombus formation. Thrombi in both arterioles and venules incorporated labeled annexin A5 (Fig. 7.9), indicating the presence of PS-exposing platelets. During the experiments no staining with FITCannexin A5 was observed inside the vessel wall or in vessels without thrombi (not shown).

The importance of PS exposure for the thrombus-forming process was further elucidated by injecting mice with a saturating dose $(7.7 \mathrm{\mu g} / \mathrm{g}$ bw) of unlabelled annexin $\mathrm{A} 5$. Quadruple-mutated annexin A5 (M1234-annexin A5) was used as a negative control. The M1234-annexin A5 has single amino acid mutations in each of the four $\mathrm{Ca}^{2+}$ binding sites, which greatly reduces its affinity for binding to PS (38). Whereas M1234-annexin A5 infusion had no significant effect on thrombus formation as compared to vehicle controls $(P \geq 0.18)$, wildtype annexin A5 almost completely inhibited this process in both arterioles and venules (Fig. 7.10A B). In fact, in none of the 7 damaged arterioles any platelet deposition was detected within the 10-min time frame, while in only 3 out of 6 venules limited adhesion of platelets assembling into very small thrombi was observed.

In thrombin generation assays in vitro, addition of $10 \mu \mathrm{g} / \mathrm{ml}$ annexin A5 to PRP was sufficient to reduce the thrombin peak to $11 \pm 1.6 \%$ of control, while M1234-annexin A5 was without effect (Fig. 7.10C). In plasma collected from mice injected with annexin A5 $7.7 \mu \mathrm{g} / \mathrm{g}$ 
A

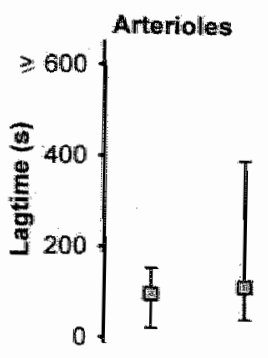

Venules
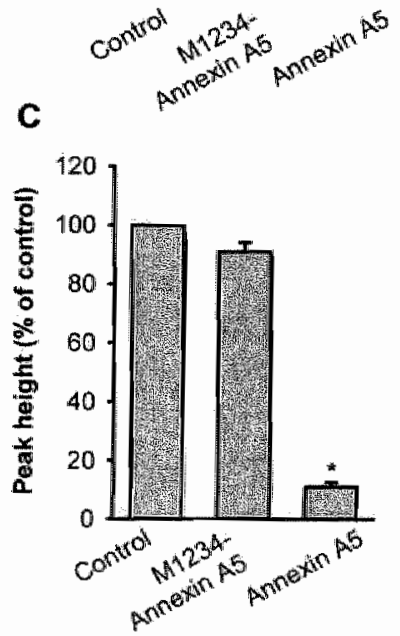

B
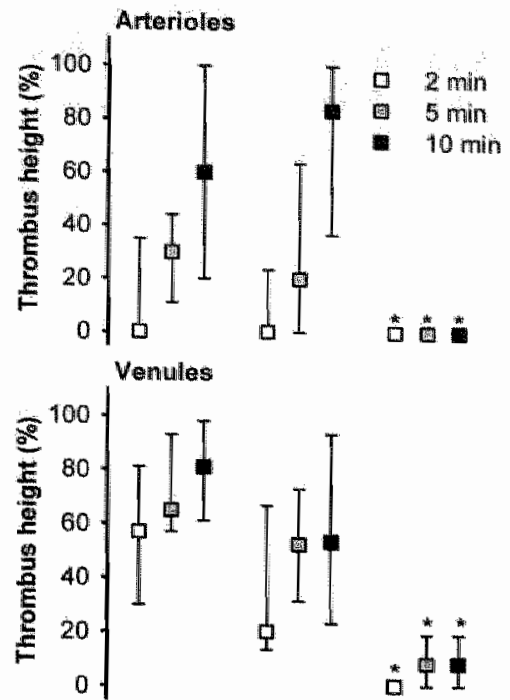

Control M1234 Annexin A5 Annexin As

Figure 7.10. Effect of annexin A5 on thrombus formation in arterioles and venules in viva. Mice were infused with $7.7 \mu \mathrm{g} / \mathrm{g}$ bw annexin A5 or mutated M1234-annexin A5, resulting in an estimated plasma concentration of $70 \mu \mathrm{g} / \mathrm{ml}$. Mesenteric vessels were damaged by topical application of $\mathrm{FeCl}_{3}$. (A) Lagtime to thrombus formation after $\mathrm{FeCl}_{3}$ application. (B) Thrombus height measured at 2,5 and 10 mir after $\mathrm{FeCl}_{3}$ application ( $\%$ of vessel diameter). Data are median values with interquartile ranges $(n=6-7)$ : ${ }^{*} \mathrm{p} \leq 0.05$ as compared to control and M1234-annexin A5. (C) In vitro effect of annexin A5 on thrombin generation in PRP. Thrombin generation was measured in PRP, treated with a moderate dose $(10 \mu \mathrm{g} / \mathrm{ml})$ mutated M1234-annexin A5 or wildtype annexin A5. Given is thrombin peak height from thrombograms as \% of control (mean $\pm S E M, n=3-4$ ) * $p \leq 0.05$ as compared to control and M1234-annexin A5.

bw), thrombin generation was reduced to $17 \pm 4 \%(n=4)$ of control plasma. Together, these data show that in either vessel type, thrombus formation appears to rely on PS exposure and ensuing thrombin generation by (activated) platelets. 


\section{Discussion}

In this paper, we investigated the contribution of platelets to the coagulant process under in vivo conditions, using a murine microvascular thrombosis model known to be sensitive to platelet and coagulation inhibitors. Both in arterioles and venules, we were able to visualize externalized PS on platelets trapped in thrombi, using fluorescently labeled annexin A5. This probe has previously been used for in vivo monitoring of apoptotic, PS-exposing cardiomyocytes in a mouse model of ischemia/reperfusion of the heart (39). The present data indicate that the PS-exposing platelets contributed to thrombin and fibrin generation and buildup of a stable thrombus. Intravenous administration of a high dose of annexin A5, sufficient to suppress PS-dependent thrombin generation in plasma, resulted in a profound delay in initiation and in almost complete suppression of thrombus formation in the observed vessels. The specificity of the intervention was demonstrated by administration of point-mutated M1234annexin $A 5$, with a low affinity for $P S$, which was without notable influence on the thrombotic process. In agreement with these results ${ }_{n}$ abuindant appearance of PS-exposing platellets under conditions of thrombin generation and formation of platelet-fibrin clots was observed in flow chamber experiments. Together, to our knowledge, this is first evidence for vivo importance of PS exposure and platelet-dependent coagulation in arterial and venous thrombosis.

This work thereby significantly extends the knowledge from experiments in test tubes, that activated platelets enhance thrombin generation by exposure of PS $(7,13)$. Indirect evidence for the clinical importance of platelet procoagulant activity is given by patients with a rare bleeding disorder, the Scott syndrome, who have a deficiency in PS exposure upon activation $(40,41)$. Furthermore, patients with the Stormorken syndrome, a thrombophilic disorder, appear to have platelets with increased PS exposure (42).

The in vivo findings also provide novel insight into thrombus-forming mechanisms that can take place in different parts of the circulation. The interventions with anti-TF antibody and active site-inhibited factor VIla, both of which inactivate TF exposed to blood, significantly reduced the thrombotic process in arterioles and venules. Moreover, the experiments with mice deficient in GPVI/ FCRy-chain indicate that also platelet-collagen interaction via GPVI contributes to the thrombus forming process in both vessel types. This agrees well with the in vitro observation that platelet activation by GPVI is a key, initiating event in PS exposure and platelet aggregation in mice $(27,43)$ and man (15). Thus, in the present model, in both arterioles and venules the thrombotic process appears to be initiated by TF and collagen.

We also note similarities in the propagation phase of arteriolar and venular thrombus formation. In either case, the thrombotic process was abrogated by infusion of melagatran at a concentration sufficiently high to completely inhibit thrombin generation; a lower melagatran dose had similar effects provided that it was given in combination with platelet-inhibiting PGE $_{1}$. Together with the inhibitory effect of annexin A5, this is strong evidence that the thrombotic 
process is driven by sequential loops of thrombin generation, platelet activation, PS exposure and prothrombinase activity. This is in agreement with published evidence that $\mathrm{FeCl}_{3}$-induced thrombus formation in murine arteries is diminished in the absence of one of the two platelet thrombin receptors, PAR-3 or PAR- $4(2,44)$.

Despite these mechanistic similarities, also typical differences between arterioles and venules are noted. Suppression of the venous thrombotic process required a more profound thrombin inhibition compared to suppression of thrombus formation in adjacent arterioles. Moderate thrombin inhibition with melagatran or platelet inhibition with $P G_{1}$ was sufficient to block arterial thrombus formation. However, the combination of both was needed to suppress venous thrombosis. Along the same line, blocking of fibrin polymerization (by GPRP) was antithrombotic in arterioles, but it did not affect thrombosis in venules. An attractive explanation is that thrombin accumulates at relatively high levels in (slowly flowing) venules, and that this process needs to be suppressed more strongly to come below the threshold level where thrombin enhances its own formation (vila activated platelets).

In venules, administration of a high dose of unfractionated heparin increased rather than decreased the formation of thrombi. This contrasts with the inhibitory effect of melagatran infusion. Unfractionated heparin is an indirect thrombin inhibitor, which effectively enhances the inactivation of formed factor $\mathrm{Xa}$ and $\alpha$-thrombin by antithrombin. This indirect way of action may explain why, even at a high heparin concentration, thrombin generation and coagulation are incompletely inhibited, in contrast to the direct antagonistic effect of melagatran. A recent report indicates that heparin promotes clot formation by interacting with platelet factor 4 (45), which may explain why heparin enhances $\mathrm{FeCl}_{3}$-induced in venules. Another effect of unfractionated heparin is enhancement of the platelet activation process, likely in a way involving autocrine ADP release (36). Thus, in addition to incomplete inhibition of thrombin generation, increased thrombotic activity in the presence of high heparin doses can also be due to a platelet-activating effect.

In vitro, platelets respond to minute (sub-nanomolar) concentrations of thrombin via their receptors (PARs), i.e. well before fibrin starts to be formed. The recognition that more complete suppression of thrombin generation is needed to inhibit venous than arterial thrombosis suggests that local thrombin generation in venules is too high to be antagonized by platelet inhibitors like $P G E_{1}$ and aspirin. Indeed in flow experiments, we have recently observed that $P G E_{1}$ is unable to completely suppress PS exposure and ensuing coagulation at low shear rate (22).

Typically, we observed a significanilly faster onset of thrombus formation in venules than in arterioles. Such a difference between vessels has also been found in other thrombosis models (reviewed in Ref. 46). There are a number of explanations for the rapid progression of the thrombotic process in venules. First, the thicker arterial wall may delay the penetration of 
FeCly. However, this is unlikely, as the walls of arterioles and venules are similarly permeable for the hydrophilic, fluorescent compound acridine red, which has a molecular weight similar to that of FeCly. Also, no correlation was found between vessell diameter (which relates to wall thickness) and lagtime to thrombus formation in arterioles $\left(R^{2}=0.007\right)$ or venules $\left(R^{2}=0.003\right)$, suggesting that vessel diameter and, hence, wall thickness does not influence the start of thrombus formation. Second, different antithrombotic properties between endothelial cells in arterioles and venules (46) may lead to a different degree of antagonism. Arterial endothelium may have a higher antithrombotic activity, e.g. increased activity of platelet-inhibiting substances like prostacyclin and $\mathrm{NO}$ (47). However, this is not consistent with the fact that endothelium in both vessel types was almost completely removed by $\mathrm{FeCl}_{3}$. Third, damaged venules may express more TF, which is known to be distributed through the vascular system in a non-uniform way (4B). Fourth, the higher flow rate in arterioles may accomplish faster dilution of locally active prothrombotic substances (e.g. factor VIla, ADP and thrombin). In fact, our finding that higher doses of thrombin inhibitors are needed to antagonize venular than arteriolar thrombosis is compatible with either of the llast two explanations.

In another mouse thrombosis model, applying laser-induced vascular injury, there is evidence that TF, platelets and fibrin gradually accumulate into developing thrombi (10). The current data cannot answer the question whether (49) or not (50) blood-borne TF is involved in the thrombotic process in arteries and veins. However, they support the proposal that inhibition of TF interaction with factor $V I I(a)$ is a promising target for new antithrombotic treatment of the thrombotic process $(51,52)$. Furthermore, the recognition that PS exposure by platelets is a key propagating step in thrombus formation in veins and arteries indicates that this process is also therapeutically interesting. Indeed, a number of new platelet inhibitors, i.e. $P 2 Y_{12}$ antagonists like clopidogrel (53) and $\alpha$ llb $\beta 3$ blockers like abciximab and eptifibatide (54) inhibit the platelet procoagulant response in addition to their anti-aggregatory action.

In conclusion, the present study provides new insights into similarities and differences in the dynamic process of arterial and venous thrombus formation. In this murine model, platelet PS exposure appears to be an important regulatory process in either vessel type integrating platelet activation and thrombin generation. This in vivo study thus indicates that platelet procoagulant activity may be a clinically relevant target for antithrombotic therapy.

\section{Acknowledgments:}

We thank M. Feijge for expert technical assistance in thrombin generation experiments. We thank Dr. M. Elg (Astra-Zeneca) for the supply of melagatran, and Dr. P. Tijburg (Novo Nordisk) for the supply of anti-tissue factor antibody and active site-inhibited factor Vlla. This work was supported by grant 2002-B014 from the Netherlands Heart Foundation. 


\section{References}

1. Kahn ML, Zheng $Y W$, Huang W. Bigornia $V$, Zeng D, Moff $S$, Farese RV, Jr., Tam $C$, Coughin $S R$. A dual thrombin receptor system for platelet activation. Nature. 1998; 394: 690-694.

2. Sambrano GR, Weiss EJ, Zheng $Y W$, Huang W, Coughlin SR. Role of thrombin signalling in platelets in haemostasis and thrombosis. Nature. 2001; 413: 74-78.

3. Turpie AG. State of the art - a journey through the world of antithrombotic therapy. Semin Thromb Hemost. 2002; 28 Suppl 3: 3-11.

4. Reverter JC, Beguin $S_{1}$ Kessels $H_{4}$ Kumar $R_{\text {, Hemker }} H_{\text {, }}$, Coller BS. Inhibition of platelet-mediated, tissue factor-induced thrombin generation by the mouse/human chimeric 7E3 antibody. Potential implications for the effect of c7E3 Fab treatment on acute thrombosis and "clinical restenosis". J Clin Invest. 1996; 98: 863-874.

5. Beguin $S$, Kumar $R$. Thrombin, fibrin and platelets: a resonance loop in which won willebrand factor is a necessary link. Thromb Haemost. 1997; 78: 590-594.

6. Butenas $S$, Cawthern KM, van't Veer $C$, DiLorenzo ME, Lock JB, Mann KG. Antiplatelet agents in tissue factor-induced blood coagulation. Blood. 2001; $97: 2314-2322$.

7. Heemskerk JWM, Bevers EM, Lindhout T. Platelet activation and blood coagulation. Thromb Haemost. 2002; 88: 186-193.

8. Swords $\mathrm{NA}_{\text {, Mann }} \mathrm{KG}$. The assembly of the prothrombinase complex on adherent platelets. Arterioscler Thromb. 1993; 13: 1602-1612.

9. Baird TR, Walsh PN. The interaction of factor Xla with activated platelets but not endothelial cells promotes the activation of factor IX in the consolidation phase of blood coagulation. J Biol Chem. 2002; 277: $38462-38467$

10. Falati $S$, Gross $P$, Merrill-Skoloff $G$, Furie BC, Furie B. Reai-time in vivo imaging of platelets, tissue factor and fibrin during arterial thrombus formation in the mouse. Nat Med. 2002; $8: 1175-1181$.

11. Balasubramanian $V$, Grabowski $E$, Bini $A$. Nemerson $Y$. Platelets, circulating tissue factor, and fibrin colocalize in ex vivo thrombi: real-time fluorescence images of thrombus formation and propagation under defined flow conditions. Blood. 2002; 100:2787-2792.

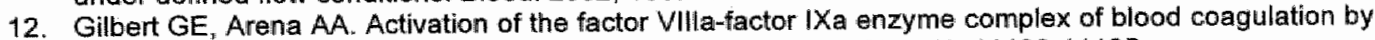
membranes containing phosphatidyl-L-serine. J Biol Chem. 1996; 271: 11120-11125.

13. Zwaal RFA, Schroit AJ. Pathophysiological implications of membrane phospholipid asymmetry in blood cells. Blood. 1997; 89: 1121-1132.

14. Heemskerk JW, Vuist WM, Feijge MA, Reutelingsperger $C P$, Lindhout $T$. Collagen but not fibrinogen surfaces induce bleb formation, exposure of phosphatidy/serine, and procoagulant activity of adherent platelets: evidence for regulation by protein tyrosine kinase-dependent $\mathrm{Ca}^{24}$ responses. Blood. 1997; 90: 2615-2625.

15. Siljander PR, Munnix IC, Smethurst PA, Deckmyn $H$, Lindhout $T$, Ouwehand WH, Farndale RW, Heemskerk. JW. Platelet receptor interplay regulates collagen-induced thrombus formation in flowing human blood. Blood. 2004; 103: 1333-1341.

16. Andersen $H_{1}$ Greenberg DL. Fujikawa $K_{4}$ Xu WF, Chung DW, Davie EW. Protease-activated receptor 1 is the primary mediator of thrombin-stimulated platelet procoagulant activity. Proc Natt Acad Sci U S A 1999; 96 : 11189-11193.

17. Denis C. Methia N. Frenette PS, Rayburn H, Ullman Cullere M, Hynes RO, Wagner DD. A mouse madel of severe von Willebrand disease: defects in hemostasis and thrombosis. Proc Natl Acad Scil S. A. 1998; 95: 9524-9529.

18. $\mathrm{Ni} \mathrm{H}$, Ramakrishnan $\mathrm{V}_{n}$ Ruggeri ZM, Papalia JM, Phillips. DR, Wagner DD. Increased thrombogenesis and embolus formation in mice lacking glycoprotein $V$. Blood. 2001; 98: 368-373.

19. André $P$. Delaney SM, LaRocca $T$, Vincent $D$, DeGuzman $F_{1}$ wurek $M_{1}$ Koller $B$, Phillips DR, Conley $\mathrm{PB} . \mathrm{P} 2 \mathrm{Y}_{12}$ regulates platelet adhesion/ activation, thrombus growth, and thrombus stability in injured arteries. J Clin Invest. 2003; 112: 398-406.

20. Takai $T$, Li M, Sylvestre $D$, Clynes $R$, Ravetch JV. FcR -chain deletion results in pleiotrophic effector cell defects. Cell. 1994; 76: 519-529.

21. Sorensen $B B, R a o L V$. Interaction of activated factor VII and active site-inhibited activated factor VII with tissue factor. Blood Coagul Fibrinolysis. 1998; 9 Suppl 1: $\$ 67-71$.

22. Kuijpers MJE, Nieuwenhuys CM, Feijge MAH, Kloots W, Giesen PL, Jerling JC, oude Egbrink MGA, Heemskerk JWM. Regulation of tissue factor-induced coagulation and platelet aggregation in flowing whole blood. Thromb Haemost. 2005; 93: 97-105.

23. van Gestel MA, Heemskerk JWM, Slaaf DW, Heijnen W. Sage SO. Reneman RS, oude Egbrink MGA. Real-time detection of activation patterns in individual platelets during thromboembolism in vivo: differences between thrombus growth and embolus formation. J Vasc Res. 2002; 39: 534-543. 
24. Dirkx AE, Oude Egbrinik MGA, Kuijpers MJE, wan der Niet ST, Heijnen VW, Bouma-ter Steege JC, Wagstaff J, Griffioen AW. Tumor angiogemesis modulates leukocyte-vessel wall interactions in wivo by reducing endothelial adhesion molecule expression. Cancer Res. 2003; 63: 2322-2329.

25. Baker $M$. Wayland $H$. On-line volume flow rate and welocity profile measurement for blood in microvessels. Microvasc Res. 1974; $7: 131-143$.

26. Tangelder $G$, Slaaf DW, Arts $T$, Reneman RS. Wall shear rate in arterioles in vivo: least estimates from platelet velocity profiles. Am J Physiol. 1988; 254: H1059-1064.

27. Kuijpers MuE, Schulte $V_{*}$ Bergmeier $W$, Lindhout $T$, Brakebusch $C$, Offermanns $S$, Fassler $R_{t}$ Heemskerk JWM, Nieswandt B. Complementary roles of glycoprotein VI and $\alpha 2 \beta 1$ integrin in collagen. induced thrombus formation in flowing whole blood ex vivo. FASEB J. 2003; 17: 685-687.

28. Hemker HC, Giesen P, Al Dieri $R$, Regnault $V$, de Smedt $E$, Wagenvoord $\mathbb{R}_{v}$ Lecompte $T$, Beguin $S$. Calibrated automated thrombin generation measurement in clotting plasma. Pathophysiol Haemosit Thromb. 2003; 33; 4-15.

29. Vanschoonbeek K, Feijge MAH, Van Kampen RJ, Kenis $H_{4}$ Hemker HC, Gilesen PL, Heemskerk JWM. Initiating and potentiating role of platelets in tissue factor-induced thrombin generation in the presence of plasma: subject-dependent variation in thrombogram characteristics. J Thromb Haemost. 2004; 2 : 476-484.

30. Gustafsson $D, E l g M$. The pharmacodynamics and pharmacokinetics of the oral direct thrombin inhibitor ximelagatran and its active metabolite melagatran: a mini-review. Thromb Res. 2003; 109 Suppl 1: \$9-15.

31. $\mathrm{Ni} \mathrm{H}$, Denis CV, Subbarao $\mathrm{S}$, Degen JL, Sato TN, Hynes $R \mathrm{O}$, Wagner DD. Persistence of platelet thrombus formation in arterioles of mice lacking both von Willebrand factor and fibrinogen. $J \mathrm{Clin}$ Invest. 2000; 106: 385-392.

32. Poole $A$, Gibbins $J M_{\text {, Turner }} M$, van Vugt $M J$, van de Winkel JG, Saito T, Tybulewicz VL, Watson SP. The $\mathrm{FC}$ receptor $\mathrm{y}$-chain and the tyrosine kinase Syk are essential for activation of mouse platelets by collagen. EMBO d. 1997; 16: 2333-2341.

33. Munnix ICA, Streh $A$, Kuijpers MJE, Auger JM, van der Meijden PEJ, van Zandvoort MAM, oude

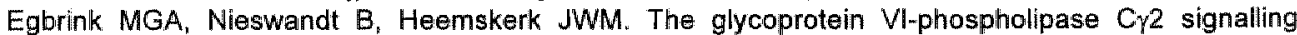
pathway controls collagen- and tissue factor-induced thrombus formation in vitro and in vivo. Atheroscl Thromb Vasc Biol. 2005; 25 . In press.

34. Jin L, Abrahams JP, Skinner R, Petitou M, Pike RN, Carrell RW. The anticoagulant activation of antithrombin by heparin. Proc Natl Acad Sci U S A. 1997; 94: 14683-14688.

35. Nieuwenhuys $C M$, Feijge MA, Beguin $S$, Heemskerk JW. Monitoring hypocoagulant conditions in rat plasma: factors determining the endogenous thrombin potential of tissue factor-activated plasma. Thromb Haemost. 2000; 84: 1045-1051.

36. Storey RF, May JA, Heptinstall S. Potentiation of platelet aggregation by heparin in human whole blood is attenuated by $P 2 Y_{12}$ and $P 2 Y_{1}$ antagonists but not aspirin. Thromb Res. 2005; 115: $301-307$.

37. Weitz Jl, Hudoba M, Massel D, Maraganore J, Hirsh J. Clot-bound thrombin is protected from inhibition

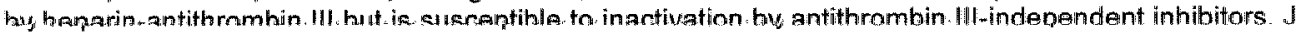
Clin Invest. 1990; $86: 385-391$.

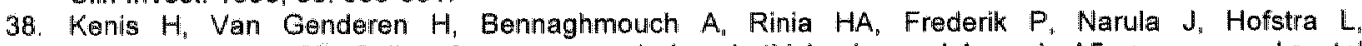
Reutelingsperger CP. Cell surface expressed phosphatidylserine and Annexin A5 open a novel portal of cell entry. J Biol Chem. 2004: 279: 52623-52629.

39. Dumont EA, Reutelingsperger CPM, Smits JFM, Daemen MJAP, Doevendans PAF, Wellens HJJ, Hofstra $L$. Real-time imaging of apoptotic cell-membrane changes at the single-cell level in the beating murine heart. Nat Med. 2001; 7: 1352-1355.

40. Rosing J, Bevers EM, Comfurius $P, H$, Hemer HC, van Diejen $G$, Weiss $H J$, Zwaal RF. Impaired factor $X$ and prothrombin activation associated with decreased phospholipid exposure in platelets from a patient with a bleeding disorder. Blood. 1985; 65: 1557-1561.

41. Weiss HJ. Scott syndrome: a disorder of platelet coagulant activity. Semin Hematol. 1994; 31: 312-319.

42. Solum NO. Pirocoagulant expression in platelets and defects leading to clinical disorders. Arterioscler Thromb Vasc Biol. 1999; 19: 2841-2846.

43. Nieswandt B. Watson SP. Platelet collagen interaction: is GPV/ the central receptor? Blood. 2003; 102 : 449-461

44. Weiss EJ, Hamilton JR, Lease KE, Coughlin SR. Protection against thrombosis in mice lacking PAR3. Blood. 2002; 100: 3240-3244.

45. Eslin DE, Zhang C, Samuels KJ, Rauova $L$, Zhai L, Niewiarowski S, Cines DB, Poncz M, Kowalska $M A$. Transgenic mice studies demonstrate a role for platelet factor 4 in thrombosis: dissociation between anticoagulant and antithrombotic effect of heparin. Blood. 2004; 104: 3173-3180.

46. oude Egbrink MGA, van Gestel MA, Broeders MD, Tangelder GJ, Heemskerk JWM, Reneman RS, Slaaf DW. Regulation of microvascular thromboembolism in vivo. Microcirculation. $2005 ; 12 ; 287-300$. 
47. Broeders MAW, Tangelder GJ, Slaaf DW, Reneman RS, oude Egbrink MGA Endogenous nitric oxide and prostaglandins synergistically counteract thromboembolism in arteroles but not in venules. Artierioscler Thromb Vasc Biol. 2001; 21: 163-169.

48. Mackman N. Role of tissue factor in hemostasis, thrombosis, and wascular development. Arterloscler Thromb Vasc Biol. 2004: 24: 1015-1022.

49. Chou J, Mackman N, Merrill-Skoloff $G$, Pedersen B, Furie BC, Furie B. Hematopoietic cell-derived microparticle tissue factor contributes to fibrin formation during thrombus propagation. Blood. 2004; 104: 3190-3197.

50. Day SM, Reeve $J L$, Pedersen B, Farris DM, Myers DD, Im M, Wakefield TW, Mackman N, Fay WP. Macrovascular thrombosis is driven by tissue factor derived primarily from the blood vessel wall. Blood. 2005; 105: 192-198.

51. Golino $P$, Cimmino $G$. Targeting tissue factor as an antithrombotic strategy. Semin Vasc Med. 2003; 3: 205-214.

52. Jacquemin $M$, Saint-Remy JM. The use of antibodies to coagulation factors for anticoagulant therapy. Curr Med Chem. 2004; 11:2291-2296.

53. Leon $C$, Ravanat $C$ "Freund $M$, Cazenave JP, Gachet $C$. Differential involvement of the P2Y, and $P 2 Y_{12}$ receptors in platelet procoagulant activity. Arterioscler Thromb Vasc Biol. 2003 "23" 1941-1947.

54. Goto $S$,Tamura $N_{\text {, }}$ Li M , Handa $M$, Ikeda $Y$, Handa $S$, Ruggeri ZM. Different effects of various antiGPillb-llla agents on shear-induced platelet activation and expression of procoagulant activity. J Thromb Haemost. $2003 ; 1: 2022-2030$. 
Chapter 8

General discussion 
Atherothrombosis, thrombus formation at the surface of ruptured atherosclerotic plaques in arteries, is major cause of cardiovascular disease. The thrombotic process starts with platelet interaction with the damaged atherosclerotic vessel wall. As an important tool in the fight against atherosclerosis, a better understanding is needed of the mechanisms involved in platelet adhesion to vessel wall components and subsequent events leading to thrombus formation. The main goal of the studies presented in this thesis was to investigate the contribution of key platelet receptors to collagen-induced platelet activation, in particullar the platelet procoagulant response. Part of the experiments were performed using an in vitro model of thrombus formation under controlled conditions of blood flow and coagulation. Also, an in vivo mouse model of intravascullar thrombus formation was used. The role of the established key receptors for collagen as well as the relationship between collagen-induced platelet aggregatory and procoagulant activity will be discussed below. Furthermore, the importance of the vessel wall in thrombus formation will be addressed. In Figure 8.1, current understanding of the interaction between platelet activation and coagulation is schematically depicted; this figure provides a framework for discussing the results from this thesis.

\subsection{Roles of GPVI and integrin $\alpha 2 \beta 1$ in platelet adhesion, activation and}

\section{thrombus formation}

Platelet interaction with subendothelial collagen is a key initial step in thrombus formation following vessel wall damage. At high shear rates, the von Willebrand factor (vWF) receptor glycoprotein (GP) Ib-V-\|X initially tethers platelets to WWF deposited on colliagen fibers. Subsequent stable adhesion irwolves two collagen receptors, the immuno-globulin receptor GPVI and the integrin $\alpha 2 \beta 1$ (GPlalla). Their relative contribution has been the subject of considerable debate in the past decades. A critical role for $\alpha 2 \beta 1$ was identified in the mid $1980 \mathrm{~s}_{\text {. }}$ when two $\alpha 2$-deficient patients were described, who presented with a bleeding phenotype and impaired platelet aggregation in response to collagen ( $1-3)$. However, later it was questioned whether the clinical symptoms were related to the proposed platelet defect (4). Further studies in the 1980 s and 1990 s established the critical role of $\alpha 2 \beta 1$ in mediating stable adhesion on collagen (5). Nevertheless, a second, unidentified collagen receptor was proposed, that mainly regulated platelet activation. This sequence of events, ile. adhesion followed by activation was termed the two-site, two-step model of platelel-collagen interaction $(6,7)$. The model was challenged after the discovery of the GPVI-Fc-receptor (FCR) $\gamma$-chain complex as the principal receptor for platelet activation by collagen $(4,8)$. Especially studies with GPVI- or a $2 \beta 1$-deficient mice were important since they demonstrated a critical role for GPVI in both adhesion and aggregation on collagen $(9,10)$. In addition, these studies showed that $\alpha .2 \beta 1$ was not required for these events; the integrin allb 33 mediated stable adhesion on collagen-bound $W W F$ in the 


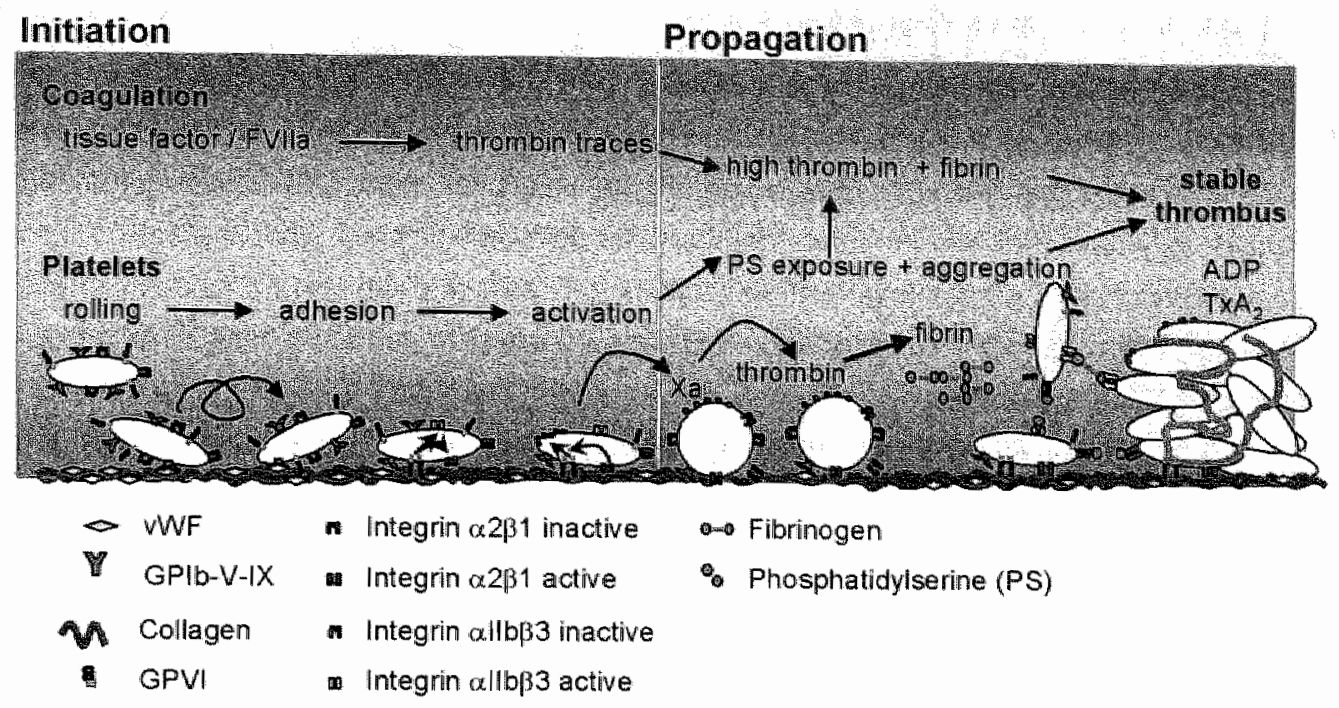

Figure 8.1 Schematic overview of platelet-dependent coagulation in thrombus formation. In the initiation phase ${ }_{*}$ tissue factor/factor VIII (a) interaction leads to formation of traces of thrombin, while platelets interact with collagen/WWf via GPIb (arteries) and the collagen receptors GPV1 and integrin $\alpha 2 \beta 1$. Platelet activation is characterized by integrin allb/3 activation and exposure of phosphatidylserine accompanied by blebbing morphology. This results in two platelet populations with aggregation on the one hand and platelet procoagulant activity on the other hand. In the propagation phase of thrombus formation, platelet aggregates as well as massive amounts of thrombin are formed. A fibrin network stabilizes the developing thrombus.

absence of $\alpha 2 \beta 1$. As a consequence, the role of $\alpha 2 \beta 1$ in platelet-collagen interaction remained unclear.

In chapter 3, experiments are described with mice deficient in FcR GPVI), $\beta 1$-integrin (lacking $\alpha 2 \beta 1$ ) or $G \alpha_{q}$ (defective responses to thromboxane $A_{2}\left(T \times A_{2}\right.$ ) and ADP). The results show that GPVI and $\alpha 2 \beta 1$ have complementary functions in collagen-induced thrombus formation during perfusion of whole blood over collagen. Integrin a $2 \beta 1$ mainly facilitates the central role of GPVI in various platelet activation processes leading to thrombus formation, i.e. $\mathrm{Ca}^{2+}$ mobilization, exposure of phosphatidy/serine (PS) and aggregation. The autocrine agents $T \times A_{2}$ and $A D P$ mainly serve to trigger aggregate formation. Several other mouse and human studies have confirmed these findings, thus re-establishing the role of $\alpha 2 \beta 1$ in platelet adhesion to collagen (11-14).

Regarding platelet adhesion, the critical role of GPVI has recently been questioned by observations that platelets from GPVI-deficient mice, as well human platelets inhibited with antiGPVI antibodies, stably adhere to collagen (14-17). This issue is addressed by Auger et al. (18), who directiy compared adhesion, activation and aggregation of human and mouse platelets. In this paper, identical or equivalent experimental tools were used with either species under the same experimental conditions. Two mechanisms of stable adhesion and activation on collagen 
were shown to co-exist. GPVI-mediated platelet activation was demonstrated to either precede or follow adhesion mediated by both $\alpha 2 \beta 1$ and GPVI. The two fundamental processes of adhesion and subsequent aggregate formation are preserved in mouse and human platelets (18). This view is supported by another study with $\alpha .2 \beta 1$-deficient mice, also indicating that GPVI and $\alpha 2 \beta 1$ play an equal role in platelet adhesion to collagen (19). Because natural collagens contain different binding sites (high and low affinity) for $\alpha 2 \beta 1$ and GPVI $(20,21)$, it is likely that individual platelets detect different micro-environments when in contact with a collagen fiber, and then respond accordingly.

A surprising observation in chapter 3 was the formation of loose platelet aggregates upon perfusion of blood from $\beta 1$-null mice over collagen. This finding raises the question whether $\alpha 2131$ plays a role in thrombus stability and embolization. This hypothesis was tested in chapter 4 by experiments with $\alpha 2$-null mice. In an in vivo thrombosis model of $\mathrm{FeCl}_{3}$ injured mesenteric arterioles, overall (cumulative) thrombus formation was similar between $\alpha 2-n u l l$ and wildtype mice. However, individual thrombi were smaller in vessels from $\alpha 2$-null mice compared to vessels from wildtype mice. Furthermore, the thrombi from $\alpha 2$-null mice frequently embolized or even completely detached from the vessel wall. Also, perfusion of blood from $\alpha 2$-null mice over collagen resulted in formation of smaller and looser thrombi, regardless of shear rate (low/high) or presence of coagulation. In addition, absence of $\alpha 2 \beta 1$ reduced fibrinogen binding to platelets and lowered PS exposure. This was accompanied by delayed and reduced thrombin generation in response to tissue factor and collagen. In addition. TxA release from platelets was reduced in the absence of $\alpha 2 \beta 1$, which could explain the formation of smaller and unstable thrombi. These results provide a mechanistic explanation for earlier studies performed with the same a2-null mice, which showed that aggregation of a2-null platelets in response to fibrillar collagen was delayed (10). In these a2-null mice in vivo thrombus formation was also similar to wildtype mice in ligation-induced collagen exposure in vessel wall of the carotid artery injury by ligation (22). In another strain of a2-null mice, thrombus formation in the carotid artery was found to be moderately delayed, but the authors did not observe differences in the formation of pulmonary emboli following intravascular injection of collagen (23). Keeping in mind that platelets may react differently when encountered with a different stimulus, the apparent differences between the two a2-deficient mouse strains may be only minimal. We conclude that $\alpha 2 \beta 1$ has a moderate but qualitatively important effect to stabilize thrombi and reduce embolization, by enhancement of GPVI-dependent platelet activation.

The studies presented in chapter 3 and 4 supplement each other with regard to the establishment of GPVI as vital collagen receptor and $\alpha 2 \beta 1$ as complementary partner mediating platelet adhesion and reinforcing GPVI-dependent activation and thrombus stabilization. This nicely fits with other studies with human platelets (12-14). Interestingly, some authors propose that $\alpha 2 \beta 1$ also contributes to the signaling process by itself $(24)$, but the present experiments 
indicate that under shear this contribution is only minimal compared to that of GPVI. The moderate effect of $\alpha 2 \beta 1$ deficiency sharply contrasted to the strongly delayed and reduced thrombus formation of murine GPVI-deficient platelets in the same flow and in vivo experiments (chapter 3, 7 and (25)).

In conclusion, in the initiation phase of platelet activation by collagen (Fig. 8.1), GPV! appears to be the essentiall receptor mediating all activation processes, but it needs to be complemented by integrin $\alpha 2 \beta 1$ activity for stable adhesion to collagen, full platelet activation and subsequent stable thrombus formation.

\subsection{Platelets and coagulation}

Platelets that come into contact with collagen, the major platelet-activating constituent of the extracellular matrix, are activated via GPVI. This GPVl-collagen interaction induces a potent and prolonged rise in cytosolic $\mathrm{Ca}^{2+}$, which is a prerequisite for $\mathrm{PS}$ exposure $(26,27)$. The exposure of PS in the outer membrane is known to be necessary for accelerated thrombin formation $(28,29)$. Chapter 2 describes that procoagulant platelets show typical morphological changes that accompany PS exposure; they can suddenly transform into balloon-shaped cells with membrane blebs. These so-called "blebbing" platelets shed microparticles, which are also known to express PS on their surface (27). That GPVI is the key receptor for this response is further demonstrated in chapter 3, in which it is shown that GPVI-deficient mouse platelets are deprived of collagen-induced calcium responses and PS exposure. Others have made complementary observations, i.e. that collagen-bound human platelets with high cytosolic $\mathrm{Ca}^{2+}$ respond by PS exposure (14), and by membrane contraction, fragmentation and microvesiculation (30). These platelets were termed to have SCIP morphology, being sustained calcium-induced platelets. In addition, the investigators demonstrated that SCIP morphology was accompanied by down-regulation of integrin allb $\beta 3$ adhesive function, involving factor $x_{111}$ and calpain (30). As PS-exposing platelets are known to be high in cytosolic $\mathrm{Ca}^{2 *}$, the SCIP morphology is likely to be related to platelet procoagulant activity. This points to the existence of two populations of activated platelets, one expressing procoagulant activity involved in coagulation, and another with activated integrin $\alpha / l b \beta 3$ involved in aggregation (see paragraph B.3).

Although collagen-induced PS exposure appears to be mainly induced by GPV! complemented by $\alpha 2 \beta 1$, which both bind collagen directly, this thesis describes that other receptors contribute to this platelet response in an indirect manner. The experiments in chapter 5 demonstrate that, under shear conditions, inhibition of GPIb, as well as blocking of WWF binding to collagen, reduced stable platelet adhesion, delayed $\mathrm{Ca}^{2+}$ responses and reduced PS exposure. Importantly, in mice expressing only 50\% of normal GPVI levels, blockage of GPlb almost completely abolished platelet adhesion and PS exposure. Hence, GPVI-dependent 
platelet activation is clearly facilitated by GPIb. In support of this, others have recently observed that GPIb and GPVI are both located in rafts, which are cholesterol-rich domains in the membrane. These rafts may physically concentrate receptors and downstream proteins involved in signaling pathways (reviewed in (31)). On the other hand, GPIb itself has also been reported to cause spiking $\mathrm{Ca}^{2+}$-elevations in platelets binding to WWF $(32-34)$. It is possible that these events contribute to the $\mathrm{Ca}^{24}$ signal in the presence of collagen. The same may hold for integrin allb33, as its binding to WWF under high shear can also cause spiking $\mathrm{Ca}^{2 *}$ responses $(33)$, which may be caused indirectly by ADP secretion and subsequent stimulation of ADP receptors. Thus, both GPlb and allbB3 promote collagen-induced PS exposure under shear conditions, either directly by causing $\mathrm{Ca}^{2 *}$ signal generation or indirectly by enhancing GPVI-collagen contact, Together, this clearly indicates that initiation of platelet adhesion to collagen and subsequent activation evolves as a series of multireceptor events with redundancy, facilitation and mutual interactions, rather than as a linear process (Fig. 8.1).

GPVI-mediated platelet adhesion to collagen and subsequent activation is not the only direct cause of PS exposure. We find that in the propagation phase of thrombus formation, platelets can also be induced to expose PS in the absence of collagen. In chapter 6 , perfusion studies were carried out with tissue factor-triggered rat and human blood over a fibrinogen surface. The results indicate that particularly under such coagulation conditions the ADP receptor $P 2 Y_{12}$ enhances platelet procoagulant activity. Furthermore, in the presence of collagen, PS exposure can be strengthened via secondary mediators. Various platelet agonists have been shown to amplify PS exposure and subsequent thrombin generation by release of $A D P$ and $P 2 Y_{12}$-receptor stimulation $(35,36)$. In the presence of collagen, autocrine ATP can play a similar indirect role, as the ATP-triggered $\mathrm{Ca}^{2+}$ channel $\mathrm{P} 2 \mathrm{X}_{1}$ mediates enhancement of collagen-induced PS exposure (37). Thrombin, generated in the onset of coagulation, may play a similar stimulating role via PAR-1 activation (38). From these findings it can be concluded that the signaling events involved in platelet procoagulant activity (i.e. PS exposure) are not limited to GPVI, but extend to receptors that mediate responses to ADP, ATP and thrombin, in the propagation phase of thrombus formation (Fig. 8.1).

That thrombin generation and platelet activation are mutually stimulatory processes has been demonstratted by many in vitro studies with isolated platelets and plasma $(39,40)$. However, in vivo evidence for interplay between thrombin generation and platelet activation, and also for a role of PS herein, was missing. This subject has been investigated in chapter 7 , where thrombus formation in mouse mesenteric vessels was triggered by $\mathrm{FeCl} \mathrm{F}_{3}$-induced exposure of vascular collagen and tissue factor. Inhibition of platelets and thrombin activity revealed synergistic effects between platelet activation and coagulation during the thrombusforming process in both arterioles and venules. Furthermore, coating of exposed PS by injection of annexin A5 almost completely abolished thrombus formation in the damaged arterioles and 
venules. Staining with fluorescently labeled annexin A5 revealed the presence of exposed PS only at sites where thrombi were present. These studies may provide first in vivo support for the importance of PS exposure in thrombosis. They point to an important role of platelet-dependent coagulation in thrombus formation in vivo. However, a contribution of exposed PS in the injured vessel wall cannot be excluded. The clinical importance of the procoagulant platelet response is apparent in patients with a rare bleeding disorder, the Scott syndrome. These patients have a deficiency in PS exposure upon platelet activation $(41,42)$.

Surprisingly, when thrombosis was induced by $\mathrm{FeCl}_{3}$ in vivo, a high dose of thrombin inhibitor or a moderate dose in combination with a platelet inhibitor was needed to suppress thrombus formation in venules, whereas in arterioles a moderate level of thrombin inhibition was already sufficient. One explanation for this finding is that thrombin generation is locally higher in venules than in arterioles. Therefore, one may speculate that the synergy between platelets and coagulation may be more powerful under venous conditions. This could be a consequence of differences in subendothelial structures (as discussed in paragraph 8.4), resulting in different mechanisms of platelet adhesion in arteries and veins. Also, the lower blood flow in veins may allow platelets to interact with higher local agonist concentrations (thrombin) during longer time periods. In addition, thrombi were larger in size in venules compared to arterioles (at least in the initial phase of thrombus formation), and hence, more activated platelets with more available PS may cause the massive generation of thrombin in veins.

Availability of procoagulant phospholipids is essential for strong prothrombin and factor $X$ activation (39). It is believed that these phospholipids act by generating binding sites for the vitamin K-dependent coagulation factors, II (prothrombin), VII, IX and X interacting via their Giadomains to PS (43). While these classical interactions are essential in thrombin generation, it cannot be excluded that also PS-independent mechanisms exist $(44,45)$. Indeed "evidence has emerged that platelet glycoproteins may serve as binding sites for certain coagulation factors, e.g. prothrombin binds to $\alpha$ llb $\beta 3(46)$ and factors $I X$ and $X I$ to GPIb (47,48). Also, transglutaminase-mediated cross-linking of serotonin is considered to generate receptor sites on platelets for coagulation factors $(49,50)$. Furthermore, the vitamin K-independent factors $V$ and VIII bind to activated platelets independently of PS, but how this occurs is presently unknown. Finally, the surface of procoagulant platelets may also activate factor XII, which may be caused by the negatively charged surface or by other structures exposed or released from platelets (51). These interesting novel mechanisms may indeed play a role in the alliance between platelets and coagulation, and might have been present during the experiments presented in this thesis. However in contrast to PS exposure, their physiological role still needs to be established. Therefore, figure 8.1 does not refer to these mechanisms.

In short, platelet activation and PS exposure in response to collagen involves a series of multireceptor events with redundancy, facilitation and mutual interactions, in which GPVI is 
essential. Moreover, PS exposure is not only mediated by adhesive receptors, but extends to receptors that mediate secondary responses to ADP, ATP and thrombin. This partinership between platelets and coagulation also plays an important role in thrombus formation in vivo.

\subsection{Platelet heterogeneity in adhesion and thrombus formation}

A striking observation throughout the studies in this thesis is the existence of different pllatelet populations after perfusion of blood over a thrombogenic surface. This is particularly visible in Figure 4.6, where fluorescently labeled fibrinogen (green), and annexin A5 (red), the latter binding to exposed PS, were added to mouse blood prior to perfusion over collagen. In wildtype blood, bright fibrinogen staining was observed in aggregates indicating activation of integrin allb 33 . Typically, annexin A5 labeling did not co-localize with fibrinogen labeling, but only single, collagen-bound platelets around the aggregates were annexin A5-positive. In all experiments in which mouse, rat or human blood was flown over collagen followed by postperfusion staining with annexin A5, typically only a fraction of (single) platelets was positive for PS (chapters 2-6), similarly as reported earlier (52). In all conditions, these PS exposing platelets had a balloon-shaped, blebbing morphology. Thus, in this flow assay, clearly the platelets that participate in aggregation are not identical to the ones that contribute to coagulation.

This heterogeneity is partly explained by the different ways of platelet attachment to collagen, which is influenced by the local conditions, including the heterogeneity in collagen binding sites for platelets. Stable platelet adhesion under flow is mediated either by GPVI or $\alpha 2 \beta 1$, and facilitated by $\alpha \mathrm{llb} \beta 3$ interaction with $W W F$, giving rise to complex receptor interplay which easily facilitates heterogeneity (18). Subsequent platelet activation by collagen involves different types of calcium responses, either spiking or prolonged elevations, depending on the particular receptor involved (chapters 3 and 5). In this activation process autocrine ADP may also play a role (chapter 6 ). The adherent platelets subsequently recruit platelets from the flowing blood, leading to the formation of aggregates. In this phase, heterogeneity is introduced When the initial adhesion of "vanguard" platelets to collagen is followed by attachment of "follower" platelets on the spread-out vanguard platelets; this latter process was shown to be allb $\beta 3$ dependent (53). Furthermore, it was demonstrated that different agonists achieve different contributions of tyrosine and serine/threonine kinases in allb $\beta 3$ activation and aggregation (54). It is likely that the relative contribution of each pathway towards platelets activation depends on microenvironmental conditions and results in platelet heterogeneity.

The concept of platelet heterogeneity is also implicitly assumed in a study directed to reveal the intercellular communication of platelets in a thrombus. It has been proposed that stationary (vanguard) platelets communicate their "calcium-activation-status" to subsequent tethering (follower) platelets, recruiting these platelets into developing aggregates (55). The 


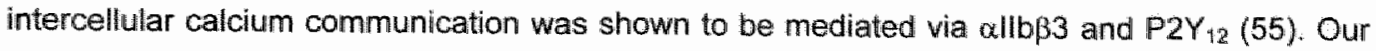
findings from perfusion experiments however indicate that even in the presence of aggregates, platelets may still bind to collagen instead of adhering to other platelets, and then 'decide' to remain single.

The observation that some collagen-adherent platelets remain single is still puzzling. The formation of blebs occurs relatively late, i.e. after several minutes, suggesting that complex or slow signaling cascades precede this dramatic loss of normal platelef structure. It has been shown that degradation of cytosolic actin fibres contributes to the changed morphology of the procoagulant cells $(56,57)$. Furthermore, protein tyrasine dephosphorylation (58) as well as the p38 mitogen-activated protein kinase (SAPK2/3) pathway are involved in actin rearrangement during the development of procoauglant activity and bleb formation (27). At present, little more is known about the signaling prerequisites for the blebbing morphology associated with PS exposure. It seems that above a certain threshold of cytosolic $\mathrm{Ca}^{2+}$ concentration, calpain and other proteases degrade actin, resulting in the destruction of platelet shape, which may even alter the aggregatory function of integrin $\alpha$ llb $\beta 3$. As a consequence, these platelets are unable to interact with other platelets, leaving them as single platelets. The present findings strongly suggest that this PS-exposing platelet population plays an important physiological role in thrombin generation and, hence, is quite distinct from the platelets recruited into aggregates. The in vitro observations that these platelets remain single, and thus are excluded from aggregates, stress their unique importance in the stimulation of coagulation.

Taking this reasoning further, it is also likely that within developing aggregates different microenvironments exist, due to locally different concentrations of released or formed A.DP. $\mathrm{TxA}_{2}$ and thrombin. Recruited platelets will react to these agonists accordingly, resulting in heterogeneity in platelet activation within a thrombus. That such heterogeneity in thrombi naturally occurs in vivo has been observed by van Gestel et al. (59) who showed that most platelets that adhered to a stationary thrombus, exhibited a prolonged rise in intracellular Ca ${ }^{2 *}$, accompanied by shape change and degranulation. In contrast, in platelets that adhered to a growing embolus the rise in intracellular $\mathrm{Ca}^{2+}$ was transient, while shape change and degranulation were absent (59). Besides the micromenvironmental differences, platelet heterogeneity may also be the result of different receptor expression on platelets even within individuals. In addition, the platelet's age may also play a role. For instance, old platellets may cluster GPib on their surface, similar to chilled blood platelets (60). This GPIb clustering may make older platelets more susceptible for tethering on (collagen-bound) VWF, or for aggregation mediated via GPIb-WWF interaction. Probably all of the explanations above are involved in the formation of heterogeneous platelet populations, and other unidentified mechanisms may contribute as well. 


\subsection{Flow chamber versus in vivo mouse models: importance of the} vessel wall

Platelet adhesion and thrombus formation have been studied using both in vitro and in vivo models. In the present thesis a paraliel-plate flow chamber was used to address the mechanisms of platelet activation and aggregation, using mostly collagen as platelet-activating surface. The major advantage of this perfusion approach is the ability to collect data under wellcontrolled conditions of exposure time, thrombogenic surface and reproducible shear stress. This setup allowed real-time monitoring of shear-dependent platelet adhesion and aggregate formation on collagen, as well as platelet activation and generation of platelet procoagulant activity using suitable fluorescent probes. Another advantage is its direct applicability to man, which can lead to a significant reduction in the need for in vivo animal models (61). Indeed, this perfusion assay allowed us to directly compare mouse, rat and human platelets under the same experimental conditions. For instance, experiments revealed that the fundamental processes of adhesion and aggregate formation on collagen are preserved in mouse and human platelets (18).

Although, the parallel-plate flow chamber is a valuable method to study (single) platelet activation and thrombus formation under controlled flow conditions, this model lacks the physiological environment of a blood vessel in the thrombotic process. Particularly the endothelial cells, lining the vessel wall, are eminently involved in the regulation of thromboembolism, and shear force is an important determinant of endothelial function (reviewed in (62)). The endothelium has many pro- and antithrombotic properties which significantly influence platelet behavior in vivo. Examples of prothrombotic substances produced and released by endothelial cells are ADP, ATP, VWF and fibrinogen. Antithrombotic substances are e.g. nitric oxide, prostacyclin and tissue factor pathway inhibitor. Furthermore, endothelial cells display different functions in different parts of the vascular bed (63), which may explain the differences we observed in thrombus formation between arterioles and venules (chapter 7 ). However, in the studies presented in this thesis the thrombotic process was induced by topical application of ferric chloride $\left(\mathrm{FeCl}_{3}\right)$, which causes endothelial denudation. Hence, the role of the endothelium in controlling thromboembolism was probably only limited in these studies. Heterogeneity in deeper vessel wall structures may also significantly influence the thrombotic process. For instance, tissue factor expression is not uniform throughout the vascular tree (64). Also collagen fibers vary greatly in type and thickness throughout the vessel wall, and variation in collagen content may coincide with diverse VWF adhesion sites. In our in vivo experiments, such differences may have contributed to the different thrombotic reactions in mesenteric arterioles and venules. In several in vivo mouse models, including our model (chapter 7 ), platelet collagen-interaction via GPVI has been shown to control thrombus formation in different 
vessel types, pointing to a general importance of collagen exposure for platelet activation in vivo $(65,66)$.

Nowadays, many animal models are being developed to study platellet-vessel wall interactions in vivo. Vascular damage can be inflicted in different vascular beds from different species using different methods (reviewed in (67)). In the studies presented in this thesis (chapters 4 and 7 ), the established $\mathrm{FeCl}_{3}$ microvascular thrombosis model was used, which causes endothelial denudation. This model was chosen, because it is sensitive to both platelet inhibition and anticoagulation, with roles for fibrin(ogen), vWF and $\alpha$ llbB3 (68-70). Plateletdependent coagulation was anticipated to play a role in the thrombotic process. Both collagen and tissue factor were found to be important for the initiation of platelet activation and coagulation in this model.

In chapter 6, another chemical method was used to trigger thrombosis in vivo in the rat femoral artery. This method, the so-called light-dye technique (67), involves endothelial activation via release of reactive oxygen species. As a result, exposure of subendothelial collagen and tissue factor is probably limited, leading to low activation of coagulation and platelets (71). Typically, the endothelium remains present and thrombi consist primarily of platelets, while fibrin formation is minimal. Hence, thrombus formation in this model depends on platelet activation. This explains why in our experiments thrombin inhibition was found to be ineffective. In contrast $t_{n}$ in the mouse $\mathrm{FeCl}_{3}$ model used in this thesis, endothelial denudation results in the exposure of both collagen and tissue factor in the mesenteric arterioles and venules (chapter 7 ). In this model, inhibitor studies indicated that platelet activation by collagen synergized with thrombin generation initiated by tissue factor. Accordingly, upon comparing these two thrombosis models, it can be concluded that the relative contribution of platelets and coagulation depends on species, vessel type (large/small) and the type and severity off injury, as proposed by others (72).

More recently, various groups have used lasers to induce endothelial damage in the microcirculation $(67,73)$. In the laser model, the accumulation of platelets in thrombi was found to coincide with the presence of fibrin and tissue factor (73). The mechanism responsible for the prothrombotic injury in this laser model remains to be elucidated (67). It will be interesting to find out whether platelet-dependent coagulation is also important in this model of laser-induced injury. Histological analysis of thrombogenic vascular tissue suggests that also in man exposed collagen and tissue factor play a role in the thrombosis process $(74 \%$. However, it should be realized that in almost all murine injury models, thrombus formation is triggered in healthy vessels, whereas thrombosis in humans mostly occurs in diseased (atherosclerotic) areas of the vascular system. Therefore, in vivo research on platelet-vessel wall interactions should be extended to the atherosclerotic situation, e.g. in ApoE-deficient mice. 


\subsection{Clinical implications of the present research}

An important question is to which extent the present data generated in mice can be extrapolated to the human situation, given the fact that clear differences exist in the thrombotic process of either species (see chapter 1). On the other hand, it must be noted that many platelet, coagulation and extracellular matrix proteins of the mouse show striking similarities in structure and function to their human counterparts. The introduction of targeted gene disruption in mice has provided unique opportunities to study platelet function, and of every known human platelet defect, a mouse deficient in the same receptor or ligand has been generated. Upon comparison of patients and transgenic mice, many similarities regarding the regulation of platelet activation and aggregation are observed (chapter 1). However, in most patients with a genetic platelet defect, procoagulant activity was not studied. Hence, the data regarding platelet procoagulant activity in mice may also be true for the human situation. Further, $\mathrm{FeCl}_{3}$-triggered thrombi in mouse blood vessels have been shown to have a similar morphology to thrombi found in human vessels (75). Hopefully, many of the observations in this animal model, including those presented in this thesis, will have direct relevance for human thrombosis and hemostasils.

Inhibition of platelet function has become an effective strategy for the control of cardiovascular disease. Lately, drugs have been developed that target the fibrinogen receptor allb $\beta 3$ or the ADP receptor $P 2 Y_{12}$, acting in the propagation phase of thrombus formation (Fig. 8.1), and severall of these compounds have been tested as promising in clinical trials. Unfortunately, many allbi3-antagonists cause bleeding complications. The development of products that interfere with the initiation steps of hemostasis (Fig. 8.1), i.e. platelet adhesion and initiation of coagulation, has not been given much attention.

There seems to be a discrepancy between the observations that mice deficient in GPVI and/or FcR $y$-chain are protected from arterial thrombosis $(16,65,66)$ on the one hand, and the fact that GPVI-deficient mice $(15,16)$ and humans $(76,77)$ do not have a major bleeding defect on the other. Mice deficient in $\alpha 2 \beta 1$ also do not have bleeding problems $(10,11)$. The data from chapter 3 demonstrate that integrin $\alpha 2 \beta 1$ has a complementary role to GPVI, which suggests that this receptor (together with aggregatory receptors) can substifute for GPVI during normal hemostasis. Since GPVI is a platelet-specific molecule and, hence, anti-GPVI agents are less likely to have side-effects, it may serve as an attractive antithrombotic target. Studies have indicated that GPVI-binding antibodies (such as JAQ1 used in chapter 3) can deplete GPVI from mouse platelets and protect the animals from thrombosis (78). Similar antibody-induced shedding of GPVI has recently also been demonstrated in humans (77). In addition, GPVI has also been implicated to be essential in plaque-induced thrombus formation $(79,80)$. This seems to plea for GPV/ntargeted antithrombotic treatment of atherothrombotic patients. In mice, however, side-effects have been seen of anti-GPVI treatment in combination with other anti- 
platelet inhibitors, leading to markedly increased bleeding $(19,81)$. The situation is quite different regarding targeting of $\alpha 2 \beta 1$. Chapter 4 describes that absence of integrin $\alpha 2 \beta 1$ resulted in frequent embolization of microvascular thrombi. This stabilizing role of $\alpha 2 \beta 1$ argues against the use of $2 \beta 1$-inhibiting agents, which may cause undesirable embolization also in humans.

Antibodies have also been developed against human GPIb. These antibodies were tested in a thrombosis model in a stenosed artery in baboons, where they showed potent antithrombotic activities, without a noteworthy prolongation of the bleeding time (82). This. makes GPIb, similarly as GPVI, an interesting candidate for antithrombotic treatment. The studies in chapter 5 demonstrated that there is some redundancy in GPVI and GPIb receptor function. Therefore, simultaneous targeting of GPVI and GPIb may not be beneficial.

\subsection{Conclusions}

The main goal of the studies presented in this thesis was to investigate the contribution of key platelet receptors to collagen-induced platelet activation, in particular the platelet procoagulant response. The results indicate that in the initiation phase of platelet activation by collagen (Fig. 8.1), GPVI is the essential receptor mediating all activation processes, but it needs to be complemented by integrin $\alpha 2 \beta 1$ (chapters 3 and 4 ), GPlb and integrin $\alpha / l b \beta 3$ (chapter 5) for stable adhesion to collagen, full platelet activation and procoagulant activity and subsequent stable thrombus formation. In the propagation phase of thrombus formation, platelets can also be induced to expose PS independently of collagen. At this level, the secondary mediators ADP (chapter 6), TXA (chapters 3 and 4), ATP and thrombin play additive roles in PS exposure. A remarkable observation is that, during the process of thrombus formation, subpopulations of platelets display a different pattern of activation (either procoagulant or proaggregatory), which likely depends both on the microenvironment and on platelet characteristics, such as receptor density and age. Regarding the microenvironment, only few platelets make direct contact with collagen, while most platelets within a thrombus bind to each other. In vivo studies complement these findings by showing that synergism between platelet activation and coagulation is important in thrombus formation in both arterioles and venules in vivo (chapter 7 ).

Hopefully, many of the observations in the mouse studies presented in this thesis, will have direct relevance for human thrombosis and hemostasis. In the future, parallels between data obtained in experimental mouse models and data from clinical settings are very likely to become available. At present both in vitro and in vivo mouse models to study platelet function have already achieved a key position in hemostasis and thrombosis research. 


\subsection{References}

1. Nieuwenhuis HK, Akkerman JW, Houdijk WP, Sixma JJ. Human blood platelets showing no response to collagen fail to express surface glycoprotein la. Nature. 1985;318:470-472.

2. Nieuwenhuis HK, Sakariassen KS, Houdijk WP, Nievelstein PF, Sixma JJ. Deficiency of platelet membrane glycoprotein la associated with a decreased platelet adhesion to subendothelium: a defect in platelet spireading. Blood. 1986;68:692-695.

3. Kehrel $B$, Balleisen $L$, Kokott $R$, Mesters $R$, Stenzinger $W$, Clemetson $K J$, van de $L o o ~ J$. Deficiency of intact thrombospondin and membrane glycoprotein la in platelets with defective collagen-induced aggregation and spontaneous loss of disorder. Blood. 1988;71: 1074-1078.

4. Nieswandt B. Watson SP. Platelet collagen interaction: is GPVI the central receptor? Blood. $2003 ; 102: 449-461$.

5. Sixma $J J$, van Zanten GH, Huizinga EG, van der Plas RM, Verkley M, Wu YP, Gros $P$, de Groot PG. Platelet adhesion to collagen: an update. Thromb Haemost. 1997;78:4344-438.

6. Morton LF, Peachey AR, Barnes MU. Platelet-reactive sites in collagens type I and type III. Evidence for separate adhesion and aggregatory siles. Biochem J. 1989;258:157-163.

7. Santoro SA, Walsh $J J$, Staatz WD, Baranski KJ. Distinct determinants on collagen support $\square 2 \square 1$ integrin-mediated platelet adhesion and platelet activation. Cell Regul. 1991:2:905-913.

8. Watson $S$, Berlanga $O$, Best D, Frampton J. Update on collagen receptor interactions in platelets: is the two-state model still valid? Platelets. 2000;11:252-258.

9. Nieswandt $B$, Brakebusch $C$, Bergmeier $W$, Schulte $V$, Bouvard $D$, Mokhtari Nejad $R$, Lindhout $T$, Heemskerk JW, Zirngibl $H$, Fassler R. Glycoprotein $V /$ but not $\alpha 2 \beta 1$ integrin is essential for platelet interaction with collagen. EMBO J. 2001;20:2120-2130.

10. Holtkotter $O$, Nieswandt B, Smyth $N$, Muller $W$, Hafner $M$, Schulte $V$, Krieg $T$, Eckes B. Integrin $\alpha 2-$ deficient mice develop normally, are fertile, but display partially defective platelet interaction with collagen. J Biol Chem. 2002;277:10789-10794.

11. Chen J, Diacovo TG, Grenache DG, Santoro SA, Zutter MM. The $c 2$ integrin subunit-deficient mouse: a multifaceted phenotype includling defects of branching morphogenesis and hemostasis. Am J Pathol. $2002 ; 161: 337-344$.

12. Polanowska-Grabowska $R$, Gibbins $J M$, Gear AR. Platelet adhesion to collagen and collagen-related peptide under flow: roles of the $\alpha 2 \beta 1$ integrin, GPVI, and Src tyrosine kinases. Arterioscler Thromb Vasc Biol. 2003;23:4934-1940.

13. Atkinson $B T$, Jarvis $G E$, Watson SP. Activation of GPVI by collagen is regulated by $\alpha 2 \beta 1$ and secondary mediators. J Thromb Haemost. 2003;1:1278-1287.

14. Siljander PR, Munnix IC, Smethurst PA, Deckmyn $H$, Lindhout $T$, Ouwehand $W H_{s}$ Farndale RW, Heemskerk $J W$. Platelet receptor interplay regulates collagen-induced thrombus formation in flowing human blood. Blood. 2004:103:1333-1341.

15. Kato $K$, Kanaji T, Russell $S$, Kunicki TJ, Furihata $K$, Kanaji $S$, Marchese $P$, Reininger $A$, Ruggeri $Z M$, Ware $J$. The contribution of glycoprotein $\mathrm{VI}$ to stable platelet adhesion and thrombus formation illustrated by targeted gene deletion. Blood. 2003:102:1701-1707.

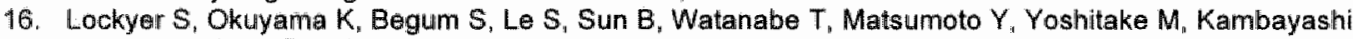
J. Tandon NN. GPVI-deficient mice lack collagen responses and are protected against experimentally induced pulmonary thromboembolism. Thromb Res. 2005. In press.

17. Lecut $C$, Feeney LA, Kingsbury $G$, Hopkins J, Lanza F, Gachet $C$, Villevall JL, Jandrot-Perrus $M$. Human platelet glycoprotein VI function is antagonized by monoclonal antibody-derived Fab fragments. J Thromb Haemost. 2003;1:2653-2662.

18. Auger JM, Kuijpers MJE, Senis YA, Watson SP, Heemskerk JWM. Adhesion of human and mouse platelets to collagen under shear: a unifying model. Faseb J. 2005;19:825-827.

19. Sarratt $K L$, Chen $H$, Zutter MM, Santoro SA, Hammer DA, Kahn ML. GPVI and a2 21 play independent critical roles during platelet adhesion and aggregate formation to collagen under flow. Blood. 2005:106(4):1268-1277.

20. Farndale RW, Sixma JJ, Barnes MJ, de Groot PG. The role of collagen in thrombosis and hemostasis. J Thromb Haemost. 2004;2:561-573.

21. Farndale RW. Platelet-collagen interactions. J Thromb Haemost. 2005;3:abstract 1825.

22. Grüner $S$, Prostredna $M$, Schulte V, Krieg $T$, Eckes $B$, Brakebusch $C$, Nieswandt $B$. Multiple integrinligand interactions synergize in shear-resistant platelet adhesion at sites of arterial injury in vivo. Blood. $2003 ; 102: 4021-2027$.

23. He L, Pappan LK, Grenache DG, Li Z, Tollefsen DM, Santoro SA, Zutter MM. The contributions of the a2:31 integrin to vascular thrombosis in vivo. Blood. 2003;102(10): 3652-3657. 


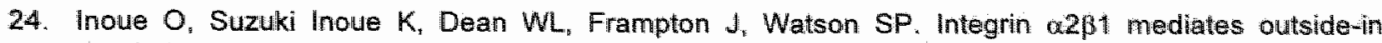
regulation of platelet spreading on collagen through activation of Src kinases and PLCY2. J Cell Biol 2003:160:769-780.

25. Munnix ICA, Strehl A, Kuijpers MJE, Auger JM, van der Meijden PEJ, van Zandvoort MAM, Oude Egbrink MGA, Nieswandt B, Heemskerk JWM. The glycoprotein W/phospholipase $C_{1} 2$ signaling pathway controls collaglen- and tissue factor-induced thrombus formation in vitro and in vivo. Atheroscl Thromb Vasc Biol. 2005;25: In press.

26. Heemskerk JW, Vuist WM, Feijge MA, Reutelingsperger $C P$, Lindhout $T$. Collagen but not fibrinogen surfaces induce bleb formation, exposure of phosphatidylserine, and procoagulant activity of adherent platelets: evidence for regulation by protein tyrosine kinase-dependent $\mathrm{Ca}^{2 *}$ responses. Blood. 1997; 90:2615-2625.

27. Siljander $P$, Farndale RW, Feijge MA, Comfurius $P$, Kos $S$, Bevers EM, Heenskerk JW. Platelet adhesion enhances the glycoprotein VI-dependent procoagulant response: Irvolvement of p38 MAP kinase and calpain. Arterioscler Thromb Vasc Biol. 2001:21:618-627.

28. Bevers EM, Ciomfurius $P$, van Rijn $\mathrm{JL}$. Hemker $\mathrm{HC}_{1}$ Zwaal RF. Generation of prothrombin-converting activity and the exposure of phosphatidylserine at the outer surface of platelets. Eur $\mathrm{J}$ Biochem. $1982 ; 122: 429-436$.

29. Zwaal RF, Schroit AJ. Pathophysiologic implications of membrane phospholipid asymmetry in blood cells. Blood. 1997;89:1121-1132.

30. Kulkarni S, Jackson SP. Platelet factor XllI and calpain neglatively regulate integrin allbß3 adhesive function and thrombus growth. J Biol Chem. 2004,279:30697-30706.

31. Lopez JA, del Conde 1, Shrimpton CNN. Receptors, rafts, and microvesicles in thrombosis and inflammation. J Thromb Haemost. 2005;3:1737-1744.

32. Mazzucato $M$, Pradella $P$, Cozzi MR, De Marco L. Ruggeri ZM. Sequential cytoplasmic calcium signals in a 2-stage platelet activation process induced by the glycoprotein Ibalpha mechanoreceptor. Blood. 2002;100:2793-2800.

33. Nesbitt WS, Kulkarni $S$, Giuliano $S_{*}$ Goncalves I, Dopheide $S M_{n}$ Yap $C L$, Harper IS, Salem HH, Jackson SP. Distinct glycoprotein $\mathrm{lb} / \mathrm{N} / \mathrm{IX}$ and integrin allib33-dependent calcium signals cooperatively regulate platelet adhesion under flow. J Biol Chem. 2002; 277:2965-2972.

34. Mangin $P$, Yuan $Y$, Goncalves I, Eckly $A$, Freund $M$, Cazenave JP, Gachet $C$, Jackson SP, Lanza $F$. Signaling role for phospholipiase $\mathrm{C}_{2} 2$ in platelet glycoprotein $\mathrm{lba}$ calcium flux and cytoskeletal reorganization. Involvement of a pathway distinct from $F \mathrm{CR}$-chain and $F \mathrm{Cr}_{\mathrm{r}} \mathrm{RIIA} \mathrm{J}$ Biol Chem. $2003 ; 278: 32880-32891$.

35. van der Meijden PE, Feijge MA, Giesen PL, Huijberts M, van Raak LP. Heemskerk. JW. Platelet P2Y $Y_{12}$ receptors enhance signaling towards procoagulant activity and thrombin generation $A$ study with healthy subjects and patients at thrombotic risk. Thromb Haemost. 2005;93:1128-1136.

36. Leon $C$, Ravanat $C$. Freund $M$, Cazenave JP, Gachet $C$. Differential involvement of the $P 2 Y_{1:}$ and $\mathrm{P}_{2} \mathrm{Y}_{12}$ receptors in platelet procoagulant activity. Arterioscler Thromb Vasc Biol. 2003;23:1941-1947.

37. Oury $C$. Kuijpers. MJE, Toth-Zsamboki $E$, Bonnefoy $A$, Danloy $S$, Vreys $\|$, Feijge MAH, De Vos $R$, Vermylen J, Heemskerk JWM, Hoylaerts MF. Overexpression of the platelet P.2X, ion channel in transgenic mice generates a novel prothirombotic phenotype. Blood. 2003;101:3969-3976.

38. Keuren JF, Wielders SJ, Ulrichts $H$, Hackeng T. Heemskerk JWM. Deakmyn H, Bevers EM, Lindhout $T$. Synergistic effect of thrombin on collagen-induced platelet procoagulant activity is mediated throught protease-activated receptor-1. Arterioscler Thromb Vasc Biol. 2005;25:1499-1505

39. Rosing J, van Rijn JL, Bevers EM, van Dieijen G, Comfurius P, Zwaal RF. The role of activated human platelets in prothrombin and factor $X$ activation. Blood. 1985;65:319-3:32

40. Beguin $S$, Kumar $R$. Thrombin, fibrin and piatelets: a resonance loop in which won Willebrand factor is a necessary link. Thromb Haemost. 1997;78:590-594.

41. Rosing $\mathrm{J}$, Bevers EM, Comfurius P. Hemker HC, van Dieijen G, Weiss HJ, Zwaal RF. Impaired factor $X$ and prothrombin activation associated with decreased phospholipid exposure in platelets from a patient with a bleeding disorder. Blood. 1985;65:1557-1561.

42. Weiss HJ. Scott syndrome: a disorder of platelet coagulant activity. Semin Hematol. 1994,31:312-319.

43. Vermeer $C$. The binding of Gla-containing proteins to phospholipids. FEBS Lett. 1984; 173:169-172.

44. Heemskerk JWM, Bevers EM, Lindhout T. Platelet activation and blood coagulation. Thromb Haemost. 2002;88:186-193.

45. Monroe DM, Hoffman M, Roberts HR. Platelets and thrombin generation. Arterioscler Thromb Vasc Biol. 2002;22:1381-1389

46. Byzova TV. Plow EF. Networking in the hemostatic system. Integrin allbp3 binds prothrombin and influences its activation. J Biol Chem. 1997;272:27183-27188.

47. Hoffman M, Monroe DM. Roberts HR. Coagulation factor IXa binding to activated platelets and platelet-derived microparticles: a flow cytometric study. Thromb Haemost. 1992;68;74-78. 


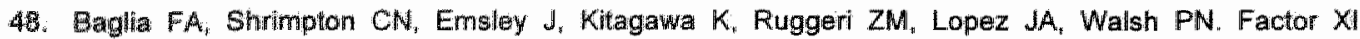
interacts with the leucine-rich repeats of glycoprotein $\mathrm{lba}$ on the activated platelet. $\mathrm{J}$ Biol $\mathrm{Chem}$. $2004: 279 \times 49323-49329$.

49. Dale GL, Friese P, Batar P, Hamilton SF, Reed GL, Jackson KW, Clemetson KJ, Alberio L. Stimulated platelets use serotonin to enhance their retention of procoagulant proteins on the cell surface. Nature. $2002: 415: 175-179$.

50. Dale GL. Coated-platelets: an emerging component of the procoagulant response. J Thromb Haemost. $2005,3,1-8$.

51. Renne $T$, Pozgajova $M$, Gruner $S$, Schuh $K$, Pauer HU, Burfeind $P$, Gallani $D$. Nieswandt B. Defective thrombus formation in mice lacking coagulation factor XIl. J Exp Med. 2005;202:271-281.

52. Briedé $J J$, Heemskerk $J W M$, Hemker $H C$, Lindhout $T$. Heterogeneity in microparticle formation and exposure of anionic phosphollipids at the plasma membrane of single adherent platelets. Biochim Biophys Actia. 1999;1451:163-172.

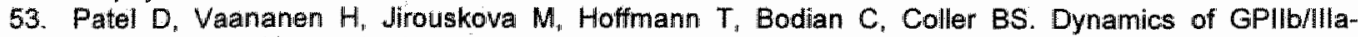
mediated platelet-platelet interactions in platelet adhesion/thrombus formation on collagen in vitro as revealed by videomicroscopy. Blood. 2003;101:929-936.

54. Hers I, Donath $J$, van Willigen $G$, Akkerman JW. Differential invalvement of tyrosine and serine/threonine kinases in platelet integrin allb $\beta 3$ exposure. Arterioscler Thromb Vasc Biol. $1998: 18: 404-414$.

55. Nesbitt WS, Giuliano S, Kulkarni S, Dopheide SM, Harper IS, Jackson SP. Intercellular calcium communication regullates platelet aggregation and thrombus growth. J Cell Biol. 2003;160:1151-1161.

56. Verhallen PF, Bevers EM. Comfurius $P_{n}$ Zwaal RF. Correlation between calpain-mediated cytoskeletal degradlation and expression of platelet procoagulant activity. A role for the platelet membrane-skeleion in the regulation of membrane lipid asymmetry? Biochim Biophys Acta. 1987;903:206-217.

57. Fox JE, Austin CD, Boyles JK, Steffen PK. Role of the membrane skeleton in preventing the shedding of procoagulant-rich microvesicles from the platelet plasma membrane. J Cell Biol. 1990;111:483-493.

58. Pasquet $J M$, Dachary-Prigent $J$, Nurden AT. Microvesicle release is associated with extensive protein tyrosine dephosphorylation in platelets stimulated by A23187 or a mixture of thrombin and collagen. Biochem J. 1998;333:5911.599.

59. van Gestel MA, Heemskerk JWM, Slaaf DW, Heijnen W, Sage SO, Reneman RS, oude Egbrink MGA. Real-time detection of activation patterns in individual platelets during thromboembolism in vivo: differences between thrombus growth and embolus formation. J Vasc Res. 2002;39:534-543.

60. Hoffmeister KM, Felbinger TW, Falet $H_{1}$ Denis CV, Bergmeier W, Mayadas TN, von Andrian $\mathrm{UH}_{\text {, }}$ Wagner DD, Stossel TP, Hartwig JH. The clearance mechanism of chilled blaod platelets. Cell. 2003;112:87-97.

61. Sakariassen KS, Turitto VT, Baumgartner HR. Recollections of the development of flow devices for studying mechanisms of hemostasis and thrombosis in flowing whole blood. $\mathrm{J}$ Thromb Haemost. 2004;2:1681-1690.

62. oude Egbrink MGA, wan Gestel MA, Broeders MD, Tangelder GJ, Heemskerk JWM, Reneman RS, Slaaf DW. Regulation of microvascular thromboembolism in vivo. Microcirculation. 2005;12:287-300.

63. Broeders MAW, Tangelder Gل, Slaaf DW, Reneman RS, oude Egbrink MGA. Endogenous nitric oxide and prostaglandins synergistically counteract thromboembolism in arterioles but not in venules. Arterioscler Thromb Vasc Biol. 2001;21:163-169.

64. Mackman N. Role of tissue factor in hemostasis, thrombosis, and vascular development. Arterioscler Thromb Vasc Biol. 2004:24:1015-1022.

65. Nieswandt $B$, Schulte $V$, Bergmeier $W$, Mokhtari-Nejad $\mathbb{R}_{n}$ Rackebrandt $K$, Cazenave JP, Ohimann $P$. Gachet $C_{i}$ Zirngibl $H$. Long-term antithrombotic protection by in wivo depletion of platelet glycoprotein Vi in mice. J Exp Medi. 2001;193:459-469.

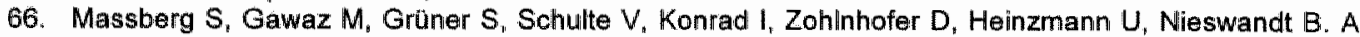
crucial rolle of glycoprotein VI for platelet recruitment to the injured arterial wall in vivo. $J$ Exp Med. 2003;197:41-49.

67. Rumbaut $R$, Slaff $D$. Burns A. Microvascular thrombosis models in venules and arterioles in vivo. Microcirculation. 2005;12:259-274.

68. Ni H, Denis $C V$, Subbarao $S$, Degen $J L$, Sato $T N$ Hynes RO, Wagner DD. Persistence of platelet thrombus formation in arterioles of mice lacking both won Willebrand factor and fibrinogen. J Clin Invest. 2000;106:385-392.

69. Nii $H_{\text {}}$ Papalia $J_{M}$ Degen $J \mathbb{L}$, Wagner $D$ D. Control of thrombus embolization and fibronectin internalization by integrin $\alpha / l b \beta 3$ engagement of the fibrinogen $\gamma$-chain. Blood. 2003;102:3609-3614.

70. Ni $H$, Yuen PS, Papalia JM, Trevithick JE, Sakai T, Fassler $R_{1}$ Hynes RO, Wagner DD. Plasma fibronectin promotes thrombus growth and stability in injured arterioles. Proc Natl Acad Sci U S A. 2003;100:2415-2419. 
71. Matsuno $H$, Uematsu $T$, Nagashima $S$, Nakashima M. Photochemically induced thrombosis model in rat femoral artery and evaluation of effects of heparin and tissue-type plasminogen activator with use of this model. J Pharmacol Methods. 1991:25:303-317.

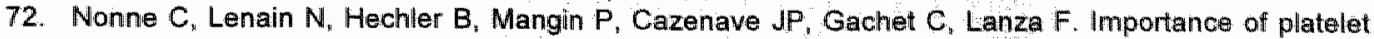
phospholipase $\mathrm{C} \gamma 2$ signaling in arterial thrombosis as a function of lesion severity. Arterioscler Thromb Vasc Biol. 2005;25:1293-1298.

73. Falati $S$, Gross $P$, Merrill-Skoloff $G$, Furie BC, Furie $B$. Real-time in vivo imaging of platelets, tissue factor and fibrin during arterial thrombus formation in the mouse. Nat Med 2002;8:1175-1181.

74. Toschi $V$, Gallo $R$, Lettino $M_{2}$ Fallon JT, Gertz SD, Fernandez-Ortiz A, Chesebro JH, Badimon $L$, Nemerson $Y$, Fuster $V$, Badimon $J \mathrm{~J}$. Tissue factor modulates the thrombogenicity of human atherasclerotic plaques. Circulation. 1997;95:594-599.

75. Farrehi PM, Ozaki CK, Carmeliet $P$, Fay WP. Regulation of arterial thrombolysis by plasminogen activator inhibitor-1 in mice. Circulation. 1998;97:1002-1008.

76. Moroi M, Jung SM, Okuma M. Shinmyozu K. A patient with platelets deficient in glycoprotein $\mathrm{W}$ that lack both collagen-induced aggregation and adhesion. J Clin Invest. $1989 ; 84: 1440-1445$.

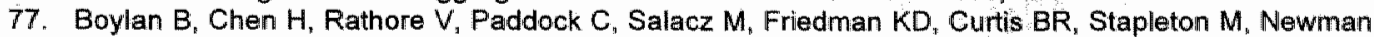
DK, Kahn ML, Newman PJ. Anti-GPVl-associated ITP: an acquired platelet disorder caused by autoantibody-mediated clearance of the GPVI/FCR $\gamma$-chain complex from the human platelet surface. Blood. 2004;104:1350-1355.

78. Schulte $V$, Rabie $T$, Prostredna $M$, Aktas $B$, Grüner $S$, Nieswandt $B$. Targeting of the collagen-binding site on glycoprotein VI is not essential for in vivo depletion of the receptor. Blood. 2003;101(10):39483952.

79. Cosemans JMEM, Kuijpers MJE, Lecut C, Loubele ST, Heeneman S, Jandrat-Perrus M, Heemskerk JWM. Contribution of platelet gllycoprotein $V \|$ to the thrombogenic effect of collagens in fibrous atherosclerotic lesions. Atherosclerosis. 2005;181:19-27.

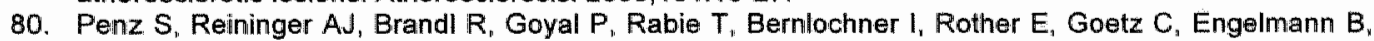
Smethurst $P A$, Ouwehand $W H$, Farndale $R$, Nieswandt $B$, Siess W. Human atheromatous plaques stimulate thrombus formation by activating platelet glycoprotein Vl. Faseb J. 2005;19:898-909.

81. Grüner S, Prostredna M, Aktas B, Moers A, Schulte $V$, Krieg T, Offermanns $S$, Eckes B, Nieswandt B. Anti-gllycoprotein VI treatment severely compromises hemostasis in mice with reduced $\alpha 2 \beta 1$ levels or concomitant aspirin therapy. Circulation. 2004;110:2946-2951.

82. Cauwenberghs $N$, Meiring $M$, Vauterin $S$, van Wyk $V_{\text {, Lamprecht }} S$, Roodt JP, Novak $L$, Harsfalvi $J$, Deckmyn $H$, Kotze HF. Antithrombotic effect of platelet glycoprotein lb-blocking monoclonall antibody Fab fragments in nonhuman primates. Arterioscler Thromb Vasc Biol. 2000;20:1347-1353. 


\section{Summary}

Samenvatting 


\section{Summary}

\section{Platelet receptors and procoagulant activity in thrombus formation}

In hemostasis and thrombosis, interactions of platelets with components from the vessel wall play a crucial role. After vascular damage, platelets adhere to the subendothelial extracellular matrix with collagen as important constituent, become activated and assemble into a platelet aggregate. Simultaneously, the coagulation process is activated, e.g. by exposed tissue factor in the injured vessel wall, which results in the generation thrombin and subsequently fibrin, consolidating the thrombus. The procoagulant response of platelets is considered to be responsible for the amplification of the coagulation process. This unique form of platelet activation involves exposure of the phospholipid phosphatidylserine (PS) on the outer platelet membrane. The exposure of PS strongly promotes the assembly of coagulation factors and the formation of thrombin. In turn, thrombin is also a potent platelet agonist. Hence, the processes of platelet activation and coagulation are closely entwined, and both thought to be essential for effective thrombus formation. The main goals of the present thesis was to investigate the involvement of key platelet receptors contributing to collagen-induced platelet activation, especially related to the platelet procoagulant response, and to demonstrate the importance of these processes in vivo.

Platelets can interact with collagen by severall receptors. Current knowledge of plateletcollagen interaction is described in detail in chapter 1. First, von Willebrand factor (WWF), present in plasma and secreted by endothelial cells, binds to collagen. Under high shear conditions, platelets bind to WWF via glycoprotein $\mathrm{lb}$ (GPIb). This is a weak interaction, which causes platelets to "roll" over the WWF/collagen surface. Following platelet rolling, direct interactions between collagen and platelets lead to strong adhesion. Platelets adhere to collagen via two receptors, GPVI and integrin $\alpha 2 \beta 1$. This stable adhesion can be strengthened by the binding of GPlb and integrin allbB3 to WWF. The direct binding to collagen induces platelet activation, which is predominantly mediated by GPVI. Platelet activation involves a rise in the intracellular $\mathrm{Ca}^{2+}$ concentration. This causes platelets to change shape and to secrete activating substances, such as thromboxane $A_{2}\left(T \times A_{2}\right)$ and adenosine diphosphate (ADP). These autocrine mediators recruit nearby platelets from flowing blood to form a platelet aggregate. Formation of a platelet aggregate is mediated by integrin ailb $\beta 3$, which binds to fibrinogen to form cross-links between platelets.

Chapter 2 addresses the present understanding of how platelet interaction with collagen supports the processes of thrombin generation and coagulation. Only part of the collagen-adhered platelets, namely those showing profound changes in shape and shedding microparticles, appear to accomplish procoagulant activity. The main signaling receptor for collagen, GPVI, plays a unique, key role in the platelet procoagulant response during collagen- 
induced thrombus formation. This is one reason why new anti-GPVI antibodies are promising antithrombotic tools.

In most of the subsequent studies described in this thesis a perfusion model is used.. This model consists of a parallel-plate perfusion chamber, which may be imagined as an artificial damaged blood vessel (chapter 1, figure 1.4). Coverslips coated with collagen or fibrinogen are mounted into the perfusion chamber. A pulse-free pump is used to perfuse isolated blood over the coverslip at a shear rate representative for arteries or veins. During and after perfusion the platelets attached to the collagen are observed with a microscope. This setup allows real-time monitoring of shear-dependent platelet adhesion and aggregate formation, as well as platelet activation and generation of platelet procoagulant activity using suitable fluorescent probes. However, the vessel wall, an important component in thrombus formation, is missing in this in vitro model. Therefore, platelet-vessel wall interactions and ensuing thrombus formation have also been studied in vivo, in an established murine microvascular thrombosis model. In this model, the thrombotic process is induced by topical application of ferric chloride $\left(\mathrm{FeCl}_{3}\right)$ on mouse mesenteric arterioles and venules, which results in endothelial denudation and the formation of intravascular thrombi. Thrombus formation has been studied in real-time using intravital microscopy.

In chapter 3, the roles of both collagen receptors GPVI and integrin $\alpha 2 \beta 1$ in thrombus formation were directly compared during perfusion of whole blood over collagen. Using either mice deficient in GPVI or blocking antibodies against this receptor it was demonstrated that GPVI is indispensable for collagen-dependent $\mathrm{Ca}^{2+}$ mobilization, exposure of PS and aggregation. In contrast, deficiency in $\beta 1$-integrin (i.e. mice lacking $\alpha 2 \beta 1$ ) considerably reduced these GPVI-evoked responses, but still allowed the formation of loose platelet aggregates. Using mice deficient in $G \mathrm{olg}_{\mathrm{g}}$ (an intracellular signaling G-protein coupled to thrombin, TxA $\mathrm{A}_{2}$ and $A D P$ receptors) or specific $T \times A_{2}$ and $A D P$ antagonists it was shown that signaling via these autocrine agents is required for aggregation, but not for collagen-induced $\mathrm{Ca}^{2+}$ mobilization and PS exposure. Collectively, these findings indicate that $\alpha 2 \beta 4$ facilitates the central function of GPVI in the platelet activation processes leading to thrombus formation, while TXA2 and ADP mainly trigger aggregate formation.

In contrast to the established platelet-activating role of GPVI, the function of integrin $\alpha 2 \beta 1$ in thrombus formation is still controversial in literature. Therefore, in chapter 4 , the role of $\alpha 2 \beta 1$ in thrombus growth and stability was investigated in $\alpha 2$-deficient (-null) mice (lacking $\alpha 2 \beta 1)$ by in vitro and in vivo studies. Using the in vivo thrombosis model it was demonstrated that thrombi formed in arterioles from a 2-null mice were smaller in size and embolized more frequently compared to thrombi in vessels from wildtype mice. Second, perfusion of blood from o.2-null mice over collagen resulted in formation of thrombi that were smaller and looser in appearance than those obtained with wildtype blood. These data indicate that $\alpha 2 \beta 1$ has a 
moderate but qualitatively important effect to stabilize thrombi. Moreover, $\alpha 2 \beta 1$ also assists GPVI in mediating fibrinogen binding to platelets, exposure of $P S$ and $T \times A_{2}$ formation. In addition, co-perfusion of blood and a stable $\mathrm{TXA}_{2}$ anallogue over collagen resulted in normalization of thrombus size in absence of $\alpha 2 \beta 1$. In summary, these data indicate that $\alpha 2 \beta 1$ enhances the following GPVI-dependent mechanisms: (1) release of TXA , (ii) activation of allb\$3 leading to irreversible aggregation, and (iii) PS exposure leading to generation of thrombin and fibrin clots. The frequent embolization in the absence of $\alpha 2 \beta 1$ argues against the use of $\alpha 2 \beta 1$ integrin inhibitors for antithrombotic therapy.

Besides direct adhesion to collagen via GPVI and integrin $\alpha 2 \beta 1$, platelets also adhere to WWF bound to collagen fibers. In chapter 5 the supportive role of platelet-WWF binding via GPlb and allbק3 in thrombus formation was investigated in mouse blood flowing over collagen at high shear rate. Inhibition of GPIb as well as blocking of WWF binding to collagen reduced stable platelet adhesion. This was accompanied by delayed platelet $\mathrm{Ca}^{2+}$ responses and reduced PS exposure, while micro-aggregates were still formed. Inhibition of integrin allb 33 with an antibody reduced PS exposure and aggregate formation. Interestingly, with blood from mice expressing $50 \%$ of normal platelet GPVI levels, GPlb blockade almost completely abolished platelet adhesion and PS exposure. Together, this work indicates that, under these conditions of flow, both adhesive receptors GPIb and allbß3, facilitate GPVI-mediated PS exposure by stabilizing platelet binding to collagen. Hence, these receptors have an assistant role in collagen-dependent thrombus formation, which becomes more prominent at reduced GPVI activity.

In chapter 6 thrombus formation was studied in rat and human blood. Rats were treated with a mild dose of classical coagulation inhibitor (heparin or warfarin), after which they were subjected to thrombosis in the femoral artery. The thrombosis tendency appeared not to be changed by these treatments. Therefore, it was considered that platelet-inhibiting agents that influence coagulation as well, may act as more potent anti-thrombotic agents compared to classical anticoagulants. This has been investigated in flow chamber studies, where whole blood was perfused over fibrinogen under coagulant condlitions. Examined were the effects of the inhibitor prostaglandin $E_{1}\left(P G E_{1}\right)$, which elevates cyclic AMP levels and thereby inhibits platelet activity, and of the P2Y, $\mathrm{Y}_{12}$ ADP-receptor antagonist, AR-C69931MX. Perfusion of rat or human blood in the presence of tissue factor resulted in deposition of activated platelets and subsequent aggregate formation, along with exposure of procoagulant PS on the platelet surface and formation of fibrin fibers. In the presence of PGE, aggregation was completely inhibited but platelet adhesion and PS exposure were only partly reduced, whille fibrin formation was hardly affected. Treatment with AR-C69931MX caused similar, but less complete effects. These results indicate that in tissue factor-triggered blood from various species under conditions of flow: (i) the platelet procoagulant response is independent of aggregate formation and (ii) the 


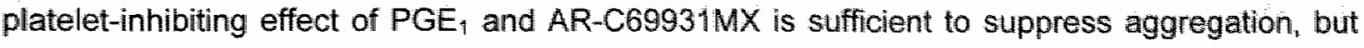
not platelet adhesion and coagulation. These platelet inhibitors thus appear to maintain their aggregation-inhibiting effect at sites where platelets participate in thrombin formation.

The mutually stimulatory processes of platelet activation and thrombin generation in arterial and venous thrombus formation in vivo are investigated in chapter 7 . In the murine $\mathrm{FeCl}_{3}$, modell, the thrombus-forming process appeared to be triggered by both collagen exposure and the complex of tissue factor and factor VIl(a). Furthermore, arterial thrombus formation was suppressed by either partial thrombin inhibition or platelet inhibition. In contrast, suppression of venous thrombus formation required either the combination of partial thrombin inhibition plus platelet inhibition or full thrombin inhibition. Antagonism of platelet procoagulant activity, by intervention with PS-binding annexin A5, completely abolished the formation of thrombi in both vessell types, while a mutant M1234-annexin A5 (incapable of PS binding) appeared to be ineffective. The presence of procoagulant platelets in arterial and venous thrombi has been confirmed by in vivo staining with fluorescently labeled annexin A5. These findings demonstrate that the propagation of thrombin generation by PS-exposing platelets is a key regulatory process in both veins and arteries. In the venous circulation, very high thrombin levels may be reached locally, which explains why only platelet inhibition is ineffective.

The significance of the findings described in this thesis is discussed in chapter 8 , particularly in the light of relevant new literature. In the initiation phase of platelet activation by collagen GPVI is the essential receptor mediating all activation processes, but it needs to be complemented by integrin $\alpha 2 \beta 1$, GPlb and integrin $\alpha$ llb $\beta 3$ for stable adhesion to collagen and subsequent responses: full platelet activation, procoagulant activity and stable thrombus formation. In the propagation phase of thrombus formation, platelets can also be induced to expose PS independently of collagien. At this level, "secondary mediators" like ADP and thrombin play additive roles in PS exposure. A remarkable observation from the perfustion

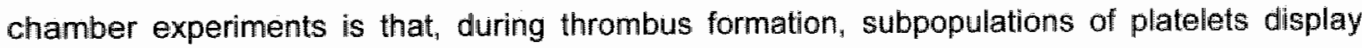
different patterns of activation (either procoagulant or proaggregatory). Finally, the in vivo studies show that the synergistic effects of platelets and coagulation are important in thrombus formation in both arterioles and venules.

Altogether, during the time in which the present thesis has been prepared, our knowledge on the roles of platelet (collagen) receptors in collagen-induced platelet activation, aggregation and PS exposure has greatly increased. Particularly, murine knock-out models have taught on the functions of these receptors. Although most of the studies of this thesis have been performed in mice, the observations in this thesis are likely to be of relevance for treating human thrombosis and maintaining normal hemostasis. It is anticipated that this knowledge will help to develop improved treatment of the numerous patients who still suffer from cardiovascular thrombotic disease. 


\section{Samenvatting}

\section{Bloedplaatjesreceptoren en procoagulante activiteit in trombusvorming}

In een volwassen mens circuleent 5 à 6 liter bloed door de bloedvaten. Het bloed transporteert onder andere bloedcellen (rode en witte bloedcellen en bloedplaatjes)، zuurstof, voedingsstoffen en hormonen. Het is dus van levensbelang dat de bloedcirculatie niet wordt verstoord. Het lichaam is in staat om enerzijds bloedverlies na beschadiging van de vaatwand tegen te gaan (hemostase), en anderzijds verstopping van intacte biloedvaten (trombose) te voorkomen. Bloedplaatjes, de kleinste cellen in het bloed, spelen een belangrijke rol in de hemostase, maar ook in de ongewenste trombose. Ze circuleren door de bloedvaten met zo'n 300 miljard per liter en bevinden zich relatief dicht bij de vaatwand. In een onbeschadigd bloedvat wordt hechting van bloedplaatjes aan de wand voorkomen door de anti-trombotische eigenschappen van endotheelcellen die de binnenbekleding van de vaatwand vormen. Wanneer het endotheel beschadigd raakt, glaan bloedplaatjes hechten (adhesie) aan de bestanddelen die zich onder de endotheellaag bevinden, zoals collageen. Collageen is een krachtige activator van bloedplaatjes. Geactiveerde bloedplaatjes gaan aan elkaar hechten (aggregatie), en er ontstaat op de plaats van beschadiging een bloedplaatjesprop of -plug die de beschadiging afdicht. Bij een valatwandbeschadiging wordt tegelijkertijd de bloedstolling op gang gebracht. Dit proces wordt gestart door weefselfactor, een eiwit in de vaatwand, en verloopt via een aantal opeenvolgende reacties tussen eiwitten in het bloed (stollingsfactoren). De stollingsibevorderende (procoagulante) respons van bloedplaatjes is van groot belang voor de versnelling van de bloedstolling. Tijdens deze respons wordt het fosfolipide fosfatidylserine (PS) naar de buitenkant van het bloedplaatjesmembraan getransporteerd. Het verschijnen van PS katalyseert de vorming van trombine, dat zorgt voor de vorming van fibrine, het eindproduct van de bloedstolling. Fibrine vormt een netwerk van draden in de bloedplaatjesprop, waardoor deze een stevig geheel (trombus) wordt. Trombine kan echter ook bloedplaatjes activeren. Bloedplaatjesactivatie en bloedstolling zijn dus nauw met elkaar verweven "en beide processen zijin essentieel voor effectieve trombusvorming. Het doel van het onderzoek in dit proefschrift was om de activatie van bloedplaatjes door collageen onder stromingscondities te bestuderen, en de bijdrage van belangrijke bloedplaatjesreceptoren hierin te bepalen. Naast aggregatie en trombusvorming is met name de procoagulante respons van bloedplaatjes onderzocht.

Bloedplaatjes kunnen via een aantal receptoren intteracties aangaan met collageen. Dit proces wordt in detail beschreven in hoofdstuk 1. Allereerst binden de bloedplaatjes op indirecte wijze aan collageen, via de von Willebrand factor (vWF). vWF is een eiwit in het plasma en de endotheelcellen, dat zelf hecht aan collageen. Bloedplaatjes kunnen binden aan WWF via glycoproteïne Ib (GPIb). Dit is echter een zwakke binding, waardoor de bloedplaatjes gaan "rollen" over het collageen. Vervolgens kan stabiele adhesie van bloedplaatjes op collageen plaatsvinden via twee receptoren, namelijk GPVI en integrine $\alpha 2 \beta 1$. De adhesie wordt 
verder versterkt door de binding van GPIb en integrine allbB3 aan WWF. Door de interactie met collageen worden bloedplaatjes geactiveerd. wat gepaard gaat met een stijging in de intracellulaire calcium-concentratie. Dit leidt vervolgens tot vormverandering van bloedplaatjes, waarbij ze ook allerlei activerende stoffen uitscheiden. Dit zijn onder andere tromboxaan $A_{2}$ $\left(T \times A_{2}\right)$ en adenosine difosfaat (ADP), die op hun beurt weer andere voorbij stromende bloedplaatjes kunnen activeren. Tenslotte aggregeren bloedplaatjes via interactie van integrine allbß3 met fibrinogeen.

Hoofdstuk 2 gaat in op de huidige kennis omtrent bloedplaatjes-interactie met collageen en de manier waarop die leidt tot trombinegeneratie en bloedstolling. Slechts een deel van de aan collageen gehechte bloedplaatjes slaagt erin om procoagulante activiteit te vertonen, namelijk dat deel dat zeer sterk van vorm verandert en microparticles afsnoert. GPVI, de belangrijkste signalerende receptor voor collageen, speelt een unieke rall in de procoagulante respons van bloedplaatjes tijdens collageen-geinnduceerde trombusvorming. Onder meer om deze reden vormen antilichamen tegen GPVI een veelbelovende vorm van antitrombotische medicatie.

In de meeste studies beschreven in de volgende hoofdstukken van dit proefschrift is gebruik gemaakt van een perfusiemodel. Dit model bestaat uit een perfusiekamer, die men zich zou kunnen voorstellen als een kunstmatig, beschadigd bloedvat (hoofdstuk 1, figuur 1.4). Hierin wordt een dekglaasje aangebracht dat bedekt is met collageen of fibrinogeen. Met behulp van een pomp stroomt geïsoleerd bloed over het glaasje met een stroomsnelheid representatief voor slagaders (arterièn) of aders (venen). Tijdens en na de perfusie worden de bloedplaatjes die gehecht zijn aan het collageen bestudeerd met een microscoop. Dit perfusiemodel is uitermate geschikt om bloedplaatjesadhesie, -activatie en trombusvorming onder gecontroleerde stromingscondities te bestuderen. Echter, in dit model ontbreekt een belangrijke component van de trombusvorming, namelijk de vaatwand. Daarom zijn ook experimenten gedaan in de levende muis, "in vivo", om bloedplaatjes-vaatwand-interacties te bestuderen in hun natuurlijke omgeving. In het gebruikte model is trombusvorming opgewekt in de bloedvaten van het darmvlies van de muis, door ijzertrichloride $\left(\mathrm{FeCl}_{3}\right)$ op het darmvlies te druppelen. Deze stof beschadigt de wand van de bloedvaten zodanig dat endotheelcellen verwijderd worden. De hieropvolgende trombusvorming kan vervolgens bestudeerd worden met een speciale lichtmicroscoop, een zogenaamde intravitaal microscoop.

In hoofdstuk 3 wordt de bijdrage van de collageenreceptoren GPVI en integrine $\alpha 2 \beta 1$ aan de trombusvorming vergeleken tijdens de perfusie van bloed over een collageen-oppervlak. Hierbij werd gebruik gemaakt van muïzen die deficiënt zijn in GPVI, $\beta 1$-integrine (waardoor $\alpha 2 \beta 1$ ontbreekt), of $\mathrm{G} \alpha_{q}$ (een intracellulair signaleringsellwit verbonden alan receptoren voor trombine, $\mathrm{T}_{X A_{2}}$, en $\mathrm{ADP}$ ), of van remmers of antilichamen die deze receptoren blokkeren. De resultaten toonden aan dat GPVI onmisbaar is voor de intracellulaire calciummobilisatie " de 
expositie van PS en de aggregatie. In müzen deficient in het $\beta 1$-integrine waren deze GPVIafhankelijke processen aanzienlijk verminderd, hoewel de vorming van losse bloedplaatjesaggegregaten nog wel optrad. In muizen die $G \alpha_{\text {q }}$ imissen, of in aanwezigheid van $T \times A_{2}$ en $A D P$ remmers, werd aangetoond dat signalering via deze secundaire mediatoren nodig is voor aggregatie, maar niet voor de collageen-geînduceerde calciummobilisatie of PS-expositie. Uit deze resultaten kan geconcludeerd worden dat $\alpha 2 \beta 1$ een faciliterende roll speelt bij de GPVIafhankelijke activatie van bloedplaatjes en de daaropvolgende trombusworming, terwijl $T \times A_{2}$ en ADP hoofidzakelijk betrokken zijn bij de aggregatie.

Terwijl de rol van GPVI in de trombusvorming, namelijk bloedplaatjesactivatie, inmiddels algemeen geaccepteerd is, is de rol van het integrine $\alpha 2 \beta 1$ controversieel in de literatuur. Daarom is in hoofdstuk 4 de rol van $\alpha 2 \beta 1$ in de trombusvorming en -stabiliteit opnieuw onderzocht, nu bij $\alpha 2$-cleficiënte (-null) muizen (waardoor $\alpha 2 \beta 1$ ontbreekt) middels in vitro en in vivo studies. Met het in vivo trombosemodel werd aangetoond, dat de trombi die werden gevormd in de arteriolen (kleine slagaders) van de $\alpha 2$-null muizen kleiner waren vergeleken met de trombi in arteriolen van wildtype (normale) muizen. Bovendien waren de trambi in de $\alpha 2$-null imuizen instabiel: er werden meer aggregaten van de trombi afgebroken (emboli) dan in de wildtype muizen. Vervolgens bleek ook in het perfusiemodel dat trombi van a2-null muizen kleiner en losser waren dan die van wildtype muizen. Deze resultaten geven aan dat $\alpha 2 \beta 1$ een bescheiden, maar belangrijk effect heeft op de stabilisatie van trombi. Bovendien assisteert $\alpha 2 \beta 1$ GPVI ook bij de binding van fibrinogeen aan bloedplaatjes, de expositie van PS en de vorming van TxA2. Perfusie van $\alpha 2$-null bloed tezamen met een stabiele TxA $\mathrm{A}_{2}$-analoog over collageen normaliseerde de grootte van de trombi. Samengevat laten deze resultaten zien dat $\alpha 2 \beta 1$ de volgende GPVI-afhankelijke mechanismen versterkt: (i) vorming van TxA , (ii) activatie van integrine allbß3, wat leidt tot irreversibele aggregatie, en (iii) PS-expositie. resulteert in de vorming van trombime en fibrine-stolsels. De frequente embolisatie die optreedt in afwezigheid van $\alpha 2 \beta 1$ pleit tegen thet gebruik van integrine $\alpha 2 \beta 1$-remmers als antitrombotische medicijn.

Behalve via directe hechting aan collageen middels GPVI en $\alpha 2 \beta 1$, hechten bloedplaatjes ook aan WWF, welke weer bindt aan collageen. In hoofdstuk 5 werd de additionele rol van plaatjes-WWF-binding via GPIb en integrine allb $\beta 3$ in de trombusvorming onderzocht in muizenbloed dat stroomde over collageen. Zowel remming van GPIb als het blokkeren van de binding van WWF aan collageen reduceerde de stabiele adhesie van bloedplaatjes bij hoge bloedstroomsnelheid (zogenoemde afschuifsnelheid). Dit ging gepaard met vertraagde calciumresponsen van bloedplaatjes en verlaagde PS-expositie, terwijl microaggregaatjes nog gevormd werden. Inhibitie van allbß33 met een antilichaam verlaagde de PSexpositie en aggregaatvorming. Vervolgens werd de trombusvorming onderzocht bij muizen met een 50\% GPVI-expressieniveau. Boven verwachting resulteerde blokkade van GPIb in het 
bloed van deze muizen in complete afwezigheid van bloedplaatjesadhesie en PS-expositie, terwijl in aanwezigheid van GPIb de trombusvorming onveranderd was. Deze experimenten duiden erop, dat onder fysiologische stromingscondities de twee adhesieve receptoren GPIb en allbB3 versterkend werken op de GPVI-gemedieerde PS-expositie door het stabiliseren van de plaatjesbinding aan collageen. Dus deze receptoren hebben een assisterende rol in de collageen-afhankelijke trombusvorming, die het meest prominent is bij verlaagde GPVI-activiteit.

In hoofdstuk 6 werd de trombusvorming bestudeerd in humaan bloed en bloed van ratten. Ratten werden al dan niet behandeld met een milde dosis van klassieke antistollingsmiddelen (heparine of warfarine), waarna zij werden blootgesteld aan vaatwandschade in de slagader van de achterpoot. De daaropvolgende trombotische reactie bleek gelijk te zijn in behandelde en onbehandelde ratten. Dit leidde tot de vraag of de rol van geactiveerde bloedplaatjes, die eveneens de bloedstolling beïnvloeden, mogeljik erg belangrijk is tijdens deze reactie. Daarom werd het effect van bloedplaatjesremmende medicatie onderzocht en vergeleken met het effect van klassieke anti-stollingsmiddelen. Hiertoe zijn perfusieexperimenten uitgevoerd, waarbij bloed werd gestroomd over een fibrinogeen-oppervlak onder condities waarbij ook de bloedstolling op gang werd gebracht. De effecten van de remmer prostaglandine $E_{1}\left(P G E_{1}\right)$, die de intracellulaire CAMP-niveaus verhoogt en daardoor de bloedplaatjesactiviteit remt, en van AR-C69931 MX, een antagonist van de ADP-receptor $P 2 Y_{12}$, werden onderzocht. De perfusie van humaan of rattenbloed resulteerde in de adhesie van bloedplaatjes en daaropvolgende aggregaatvorming, tezamen met PS-expositie en de vorming van fibrinedraden. In aanwezigheid van $P G E_{1}$ werd de aggregatie volledig geremd, maar de adhesie en PS-expositie waren slechts deels gereduceerd. De vorming van fibrine was nauwelijks veranderd. Behandeling met AR-C69931 MX leidde tot vergelijkbare, maar minder complete effecten. Deze resultaten geven aan dat, in het bloed van mens en rat, de procoagulante respons van bloedplaatjes onafhankelijk is van de aggregaatvorming. Verder dat het plaatjesremmende effect van $\mathrm{PGE}_{1}$ en $\mathrm{AR}-\mathrm{C69931} \mathrm{MX}$ voldoende is om de aggregatie te onderdrukken, maar niet de plaatjesadhesie en bloedstolling. Deze plaatjesremmers lijken dus hun remmende effect op de aggregatie te behouden wanneer bloedplaatjes betrokken zijn bij de vorming van trombine.

De interactie tussen bloedplaatjesactivatie en trombinegeneratie in arteriële en veneuze trombusvorming in vivo is onderzocht in hoofdstuk 7 . In het trombosemodel bleek na vaatwand-beschadiging het proces van trombusvorming op gang te worden gebracht door blootstelling van het bloed aan zowel collageen als weefselfactor. De trombusvroming in arteriolen kon worden geremd door ofwel een lage dosering van een trombine-remmer ofwel plaatjesremming. Echter, am de trombusvorming in de venulen te onderdrukken was een combinatie van beide nodig, ofwel een complete onderdrukking van trombinevorming. De procoagulante respons van bloedplaatjes kan worden onderdrukt door annexine A5, een eiwit 
dat bindt aan PS. Toedienen van annexine A5 aan de muizen resulteerde in complete onderdrukking van de trombusvorming in beide typen bloedwaten. De aanwezigheid van procoagulante bloedplaatjes in arterielle en veneuze trombi werd bevestigd door deze in vivo aan te kleuren met annexine A5, waaraan een fluorescerend label gebonden was. Deze bevindingen demonstreren dat de versterking van trombine-generatie door PS-presenterende bloedplaatjes een belangrijk proces is in zowel venen als arterièn. In de veneuze circulatie lijkt het erop dat lokaal zeer hoge trombine-niveaus kunnen worden bereikt, waardoor bloedplaatjesremmers alleen niet effectief zijn in het onderdrukken wan trombose.

In hoofdstuk 8 wordt de significantie van de bevindingen beschreven in dit proefschrift bediscussieerd in het licht van recente literatuur. Tijdens de initiatiefase van bloedplaatjesactivatie door collageen is GPVI de essentiële receptor, die alle activatieprocessen medieert. Echter, GPVI wordt hierbij gecomplementeerd door integrine $\alpha 2 \beta 1$, GPIb en integrine allb 33 , zodat stabiele adhesie aan collageen optreedt met volledige pllaatjesactivatie, procoagulante activiteit en uiteindelijk een stabiele trombus gevormd wordt. In de propagatiefase van trombusvorming kunnen bloedplaatjes ook onafhankelijk van collageen gestimuleerd worden om PS te exposeren. Hierbij spelen de "secundaire mediatoren" zoals ADP en trombine een aanvullende rol. Een opmerkelijke observatie tijdens de perfusiekamerexperimenten is dat tijdens de trombusvorming twee subpopulaties van bloedplaatjes ontstaan, die verschillen in hun activatiepatroon. De meeste bloedplaatjes gaan aggregeren en komen in trombi terecht, maar sommige bloedplaatjes worden procoagulant en blijven apart op het collageen liggen. Tenslotte laten de in vivo studies zien dat de synergistische effecten van bloedplaatjes en -stolling belangrijk zijn in de trombusworming in zowel arteriolen als venulen.

Dit proefschrift is een toevoeging aan de kennis over de bijdragen van bloedplaatjes(collageen)-receptoren in de collageen-geinduceerde activatie van bloedplaatjes, aggregatie en PS-expositie. Hoewel het merendeel van de studies in dit proefschrift met muizen zijn uitgevoerd, zijn de uitkomsten naar verwachting ook relevant voor het handhaven van de normale hemostase en de behandeling van trombose bij de mens. Hopelijk zullen de resultaten bijdragen aan de ontwikkeling van nieuwe behandelingsmethoden van de vele patiënten die lijden aan cardiovasculaire aandoeningen. 


\section{Dankwoord}

Onderzoek doen is teamwork en dit proefschrift zou er niet zijn gekomen zonder de samenwerking met anderen. Ik wil daarom iedereen bedanken die mij in de afgelopen vijf jaar heeft bijgestaan, op welke manier dan ook. Een aantal personen verdienen hierbij speciale aandacht:

Johan, als mijn begeleider ben je de drijvende kracht achter dit proefschrift. lk kon altijd bij je binnenlopen, waarwoor dan ook. Je wist altijd waar ik mee bezig was, ondanks alle andere promovendi, studenten en gasten die je ook begeleidt. Wanneer ik vaak blij was met het resultaat van een geslaagde proef, bedacht jij meteen weer welke proeven er nu weer moesten worden gedaanll $\mathrm{k}$ bewonder de manier waarop je van elk project een succes weet te maken. Je bent altijd super-enthousiast bezig met onderzoek en ik heb de afgelopen jaren met veel plezier met je gewerkt. Gelukkig mag ik nog een aantal jaren met je verder werken en hopelijk zijn deze even succesvol als de afgelopen vijf jaar!

Mirjam, bij jou ben ik zeven jaar geleden als stagiaire in het onderzoek begonnen. Toen is mijn enthousiasme voor (proefdier-) onderzoek ontstaan. Jle bent altijd zeer betrokken

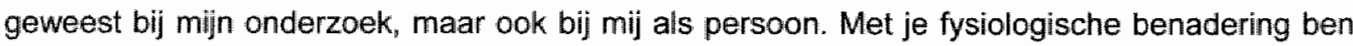
je de perfecte aanvulling op de biochemische kijk op onderzoek! Ik heb je inbreng altijd zeer gewaardeerd en hopelijk zullen we in de toekomst nog veell samenwerken. Bedankt voor alles!

Jan, als mijn promotor heb je mijn dagelijkse begeleiding aan Johan overgelaten, maar als vakgroepvoorzitter heb je de belangrijke taak om ervoor te zorgen dat het iedereen van Biochemie, en dus ook mij, goed gaat. Je stelde altijd kritische vragen als ik een werkbespreking hield en hebt met dezelfde kritische blik dit proefschrift gelezen en gecorrigeerd. Bedankt hiervoor!

Op het lab heb ik de afgelopen jaren heel wat lief en leed gedeeld. In de eerste plaats had ik hier mijn kamergenoten voor. Marion, jou bijdrage aan onze groep is niet in woorden uit te drukken. Je staat altijd voor iedereen klaar en ik heb vooral je luisterend oor altijd erg gewaardeerd. Ik ben erg blij dat je mijn paranimf bent! En Jeffrey, met je nuchtere opmerkingen heb je ons regelmatig aan het lachen gemalkt. Ook met de andere AlO's uit de groep heb ik veel meegemaakt. Imke, jij kletst en lacht heel wat af! We hebben heel wat weken samen muizen geopereerd en experimenten gedaan. Dat was altijd erg gezellig. Maar ook naast het werk zijn we veel samen opgetrokken: aerobics, skaten, naar huis lopen, enz. Ik wil je bedanken voor je vriendschap en ik vind het leuk dat je mijn paranimf bentl Veel succes met het afronden van je eigen proefschrift. Sandra, Paola en Judith, stuk voor stuk dragen jullie bij aan de gezellige, motiverende sfeer op het lab. Ook jullie wens ik veel succes voor de rest van jullie promotietijd, en ook daarna nog natuurlijk! Kristof, aok al ben je al enige tijd vertrokken naar Humane Biologie, je kamer op de derde verdieping is makkelijk te vinden als we je hulp nodig hebben. Ook jou wens ik alle goeds in je verdere loopbaan. 
Theo, jij bent altijd geinteresseerd en betrokken bij het onderzok wan ond

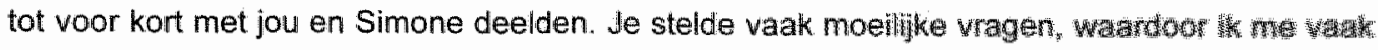

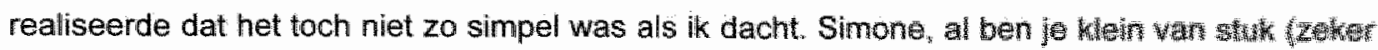

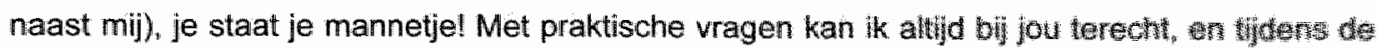
lunch weet je vaak leuke verhalen te vertellen. Mieke, met je (h)entike wispraken hob je ons vaak aan het lachen gemaakt! Hopelijk kunnen we nog vaak een mooie wandeling naken?

Ook mijn collega-AlO's van Biochemie: Heidi, Rory "Kristin, Jeroen, Km, Sarah, Ame, Machiel, Hugo, Lisbeth, Kenneth, Svetlana, Erik en Rachelle wil ik veel succes wensen met hum promatie en/of verdere carrière. Berry, ik ben je ontzettend veel dank verschuldigd voor de ontelbare keren dat je me bij mijn computerproblemen hebt geholpenl Alle overige leden van de capgroep Biochemie wil ik bedanken voor de samenwerking en/of gezelthoheid wjons hetwerk en dagjes uit. Verder wil ik liedereen van Microcirculatie bedanken voor de plezienge samenwerking: Mirjam, Viviane, Dick, Marc, Wim, Miriam, Anita veerle, lacquelne, Gestie, Alexandra, Remco en Sietze. Viviane, geduldig heb je mij geleerd om muizen onder anesthesie te brengen en vervolgens te opereren. Heel erg bedankt! Dick, bij koningin Beatrix is het wit jaar geleden begonnen! Jij hebt me mede overgehaald om AlO te worden en nu ben je de voozitter van mijn beoordelingscommissie! Dankjewel! Ook woorden van dank aan de medewerkers van de Centrale Proefdier Voorzieningen voor hun onmisbare verzorging van de muizen.

During my PhD period, PhD students from other labs came to work in our lab. Christelle from Paris, you stayed in Maastricht for one year. I really enjoyed the time we spent together, both in the lab and out! Jocelyn from Birmingham, you were with us for four morths and I will always remember your enthusiasm! Amrei from Wurzburg. you stayed in our lab for three months, and even took Dutch lessons! Ik vond het heel leuk dat je in Maastricht was! / wish all of you all the best for the future and hopefully we will meet again and maybe even work together some day!

I have visited the lab of Dr. Bernhard Nieswandt in Würzburg several times. Bernhard, thank you very much for all collaborations on several of my projects and also for the pleasant times I spent in your lab. Valerie, Sabire, Mirka, Rasti and Amrei, thank you all very much for your help with experiments and social events (I especially liked the Christmas market with Gluhwein and Weinfest at the Residenz, even though it poured with rain!).

Marije, Yvonne en Else, sinds onze studietijd zijn we hele goede vriendinnen. Ook al wonen we nu in Montréal, Maastricht en Amsterdam, en zien we elkaar maar weinig, er wordt toch regelmatig "even" bijgekletst per tellefoon of e-maill Marije, heel veel succes bij het behalen van je PhD! Hopelijk kom je over niet al te lange tijd weer terug naar Europa. Yvonne, ik ben erg blij dat je na je tijd in Brussel nu je draai weer hebt gevonden in Maastricht! Veel succes bij je opleiding tot huisarts en veel plezier in je nieuwe huis! Ik vind onze "bijklets-zwem-avonden. eventueel met eten" altijd erg gezellig; die mogen van mij een wekelijkse traditie worden! Else, 
onze stagetijd in Cambridge was echt geweldig en zal ik nooit vergeten! Jij ook heel veel succes voor de toekomst!

Papa en mama, ik zou nooit zover zijn gekomen als jullie mij niet altijd onvoorwaardelijk hadiden gesteund. Jullie hebben mij de mogelijkheid gegeven om een goede opleiding te volgen, en hebben mij altijd vrij gelaten om mijn eigen keuzes te maken. Mijn dankbaarheid thiervoor is niet in woorden uit te drukken! Mijn zussen Ineke en Annelies: ontzettend bedankt voor jullie steun. I $\mathrm{k}$ weet dat wij altijd op elkaar kunnen rekenen en ik ben ook geweldig trots op alles wat jullie hebben bereikt! Natuurlijk wil ik ook Jurgen en Arie bedanken, en ook mijn ooms en tantes: Jan en Anja, Els en Kees bediankt voor jullie steun!

Naast mijn eigen familie heb ik een leuke schoonfamillie. Han en Marianne, jullie hebben me meteen in jullie gezin opgenomen en dit betekent heel veel voor me! Vincent en Monique, jullie zijn voor mij bijna broer en zus, ook jullie bedlankt voor alles! Heel veel plezier in jullie nieuwe huis! Naomi en Esmee, ook al zijn jullie nog klein, de wereld ligt voor jullie open en jullie kunnen altijd op mij rekenenl Ook wil ik oma, alle andere familieleden en mijn goede vrienden Tijs en Sietske, Joost en Regine, en Robbert bedanken voor alle steun "op afstand".

En tenslotte de allerbelangrijkste: Paul, vijf jaar geleden hebben we samen besloten dat ik deze AlO-baan moest nemen in Maastricht en heb jij je baan opgezegd en bent met me meegegaan. Zonder jou was ik er nooit aan begonnen en in feite zou dit proefschrift er niet zijn geweest als jij dit "offer" niet had gemaakt. Gelukkig hebben we samen onze draai in Limburg gevonden! Jij hebt aitijd achter me gestaan door dik en dun: heel erg bedankt!

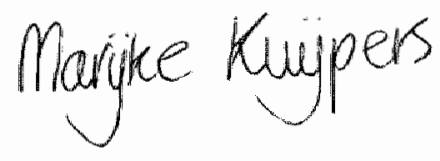

februari 2006 


\section{Curriculum vitae}

Marijke Kuijpers werd geboren op 20 juli 1977 te Weert. De eerste vier jaar van haar leven woonde zij in Maarheeze, in 1981 verhuisde zil naar Etten-Leur. Na het verlaten van de Gerardus Majella basisschool begon zij in 1989 aan het Voorbereidend Wetenschappelijk Onderwijs (VWO) op de Katholieke Scholengemeenschap te Etten-Leur. In 1995 behaalde zij het WWO-diploma, waarna ze startte met de opleiding Gezondheidswetenschappen aan de Universiteit Maastricht. Na ontvangst van het propedeuse in 1996 vervolgde zij deze studie in de richting Biologische Gezondheidskunde. Tijdens haar studie verwierf ze de status van artikel 9-deskundige volgens de Wet op de Dierproeven. Haar éénjarige afstudeerstage liep zij in 1999 bij de capgroep Fysiologie, laboratorium voor Microcirculatie onder begeleiding van Dr. M.G.A. oude Egbrink, Dr. A. Griffioen en Dr. J.W.M. Heemskerk. Voor een extra buitenlandstage vertrok ze begin 2000 voor zes maanden naar Cambridge, Engeland. Hier deed zij onderzoek bij the Department of Haematology, Division of Transfusion Medicine, University of Cambridge, onder begeleiding van Dr. N.A. Watkins en Dr. W.H. Ouwehand. Op. 31 augustus 2000 mocht zij haar universitaire diploma in ontvangst nemen en in januari 2001 ontving zij de Studentenprijs 2000 voor Wetenschapsbeoefening van de Universiteit Maastricht, uitgereikt door h.k.h. Koningin Beatrix. Op 1 mei 2001 begon zij als Assistent in Opleiding (AlO) binnen het Cardiovascular Research Institute Maastricht (CARIM) bij de capgroep Biochemie van Prof. Dr. J. Rosing. Het onderzoek dat zij daar deed en wat beschreven staat in dit proefschrift vond plaats onder directe begeleiding van Dr. J.W.M. Heemskerk en Dr. M.G.A. oude Egbrink. Na het volgen van verscheidene cursussen werd haar in 2004 het CARIM PhD-Training Certificate uitgereikt. Tijdens haar AlO-periode bezocht zij congressen in onder andere Birmingham. Nottingham, Oxford, Eberbach, Erfurt en Sydney en won zij tweemaal een "young investigator award" voor haar abstracts of mondelinge presentatie. Zij bezocht verscheidene malen het laboratorium van Dr. B. Nieswandt in Würzburg, Duitsland, om daar proeven te doen. Tevens bezocht zij het laboratorium van Prof. Dr. S. Watson in Birmingham, Engeland. Op 21 oktober 2004 werd haar door de faculteit de Geneeskunde een "Kootstra Fellowship" toegekend, bedoeld voor tallentvolle AlO's om de periode tussen het afronden van het proefschrift en de indiensttreding als Post-doc, te overbruggen. Sinds 15 december 2005 is zij werkzaam als Postdoc bij de capgroep Biochemie van de Universiteit Maastricht. 


\section{Curriculum vitae}

Marijke Kuijpers was born on July $20^{\text {th }} 1977$ in Weert, the Netherlands. The first 4 years of her life she lived in Maarheeze, and in 1981 she moved to Etten-Leur. After leaving the Gerardus Majelia primary school in 1989, she started highschool (VWO) at the Catholic School in Etten-Leur. In 1995 she received her VWO-diploma, after which she started to study Biological Health Sciences at the University of Maastricht. During her study she obtained her status of article 9-expert according to the Law on Animal experiments. In 1999 she followed her graduation internship at the Department of Physiology, Jaboratory for Microcirculation under supervision of Dr. M.G.A. oude Egbrink, Dr. A. Griffioen and Dr. J.W.M. Heemskerk. In 2000 she spent six months in Cambridge, England, to perform research at the Department of Haematology, Division of Transfusion Medicine, University of Cambridge, under guidance of Dr. N.A. Watkins and Dr. W.H. Ouwehand. On August $31^{\text {st }} 2000$ she received her Master's Degree and in January 2001 she won the student award 2000 of the Faculty of Health Sciences on behalf of the Foundation for Practice of Science, University of Maastricht, procured by Her Majesty Queen Beatrix. On May $1^{\text {st }} 2001$ she started as PhD student at the Cardiovascular Research Institute Maastricht (CARIM) at the Department of Biachemistry of Prof. Dr. J. Rosing. The research that she performed there and which is described in this thesis, was supervised by Dr. J.W.M. Heemskerk and Dr. M.G.A. oude Egbrink. After taking several courses, she received the CARIM PhD-Training Certificate in 2004. During her PhD-period she visited congresses in among others Birmingham, Nottingham, Oxford, Eberbach, Erfurt and Sydney, and twice she won a "young investigator award" for her abstracts or oral presentation. She visited the laboratory of Dr. B. Nieswandt in Würzburg, Germany, several times to perform experiments. She also visited the laboratory of Prof. Dr. S. Watson in Birmingham, England. On October $21^{\text {st }}$ 2004 she received a "Kootstra Fellowship talented candidate postdoc", from the Faculty of Medicine, intended for talented PhD-students to overcome the period between finishing the PhD thesis and starting as a Post-doc. Since December $15^{\text {th }} 2005$ she is working as a Post-doc at the Department of Biochemistry at the University of Maastricht. 


\section{List of publications}

\section{Papers}

- Dirkx AEM, oude Egbrink MGA, Kuilipers MJE, van der Niet ST, Heijnen VVT, Bouma-ter Steege JCA, Wagstaff $\mathrm{J}$ and Griffioen $A$. Tumor angiogenesis modulates leukocyte-vessel wall interactions in vivo by reducing endothelial adhesion molecule expression. Cancer Res. 2003; 63 (9): 2322-2329.

- Kuijpers MJE, Schulte V, Bergmeier W, Lindhout T, Brakebusch C, Offermanns S, Fässler R, Heemskerk JWM and Nieswandt B. Complementary roles of platelet glycoprotein VI and $\alpha 2 \beta 1$ integrin in collagen-induced thrombus formation in flowing whole blood ex vivo. FASEB J. 2003; 17:685-687.

- Oury C, Kuilpers MuE, Toth-Zsamboki E, Bonnefoy A, Danloy S, Vreys I, Feijge MAH, De Vos $R_{a}$ Vermylen J, Heemskerk JWM. and Hoylaerts MF. Overexpression of the platelet $\mathrm{P} 2 \mathrm{X}_{1}$ ion channel in transgenic mice generates a novel prothrombotic phenotype. Blood. 2003; 101 (10): 3969-3976.

- Watkins NA, Dafforn TR, Kuijpers MJE, Brown C, Javid B, Lehner PJ, Navarrete $C$ and Ouwehand WH. Molecular refinement of anti-HLA-A2 using light chain shuffling: a structural model for HLA antibody binding. Tissue Antigens. 2004; 63 (4): 345-354.

- Kuijpers MJE, Schulte V, Oury C, Lindhout T, Broers JL, Hoylaerts MF, Nieswandt B and Heemskerk JWM. Facilitating roles of murine platelet glycoprotein lb and $\square \mathrm{llb} \square 3$ in phosphatidylserine exposure during WWF-collagen-induced thrombus formation. J Physiol. 2004. 558 (2): 403-415.

- Lecut C, Schoolmeester A, Kuijpers MJE, Broers JL, Van Zandvoort MAM, Vanhoorelbeke

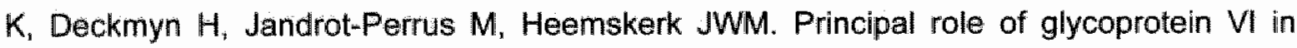
$\alpha 2 \beta 1$ and $\alpha$ llb $\beta 3$ activation during collagen-induced thrombus formation. Arterioscler Thromb Vasc Biol. 2004; 24 (9): 1727-1733.

- Auger JM, Kuljpers MJE, Senis YA, Watson SP and Heemskerk JWM. Adhesion of human and mouse platelets to collagen under shear: a unifying model. FASEB J. 2005; 19 (7); 525-827

- Kuijpers MJE, Nieuwenhuys CMA, Feijge MAH, Giesen PLA, Kloots W, Jerling JC, oude Egbrink MGA and Heemskerk JWM. Regulation of tissue factor-induced coagulation and platelet aggregation in flowing whole blood. Thromb Haemost. 2005; 93: 97-105.

- Cosemans JMEM, Kuijpers MJE, Lecut C, Loubele STBG, Heeneman S, Jandrot-Perrus M, Heemskerk JWM. Contribution of platelet glycoprotein VI to the thrombogenic effect of collagens in fibrous atherosclerotic lesions. Atherosclerosis. 2005; 181 (1): 19-27. 
- Heemskerk JWM, Kuijpers MJE, Munnix, ICA and Sijjander PRM. Platelet collagen receptors and coagulation. A characteristic platelet response as possible target of antithrombotic treatment. Trends Cardivasc Med. 2005; 15(3):86-92.

- Munnix ICA, Strehl A, Kuijpers MJE, Auger JM, van der Meijden PEJ, van Zandvoort MAM, oude Egbrink MGA, Nieswandt $B$ and Heemskerk JWM. The glycoprotein VI phospholipase $C_{\gamma} 2$ signaling pathway controls collagen- and tissue factor-induced thrombus formation in vitro and in vivo. Arterioscler Thromb Vasc Biol. 2005; 25 (12): 26732678.

- Kuijpers MJE, Munnix ICA, Cosemans, JMEM, Reutelingsperger CPM, oude Egbrink MGA and Heemskerk JWM. Role of platelet procoagulant response in tissue factor- and collagen-induced thrombosis in arterioles and venules. 2005; Submitted.

- Kuijpers MJE, Pozgajova M, Munnix ICA, Eckes B, Nieswandt $B$, and Heemskerk JWM. Unidentified role of integrin $\alpha 2 \beta 1$ in thrombus stabilization and embolization. 2005; Submitted.

\section{Abstracts}

- Kuilpers MJE, Schulte V. Bergmeier W, Lindhout T, Brakebusch $C$, Offermanns S, Fässler $R$, Heemskerk JWM, and Nieswandt B. Roles of glycoprotein $V I$ and $\alpha 2 \beta 1$ integrin in thrombus formation and procoagulant activity following platelet interaction with collagen. Platelets. 2002: 13: 50-51.

- Kuijpers MJE, Oury C, Feijge MAH, Hoylaerts MF, Lindhout T, Nieswandt B, and Heemskerk JWM. Contribution of platelet glycoprotein Ib and integrin allb $\beta 3$ to VWFcollagen mediated thrombus formation under flow. Platelets. 2002; 13: 345-346.

- Kuijpers MJE, Schulte V, Oury C, Lindhout T, Broers J, Hoylaerts MF, Nieswandt B and Heemskerk JWM. Glycoprotein Ib and integrin $\alpha / 1 \mathrm{~b} \beta 3$ contribute to GPVI-dependent WWFcollagen induced thrombus formation under flow. J Thromb Haemost 2003; 1 (7): supplement.

- Oury C, Kuijpers MJE, Toth-Zsamboki E, Bonnefoy A, Danloy S, Vreys I, Feijge MAH, De Vos R, Vermylen J, Heemskerk JWM and Hoylaerts MF. Overexpression of the platelet $\mathrm{P} 2 \mathrm{X}_{1}$ ion channel in transgenic mice generates a novel prothrombotic phenotype. $\mathrm{J}$ Thromb Haemost. 2003; 1 (7): supplement.

- Kuijpers MJE, Munnix ICA, Reutelingsperger $C_{1}$ oude Egbrink MGA and Heemskerk JWM. Thrombus formation relies on platelet-dependent coagulation in vivo. Platelets. 2004. 15 (6): 374.

- Auger JM, Kuijpers MJE, Senis YA, Watson SP and Heemskerk JWM. Src kinasedependent and -independent adhesion to collagen under flow: a unifying model. Platelets. $2004 ; 15$ (6): 356. 
- Kuipers MJE, Munnix ICA, Reutelingsperger C, oude Egbrink MGA. and Heemskerk JWM. Thrombus formation relies on platelet-dependent coagulation in vivo. Platelets. 2004; 15 (8): $497-498$.

- Cosemans JMEM, Kuijpers MJE, Lecut C. Heeneman S, Jandrot-Perrus M and Heemskerk JWM. Thrombogenic effect of human collagens. Platelets. 2004; 15 (8): 487.

- Munnix ICA, Kuijpers MJE, Reutelingsperger CPM, van Zandvoort MAMJ, oude Egbrink MGA and. Heemskerk JWM. Platelet-dependent coagulation in venous and arterial thromboembolism: a vital imaging approach using mouse models. Platelets. 2004; 15 (8): 505-506.

- Munnix ICA, Strehil A, Kuijpers MJE, Auger JM, van Zandvoort MAMJ, oude Egbrink MGA, Nieswandt $B$, Heemskerk JWM. Crucial role of glycoprotein $V I$ in murine thrombus formation and coagulation in both venous and arterial thrombosis. J Thromb Haemost. 2005; 3: supplement 1 .

- Kuijpers MJE, Munnix ICA, Reutelingsperger CPM, oude Egbrink MGA and Heemskerk JWM. Tissue factor- and collagen triggered thrombosis in vivo relies on platelet-dependent thrombin generation in both arterioles and venules. J Thromb Haemost. 2005; 3: supplement 1.

- Strehl A, Munnix ICA, Kuijpers MJE, Nieswandt B and Heemskerk JWM. (2005). Inhibition of protein kinase $C$ results in altered thrombus phenotype with suppressed platelet aggregation and increased platelet coagulant activity. J Thromb Haemost. 2005; 3 : supplement 1.

- Kuijpers MJE, Grüner S, Munnix ICA, Pozgajova M, Auger JM, Eckes B, Nieswandt B, and Heemskerk JWM. Role of integrin $\alpha 2 \beta 1$ in thrombus stabilization and embolization. I Thromb Haemost. 2005; 3: supplement 1.

- Munnix ICA, Kuijpers MJE, Thomassen MCLGD, van der Meijden PEJ, oude Egbrink MGA, van Zandvoort MAMJ, Rosing J, Siljander RPM and Heemskerk JWM. Disclosure of microdomain structure and function in arterial thrombi of heterogeneous composition. $J$ Thromb Haemost. 2005; 3: supplement 1.

Awards

- Student award 2000 of the Faculty of Health Sciences on behalf of the Foundation for Practice of Science, University of Maastricht, procured by Her Majesty Queen Beatrix (January 2001).

- Young investigator award of the International Society on Thrombosis and Haemostasis, XIXth Congress ISTH, Birmingham, UK (July 2003).

- Best contribution of young scientist, $10^{\text {th }}$ Erfurt European Conference on Platelets, Erfurt, Germany (June 2004). 
- Kootstra Fellowship talented candidate postiloc Faculty of Medicine, University of Maastricht, intended for the period between the accomplishment of the PhD degree and the appointment of a talented student as postdoc (May 2005). 